\title{
Comprehensive and Integrated Model for Atmospheric Status in Sealed Underground Mine Areas
}

Jianwei Cheng

West Virginia University

Follow this and additional works at: https://researchrepository.wvu.edu/etd

\section{Recommended Citation}

Cheng, Jianwei, "Comprehensive and Integrated Model for Atmospheric Status in Sealed Underground Mine Areas" (2012). Graduate Theses, Dissertations, and Problem Reports. 3611.

https://researchrepository.wvu.edu/etd/3611

This Dissertation is protected by copyright and/or related rights. It has been brought to you by the The Research Repository @ WVU with permission from the rights-holder(s). You are free to use this Dissertation in any way that is permitted by the copyright and related rights legislation that applies to your use. For other uses you must obtain permission from the rights-holder(s) directly, unless additional rights are indicated by a Creative Commons license in the record and/ or on the work itself. This Dissertation has been accepted for inclusion in WVU Graduate Theses, Dissertations, and Problem Reports collection by an authorized administrator of The Research Repository @ WVU.

For more information, please contact researchrepository@mail.wvu.edu. 


\title{
Comprehensive and Integrated Model for Atmospheric Status in Sealed Underground Mine Areas
}

\author{
Jianwei Cheng \\ Dissertation submitted to the \\ College of Engineering and Mineral Resources \\ at West Virginia University \\ in partial fulfillment of the requirements \\ for the degree of
}

Doctor of Philosophy

in

Mining Engineering

\author{
Yi Luo, Ph.D., Chair \\ Christopher J. Bise, Ph.D. \\ Keith A. Heasley, Ph.D. \\ Lian-Shin Lin, Ph.D. \\ Lihong Zhou, Ph.D. \\ Department of Mining Engineering \\ Morgantown, West Virginia \\ 2012
}

Keywords: Modeling; Mine atmospheric status model; Mine gas explosibility

Copyright 2012 Jianwei Cheng 


\title{
ABSTRACT \\ Comprehensive and Integrated Model for Atmospheric Status in Sealed Underground Mine Areas
}

\begin{abstract}
Jianwei Cheng
Mine gas explosion is one of the most feared hazards in the coal industry worldwide. More often one gas explosion related accident can cause the death of multiple coal miners. Since the beginning of coal mining, numerous mine workers have lost their lives as a result of gas explosions. Such occurrences have long been a major concern for mining engineers. Examination of two coal mine disasters (Sago mine and UBB mine) that have occurred in the U.S. in recent years reveals that all explosions originated from or around the sealed areas. Therefore, a good understanding of the atmospheric status in a sealed coal mine area is crucial in preventing and reducing accidents associated with mine combustible gases and also for planning and implementing a mine rescue strategy. Due to the lack of comprehensive research carried out so far in this area, this dissertation work seeks to contribute to understanding the behavior of a coal mine sealed volume and improving safety in coal mines. The following improvements have been made in this research:
\end{abstract}

- Important influential factors to control the mine atmospheric compositions has been investigated and analyzed. They are: (1) effect of the barometric pressure change; (2) effect of coal mine seals; and (3) categories of gases making up the sealed atmosphere and their changing characteristics.

- Based on the principle of mass conservation and the ideal gas law, a stepwise dynamic mathematical model that uses the control volume approach to simulate the sealed mine atmospheric gas species changes over time has been developed. All the above mentioned influential factors have been incorporated into the mathematical model. 
- A modified Coward explosibility diagram method is proposed to analyze the explosive mine atmosphere. The improvements include: (1) expanding the original Coward diagram; (2) corrections of flammable limits; (3) redefining the nose limit for each combustible gas; (4) developing an equation to predict the excess amount of inert gas for each combustible gas; and (5) introducing the concept of explosibility Safety Factor (SF) which improves the Coward diagram's further applications.

In order to facilitate these researches findings and improvements, a new software program, CIMMAS (Comprehensive and Integrated Model for Mine Atmospheric Status), has been developed. The program is coded using an objectoriented programming (OOP) language, Visual Basic 6.0. It offers friendly graphical user interfaces with schematic views and allows users to reduce input works and understand the program outputs. 


\title{
DEDICATION
}

To

\author{
My wife: Mrs. Jian Wang \\ My son: Evan J. Cheng
}

who give me their loves and allow me to achieve this goal at their expense.

To

My father: Mr. Xianming Cheng

My mother: Mrs. Xiaoli Chen

My father-in-law: Mr. Zhaoshi Wang

My mother-in-law: Mrs. Jichun Xu

who give me strong roots and understanding supports and sacrifices.

In

Memory of the past ten years 2001-2011.

To you they cried out, and they got away safe; In you they trusted, and they did not come to shame.

Psalms 22:5 


\section{ACKNOWLEDGMENTS}

I would like to thank all my committee members Dr. Christopher J. Bise, Dr. Keith A. Heasley, Dr. Lian-Shin Lin and Dr. Lihong Zhou for spending their precious time in going through this dissertation, and for giving their valuable suggestions throughout my dissertation work. His experiences in computer application in numerical modeling, mining design and rock mechanics have constantly inspired me.

I take this opportunity to express my sincere gratitude to my advisor Dr. Yi Luo for his supports; encouragements and advices during my course works and researches at West Virginia University (WVU). Without his abundant help and invaluable assistance, this dissertation cannot be accomplished so smoothly.

I would like to thank my advisor Dr. Shengqiang Yang when I was finishing my master degree at China University of Mining and Technology (CUMT). It is he who led me to this interesting research area-mine ventilation. It will be my lifelong career.

I would like to express my deep and sincere gratitude to my friends, Derrick Poage and Bongani Dlamini, and special thank for June Jones. They cleared all the grammar and spelling errors for me and made my dissertation much more professional. I am so grateful I have these friends who are always there to help. 


\section{TABLE OF CONTENTS}

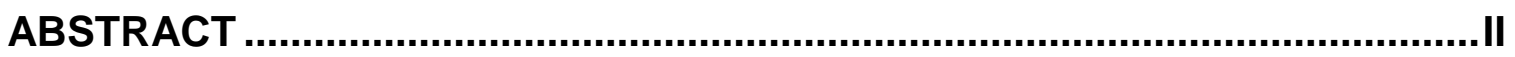

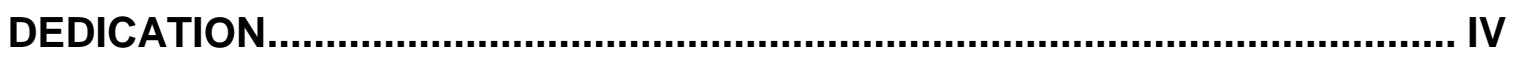

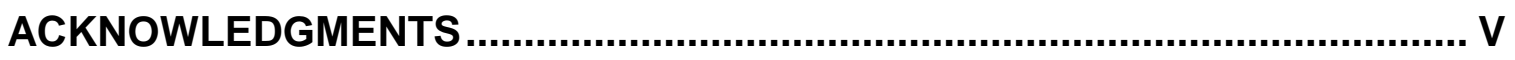

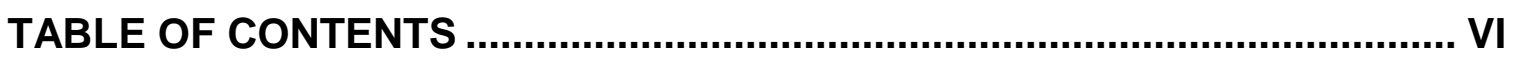

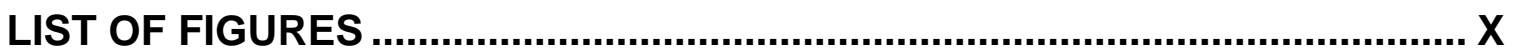

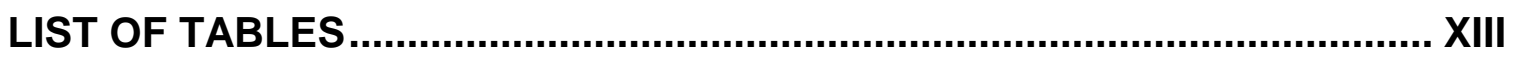

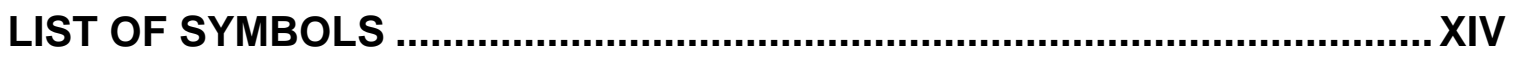

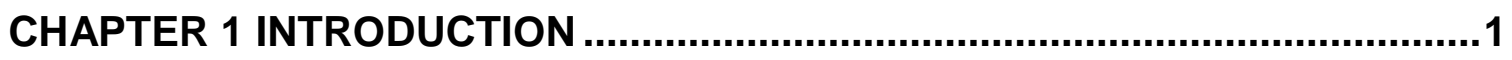

1.1 Mine Gas Explosion Accidents ...................................................

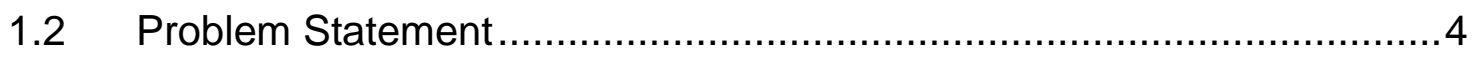

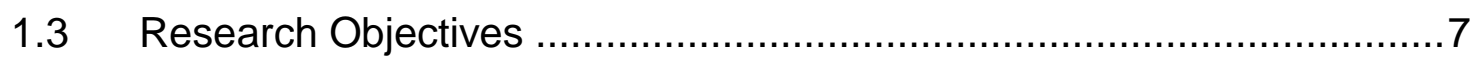

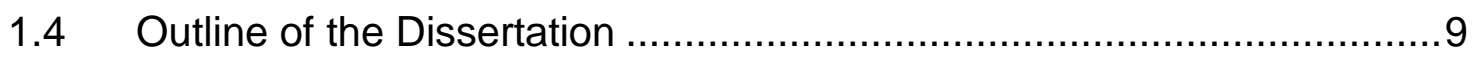

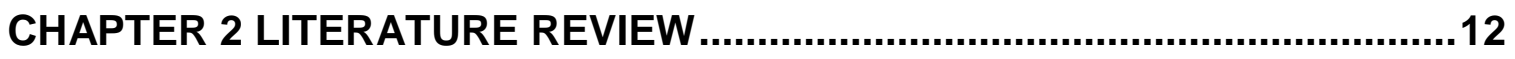

2.1 Coal Mine Sealed Atmosphere Modeling.........................................12

2.1.1 Coal mine gas emission ....................................................12

2.1.2 Effects of barometric pressure ............................................15

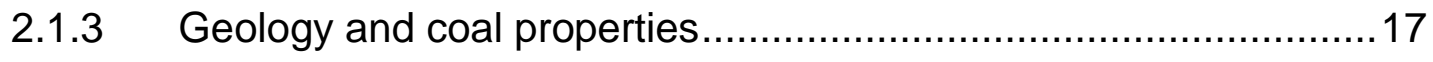

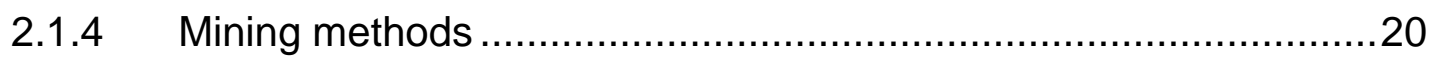

2.1.5 Chemical reactions in gob area .............................................21

2.2 Techniques to Analyze or Control the Sealed Mine Volume.................22 


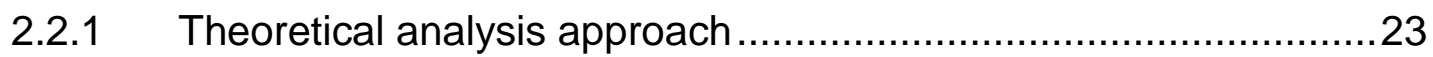

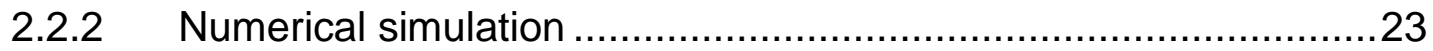

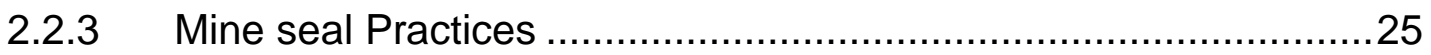

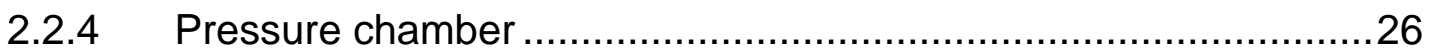

2.2.5 Positive pressure chamber ...............................................27

2.3 Determination of Mine Gas Explosibility ......................................28

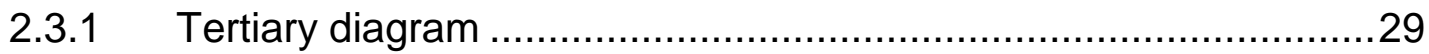

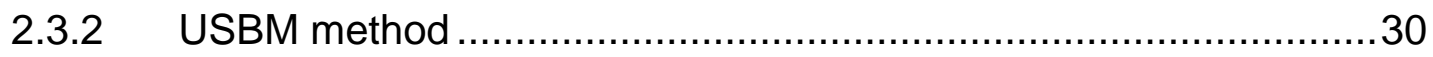

2.3.3 Maximum Allowable Oxygen (MAO) analysis .............................32

2.3.4 Revised Le Chatelier's method..................................................33

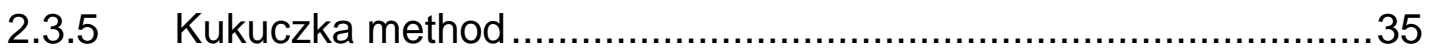

CHAPTER 3 MATHEMATICAL MODEL FOR SIMULATING ATMOSPHERE IN

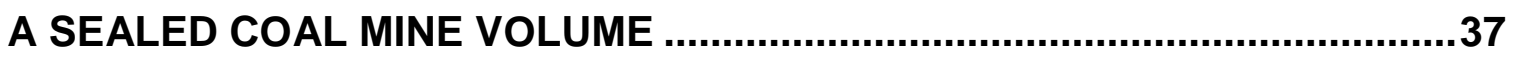

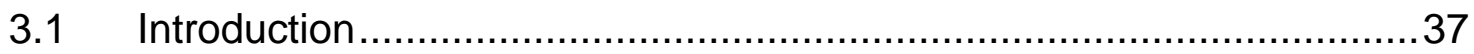

3.2 Factors Controlling the Mine Atmospheric Compositions ....................38

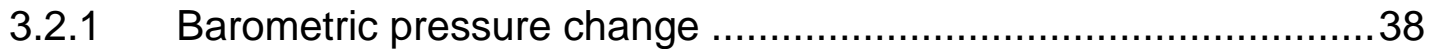

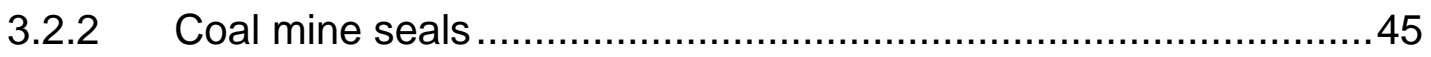

3.2.3 Gas compositions in a sealed mine volume ..............................51

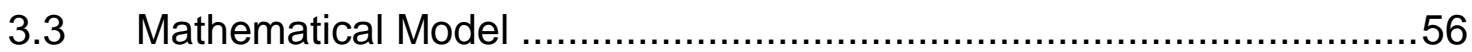

3.3.1 Control volume approach …................................................

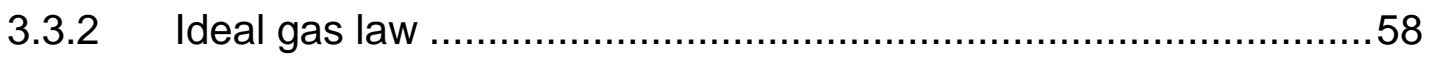

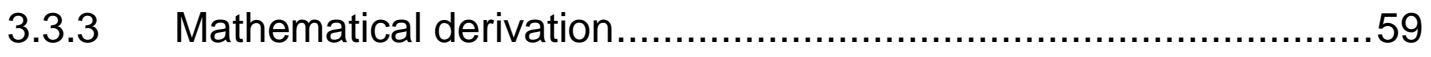

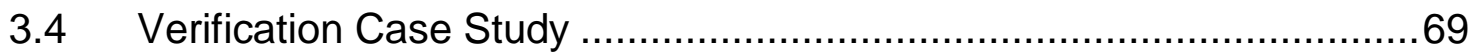




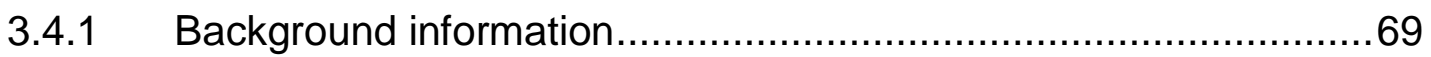

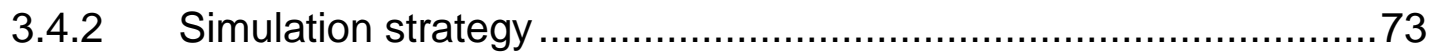

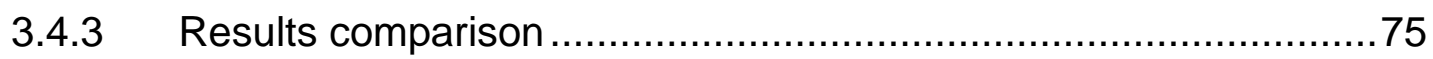

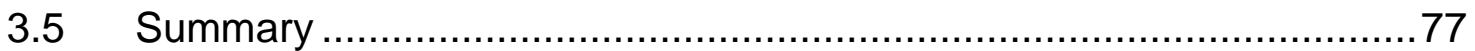

\section{CHAPTER 4 MODIFIED COWARD EXPLOSIBILITY DIAGRAM METHOD .....80}

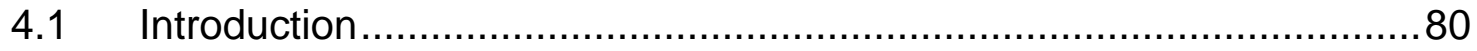

4.2 The Coward Explosibility Diagram ................................................ 83

4.3 Common Combustible Gases in Sealed Mine Atmosphere ..................86

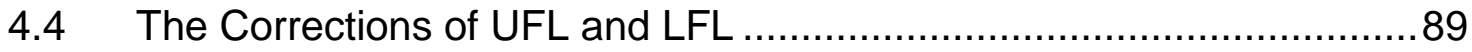

4.4.1 Effects of nitrogen and carbon dioxide ....................................90

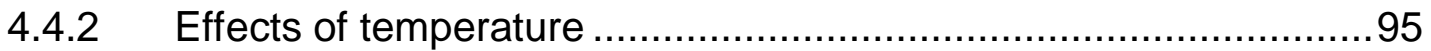

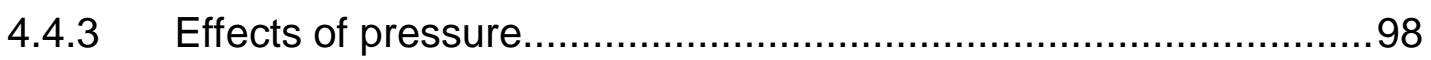

4.5 Redefining the Nose Limit.......................................................100

4.6 Determination of Quantity of Excess Inert Gas ...............................101

4.7 Development of Safety Factor to Assist Using the Coward Method ...103

4.8 Modified Coward Explosibility Diagram Method...............................112

4.9 Cross-verification Study ........................................................113

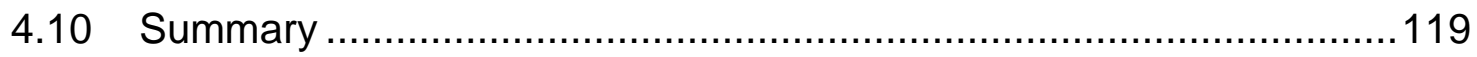

CHAPTER 5 CIMMAS PROGRAM DEVELOPMENT WITH VISUAL BASIC..121

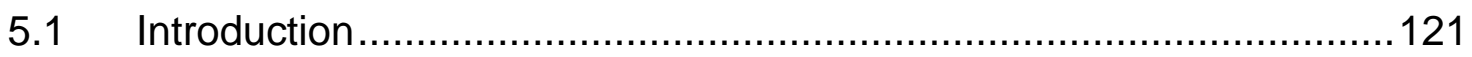

5.2 Object-Oriented Programming (OOP) and Microsoft Visual Basic

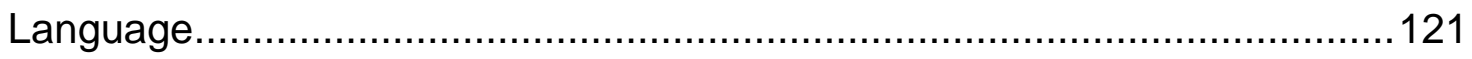

5.2.1 Object-Oriented Programming (OOP) .....................................122 
5.2.2 Microsoft Visual Basic language .............................................123

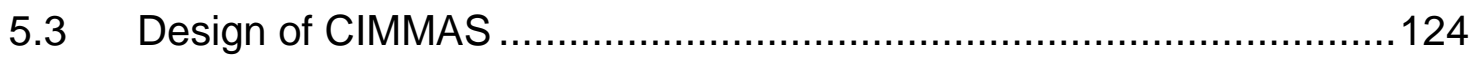

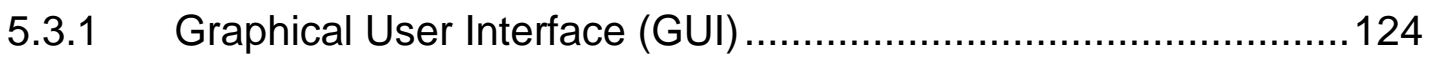

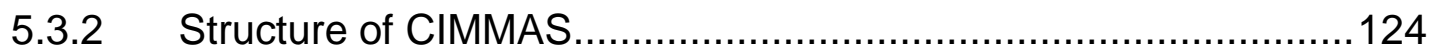

5.3.3 Required input data ....................................................... 126

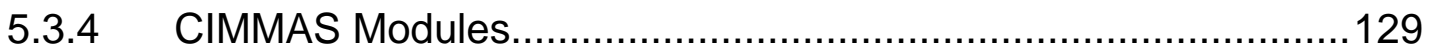

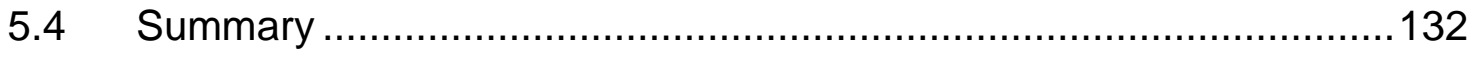

CHAPTER 6 ILLUSTRATIVE EXAMPLES OF CIMMAS ..............................133

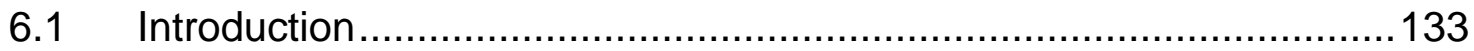

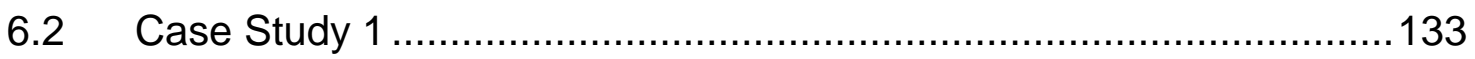

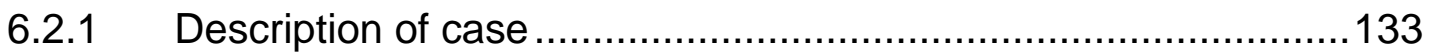

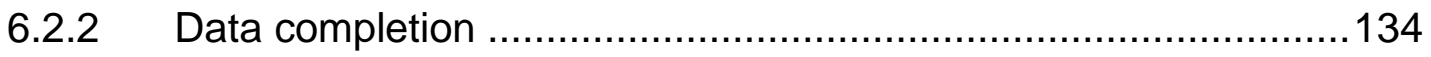

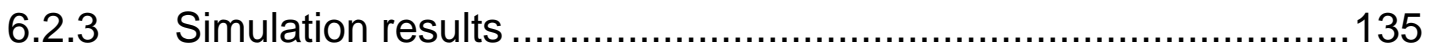

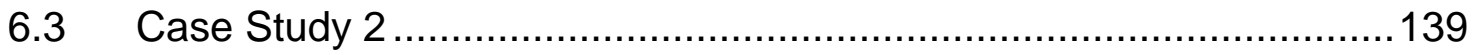

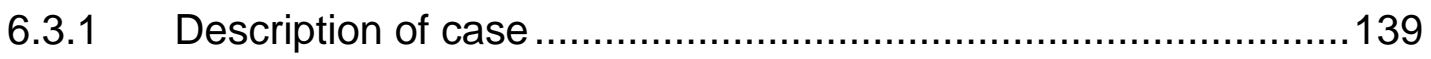

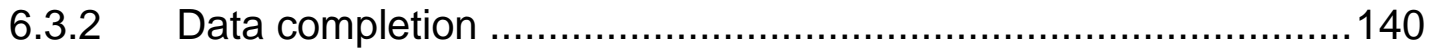

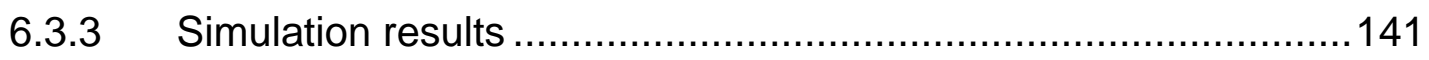

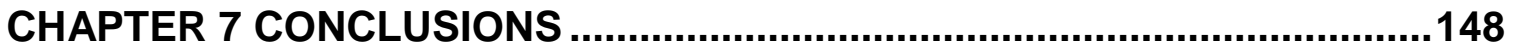

7.1 Summary and Conclusions .......................................................... 148

7.2 Recommendations for the Future Research .................................. 151

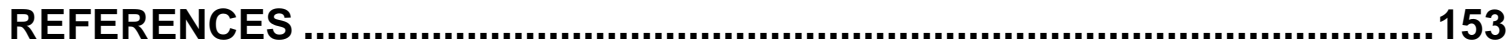




\section{LIST OF FIGURES}

Figure 2.1 Screenshots of CMGGP (Lunarzewski, 2010) .............................. 14

Figure 2.2 Explosibility changes over time (Francart \& Beirer, 1997) ................16

Figure 2.3 Typical adsorption isotherms as a function of coal rank (GRI, 1996).19

Figure 2.4 Pressure chamber (Smith, et al., 1994) ….................................27

Figure 2.5 Positive pressure chamber (Brady, et al., 2008) ............................28

Figure 2.6 Tertiary diagram for hydrogen, oxygen and nitrogen .......................30

Figure 2.7 Methane explosibility diagram (Zabetakis, et al., 1959b) .................31

Figure 2.8 Determining MAO (Timko \& Derick, 2006) .....................................33

Figure 2.9 Limits of flammability of hydrogen, carbon monoxide, and methane containing various amounts of carbon dioxide and nitrogen (Greuer, 1974) .......34

Figure 3.1 Typical barometric pressure fluctuation curves ............................. 41

Figure 3.2 Monthly barometric pressure fitting ….......................................... 43

Figure 3.3 Gob seal constructed with steel Kennedy panels and Omega blocks (Stephens, 2011) 46

Figure 3.4 Longwall extraction and sealed gob gas emission trend changes

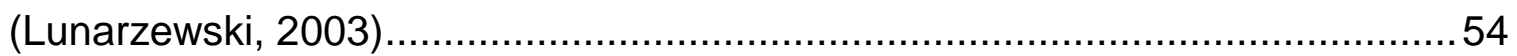

Figure 3.5 Fluid flow through a control volume ….......................................5

Figure 3.6 Volume of the sealed atmosphere and its leakage depending on the differential pressure (after Zipf \& Mohamed, 2010) .......................................6

Figure 3.7 Area of interest in the coal mine ……....................................... 71 
Figure 3.8 Interested sealed area in the longwall panel and its ventilation airflow pattern. 72

Figure 3.9 Simulation results vs. Field measurement data 76

Figure 4.1 An event tree showing typical consequences of accidental releases of combustible gas or liquid into the atmosphere (Bjerketvedt, et al., 1997)

Figure 4.2 Coward explosive triangles for methane, carbon monoxide and hydrogen

Figure 4.3 Limits of flammability of methane in separate mixtures of air with carbon dioxide, water vapor, nitrogen, helium and argon (Coward \& Jones, 1952; Zabetakis, 1965)

Figure 4.4 Comparison between the observed and calculated values of flammability limits of methane-nitrogen blend of various compositions (Kondo, et al., 2006a) 92 Figure 4.5 Variation of flammability limits as a function of temperature (Arnaldos, et al., 2011) 96 Figure 4.6 Variation of flammable limits for different gas-mixture, as a function of pressure (Arnaldos, et al., 2001). 99

Figure 4.7 Coward explosive triangle for methane, carbon monoxide and hydrogen (McPherson, 1993) 102

Figure 4.8 Comparing scenarios with different risks 105

Figure 4.9 Illustration of Coward diagram characterizes 106

Figure 4.10 Defining SF for Zone ABN 107

Figure 4.11 Defining SF for Zone CDN 108 
Figure 4.12 Defining SF for Zone DFN

Figure 4.13 Defining SF for Zone AEN

Figure 4.14 Defining SF for Zone ENFO.

Figure 4.15 SF distributions based on mine gas samples.

Figure 4.16 Flowchart of modified Coward explosibility method

Figure 4.17 Determining mine atmospheric explosibility using three methods for testing cases

Figure 5.1 Main view of CIMMAS. 125

Figure 5.2 Schematic structure of the CIMMAS program system 125

Figure 5.3 Typical data flow chart of sealed mine atmospheric status analysis 128

Figure 5.4 Screenshot of atmospheric gas species change predication module130

Figure 5.5 Screenshot of explosibility analysis module. 131

Figure $6.1 \mathrm{CH}_{4}, \mathrm{~N}_{2}$, and $\mathrm{O}_{2}$ change over time in the sealed volume 136

Figure 6.2 Effects of different number of mine seals used 138

Figure 6.3 Explosibility analysis 139

Figure 6.4 longwall panel layout. 140

Figure 6.5 Different gas species changes over time in the sealed volume at point crosscut 21 143

Figure 6.6 Different gas species changes over time in the sealed volume at point $32_{2} 13_{(1)}$ main return 144

Figure 6.7 Time-series plots of the explosibility triangles and the mixture points 147 


\section{LIST OF TABLES}

Table 1.1 List of coal mine disasters due to gas explosions (1970-2010).............

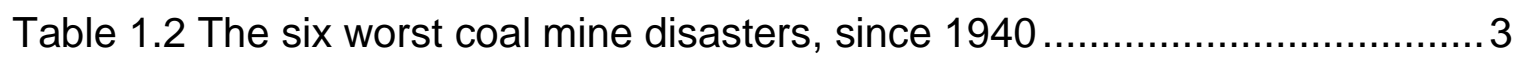

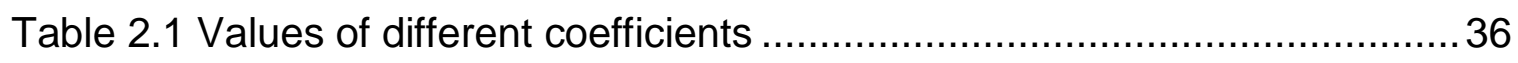

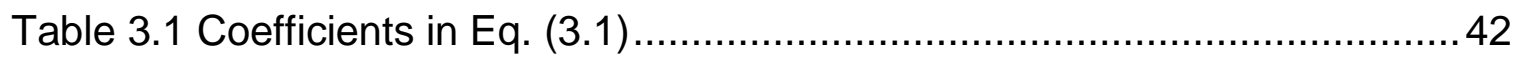

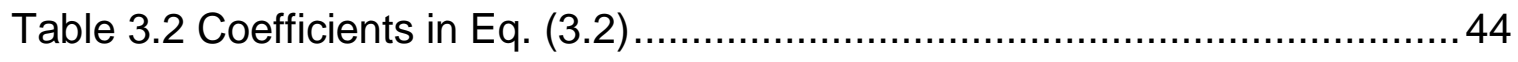

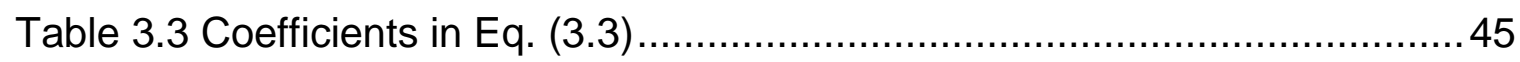

Table 3.4 MSHA-established tentative guidelines for air leakage through a seal

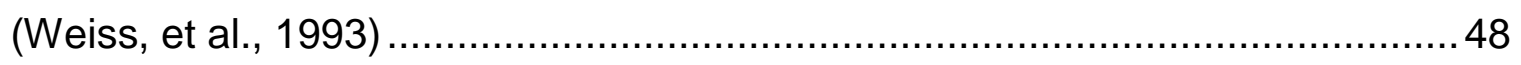

Table 3.5 Values for leakage coefficient into sealed atmosphere (Weiss, et al.,

1993, Weiss, et al., 1996; Zipf, et al., 2010).............................................. 48

Table 3.6 Suggested resistance values for stoppings and seals $\left(\mathrm{Ns}^{2} / \mathrm{m}^{8}\right)$ (After

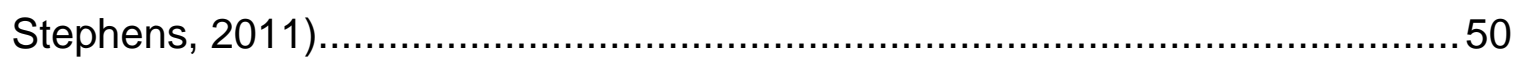

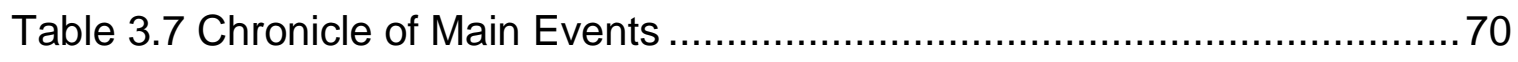

Table 4.1 Vertices of the explosive triangles (percentages) .............................. 85

Table 4.2 Vertices of explosive triangles (percentages) ……........................... 89

Table 4.3 Parameters values (Kondo, et al., 2006a) ......................................94

Table 4.4 Parameters values (Kondo, et al., 2006b) ...................................... 95

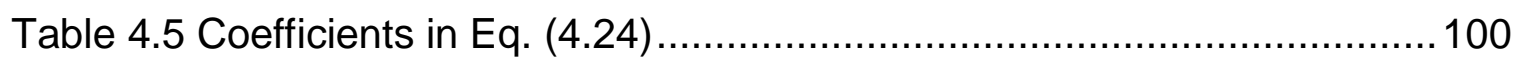

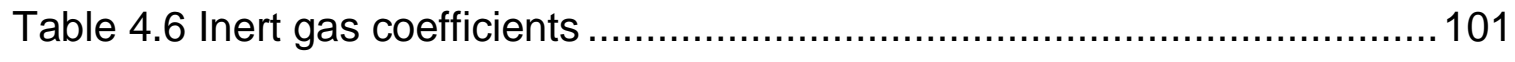

Table 4.7 Recommended SF Values for different risk levels .......................... 111

Table 4.8 Composition data recorded during a real mine fire ......................... 115

Table 6.1 Chronicle of Main Events ........................................................ 140 


\section{LIST OF SYMBOLS}

\begin{tabular}{|c|c|}
\hline$P_{b}(t)$ & barometric pressure \\
\hline$t$ & time \\
\hline$P_{t}(t)$ & total pressure of the sealed atmosphere at time $t$ \\
\hline$Q_{L}$ & air-leakage flowrate \\
\hline$L_{C}$ & leakage coefficient \\
\hline$\Delta p$ & differential pressure \\
\hline$L$ & entry length \\
\hline 0 & perimeter of the mine entry \\
\hline V & average velocity \\
\hline$A$ & cross-sectional area \\
\hline$k$ & friction coefficient \\
\hline$Q$ & airflow quantity \\
\hline$R$ & a single air resistance value \\
\hline$N$ & number of airways in parallel \\
\hline $\boldsymbol{v}$ & velocity vector \\
\hline$n$ & normal vector \\
\hline$\theta$ & $\begin{array}{l}\text { angle between the velocity vector and the outward directed unit } \\
\text { normal vector }\end{array}$ \\
\hline
\end{tabular}




\begin{tabular}{|c|c|}
\hline$P$ & partial pressure of a given gas \\
\hline$V$ & sealed volume value \\
\hline$T$ & absolute temperature \\
\hline$\dot{m}_{\text {air }}$ & inflow rate of air in the control volume \\
\hline$\dot{m}_{\mathrm{CH}_{4}}$ & inflow rate of air in the control volume \\
\hline$\dot{m}_{\mathrm{N}_{2}}$ & inflow rate of nitrogen in the control volume \\
\hline$\dot{m}_{\mathrm{CO}_{2}}$ & mass inflow rate of carbon dioxide in the control volume \\
\hline M & total mass in the control volume at any time \\
\hline$M_{0}$ & initial mass in the control volume \\
\hline$\rho_{\text {air }}$ & air density \\
\hline$\dot{m}_{\operatorname{mix}}$ & mass leakage rate from the sealed volume at a given time \\
\hline$\rho_{\operatorname{mix}}$ & density of gas mixture leaking through the mine seals \\
\hline$\dot{m}_{i}$ & rate of change of gas $i$ in the volume \\
\hline$m_{i}$ & total mass of gas $i$ in the volume and is a function of time \\
\hline$R_{i}$ & specific gas constant of gas $i$ \\
\hline$\rho_{i}$ & density of gas $i$ \\
\hline$P_{i}$ & partial pressure of gas $i$ \\
\hline$n$ & number of the seals used \\
\hline$K$ & the reaction rate constant \\
\hline
\end{tabular}




\footnotetext{
$C_{1} \quad$ volume percentages of the three combustible gases

$L_{i} \quad$ lower limits of the gas $i$ are substituted in the places of

$N_{e x} \quad$ excessive volume of nitrogen

$L_{n} \quad$ nose flammability of the mixed gases

$O_{n} \quad$ oxygen percentage at the nose limit

$L \quad$ lower flammable limit of the combustible gas in air

$U \quad$ lower flammable limit of the combustible gas in air

$L^{\prime} \quad$ corrected lower flammable limit mixture of the blend and air

U' corrected lower flammable limit mixture of the blend and air

$c_{1} \quad$ fraction of combustible gas in an assumed blend gas only consisted of this combustible gas and the nitrogen

$c_{\text {in }} \quad$ fraction of inert gas in the above assumed blend gas

$n_{1} \quad$ moles of oxygen when one mole of combustible gas is consumed at the upper flammable limit

$L F L_{T} \quad$ lower flammable limit at the given temperature, $T$

$L F L_{298} \quad$ lower flammable limit at the temperature of $298 \mathrm{~K}$

$T_{\min } \quad$ minimum temperature which must be reached to allow flame propagation

$C_{p} \quad$ specific heat of fuel-air mixture

$\Delta H_{c} \quad$ heat of combustion of the fuel

$U F L(T) \quad$ upper flammable limit at the current temperature $T$

$U F L(P) \quad$ upper flammable limit at the current pressure $P$
} 
$K_{i, j} \quad$ inert ratio of inert gas $j$ to combustible gas $i$

SF safety factor value

$E L_{c} \quad$ explosive range induced by adding or subtracting more combustible gas

$E L_{a} \quad$ explosive range induced by adding or subtracting the air quantity 


\section{CHAPTER 1 INTRODUCTION}

\subsection{Mine Gas Explosion Accidents}

During 1900-2006, a total of 11,606 underground coal mine workers died in 513 U.S. underground coal mining disasters ${ }^{1}$. However, most of disasters were resulted from mine gas and coal dust explosions. Actually, 420 gas explosion disasters were responsible for 10,390 deaths which represented $89.52 \%$ of all fatalities in coal mine disaster (CDC, 2009). Hence, gas and coal dust explosion is the most feared hazard in the coal industry and it has long been a concern for mining engineers. In most cases, coal mine explosions initially start with the ignition of the underground combustible gases. Generally, the most commonly encountered explosive gas in underground mines is methane. Methane is also the most dangerous and hazardous gas in underground mining extracting sedimentary minerals such as coal, trona, potash, limestone, oil shale and salt. Methane with most of it to be $\mathrm{CH}_{4}$ is lighter than air and easy to accumulate along the mine roofline and cavities if sufficient ventilation is not provided. Methane has an explosive range between $5 \%$ and $15 \%$ and $9.5 \%$ is the most dangerous due to complete combustion of the air-methane mixture. In addition, other underground combustible gases in the underground mine atmosphere include carbon monoxide, hydrocarbons, hydrogen sulfide etc., which can also contribute to explosions. Most of these gases are by-products of the coal formation process.

\footnotetext{
${ }^{1}$ According to WebPages of the United States Mine Rescue Association, the term "mine disaster" historically has been applied to mine accidents claiming five or more lives.
} 
The majority of deaths arising from mine explosions are caused, not by blast effect itself, but by the inhalation of toxic residual gases, which are generated by the explosion chemical reactions. The most hazardous of these residual is carbon monoxide. Carbon monoxide is a colorless, odorless, and tasteless gas which is slightly lighter than air and is highly toxic to humans since it has strong ability to combine with hemoglobin to produce carboxyhemoglobin, which interferes with the delivery of oxygen to body tissues.

Mine gas explosions present the most feared hazards in the coal industry worldwide. In 2009, a total of 157 gas explosions were responsible for 755 fatalities in Chinese coal mines. This number represented $28.7 \%$ of all Chinese coal mine fatalities (Huang, 2010). Two explosions in the Pike River Mine disaster began on November 19, 2010 in New Zealand killed 29 miners. This mine accident ranks as New Zealand's worst mining disaster since 43 men died at Ralph's Mine in Huntly in 1914 (Wikipedia, 2010). On March 21, 2011, a serious gas explosion in Pakistan's Sorange mine killed 43 miners (CNN, 2011). In the U.S. coal mining history, gas explosions are also considered as the most dangerous hazard. The Monongah Mine disaster in Monongah, West Virginia that occurred on December 6, 1907 has been described as "the worst mining disaster in American history." The lives of 362 workers including children were lost in this underground explosion.

Statistics from the Mine Safety and Health Administration (MSHA) shows the historic underground coal mine disasters due to gas explosions from 1970 to 2010 as listed in Table 1.1. It can be seen that more than half of the disasters re- 
sulted in 10 more coal miners killed at one accident. In addition, the six worst coal mine disasters since 1940 are also listed in Table 1.2.

Table 1.1 List of coal mine disasters due to gas explosions (1970-2010)

\begin{tabular}{ccccccc}
\hline No & Year & Day & Mine Name & Location & Type & Death \\
\hline 1 & 2010 & $4-5$ & Upper Big Branch Mine & Montcoal, WV & Explosion & 29 \\
2 & 2006 & $5-20$ & Darby Mine No.1 & Holmes Mill, KY & Explosion & 5 \\
3 & 2006 & $1-2$ & Sago Mine & Tallmansville, WV & Explosion & 12 \\
4 & 2001 & $9-23$ & No. 5 Mine & Brookwood, AL & Explosion & 13 \\
5 & 1992 & $12-7$ & No.3 Mine & Wise, VA & Explosion & 8 \\
6 & 1989 & $9-13$ & William Station No. 9 Mine & Sullivan, KY & Explosion & 10 \\
7 & 1983 & $6-21$ & McClure No.1 Mine & Dickinson, VA & Explosion & 7 \\
8 & 1982 & $1-20$ & No.1 Mine & Floyd, KY & Explosion & 7 \\
9 & 1981 & $12-8$ & No.21 Mine & Marion, TN & Explosion & 13 \\
10 & 1981 & $12-7$ & No.11 Mine & Knott, KY & Explosion & 8 \\
11 & 1981 & $4-15$ & Dutch Creek No. 1 & Redstone, CO & Explosion & 15 \\
12 & 1980 & $11-7$ & Ferrell No.17 & Boone, WV & Explosion & 5 \\
13 & 1976 & $3-9$ & Scotia Mine & Oven Fork, KY & Explosion & 26 \\
14 & 1972 & $12-16$ & Itmann No. 3 Mine & Wyoming, WV & Explosion & 5 \\
15 & 1970 & $12-30$ & No. 15 and 16 Mines & Hyden, KY & Explosion & 38 \\
\hline
\end{tabular}

Table 1.2 The six worst coal mine disasters, since 1940

\begin{tabular}{ccclllc}
\hline No & Year & Day & \multicolumn{1}{c}{ Mine Name } & \multicolumn{1}{c}{ Location } & Type & $\begin{array}{c}\text { Death } \\
\text { s }\end{array}$ \\
\hline 1 & 1968 & $11-20$ & CONSOL No. 9 & Farmington, WV & Explosion & 78 \\
2 & 1951 & $12-21$ & Orient No. 2 & West Frankfort, IL & Explosion & 119 \\
3 & 1947 & $5-25$ & Centralia No. 5 & Centralia, IL & Explosion & 111 \\
4 & 1943 & $3-16$ & Smith Mine & Washoe, MT & Explosion & 74 \\
5 & 1940 & $3-16$ & Willow Grove No. 10 & St. Clairsville, OH & Explosion & 72 \\
6 & 1940 & $1-10$ & Pond Creek No. 1 & Bartley, WV & Explosion & 91 \\
\hline
\end{tabular}


From these two tables, it can be seen that both number of mine explosion and severity have declined dramatically. Today, mine accidents resulting in five or more deaths are no longer common. However, it should be noted that mine explosions not only cause fatalities, but also result in production losses and huge financial burdens for mining companies (Zhou, 2009). For instance, due to the Sago mine disaster, besides the thousands, even millions, of dollars of safety violation fines issued by MSHA and the mine property damages, the International of Coal Group (ICG), the owner of the mine, finally decided to close the mine permanently under the pressures of social blame.

\subsection{Problem Statement}

According to the investigative report of the Sago mine disaster, the original location of the explosion that occurred on January 2, 2006 was in a newly sealed section of the mine. Not unique, but in a similar manner, another coal mine explosion resulted in five fatalities in the Darby mine No. 1 on May 20, 2006 which also originated from a sealed mine section. Hence, a problem and challenge on how to safely manage the mine sealed volume to avoid any accidents associated with mine combustible gases arise for mining engineers. This is a safety problem that needs to be resolved.

When the coal production in an active mine section ends, mine operators usually choose to build mine seals to isolate the abandoned area. The functions of mine seals are built to withstand potential explosion pressures and to prevent or control leakage of potential explosive or toxic gases, such as methane, carbon 
monoxide, etc., into the active mine workings (Kallu, 2009). However, due to the inaccessibility to the sealed areas, it is hard to understand what the composition of gases is in the sealed volume and how the gas species change over time. This may result in difficulties in ventilation management of the sealed areas. In general, the explosibility of the mine atmosphere depends on the composition of oxygen, combustible and inert gases. Once the inactive mining areas are sealed, methane or other combustible gases may be continuously released from the surrounding strata or remnant coal. The concentrations of these gases could change with time. Eventually, the air-gas-mixture would pass the so-called explosive range; explosions could occur when sufficient ignition energy (e.g., a flame or spark) is provided under the condition of sufficient oxygen. However, the gas species change over time are governed by many factors including inflows of combustible gases, air leakage, inert gases injected, barometric pressure effects, etc. Each of these factors is controlled by physical processes, chemical reactions or environmental effects, and needs to be carefully analyzed and calculated in the process to develop a reliable prediction tool.

On the other hand, some new findings and developments in recent years should also be well considered in order to finish such predicting simulation of the dynamic process of the atmospheric gas species change in a sealed area. Hence, a comprehensive mathematical model that considers all the factors and previous researches should be developed to assist in managing the sealed volumes. 
Additionally, a proper method to determine the coal mine gas explosibility is another very important subject following up the previous prediction works. Determination of explosibility is definitely a significant work for mine safety especially when planning and implementing any mine rescue strategies.

Under normal coal mine production situations, the explosibility of the mine atmosphere, especially for the sealed volume, should be monitored and determined in a timely matter. The critical time when the methane or other combustible gases build up and enter the explosive range and may trigger a potential explosion should be carefully watched. The correlative emergency managements for critical circumstances are also needed to reduce the potential accidents.

Determination of the explosibility is also critical for mine rescues and controlling the severity of a mine accident especially for a gas explosion event. After a large scale coal mine fire, explosion or discovery of a concealed thermal event, a common practice is to seal the related area, and then inject inert gas $\left(\mathrm{N}_{2}\right.$ or $\mathrm{CO}_{2}$ ) into the sealed area to extinguish the fire and prevent potential explosions from occurring. At the same time, rescue efforts will be immediately organized to perform the related works. In most cases, in order to prevent the risk associated with a potential secondary explosion and to protect rescue workers' safety and their lives, they are not allowed to go underground until the atmosphere of the sealed area has sufficient safety margin to prevent potential explosions.

In summary, an integrated model, which is capable of both predicting the changes of gas species over time in a sealed volume and accurately and quickly determining the potential mine gas explosion, is needed. It also can be as a use- 
ful tool to improve the mine safety management and a reference to guide coal mine rescues efforts.

\subsection{Research Objectives}

Methane explosions are the most feared hazards in the coal industry worldwide. Nearly all coal mine explosions initially started with the ignition of combustible gases such as methane, carbon monoxide, etc. Both the Sago mine disaster and the Darby mine No. 1 explosion caused huge property damage and loss of life. Hence, how to manage sealed mine areas and keep them under effective controls and to avoid any potential risks, are intractable problems for mining engineers and researchers.

Due to the inaccessibility of a mine sealed area, it is nearly impossible to implement directly measurements for the overall atmospheric compositions in the entire sealed area for safety assessment. However, the gas composition in a sealed mine area changes with time especially in the first few weeks or months after being sealed. Sometimes, this time range is often called "critical" period which historically indicates most explosions have occurred during this time. Hence, it should be carefully watched and well controlled. Generally speaking, the gas species changes with time are governed by various influential factors. It is a complicated work to reach an accurate prediction. But some new findings and research developments in recent years may provide possible approaches to finish such dynamic prediction simulation of the atmospheric gas species changes in a sealed area. Therefore, a useful tool, essentially a mathematical 
model which can inosculate the field reality, to perform such simulation is urgently desired. In other words, a good understanding of the behavior of gas in a sealed mine volume is needed for coal mine operators.

In order to adequately address the previous problem concern, the following questions may arise: is there any potential risk, what is the probability of an explosion occurring and how severe will it be? In order to answer these questions, an effective way is to develop a reliable method to determine the mine gas explosibility for the sealed mine atmosphere. This task is also very critical for managing the sealed mine area, especially for planning and implementing a mine rescue strategy after an accident.

In addition, a computer software incorporating all the above works to offer time-dependent comprehensive analysis about the behavior of sealed coal mine atmosphere is also needed to help the users understand the mine atmosphere. Therefore, an object oriented programming language, Visual Basic 6.0, is employed to code the program. Friendly graphical user interfaces with schematic views are also designed and provided for offering easy input works and displays of the program outputs.

In summary, this dissertation research work has contributed to an improved ability to understand and analyze the sealed mine atmosphere. Such ability could be used to improve mine safety. The major dissertation tasks are: (1) Analyze the most important influential factors controlling the atmosphere compositions, such as barometric pressure changes, mine seals, gas categories and their change characteristics. Then based on these analyses, a methodical model 
to simulate the sealed mine atmospheric gas species changes over time has been developed. Such a model can provide a useful tool for mining engineers to understand and effectively manage the sealed mine atmosphere. (2) Modify and improve an explosibility determination method for the gas-mixture in a sealed mine volume. The new proposed explosibility diagram method has considered the effects caused by various environmental factors, such as: pressure, temperature, contained inert gas, etc., on the upper flammable limits and the lower flammable limit of each combustible gas in a sealed mine atmosphere. Other important parameters to construct the explosive triangle, such as nose limits, etc., have also been calibrated. (3) Incorporate these tasks or improvements into a computer program which can offer a useful software program easily used by mine operators.

\subsection{Outline of the Dissertation}

The complete work carried out in this research has been organized in 7 chapters commencing with Chapter 1 introducing the accidents, challenges or problems with mine explosions, and the scope of present work.

Chapter 2 includes a thorough literature review related to the coal mine sealed atmosphere modeling and introductions of various methods to determine the mine gas explosibility.

Chapter 3 deals with the development of the time-dependent mathematical model of simulating sealed mine atmospheric gas species changes. The mathe- 
matical derivations are based on the combination of the law of mass conservation and the ideal gas law by using the control volume approach. The most important factors to control the mine atmospheric gas species changes in a mine sealed volume, such as inflows of methane and other combustible gases, air leakage through the seals, inert gases injected into the sealed volume, and quality of mine seals, etc. are discussed and considered. Therefore, the developed model is capable of representing the gas species changes more realistically. At the end of the chapter, a verification case study has been done to test the practicability of the developed model.

Determination of the explosibility is also a very important task following up the contents stated in Chapter 3. It should be noted that a good understanding of that is particularly critical for planning and implementing a successful mine rescue strategy. In Chapter 4, after briefly introducing one of the popular methods, the Coward explosibility diagram method, which is widely considered as a fast and easy way to determine mine gas explosibility, some of the unique influential factors existing in a mine sealed volume which may greatly change the determination judgments are reviewed and presented. Without considering the effects induced by these factors, errors may be introduced and result in a huge risk for mine accident rescue efforts. Unfortunately, the original Coward explosibility diagram fails to take these into account. In order to achieve better and more accurate explosibility judgments, a modified Coward explosibility diagram method is proposed in this chapter. The important characteristic points or parameters to construct the explosibility triangle such as: upper flammable limit, lower flamma- 
ble limit, nose limit, etc. are corrected or modified. The cross-verification study using the USBM explosibility diagram served as a double check and has also been referenced at the end of this chapter.

Chapter 5 deals with coding the software program with the Visual Basic language. The computer program named "CIMMAS" (Comprehensive and Integrated Model for Mine Atmospheric Status) which is capable of both predicting the gas species change trends and tracking of the explosibility of mine atmosphere at any time points has been developed. An object oriented programming language, Visual Basic 6.0, is employed to code CIMMAS. Such program can be run under the Windows environment and offers friendly graphical user interfaces. Users can easily input the data and the computer then automatically calculates results and displays the outputs with schematic and tabular views. They are very helpful and useful for the users to perform the secondary analysis or take proper management strategies.

In Chapter 6, examples are given to illustrate the applications of "CIMMAS", the developed computer program.

The dissertation is ended with the Chapter 7 , which concludes the whole research work, lists the new findings and also discusses the research ideas for the future. 


\section{CHAPTER 2 LITERATURE REVIEW}

\subsection{Coal Mine Sealed Atmosphere Modeling}

In order to improve mine ventilation efficiency and to deal with mine fire and explosion events, mine operators often choose to seal the non-active mine area after coal is extracted. Technically speaking, a sealed atmosphere in a mined-out area of an underground coal mine is simply a volume governed by boundary conditions. Due to the Sago mine disaster in 2006, the proposed new criteria for mine seals indicates that the U.S. mining industry become more aware of the atmospheric composition within sealed atmospheres (Zipf \& Mohamed, 2010). Actually, mining engineers have already previously noticed the behavior of the sealed atmosphere and have discussed the controlling factors since the 1950s. However, although people have known these factors and their effects for a long time, there has been no extensive scientific research work carried out so far. Many researchers started their researches only from one or few discrete aspects with simply analyzing the sealed atmosphere and its potential effects on a mine ventilation system. Each of the previous research efforts will be summarized separately in the following sections.

\subsubsection{Coal mine gas emission}

Coal mine gas is stored in the host strata which are mainly the coal seams. The formation of coal gases along with the coalification is a geological process that needs thousands or millions of years to complete. These gases are 
released from the surrounding strata or broken coal pieces into mine atmosphere when the virgin coal is extracted in mining activities.

The emissions of the mine gases may greatly change the ingredients of the mine atmospheres. Due to their continuous flow into an underground sealed area, an accumulation of the gases occur. However, the gas emission rates are controlled by various factors. The most obvious factor is the mining production status. Different mining stages have different gas emission curves. Fortunately, extensive studies on gas emission for mine gob have been conducted. Professional engineering software titled "Coal Mine Goaf Gas Predictor (CMGGP)" has been developed by Australian researchers. CMGGP is a simulation software for predicting the declining rate of gas generation and calculating the gas reservoir capacity of coal mine gobs. The software comprises of three main modules which are "Coal mine parameters", "Gas reservoir characteristics" and "Methane decline curves and gas reservoir" (Lunarzewski, 2010). Figure 2.1 shows the input screenshots of the software.

The U.S. Environmental Protection Agency (EPA) has also focused attention on methane emissions from the abandoned underground coal mine. Starting from 2000, the EPA has released a number of publications to discuss the abandoned coal mine as a source of methane emissions and to present various technical methodologies to predict methane emissions from the sealed mines in the United States (EPA, 2002; EPA, 2008). For example, a research to estimate abandoned mine emissions in 1995 has been conducted by Kirchgessner based on pre-abandonment data and vent pipe emissions measured at 21 abandoned 
underground coal mines in the Appalachian and Black Warrior basins (Kirchgessner, et al., 2001).

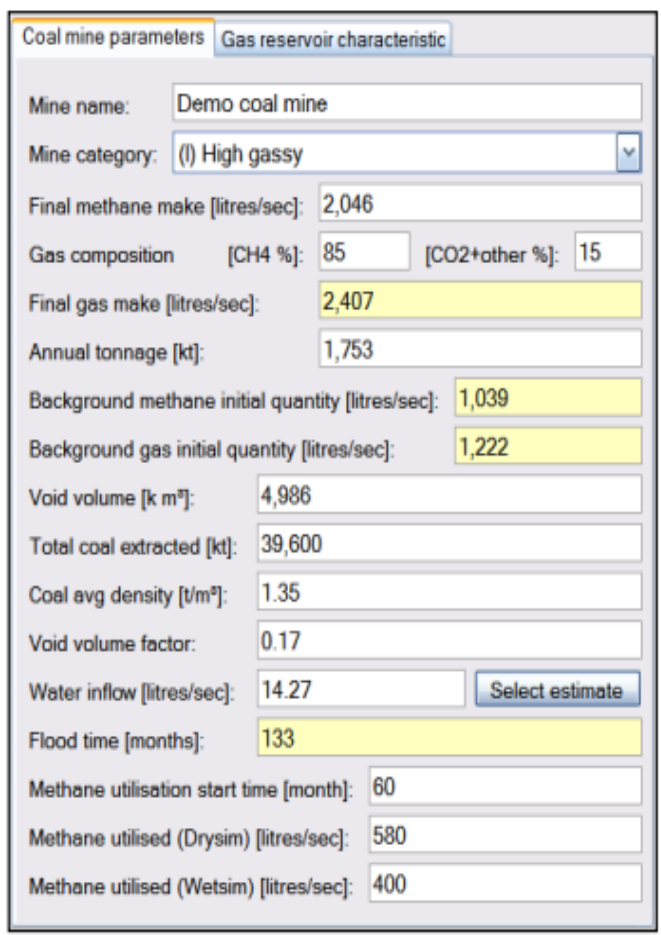

\begin{tabular}{|c|c|c|c|c|c|}
\hline Coal mine parameters & \multicolumn{3}{|c|}{ Gas reservoir characteristic } & & \\
\hline \multicolumn{6}{|c|}{ Districts / Boreholes } \\
\hline \multicolumn{2}{|c|}{ DD0450 } & \multirow{3}{*}{\multicolumn{2}{|c|}{$\begin{array}{l}\text { Borehole: } \\
\text { Extracted area }\left[\mathrm{m}^{2}\right] \text { : } \\
\text { Worked seam: }\end{array}$}} & \multicolumn{2}{|l|}{ DD0450 } \\
\hline & & & & \multicolumn{2}{|l|}{$9,000,000$} \\
\hline & & & & \multirow{2}{*}{\multicolumn{2}{|c|}{ GC-WS }} \\
\hline Add & Remove & & & & \\
\hline \multicolumn{6}{|c|}{ Gas reservoir (Stratigraphy) } \\
\hline Seam & $\begin{array}{l}\text { Depth } \\
\text { [m] }\end{array}$ & $\begin{array}{l}\text { Thickness } \\
\text { [m] }\end{array}$ & \multicolumn{2}{|c|}{$\begin{array}{l}\text { Methane } \\
\text { content }\left[\mathrm{m}^{2} / t\right]\end{array}$} & 스 \\
\hline R5 & 231.2 & 0.01 & \multicolumn{2}{|c|}{6.47} & \\
\hline $\mathrm{R} 4$ & 239.2 & 0.01 & \multicolumn{2}{|l|}{6.7} & \\
\hline R3 & 276.8 & 1.02 & \multicolumn{2}{|l|}{7.75} & \\
\hline R2 & 283.9 & 0.97 & \multicolumn{2}{|l|}{7.95} & \\
\hline R1 & 293.8 & 0.43 & \multicolumn{2}{|l|}{8.23} & $=$ \\
\hline Ro & 304.6 & 0.06 & \multicolumn{2}{|l|}{8.53} & \\
\hline \multicolumn{2}{|l|}{ GC - WS } & 2.75 & \multicolumn{2}{|l|}{8.8} & $\nabla$ \\
\hline Add & Remove & & & & \\
\hline \multicolumn{6}{|c|}{ Gas reservoir } \\
\hline \multirow{2}{*}{\multicolumn{2}{|c|}{$\begin{array}{l}\text { Available methane }\left[\mathrm{M} \mathrm{m}^{2}\right] \text { : } \\
\left.\text { Available gas [M m }{ }^{2}\right] \text { : }\end{array}$}} & \multicolumn{4}{|l|}{164.23} \\
\hline & & \multicolumn{4}{|l|}{205.29} \\
\hline
\end{tabular}

Figure 2.1 Screenshots of CMGGP (Lunarzewski, 2010)

The EPA has also proposed regression fitted functions to predict the emission rate for three different mine status: Venting mines, Flooded mines and Sealed mines. Based on the historical mine data from Mine Safety and Health Administration (MSHA) and the United States Bureau of Mines (USBM), they incorporated a probabilistic analysis (Monte Carlo simulation) to develop a range of emission estimates with a high degree of confidence (EPA, 2004). 


\subsubsection{Effects of barometric pressure}

It is well known that the barometric pressure can affect atmospheric conditions in mines. The barometric pressure variations can change the in-mine gas air density, and the differential pressure between the sealed areas and the active mining workings can induce the mass exchange. Fauconnier conducted statistical analyses of explosions in South African coal mines and found that barometric pressure drops longer than 1 day were a contributing factor to gas explosions (Fauconnier, 1992).

Barometric pressure changes also have been an important consideration in a mine sealing operation. They can induce airflows across the seals which may create explosive mixture of mine gases, cause intensification of mine fires and create irrespirable atmosphere outby the seals (Francart \& Beiter, 1997). A real case was presented to demonstrate the effect of a falling barometer on the explosibility of samplings from an area which was not yet completely sealed. Figure 2.2 shows the explosibility compositions changes for the case.

Fauconnier, et al. (1978) correlated measured barometric and sealed atmospheric pressure changes, and showed that a time lag between the two.

Stevenson conducted consecutive $\mathrm{CH}_{4}$ observation works in an underground mine. He investigated the influence of atmospheric pressure changes exerting in a gassy coal mine on a ventilating air current with a system of bleeder entries. He found that the rate of coal production caused a more significant change in methane concentration than the barometric change did, but the hazard that accompanies methane release due to expansion of the gob gases during 
atmospheric lows was minimized by the effective bleeder system (Stevenson, 1968).

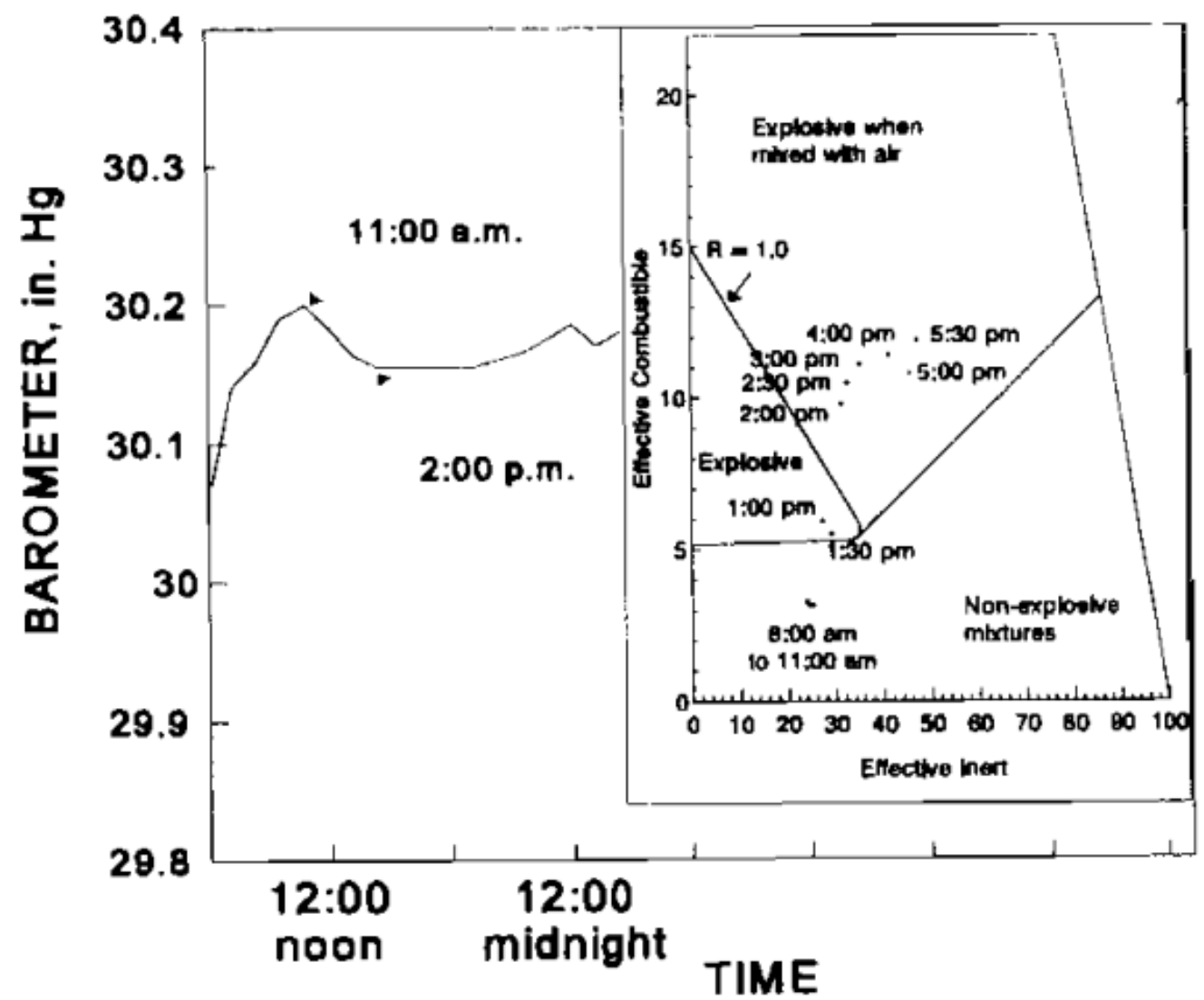

Figure 2.2 Explosibility changes over time (Francart \& Beirer, 1997)

Preliminary theoretical analysis for the effect of the barometric pressure was conducted by some researchers. The following equation was proposed to calculate the mass flowrate of gas (Hemp, 1994):

$$
M=\frac{V}{R_{g} T} \cdot \frac{d P}{d t}
$$

where: $P$ is the absolute pressure;

$V$ is the total volume;

$M$ is the mass flowrate of gas (air); 
$R_{g}$ is the gas constant;

$T$ is the absolute temperature.

This simple relationship can be used to calculate the mass flows into and out of an area by a given variation in barometric pressure. Such flows are analogous to the flow of electric current in a series resistance capacitance circuit, and this gave some useful indications as to methods for the analysis of the results (Hemp, 1994).

However, it is just a rough equation to estimate the mass exchange since the assumption neglects the mixing of in-flowing fresh air with the gas mixture existing in a sealed volume.

Hemp (1994) also performed computer simulation works of the barometric pressure variation. Besides to estimate possible leakages, simulations were also used to assess the performance of existing seals and determine sampling times for obtaining reliable gas samples from a sealed area.

\subsubsection{Geology and coal properties}

Geology and coal properties are the primary factors to control the gas content of coal, which mainly are:

- Geologic structure;

- Coal rank, type and quality;

- Depth;

- Sorption and diffusion properties of the coal. 
Geologic structure is the most important factor to impact the gas storage in coal seams. For example, common types of folded structures (i.e., anticline and syncline) have different effects in storing the gas. Anticline, which is a series of up-arched strata with side portions dipping in opposite directions away from the central portion of fold split by the axial plane (convexly bent), has a good place, like "dome", to store the coal gas due to its enclosed structure (Enotes, 2012). On the contrary, syncline, which is a series of down-arched strata with limbs dipping inwards in opposite directions towards the fold axis (Enotes, 2012), has an opened structure and may connect the surface to result in the coal gas draining away.

The natural fracture is another typical geologic structure. It can greatly change the average permeability of a certain area and affect the coal gas migration within coal seams.

Coal rank represents the level of maturation reached, ranging from peat through anthracite. The three typical levels of coal ranks are: Lignite, Bituminous and Anthracite.

Coal rank profoundly influences the gas content in coal seams. The processes of coalification (both thermogenic and biogenic) are associated with the generation of oil and gas in the subsurface. Thus, a substantial proportion of methane, carbon dioxide, and other occluded volatile components of coal may have been generated from the coal itself as by-products of coalification (GRI, 1996). 
The relationship between gas content and depth is also distinct and wellknown (Eddy \& Rightmire, 1982). The impacts of depth consist of two aspects. First, greater depth causes higher pressure. High pressure can increase the quantity of gas adsorbed on the coal surface. Second, greater burial depths normally result in more effective sealing of strata, reducing gas losses (English, 1997). Figure 2.3 shows typical desorption isotherms as a function of coal rank.

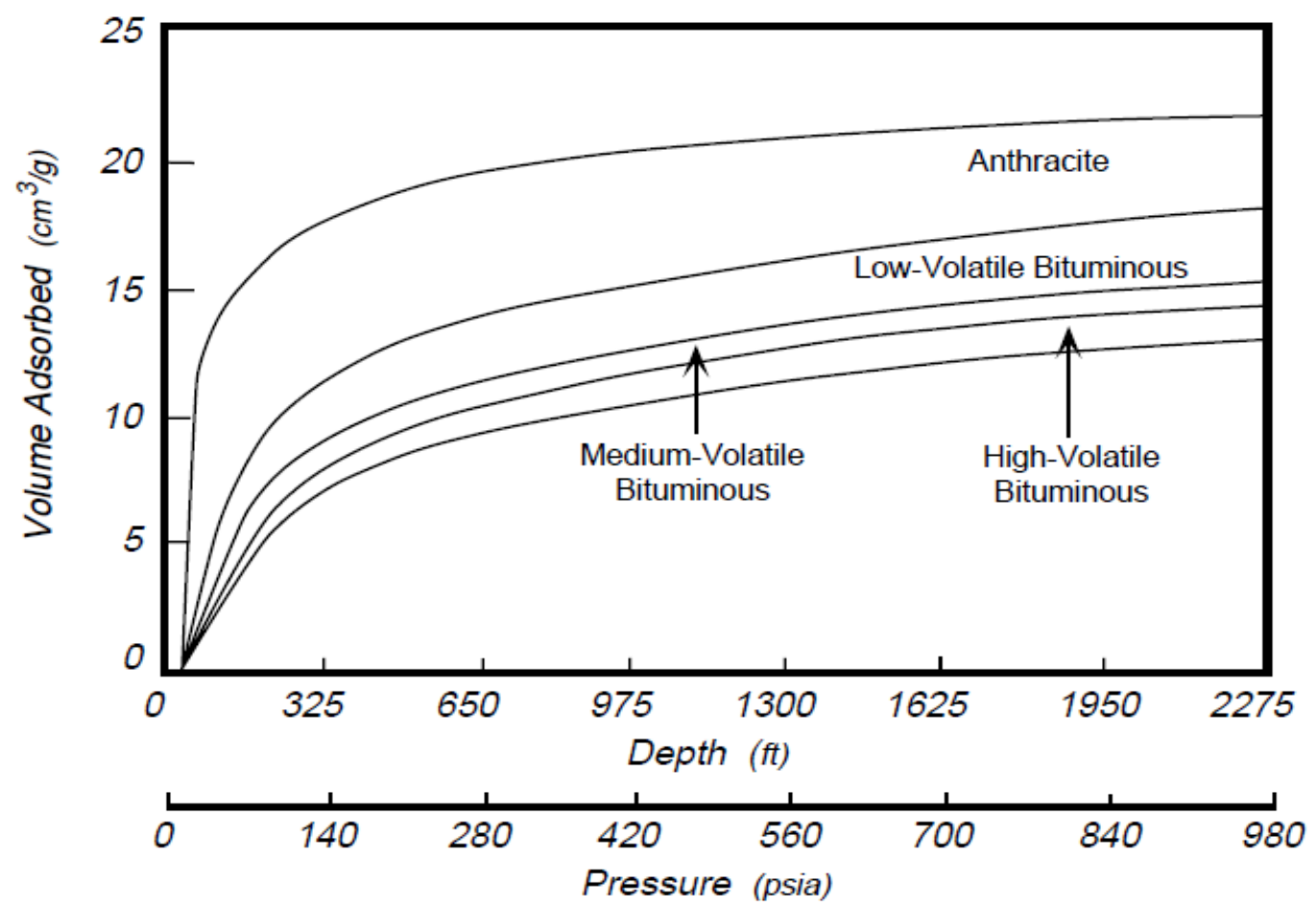

Figure 2.3 Typical adsorption isotherms as a function of coal rank (GRI, 1996)

One function commonly used for methane adsorption on coal is called the Langmuir isotherm, which is based on the ideal case of a single layer of molecules adsorbed on the coal surface (EPA, 2004). The Langmuir isotherm is generally expressed as:

$$
V=\frac{V_{L} P}{P+P_{L}}
$$


where: $V$ is the volume of methane at standard temperature and pressure per ton of coal, $\mathrm{m}^{3} /$ ton;

$V_{L}$ is the Langmuir volume constant, $\mathrm{m}^{3} / \mathrm{ton}$;

$P$ is the pressure in the coal cleat system, $\mathrm{kPa}$;

$P_{L}$ is the Langmuir pressure constant, $\mathrm{kPa}$.

In the desorption stage, the desorption isotherm is the link between the flow in the coal matrix system (where gas flow is controlled by concentration gradients) and flow in the coal cleat system (where gas flow is controlled by pressure gradients). At low pressures, the relationship between gas content and pressure is linear and is referred to as a Henry's Law isotherm. At very high pressures, all of the storage sites will be occupied if sufficient molecules are available, and the storage capacity will reach its maximum value equal to the Langmuir storage capacity (GRI, 1996).

\subsubsection{Mining methods}

There are mainly two mining methods used to extract coal in U.S. underground coal mines. They are room-and-pillar mining and longwall mining.

In 2006, nearly 48.8 percent of underground coal production was produced by using the room-and-pillar mining methods while the longwall mining method took up to 50.2 percent (Peng, 2008). Practically speaking, the mining rate of a room-and-pillar mine is slower than that of a longwall mine and the extraction ratio rarely reaches $100 \%$ as it does in longwall operations (English, 
1997). Longwall mining allows the full collapse of overlaying strata to form a gob zone, and it also destroys strata and breaks coals more than room-and-pillar mining does. Strata exposed above the coal seam extraction area are greatly increased due to the creation of the gob. The distance of the relaxed zone extends in the roof is equal to or greater than the longwall width and extends in the floor up to half of the longwall width (Lunarzewski, 1998). Therefore, desorbed and released gas more easily emit into the underground workings.

An empirical equation, which describes the relationship between the gas emission and associated tonnage of extracted coal, has also been given as the following (Lunarzewski, 1998):

$$
Q=a \sqrt{C P}+b
$$

where: $Q$ is the total methane emission rate expressed in liters $\mathrm{CH}_{4}$ per second;

$C P$ is the daily coal production rate expressed in tons; $a$ and $b$ are empirical coefficients related to weekly coal production levels and number of working days per week.

\subsubsection{Chemical reactions in gob area}

In the U.S., whether in the room-and- pillar or the longwall mines, the extensive use of multiple-development entries leads to the need to build numerous mine seals in the underground to isolate the gob or sealed areas (Smith, et al., 1994). However, due to air-leakage across the seals, oxygen is sufficiently pro- 
vided with the leakage airflow and coal oxidation or spontaneous combustion may occur. In such conditions, coal self-heating around seals would greatly change the atmospheric composition of a sealed area.

Generally, three categories of gases make up the atmospheric mixture in such sealed mine areas. They are: (1) atmospheric gases, (2) products of low temperature oxidation, combustion or explosion (Timko \& Derick, 2006), and (3) the gas emitted from the coal seam such as $\mathrm{CH}_{4}$ and $\mathrm{CO}_{2}$.

Atmospheric gases are typical gases found in the normal air including nitrogen $\left(\mathrm{N}_{2}\right)$, oxygen $\left(\mathrm{O}_{2}\right)$, argon $(\mathrm{Ar})$, and carbon dioxide $\left(\mathrm{CO}_{2}\right)$. The byproduct gases of coal oxidation in the sealed volume are $\mathrm{CO}_{2}, \mathrm{CO}$, and $\mathrm{C}_{\mathrm{x}} \mathrm{H}_{\mathrm{y}}$ as shown in the following chemical reaction equation.

Coal oxidation: $\quad a C o a l+b_{2}=c C O+d C_{2}+e H_{2} \mathrm{O}+\mathrm{fC}_{x} \mathrm{H}_{\mathrm{y}}$

In Eq. (2.4), $a, b, c, d, e$ and $f$ are stoichiometric coefficients. Field experiences show $\mathrm{C}_{x} \mathrm{H}_{y}$ is generally the alkane $\left(\mathrm{C}_{n} \mathrm{H}_{2 n+2}\right)$, alkene $\left(\mathrm{C}_{n} \mathrm{H}_{2 n}\right)$ or alkyne $\left(\mathrm{C}_{n} \mathrm{H}_{2 n-2}\right)$ series of hydrocarbon gases.

\subsection{Techniques to Analyze or Control the Sealed Mine Volume}

Explosions originating from or around the sealed areas in underground coal mines present a serious safety threat. In order to improve mine safety, proper monitoring and control of the sealed volume are needed by mine operators. For many years, mining engineers and researchers did numerous investigations for controlling the composition changes in sealed areas. Some typical research findings and practices will be discussed separately in the following sections. 


\subsubsection{Theoretical analysis approach}

The "Gob Assistant Program", which was published by (Foster-Miller, 1988), may have been the first effort to understand the sealed atmosphere quantitatively and to calculate leakage quantity in and out. The aim of this developed program was only to investigate and simulate the changes of $\mathrm{CH}_{4}$ behind seals. Zipf, et al. (2010) carried on the ideas and expanded their model that can handle up to four different gas species, which are $\mathrm{O}_{2}, \mathrm{~N}_{2}, \mathrm{CO}_{2}$ and $\mathrm{CH}_{4}$. Systems of differential equations in their model are also derived based on the time rate of change for each gas species. It is an assistant tool when designing the seals and the sealed area with controlling leakage to remain the inert sealed atmosphere and to minimize the explosion hazard. However, considering mine safety issues, it should be noted that oxidation of wood and coal at ambient temperature would likely occur in the sealed areas. In such case, various combustible gases besides $\mathrm{CH}_{4}$ may exist in the sealed area. Therefore, more gas species should be considered in order to more accurately analyze the atmospheric status of a sealed volume.

\subsubsection{Numerical simulation}

The rapid growth of computational power and the corresponding maturing of computational fluid dynamics (CFD) have led to the development of CFD based "field" models applied to coal mine fire research problems (McGrattan, et 
al., 2007). CFD models can separate a compartment into hundreds to thousands of tiny calculation cells and then calculate composition in each cell using higher level mathematics to specifically relate energy transfer and flow of fluids to each other. The calculations are based on the laws of mass, momentum, energy conservation, etc. and are applied in each cell and balanced with all adjacent cells. CFD can output much more details about the fluid, such as temperature, velocity and concentration of chemical species (Zhou, 2009). CFD is a well-know tool of analyzing the mine atmosphere.

Lolon, et al., (2009) conducted both experimental measurements and CFD simulation to identify the hot spots, where most coal fires starts. They designed four different gob scenarios to simulate the potential coal self-heating process, and the results showed that the hot spots always started in the consolidated area near the bleeder shaft for the bleeder system but not in the unconsolidated area along the face line. The leakage flows though the gob played an important role in determining the size and location of the hot spot.

Yuan, et al., (2007) noted that the barometric pressure change is an important factor affecting the air density change, and the mass of the gas in the gob. Therefore, they performed CFD simulations which were used to investigate the potential effect of barometric pressure changes on spontaneous heating of coal in a bleederless longwall gob area.

Simulation results from their works demonstrate that the effect of barometric pressure changes on the spontaneous heating is found to be dependent on the gob permeability and the coal oxidation rate. Oxygen concentrations and 
temperature in the gob are also examined in their CFD results. However, due to the complexity of the problem and lack of field data, the results reported are needed to validate and calibrate to cooperate with U.S. coal mines in the future study.

\subsubsection{Mine seal Practices}

On November 20, 1968, an explosion occurred at Consolidation Coal Co.'s No. 9 mine near Farmington, WV, resulting in the deaths of 78 miners, The Farmington disaster led to passage by Congress of the Federal Coal Mine Health and Safety Act of 1969 (1969 Coal Act). The 1969 Coal Act was more comprehensive and more stringent than any previous federal legislation governing the mining industry (Breslin, 2010). It first recognized that an underground mine must use "solid, substantial, and incombustible" mine seals to isolate mine abandon areas. Following the 1969 Coal Act, both the number of mine explosions and severity have declined dramatically. The use of mine seals may have contributed to fewer explosions in active mine areas.

On the other hand, to control methane in mined-out areas of coal mines and thereby reduce explosion risks from methane buildup, current mining regulations require mining companies to either ventilate or seal abandoned mining areas (Zipf, et al., 2007). However, due to the high operating costs to continuously ventilate abandoned areas, sealing is generally more economical and possibly a safer alternative to ventilation. Without sealing, large mined-out areas still re- 
quire regular inspections and can expose miners to a variety of underground hazards (Zipf, et al., 2007). Therefore, seals are extensively used throughout the U.S. coal mines to isolate abandoned mining areas from the active workings.

Four seal applications are currently used, they are: (1) panel seal, (2) district seal, (3) crosscut seal, and (4) fire seal (Zipf, et al., 2007). Mine seals generally affect the air exchange between a sealed area and an active working. It has two effects: location and quality. The seal location is crucial in their ability to limit air exchange. Seals should be generally located in areas where entry closure or seal crushing is minimal so airflow leakage can be minimized (Smith, et al., 1994). On the other hand, high quality construction can also reduce leakage. The mine seal quality is controlled by various factors, such as: roof and floor convergence, seal materials, explosion-loading, etc.

Timko, et al. (1987) measured gas velocity through longwall gobs and sealed atmospheres that ranged from 0.0051 to $0.0150 \mathrm{~m} / \mathrm{s}$. By this rate, gas might take about 8 hrs to cross a $300-\mathrm{m}$ wide longwall panel. The measured gas leakage through each $140 \mathrm{kPa}$ seal ranged from 0.12 to $0.24 \mathrm{~m}^{3} / \mathrm{s}$.

\subsubsection{Pressure chamber}

Seal leakages induced by barometric pressure are amplified in larger mined-out areas. A common way to reduce atmosphere exchanges within a sealed area is to construct pressure chambers. These can be used to pressure balance the sealed areas to limit atmosphere exchanges with the mine. 
The pressure chamber is located on the lower ventilation-pressure side of the sealed area and is composed of a series of seals and a void space. The void space is then pressurized by connecting it with a duct to a high-pressure ventilation network in the mine. An exhaust regulator on the outer seal is then adjusted to equalize the atmospheric pressure behind the inner seal with the void space pressure (Smith, et al., 1994). Figure 2.4 illustrates the pressure chamber.

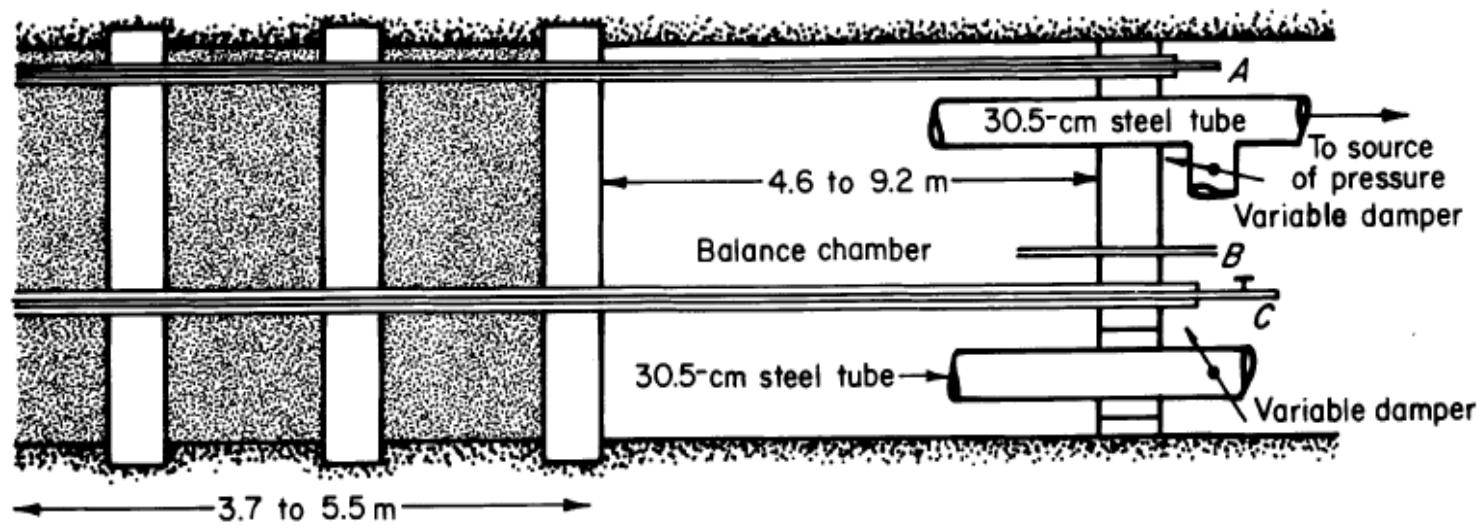

Figure 2.4 Pressure chamber (Smith, et al., 1994)

\subsubsection{Positive pressure chamber}

The positive pressure chamber (Figure 2.4) is a new proactive method of mitigating the risks associated with active and sealed gobs to manage the atmosphere in the fire affected sealed area. This method has been applied in Australia and the related practices show it has a good applicability (Brady, et al., 2008). 


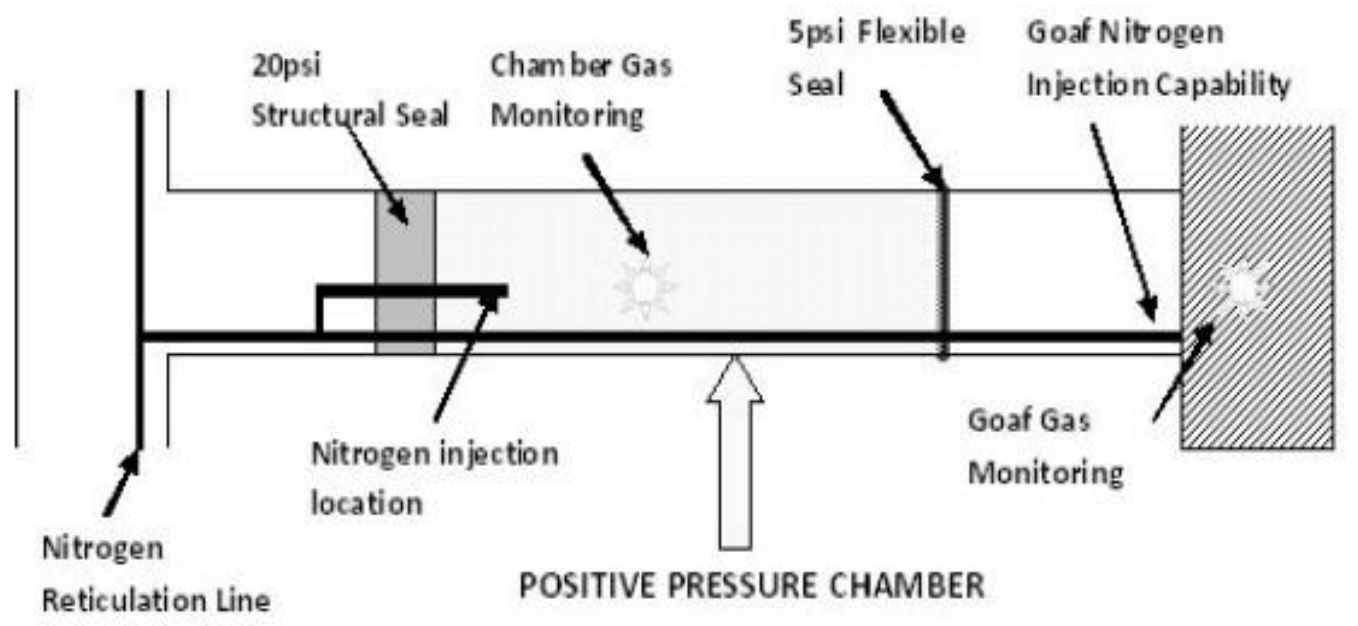

Figure 2.5 Positive pressure chamber (Brady, et al., 2008)

The positive pressure chamber includes the erection of a rated 5 psi flexible seal on the gob side of the chamber and a rated 20 psi outer structural seal. The 5 psi seal has been designed to overcome significant strata deformation and is responsible for damaging conventional gob seals. The outer seal is designed to counter strata convergence. Nitrogen is then injected into the chamber and the quantity of nitrogen injected at each site is measured with pressure and atmosphere monitoring available both within the chamber and the gob.

\subsection{Determination of Mine Gas Explosibility}

For many years, mining engineers and researchers have developed a number of methods for assessing the explosibility of the air-gas mixture. Kukuczka analyzed the composition of the coal mine gas and created a model to determine the explosibility through a mathematical transformation to convert intricate combustible contents into a single gas (Kukuczka, 1982). Zigmund and Janovsky developed the graphical computer software named "Vybuchovy trojuhelnik" for 
assessing the explosibility of fuel-air mixture (Zigmund \& Janovsky, 2007). Jacobs and Porter proposed their algorithms to generate a control chat depicting the changes in percent of combustibles and the lower and upper explosive limits of the mine atmosphere (Jacobs \& Porter, 1998). It also provided a predictive option for the user to look into the potential changes in the atmosphere over a period of time. The USBM explosibility diagram is a method widely used in the U.S. mining industry (Ray, et al., 2004). This method uses the effective combustibles (converted from the methane, hydrogen, and carbon monoxide) and the effective inert (converted from the carbon dioxide and nitrogen) in the atmosphere to assess the explosibility of the mine atmosphere. Some of the typical methods will be introduced and discussed separately in the following sections.

\subsubsection{Tertiary diagram}

Dwyer, et al., (2003) introduced the tertiary diagram to determine the explosibility of the fuel-air-inert mixtures. Figure 2.6 a shows a tertiary diagram for any ratio of hydrogen, oxygen and nitrogen at ambient conditions. The top of the triangle represents $100 \%$ hydrogen and the base of the triangle represents $0 \%$ hydrogen, so as oxygen and nitrogen. Using line A as an example, it represents $30 \%$ hydrogen. Hence, line B and line C can represent $30 \%$ oxygen and $30 \%$ nitrogen, respectively. Similarly, the example point D consists of $30 \%$ hydrogen, $27 \%$ oxygen and $43 \%$ nitrogen, and point E represents pure air ( $21 \%$ oxygen and $79 \%$ nitrogen). 
Figure 2.6b provides the full tertiary diagram for hydrogen, oxygen and nitrogen including the flammability envelope for ambient conditions. Mixtures inside the envelope are flammable. Line $F$ is drawn from air (point $E$ in Figure 2.6a) to $100 \%$ hydrogen and thus any mixture of hydrogen and air alone must lie on line F. Note the conventional lower flammable limit (LFL) and upper flammable limit (UFL) points for hydrogen in air (4\% hydrogen and 75\% hydrogen, respectively). Note also the LFL and UFL of hydrogen in oxygen (4\% hydrogen and $94 \%$ hydrogen, respectively) (Dwyer, et al., 2003).

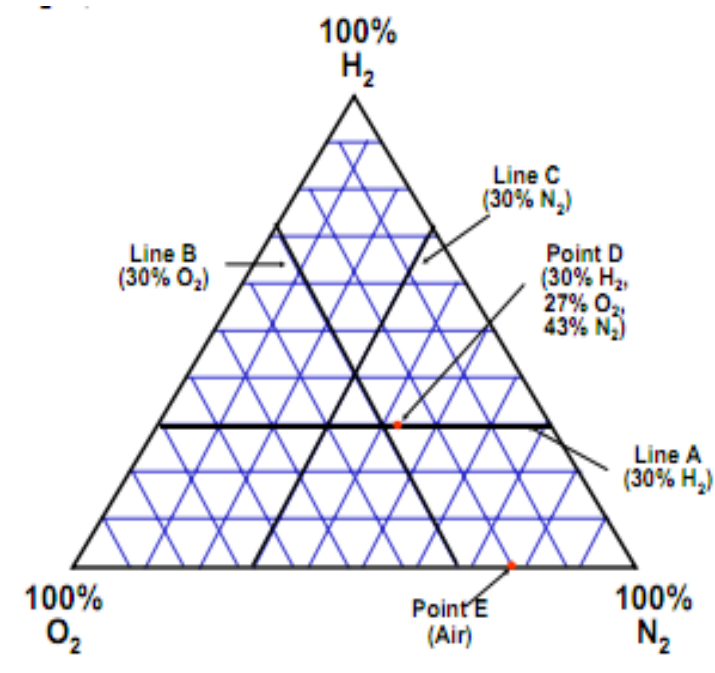

a) without flammability envelope

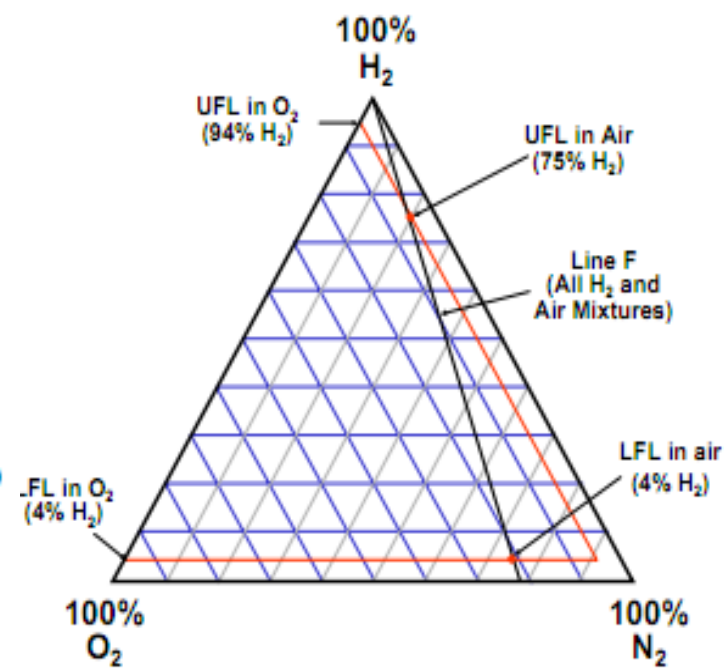

b) with flammability envelope

Figure 2.6 Tertiary diagram for hydrogen, oxygen and nitrogen

\subsubsection{USBM method}

Zabetakis presented a simplified graphic method for determining the explosibility of mine atmospheres under mine fire conditions from mine atmosphere composition data (Zabetakis, et al., 1959b). This method is also called the USBM 
explosibility diagram. It is a popular method widely used in the U.S. mining industry.

Figure 2.7 shows the diagram developed by Zabetakis. This diagram shows that methane-air-inert gas mixtures fall into one of three categories: (A) explosive, (B) explosive when mixed with air, or (C) non-explosive, depending on the percentage of methane and the percentage of "effective inert." (Kissell, 2006). The effective inert can be obtained from the excess nitrogen percentage and the carbon dioxide percentage. The arrows in the diagrams indicate how the composition point moves if more methane, air or inert gas is added within this diagram. It is a simple method to determine the explosibility of the gas-mixture.

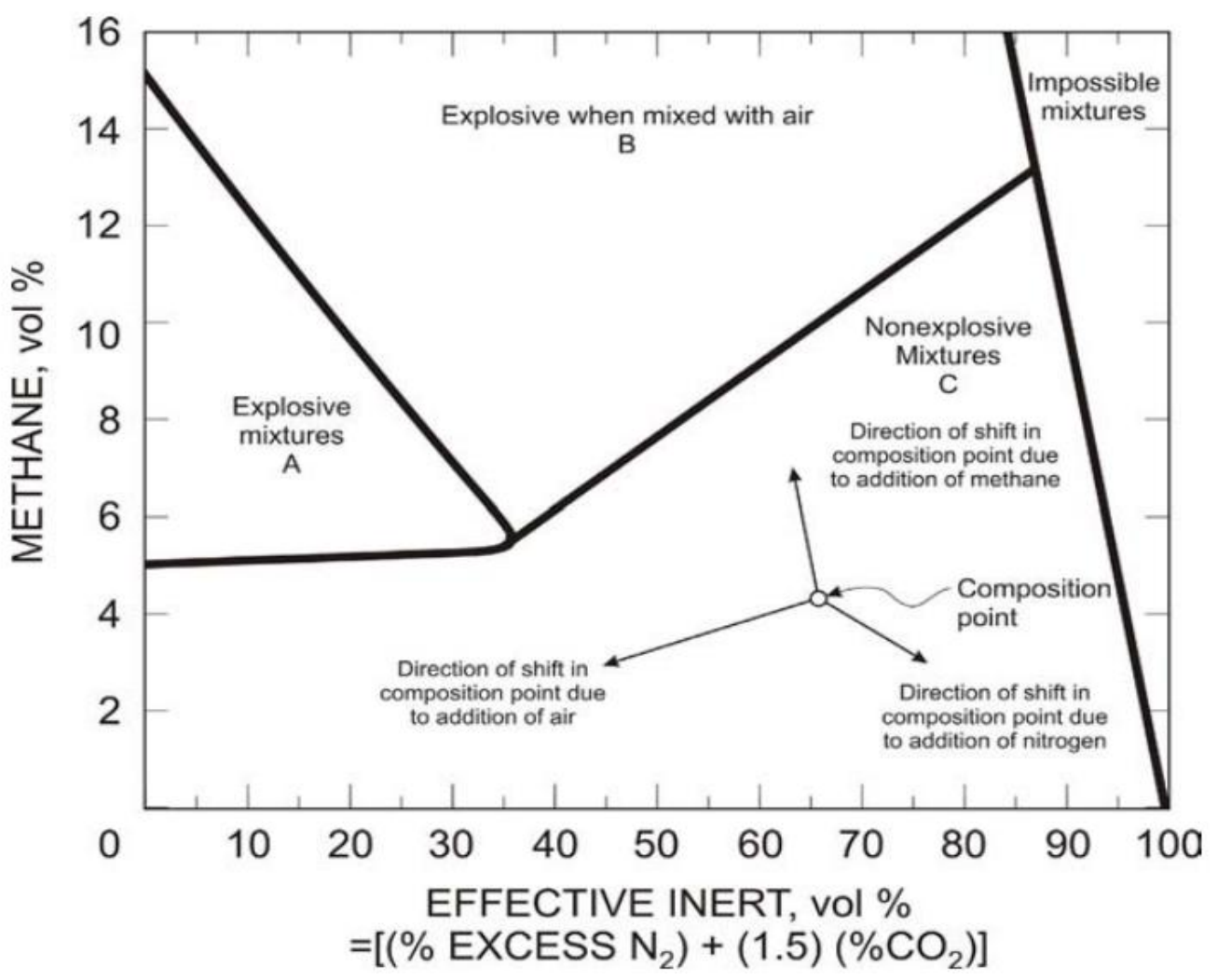

Figure 2.7 Methane explosibility diagram (Zabetakis, et al., 1959b) 


\subsubsection{Maximum Allowable Oxygen (MAO) analysis}

A quantity of oxygen required for a flame propagation. Therefore, the Maximum Allowable Oxygen (MAO) analysis can be used to determine if the atmosphere is inert or will become explosive (Timko \& Derick, 2006). To use this method, the ratio $\mathrm{R}$ should be calculated using the following equation:

$$
R=\frac{\% \mathrm{CH}_{4}}{\% \mathrm{CH}_{4}+\% \mathrm{H}_{2}+\% \mathrm{CO}}
$$

Then, using the R-value to find the corresponding MAO value by referring to Figure 2.8, the status of the atmosphere could be determined. If the actual measured oxygen concentration is less than the MAO, the atmosphere cannot be ignited in its present state. Conversely, it may be considered as explosive. However, the non-explosive atmosphere may become explosive when mixed with air since more oxygen would make the oxygen concentration over the MAO.

The MAO analysis provide an easy and simply way to judge the status of the sealed atmosphere. But a big drawback of this method is hard to tell whether the atmosphere is explosive if the measured oxygen value is greater than the MAO. Under such conditions, the explosibility diagrams need to be used to analyze the composition again. 


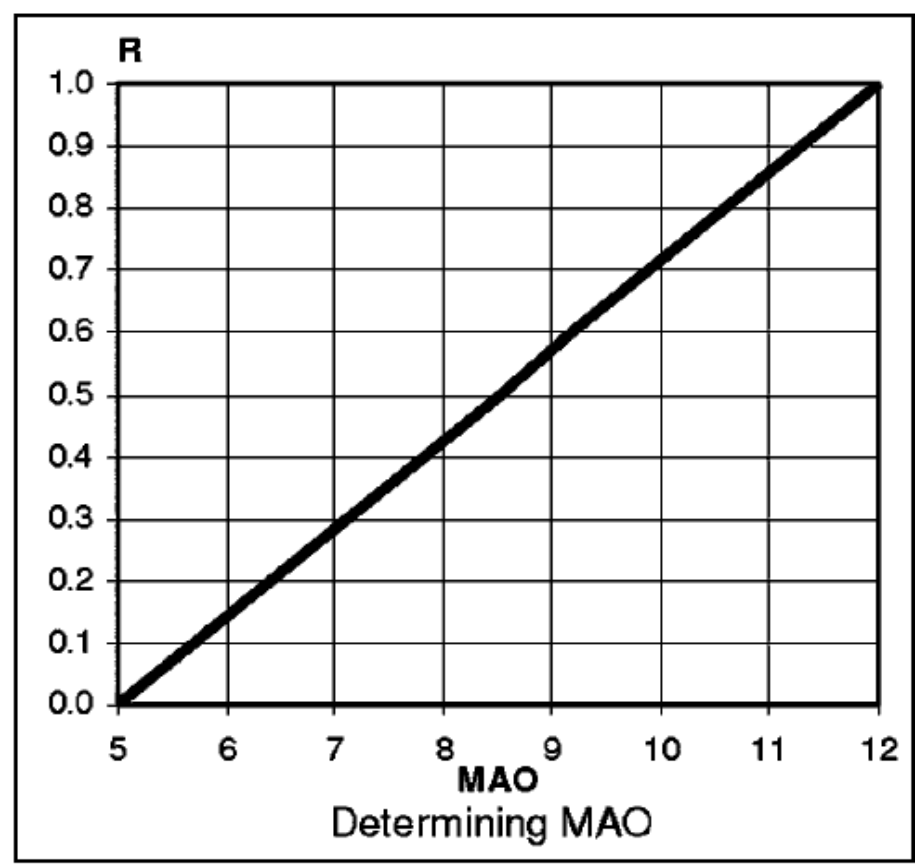

Figure 2.8 Determining MAO (Timko \& Derick, 2006)

\subsubsection{Revised Le Chatelier's method}

The flammability limits of complex gases, which are a mixture of several flammable gases, can be derived with the help of Le Chaterlier's rule. This rule is based on the assumption that the individual flammable constituents do not react with or on one another nor do they have any catalytic influence upon each other.

For mixtures of complex gases with air and inert diluents, the influence of the ratio of inert gas on the flammability limits has to be taken into account (Greuer, 1974). Figure 2.9 shows these limits for hydrogen, carbon monoxide and methane diluted with nitrogen or carbon dioxide when mixed with air. The upper and lower limits of mixtures of complex gases with inert gases is dissected into simpler mixtures, each of which contains only one flammable gas and mix- 
tures are determined from tables or graphs like Figure 2.9. If $P_{n}$ is the volume percent of the dissected mixtures and $N_{n}$ is the corresponding flammable limit. The resultant flammable limit, $L$, of the total mixtures of complex and inert gases when mixed with air can also be calculated based on the Le Chaterlier's principles:

$$
L=\frac{100}{\frac{P_{1}}{N_{1}}+\frac{P_{2}}{N_{2}}+\cdots \cdots+\frac{P_{n}}{N_{n}}}
$$

This method has shown sufficient accuracy for mixtures of hydrogen, carbon monoxide and methane with nitrogen, and carbon dioxide and can therefore be used for mine fire gases.

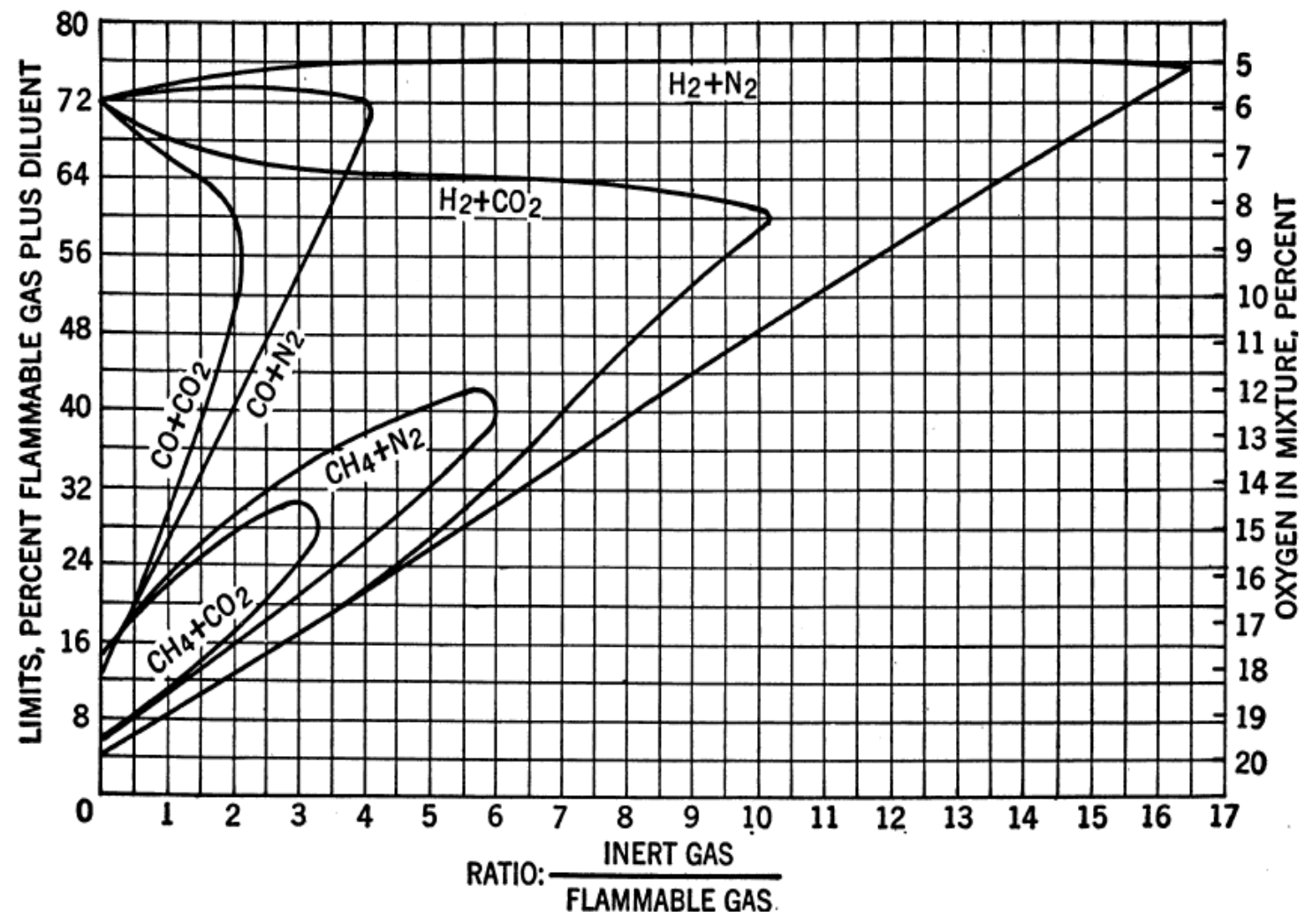

Figure 2.9 Limits of flammability of hydrogen, carbon monoxide, and methane containing various amounts of carbon dioxide and nitrogen (Greuer, 1974) 


\subsubsection{Kukuczka method}

A polish scientist, Kukuczka, also analyzed the problem of influences by inert gas on flammability limits and developed a series of mathematical formulas to correct the position of the mixture gas point in his explosive determination model (Kukuczka, 1982). The calculation procedure is described as follows (Yu, 1992):

- Determine the explosive triangle;

- Determine the influential factor " $\alpha$ " for the flammable limit due to the contained carbon dioxide;

$$
\alpha=\frac{P_{\mathrm{CO}_{2}}-0.03}{P_{\mathrm{CO}_{2}}+P_{\mathrm{N}_{2}}-3.778 \times P_{\mathrm{O}_{2}}}
$$

- Determine the total combustibles percentage;

$$
\begin{aligned}
P_{T}= & P_{\mathrm{CH}_{4}}+P_{C O}+P_{\mathrm{H}_{2}}+P_{\mathrm{C}_{2} \mathrm{H}_{2}} \\
& +P_{\mathrm{C}_{2} \mathrm{H}_{4}}+P_{\mathrm{C}_{2} \mathrm{H}_{6}}+P_{\mathrm{C}_{3} \mathrm{H}_{6}}+P_{\mathrm{C}_{3} \mathrm{H}_{8}}
\end{aligned}
$$

- Determine the influential factor " $\beta$ "for each combustible gas due to the contained carbon dioxide;

$$
\beta_{i}=\frac{20.93-\left(P_{O_{2}}+0.2093 P_{T}\right)}{a_{i}-b_{i} \alpha}
$$

Note: If the value of " $\beta$ "is over "1", it must be reset as "1".

- Determine the position of the actual gas-mixture point or state point;

a) Eq. (2.9) can be used to compute the "X" coordinates (Combustible gas percentage) 


$$
X=\sum_{i=1}^{n}\left(c_{i}+d_{i} P_{T}+e_{i} P_{O_{2}}+\alpha \beta_{i} f_{i}\right) \times \frac{P_{i}}{P_{T}}
$$

b) Eq. (2.10) can be used to compute the "Y" coordinates (Oxygen percentage)

$$
Y=\sum_{i=1}^{n}\left(c_{i}^{\prime}+d_{i}^{\prime} P_{T}+e_{i}^{\prime} P_{O_{2}}+\alpha \beta_{i} f_{i}^{\prime}\right) \times \frac{P_{i}}{P_{T}}
$$

Where $P_{i}$ is the volumetric percentage of a certain combustible gas, $a_{i}, b_{i}, c_{i}, d_{i}, e_{i}, f_{i}, c_{i}^{\prime}, d_{i}^{\prime}, e_{i}^{\prime}, f_{i}^{\prime}$ are corresponding coefficients for different combustibles and their values are listed in Table 2.1.

The relative position between the explosibility triangle and the state point shows the explosibility status of the air-gas-mixture at the current state and the potential when conditions change.

\begin{tabular}{|c|c|c|c|c|c|c|c|c|c|c|}
\hline \multirow[b]{2}{*}{ Gas } & \multicolumn{10}{|c|}{ Coefficients } \\
\hline & $a_{i}$ & $b_{i}$ & $c_{i}$ & $d_{i}$ & $e_{i}$ & $f_{i}$ & $c_{i}^{\prime}$ & $d_{i}^{\prime}$ & $e_{i}^{\prime}$ & $f_{i}^{\prime}$ \\
\hline Methane $\left(\mathrm{CH}_{4}\right)$ & 10.376 & 3.016 & 0 & 1 & 0 & -0.78 & 0 & 0 & 1 & $\begin{array}{c}- \\
2.852\end{array}$ \\
\hline Hydrogen $\left(\mathrm{H}_{2}\right)$ & 14.918 & 3.533 & 4.643 & 0.140 & $\begin{array}{c}- \\
0.010\end{array}$ & $\begin{array}{c}- \\
0.107\end{array}$ & 5.401 & 0.116 & 0.698 & $\begin{array}{c}- \\
2.435\end{array}$ \\
\hline $\begin{array}{l}\text { Carbon monox- } \\
\text { ide (CO) }\end{array}$ & 13.039 & 3.396 & 3.117 & 0.161 & $\begin{array}{c}- \\
0.007\end{array}$ & $\begin{array}{c}- \\
0.400\end{array}$ & 3.622 & 0.133 & 0.797 & $\begin{array}{c}- \\
2.619\end{array}$ \\
\hline Ethylene $\left(\mathrm{C}_{2} \mathrm{H}_{4}\right)$ & 14.269 & 3.526 & 4.121 & 0.385 & $\begin{array}{c}- \\
0.009\end{array}$ & $0 . \overline{-} 16$ & 4.849 & 0.072 & 0.729 & $2 . \overline{-}$ \\
\hline Ethane $\left(\mathrm{C}_{2} \mathrm{H}_{6}\right)$. & 11.872 & 2.909 & 1.937 & 1.052 & 0.005 & $0 . \overline{724}$ & 2.233 & $\begin{array}{c}- \\
0.037\end{array}$ & 0.875 & $2 . \overline{-}$ \\
\hline Propene $\left(\mathrm{C}_{3} \mathrm{H}_{6}\right)$. & 12.869 & 3.383 & 2.934 & 1.098 & $0 . \overline{-}$ & $0 . \overline{4} 29$ & 3.442 & 0.061 & 0.808 & 2.637 \\
\hline Propane $\left(\mathrm{C}_{3} \mathrm{H}_{8}\right)$ & 12.105 & 3.294 & 2.164 & 1.382 & $\begin{array}{c}- \\
0.005\end{array}$ & $\begin{array}{c}- \\
0.538\end{array}$ & 2.537 & $\begin{array}{c}- \\
0.110\end{array}$ & 0.858 & $\begin{array}{c}- \\
2.710\end{array}$ \\
\hline Acetylene $\left(\mathrm{C}_{2} \mathrm{H}_{2}\right)$ & 15.308 & 3.577 & 4.901 & 0.127 & $\begin{array}{c}- \\
0.011\end{array}$ & $\begin{array}{c}- \\
0.045\end{array}$ & 5.719 & 0.115 & 0.680 & $\begin{array}{c}- \\
2.415\end{array}$ \\
\hline
\end{tabular}

\section{Table 2.1 Values of different coefficients}




\section{CHAPTER 3 MATHEMATICAL MODEL FOR SIMU- LATING ATMOSPHERE IN A SEALED COAL MINE VOLUME}

\subsection{Introduction}

Coal mine explosions from the sealed area often cause large casualties and enormous property damage. They present the most hazards for the coal mining industry. In order to eliminate the risk of mine explosion, sealing off the old mine workings in an extensively used measure in underground coal mines. The functions of sealing are shown in the following aspects. Firstly, it is a good way to improve mine ventilation efficiency. Normally, underground coal mines choose to seal old mined-out areas so that ventilation to these areas is no longer needed to save the ventilation costs. Secondly, sealing the old mine areas can isolate the contaminants generated in the sealed volume and their associated hazards from the active mine workings. For an example, building seals is often implemented to extinguish large mine fire events. It can provide a help to reduce numerous air-gas-exchanges between the mine fire zone and the active working areas. As the combustion-support (oxygen) in the sealed area depletes, the mine fire will enter the "decay" stage. In other words, mine fires can be controlled sooner.

In general, once a mined area is sealed the atmospheric composition concentrations would change over the time. However, because of its inaccessibility, it is impossible to perform any direct measurements. For effectively managing the atmosphere in the sealed areas, it is very important to know the gas composi- 
tions and their changing patterns in advance. This chapter deals with the development of the mathematical model for simulating the atmospheric compositions in the sealed mine areas.

\subsection{Factors Controlling the Mine Atmospheric Compositions}

\subsubsection{Barometric pressure change}

Barometric pressure is the force that is exerted on objects by the weight of the air above them. Because of the effect of earth's gravity upon the air, the air pressing down to the earth causes air pressure. When it is measured, this force is referred to as barometric pressure. Sometimes, barometric pressure is often referred to as atmospheric pressure.

The barometric pressure changes depend on a number of factors, such as temperature, elevation, location, weather condition, etc. Essentially, the changes are caused by the atmospheric heating and cooling on the surface of earth. Due to the uneven heat distribution in a region, the thermodynamic relationships for gases can make the expansion or contraction of a body of gas so as to change the barometric pressure.

The effect of the barometric pressure changes to influence gas compositions in a sealed volume is shown in the following aspects. First, when the barometric pressure changes, it can affect the gas emission not only from the active mining seam itself, but also from the overlying and underlying strata into the mined coal seam (Yuan \& Simth, 2007). Second, the expansion or contraction of 
the gas within a sealed volume is related to the change of barometric pressure. As the atmosphere within a sealed area expands, gases leave the sealed area at a certain rate through the mine seals or other leakage paths. Francart \& Beiter (1997) reported that, based on the Boyle's law, a barometric pressure change of 0.50 inches of mercury over 12 hours can create the expansion of 235 cubic feet per minute for an unrestricted air volume of 10,000,000 cubic feet. In addition, in some circumstances, the change of the barometric pressure is even more a mine fan can provide. According to the base method for estimating ventilation requirement listed in SME handbook, the mine fan head for a coal mine with 10,000 tons daily production (3.65 M tons/year) can be estimated as 0.44 inches of mercury. On the other hand, based on a recorded typical barometric pressure variation over a 22-day period in western Pennsylvania area reported by Yuan \& Smith (2007), the biggest pressure change can be expected as 1.3 inches of mercury which is more than two times of a mine fan' ability.

Measurements of surface barometric pressure reveal that their fluctuations underlying any short-term or longer-term variations (Platzman, 1996). The typical curves of barometric pressures include a diurnal, a monthly and an annual fluctuation curve.

The diurnal fluctuation rhythm is the result of surface temperature variations. Due to the warming of the upper atmosphere (mainly the thermosphere) by the sun, Bernhard discovered that waves move across the upper atmosphere, westward with the speed of the sun. Upper level variations of temperature distort isobaric surfaces (Platzman, 1996). According to surface pressure measure- 
ments, a-rule-of-thumb shows that the pressure is typically the lowest around 4 p.m. and the highest around 10 a.m. local standard time. A typical diurnal pressure fluctuation can be shown in Figure 3.1.

The seasonal or annual barometric pressure variation is also induced by the temperature. Throughout the year, as the earth orbits the sun, many parts of the earth experience changing seasons. That is because the axis of the earth is tilted slightly resulting in part of the earth leaning towards the sun, while part of it is hidden either beneath the earth or above it. Thus, different parts of the earth's surface receive a different amount of sunlight and heat. Figure 3.1 also illustrates a short-term (2 weeks) behavior of the barometric pressure fluctuation.

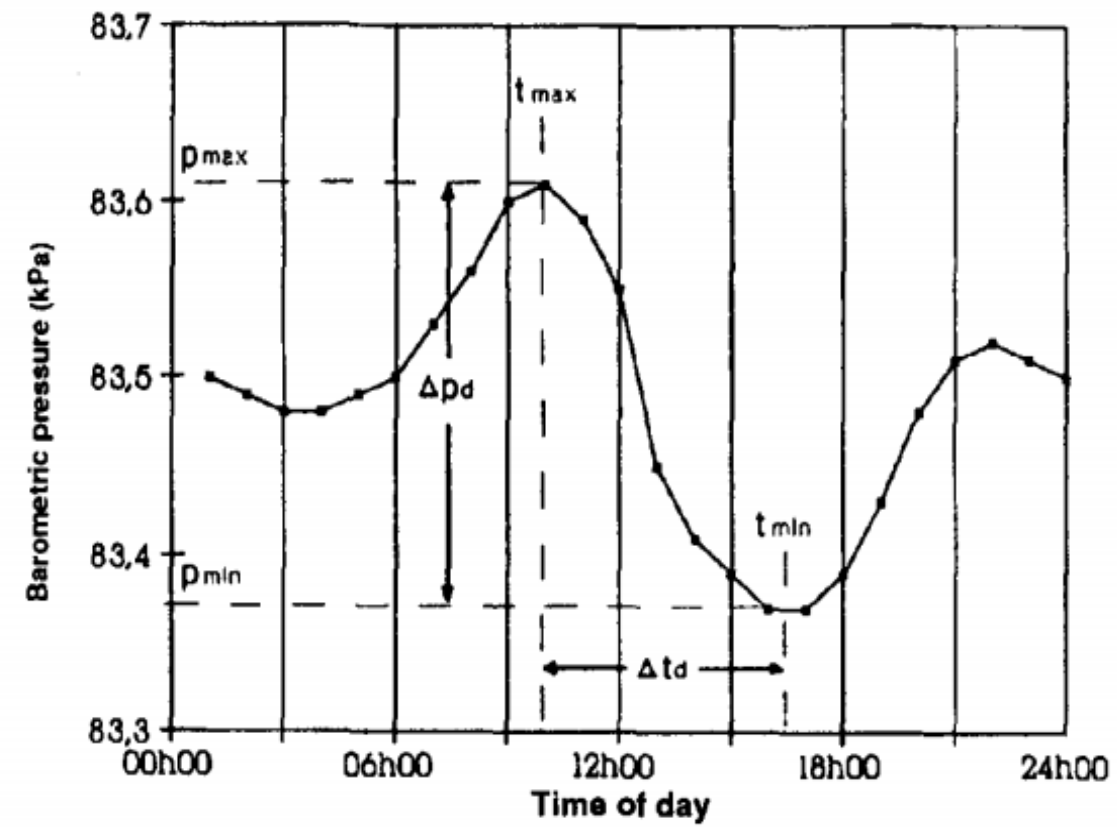

a) Diurnal barometric pressure change (Francart \& Beiter, 1997) 


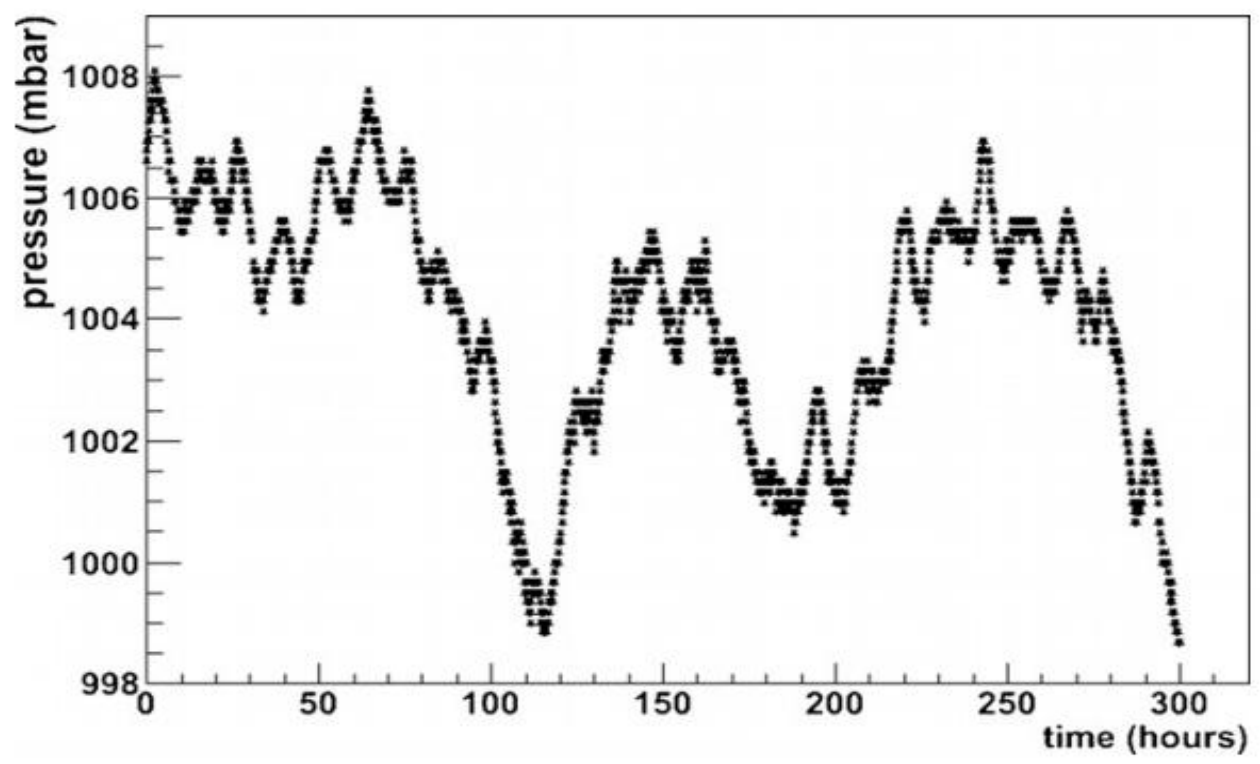

b) Short-term (2 weeks) barometric pressure change (Rocca, et al., 2010)

Figure 3.1 Typical barometric pressure fluctuation curves

Due to the importance of effects on atmospheric compositions in a sealed volume induced by natural barometric pressure, a comprehensive research study should be carried out to quantitatively analyze the barometric pressure and its changing patterns. According to the coalfield distributions in the United States, three typical locations are selected: the Northern Appalachian coalfield, the Central Appalachian coalfield and the Illinois Basin, respectively. In order to accurately represent the typical barometric pressure curve, proper functions can be selected to describe corresponding pressure curves by using mathematical curve fitting of the measurements of local barometric pressures.

For diurnal pressure fluctuation curves, $5^{\text {th }}$ degree polynomial function could be used to fit the actual data by using least-squares method and the vertical deviation $R^{2}$ of fitting is over 0.96 . The general mathematical expression equation is shown in Eq. (3.1). Table 3.1 summarizes all coefficients used in Eq. (3.1). 


$$
P_{b}=a t^{5}+b t^{4}+c t^{3}+d t^{2}+e t+f
$$

where: $P_{b}$ is the barometric pressure, in- $\mathrm{Hg}$;

$t$ is the time, s;

$a, b, c, d, e$ and $f$ are coefficients.

Table 3.1 Coefficients in Eq. (3.1)

\begin{tabular}{lcccccc}
\hline \multirow{2}{*}{ Location } & \multicolumn{5}{c}{ Coefficients } \\
\cline { 2 - 7 } Northern & $a$ & $b$ & $c$ & $d$ & $e$ & $f$ \\
$\begin{array}{l}\text { Appalachian } \\
\text { Central }\end{array}$ & $-1.2803 \mathrm{E}-10$ & $4.4386 \mathrm{E}-08$ & $-5.3379 \mathrm{E}-06$ & $2.7816 \mathrm{E}-04$ & $-8.0211 \mathrm{E}-03$ & $3.0011 \mathrm{E}+01$ \\
$\begin{array}{l}\text { Appalachian } \\
\text { Illinois }\end{array}$ & $8.1510 \mathrm{E}-10$ & $-4.5315 \mathrm{E}-08$ & $-3.9332 \mathrm{E}-06$ & $2.6956 \mathrm{E}-04$ & $-3.4592 \mathrm{E}-03$ & $3.0130 \mathrm{E}+01$ \\
Basin & $2.8845 \mathrm{E}-09$ & $6.1585 \mathrm{E}-07$ & $-4.6574 \mathrm{E}-05$ & $1.4908 \mathrm{E}-03$ & $-1.5435 \mathrm{E}-02$ & $3.0003 \mathrm{E}+01$ \\
\hline
\end{tabular}

For a monthly pressure fluctuation curve, due to noises existing in the actual data set, it is hard to capture an important pattern within the data. Therefore, smoothing a data set is very useful for identifying important trends in the data and helping to create an approximating function to represent themselves without noise phenomena. "7-Span quadratic smoothing" algorithm is used here for smoothing the data. Figure 3.2 shows their comparisons. 


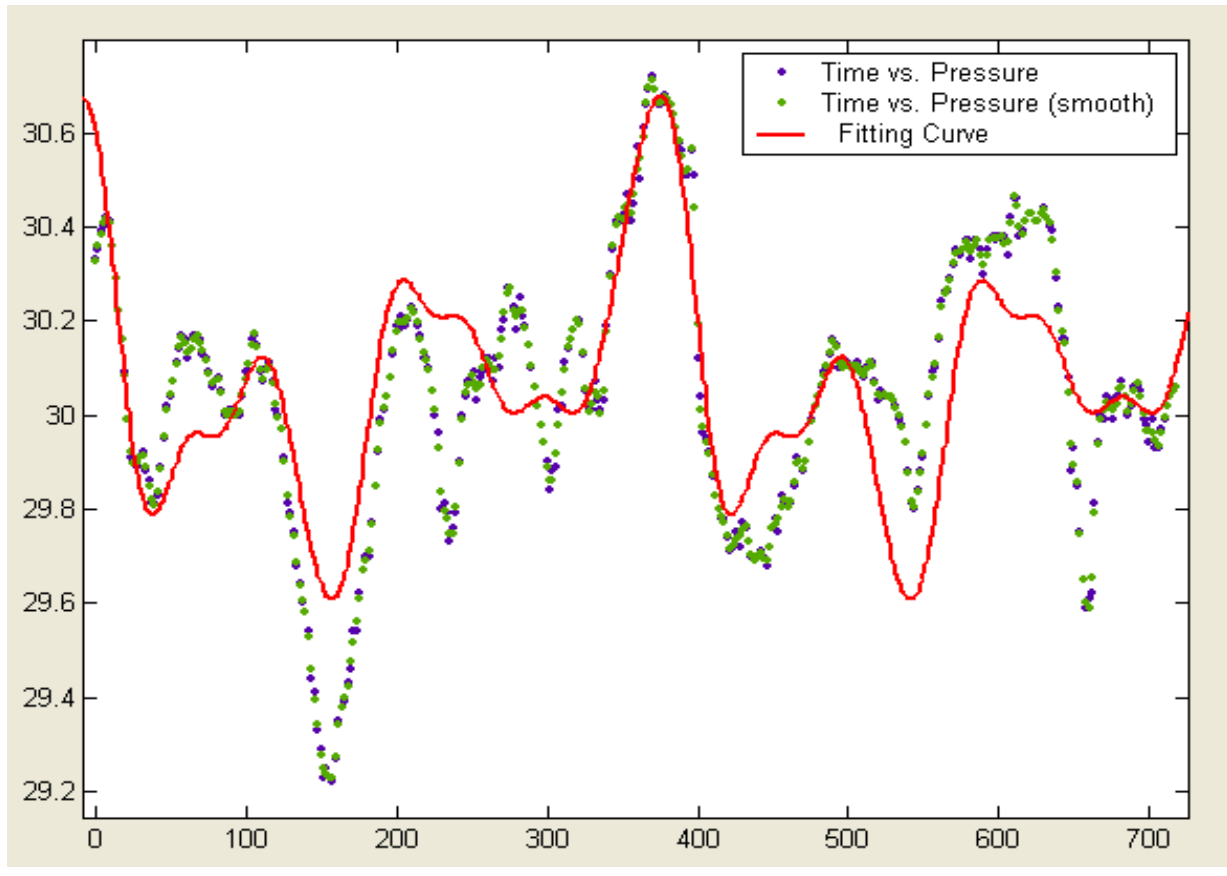

Figure 3.2 Monthly barometric pressure fitting

The purple dots stand for the raw data while the green dots stand for the data after smoothing. Based on the "smoothed" data, the best equation to capture the pattern of the monthly barometric pressure is $8^{\text {th }}$ degree Fourier function.

The general mathematical expression equation for the monthly barometric pressure is shown in Eq. (3.2). Table 3.2 summarizes all coefficients used in Eq. (3.2).

$$
\begin{aligned}
& P_{b}=a 0+a 1 * \cos (t * w)+b 1 * \sin (t * w) \\
& +a 2 * \cos (2 * t * w)+b 2 * \sin (2 * t * w)+a 3 * \cos (3 * t * w)+b 3 * \sin (3 * t * w) \\
& +a 4 * \cos (4 * t * w)+b 4 * \sin (4 * t * w)+a 5^{*} \cos (5 * t * w)+b 5 * \sin (5 * t * w) \\
& +a 6 * \cos (6 * t * w)+b 6 * \sin (6 * t * w)+a 7 * \cos (7 * t * w)+b 7 * \sin (7 * t * w) \\
& +a 8 * \cos (8 * t * w)+b 8 * \sin (8 * t * w)
\end{aligned}
$$

where: $P_{b}$ is the barometric pressure, in. $\mathrm{Hg}$;

$t$ is the time, hr; 
$a 0 \ldots a 8, b 1 \ldots b 8$ and $w$ are coefficients;

Table 3.2 Coefficients in Eq. (3.2)

\begin{tabular}{cccc}
\hline \multirow{2}{*}{ Coefficients } & \multicolumn{3}{c}{ Location } \\
\cline { 2 - 4 } & $\begin{array}{c}\text { Northern } \\
\text { Appalachian }\end{array}$ & $\begin{array}{c}\text { Central } \\
\text { Appalachian }\end{array}$ & $\begin{array}{c}\text { Illinois } \\
\text { Basin }\end{array}$ \\
a0 & $3.0050 \mathrm{E}+01$ & $3.0090 \mathrm{E}+01$ & $2.3920 \mathrm{E}+01$ \\
a1 & $-3.4650 \mathrm{E}-02$ & $9.7090 \mathrm{E}-02$ & $-8.4780 \mathrm{E}+00$ \\
a2 & $1.3930 \mathrm{E}-01$ & $4.8770 \mathrm{E}-02$ & $1.3090 \mathrm{E}+00$ \\
a3 & $-1.1130 \mathrm{E}-01$ & $2.2920 \mathrm{E}-02$ & $9.8570 \mathrm{E}+00$ \\
a4 & $-2.5960 \mathrm{E}-02$ & $-1.2580 \mathrm{E}-03$ & $7.9450 \mathrm{E}+00$ \\
a5 & $-1.3160 \mathrm{E}-01$ & $9.3550 \mathrm{E}-03$ & $4.7450 \mathrm{E}-02$ \\
a6 & $7.9240 \mathrm{E}-02$ & $1.1740 \mathrm{E}-02$ & $-3.3360 \mathrm{E}+00$ \\
a7 & $1.2990 \mathrm{E}-01$ & $1.5370 \mathrm{E}-02$ & $-1.3470 \mathrm{E}+00$ \\
a8 & $5.8080 \mathrm{E}-03$ & $-1.8310 \mathrm{E}-02$ & $1.4120 \mathrm{E}-01$ \\
$b 1$ & $-1.0990 \mathrm{E}-01$ & $6.3000 \mathrm{E}-02$ & $8.9470 \mathrm{E}+00$ \\
$b 2$ & $-1.0210 \mathrm{E}-01$ & $1.8450 \mathrm{E}-02$ & $1.2230 \mathrm{E}+01$ \\
$b 3$ & $4.7700 \mathrm{E}-02$ & $-3.9050 \mathrm{E}-03$ & $5.5760 \mathrm{E}+00$ \\
$b 4$ & $1.1630 \mathrm{E}-01$ & $6.3450 \mathrm{E}-03$ & $-4.3720 \mathrm{E}+00$ \\
$b 5$ & $-7.4490 \mathrm{E}-02$ & $2.8460 \mathrm{E}-02$ & $-6.3570 \mathrm{E}+00$ \\
$b 6$ & $7.0680 \mathrm{E}-02$ & $-5.3830 \mathrm{E}-03$ & $-1.8070 \mathrm{E}+00$ \\
$b 7$ & $-5.1330 \mathrm{E}-02$ & $-2.8230 \mathrm{E}-02$ & $1.1140 \mathrm{E}+00$ \\
$b 8$ & $9.1940 \mathrm{E}-02$ & $1.1920 \mathrm{E}-02$ & $4.2740 \mathrm{E}-01$ \\
$w$ & $8.9700 \mathrm{E}-03$ & $8.4020 \mathrm{E}-03$ & $5.5970 \mathrm{E}-03$ \\
\hline
\end{tabular}

Like fitting a monthly pressure fluctuation curve, smoothing is also needed when processing the measured annual pressure data, and the $6^{\text {th }}$ degree Fourier function is used to describe the wave fluctuation of an annual barometric pressure. The general mathematical expression equation for annual barometric pressure is shown in Eq. (3.3). Table 3.3 summarizes corresponding coefficients.

$$
\begin{aligned}
P_{b}=a 0 & +a 1^{*} \cos \left(t^{*} w\right)+b 1^{*} \sin \left(t^{*} w\right)+a 2^{*} \cos \left(2 * t^{*} w\right)+b 2 * \sin \left(2 * t^{*} w\right) \\
& +a 3^{*} \cos \left(3^{*} t^{*} w\right)+b 3 * \sin \left(3^{*} t^{*} w\right)+a 4^{*} \cos \left(4 * t^{*} w\right)+b 4 * \sin \left(4 * t^{*} w\right) \\
& +a 5^{*} \cos \left(5 * t^{*} w\right)+b 5 * \sin \left(5 * 5^{*} w\right)+a 6^{*} \cos \left(6 * 6^{*} w\right)+b 6 * \sin \left(6 * 6^{*} w\right)
\end{aligned}
$$

where: $P_{b}$ is the barometric pressure, in. $\mathrm{Hg}$;

$t$ is the time, $\mathrm{hr}$;

$a 0 \ldots a 6, b 1 \ldots b 6$ and $w$ are coefficients; 
Table 3.3 Coefficients in Eq. (3.3)

\begin{tabular}{|c|c|c|c|}
\hline \multirow{3}{*}{ Coefficients } & \multicolumn{3}{|c|}{ Location } \\
\hline & Northern & Central & Illinois \\
\hline & Appalachian & Appalachian & Basin \\
\hline a0 & $3.0050 E+01$ & $3.1050 E+01$ & $-4.9650 E+09$ \\
\hline a1 & -3.0530E-02 & 7.5590E-01 & $7.9600 \mathrm{E}+09$ \\
\hline a2 & $-6.2490 \mathrm{E}-02$ & $-9.6030 \mathrm{E}-01$ & $-3.9760 E+09$ \\
\hline a3 & $3.2580 \mathrm{E}-02$ & $-1.0360 \mathrm{E}+00$ & $1.0810 \mathrm{E}+09$ \\
\hline a4 & $-2.2150 \mathrm{E}-02$ & $-1.0740 \mathrm{E}-01$ & $-6.7950 E+07$ \\
\hline a5 & 3.0870E-02 & 2.9800E-01 & $-3.8120 E+07$ \\
\hline$a 6$ & $-5.3900 \mathrm{E}-02$ & $1.1320 \mathrm{E}-01$ & $7.2070 \mathrm{E}+06$ \\
\hline b1 & 2.0120E-02 & $-1.7310 E+00$ & $3.0840 \mathrm{E}+09$ \\
\hline$b 2$ & $-2.3550 \mathrm{E}-02$ & $-1.1970 E+00$ & $-3.6260 E+09$ \\
\hline b3 & 4.9130E-02 & 2.3570E-01 & $2.1730 \mathrm{E}+09$ \\
\hline b4 & $-2.7550 \mathrm{E}-02$ & $6.5450 \mathrm{E}-01$ & $-7.3970 E+08$ \\
\hline b5 & -1.5070 E-03 & $1.8940 \mathrm{E}-01$ & $1.3330 \mathrm{E}+08$ \\
\hline$b 6$ & -3.1790E-02 & $-7.5560 \mathrm{E}-02$ & $-9.4980 E+06$ \\
\hline$w$ & $1.4610 \mathrm{E}-03$ & 4.8560E-04 & 8.4330E-05 \\
\hline
\end{tabular}

Generally, base on the period of the prediction time, three typical barometric pressure fluctuation curves can be wisely chosen by the simulation mathematical model (will be discussed later in this chapter). For example, if a time span of less than 24 hours is needed to be simulated, the diurnal mathematical fitting equation is going to be used to generate the pressure fluctuation curve, or, if a time span of 240 hours (10 days) is needed, the monthly pressure fluctuation curve can be generated by the corresponding mathematical expression equation to represent the local barometric pressure.

\subsubsection{Coal mine seals}

The Federal Coal Mine Health and Safety Act of 1969 (Coal Act), the predecessor to the existing MINER Act, first recognized that mine operators must seal abandoned and isolated areas of underground coal mines with "explosion 
proof bulkheads" that are to be constructed with "solid, substantial and incombustible materials" for the protection of miners' safety (Kallu, 2009). Currently, mine seals are widely constructed in U.S. underground coal mines. The purpose of building seals is not only to improve the ventilation efficiency with isolating the waste areas of a mine from active workings but also to prevent an explosion which may occur in the sealed atmosphere from propagating to the outside of the seals (Kallu, 2009). Generally, the mine seals are capable of preventing potential explosion, controlling toxic gas leakage into the active mining areas, and also minimizing fresh air leaking into the sealed areas. Building mine seals is also a measure to mitigate the mine accidents especially if there is a risk of spontaneous combustion (Chalmers, 2008). An example gob seal is shown in Figure 3.3.

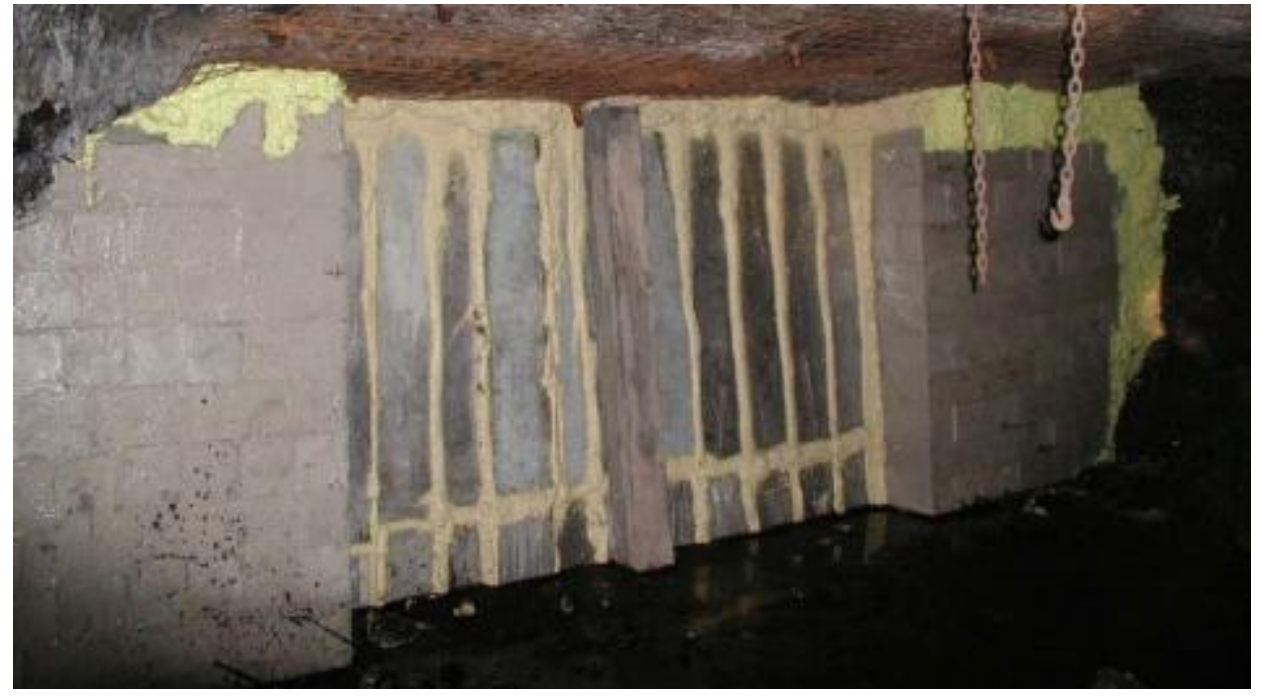

Figure 3.3 Gob seal constructed with steel Kennedy panels and Omega blocks (Stephens, 2011)

The effect of mine seals can be discussed in the following two aspects: The first consideration is the quality of mine seals. Prior to 2006, federal regulations required seals to withstand a 20-psi explosion pressure. Following the Sago 
Mine disaster, Federal regulators prepared to greatly increase the strength requirements for underground mine seals to protect mine workers. On April 18, 2008, MSHA issued "Sealing of Abandoned Areas; Final Rule" which includes requirements for seal strength, design, and construction of seals. The MSHA's new rule requires that mine seals must (MSHA, 2008):

- Withstand 50 psi if the sealed area is monitored and maintained inert;

- Withstand 120 psi if the sealed area is not monitored;

- Withstand greater than $120 \mathrm{psi}$ if the area is not monitored and certain conditions exist that might lead to higher explosion pressure.

Due to the higher requirements, new design methods and materials to build the seals are needed in order to meet the new explosion pressure design criteria. Considering the previously mentioned high design criteria, a better structural integrity of the mine seal is required. That must result in increasing the seal thickness, the shear resistance, or internal bending resistance, etc. Thus, new seals can offer higher capacity to effectively guard against gas expansion (Francart \& Beiter, 1997) and higher air resistance to minimize air-leakage through them.

Researchers and mining engineers have already considered the airleakage across the mine seals. MSHA personnel have developed tentative guidelines for acceptable air-leakage rates through a seal (Weiss, et al., 1993). Table 3.4 shows these maximum acceptable air leakage rates, in $\mathrm{ft}^{3}$ per minute. 
Table 3.4 MSHA-established tentative guidelines for air leakage through a seal

(Weiss, et al., 1993)

\begin{tabular}{cc}
\hline Pressure differential $\left(\right.$ in- $\left.\mathrm{H}_{2} \mathrm{O}\right)$ & Air-leakage through seals $\left(\mathrm{ft}^{3} / \mathrm{min}\right)$ \\
\hline Up to 1.0 & $\leq 100$ \\
Up to 2.0 & $\leq 150$ \\
Up to 3.0 & $\leq 200$ \\
More than 3.0 & $\leq 250$ \\
\hline
\end{tabular}

Zipf \& Mohamed (2010) proposed the following equation to calculate the quantity of air-leakage through a mine seal.

$$
Q_{L}=L_{C} \sqrt{\left|P_{t}(t)-P_{b}(t)\right|}
$$

where: $Q_{L}$ is air-leakage flowrate;

$L_{C}$ is leakage coefficient;

$P_{t}(t)$ is total pressure of the sealed atmosphere;

$P_{b}(t)$ is barometric pressure outside of the sealed atmosphere.

The value of leakage coefficient, $L_{C}$, can be referred as Table 3.5.

Table 3.5 Values for leakage coefficient into sealed atmosphere (Weiss, et al., 1993, Weiss, et al., 1996; Zipf \& Mohamed, 2010)

\begin{tabular}{cccc}
\hline & $\begin{array}{c}\text { Leakage } \\
\text { quantity } \\
\left(\mathrm{m}^{3} / \mathrm{s}\right)\end{array}$ & $\begin{array}{c}\text { Pressure } \\
\text { differential } \\
(\mathrm{Pa})\end{array}$ & $\begin{array}{c}\text { Leakage } \\
\text { coefficient } \\
\left(\mathrm{m}^{3} / \mathrm{s} / \mathrm{Pa}^{1 / 2}\right)\end{array}$ \\
\hline $\begin{array}{c}\text { Lowest values measured at } \mathrm{NIOSH} \\
\text { Old MSHA guideline for } 140 \mathrm{kPa} \\
\text { seals }\end{array}$ & 0.019 & 1000 & 0.0006 \\
\hline
\end{tabular}

In 1854, J.J. Atkinson published an equation that was originally derived from the Chezy-Darcy fluid flow equation. It is perhaps the most widely used equation in mine ventilation.

$$
\Delta P=\frac{k \cdot L \cdot O \cdot V^{n}}{A}
$$

where: $\Delta p$ is differential pressure; 
$L$ is length of the mine entry;

$O$ is perimeter of the mine entry;

$V$ is average velocity;

$n$ is power coefficient, : laminar flow, $n=1$; turbulent flow, $n=2$;

$A$ is cross-sectional area;

$k$ is friction coefficient;

In mines, airflow quantities are calculated from of the average air velocity and cross-sectional area of an airway.

$$
Q=V \cdot A
$$

where: $Q$ is airflow quantity.

Generally, the state of airflow though the mine seals is turbulent flow. Therefore, substituting Eq. (3.6) into Eq. (3.5) yields:

$$
\Delta P=\left(\frac{k \cdot L \cdot O}{A^{3}}\right) \cdot Q^{2}
$$

The first part on the right side of Eq. 3.7 containing coefficient $k$ and airway parameters $L, O$ and $A$ is termed the airway resistance, $R$. Thus, the above Equation can be simplified to what is commonly called the Square Law of mine ventilation. The typical $R$ values for mine stoppings and seals are shown in Table 3.6.

$$
\Delta P=R \cdot Q^{2}
$$


Table 3.6 Suggested resistance values for stoppings and seals $\left(\mathrm{Ns}^{2} / \mathrm{m}^{8}\right)$ (After Stephens, 2011)

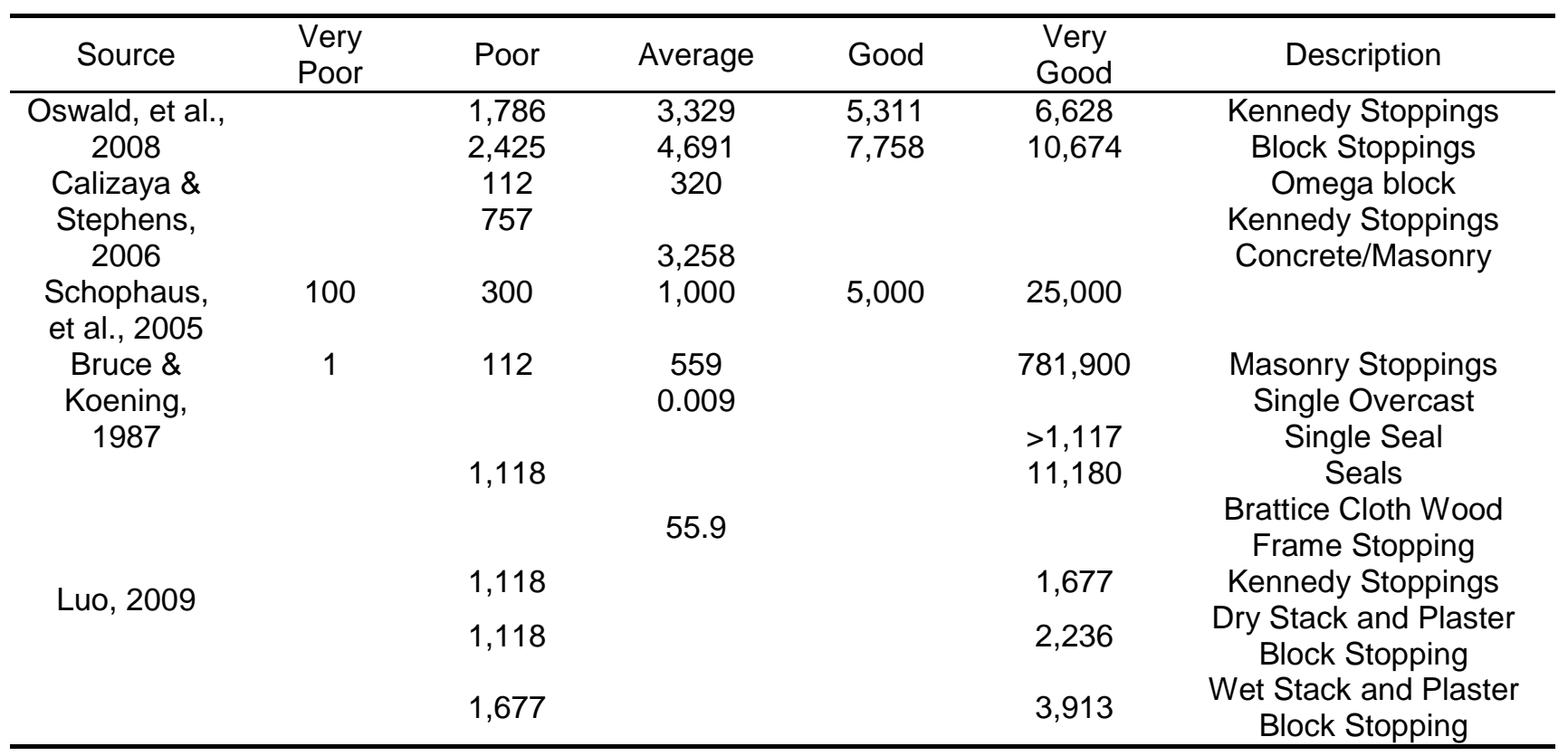

The second consideration is the number of mine seals used during sealing of an abandoned area in underground mines. Seals are often built in entries around the sealed area. Logically speaking, these seals are parallel with each other and can be considered in parallel relationship. Based on Kirchhoff's Voltage Law (KVL), an equivalent resistance $R_{e}$ for $n$ number of airways in parallel can be determined by:

$$
\frac{1}{\sqrt{R_{e}}}=\frac{1}{\sqrt{R_{2}}}+\frac{1}{\sqrt{R_{2}}}+\ldots+\frac{1}{\sqrt{R_{n}}}
$$

The prerequisite to use Eq. (3.9) is that all the seals share two common pressure nodes and thus subjected to the same pressure head. It may not be met in the underground reality. However, since the pressure differences of all the parallel seals are insignificant, therefore, it can be used to determine the equivalent resistance. 
In the case of coal mines, similar characteristics, such as physical dimension, materials, etc., are often encountered in mine seals. Therefore, assuming the resistances of all the seals have same characteristics and Eq. (3.9) is more usefully written as:

$$
R_{e}=\frac{R}{n^{2}}
$$

The resultant equation for a set of $n$ mine seals with combining Eq. (3.8) and Eq. (3.10) yields:

$$
\Delta P=\frac{R}{n^{2}} \cdot Q^{2}
$$

or

$$
Q=n \sqrt{\frac{\Delta P}{R}}
$$

It shows that the more seals used results in more airflow quantity leaking though seals.

\subsubsection{Gas compositions in a sealed mine volume}

In a sealed mine volume, the following categories of gases make up the sealed mine atmosphere. They are: (1) atmospheric gases, (2) products of chemical reactions in underground mines including low temperature coal oxidation, combustion or gas explosions, and (3) coal gases emitted from the virgin coal seams, such as $\mathrm{CH}_{4}, \mathrm{CO}_{2}$ and $\mathrm{H}_{2}$; and other inert gas, $\mathrm{N}_{2}$ or $\mathrm{CO}_{2}$, injected into 
the sealed volume in order to extinguish the mine fire events or minimize the risk of potential explosions.

Atmospheric gases refer to the gases found in an ambient gas sample. Almost $99 \%$ consist of nitrogen and oxygen; the remaining gases are very small quantities of argon and carbon dioxide.

Products of chemical reactions in underground mine include the alkane $\left(\mathrm{C}_{n} \mathrm{H}_{2 n+2}\right)$, alkene $\left(\mathrm{C}_{n} \mathrm{H}_{2 n}\right)$ and alkyne $\left(\mathrm{C}_{n} \mathrm{H}_{2 n-2}\right)$ series of hydrocarbon gases. These gases are not often detected in underground atmosphere. Only when a chemical reaction such as mine fire, coal oxidation, combustion, etc. exists, these gases can be produced in significant amounts. The progression of evolving gases is dependent on the temperature of oxidation.

The total amount of the hydrocarbon gases is not very larger. Typically, it only makes up to less $1 \%$ (can be slightly higher when mine fire is severe). However, due to their wide explosive ranges, they have a great effect on the explosibility of a sealed volume.

Coal gases liberated from the virgin coal seams include $\mathrm{H}_{2} \mathrm{~S}, \mathrm{CO}_{2}, \mathrm{CH}_{4}$; etc. The most important gas is $\mathrm{CH}_{4}$ that is produced by bacterial and chemical action on organic materials. It is evolved during the formation of coal. $\mathrm{CH}_{4}$ is particularly dangerous because coal contains a large amount and it is easily flammable and can form an explosive mixture with air. $\mathrm{CH}_{4}$ is retained by coal on its micro-surfaces and in its voids and pores. When the strata are disturbed and coal is mined, the gas pressure gradient that is created induces migration of the $\mathrm{CH}_{4}$ 
towards those mine openings through natural or mining-induced fracture patterns (McPherson, 1993).

Coal gas (mainly $\mathrm{CH}_{4}$ ) emission in the underground mine is influenced by various factors, such as: gassy condition, geological condition, barometric pressure, etc. For an instance, Mitchell (1996) reported that a short-term high gas emission rate would happen during periods of falling barometric pressure, and it may cause explosive gas leakage flowing into the active mine atmosphere from sealed areas and result in an explosion hazard somewhere in the mine.

Mine gas emission is also affected by the mining activities. Figure 3.4 shows different gas emission in different stages. When the longwall face is in production, gas emission keeps at a high rate due to large gases librated from broken coal. However, once the longwall face stops production or the panel is sealed, the gas emisson goes into the decline stages. In post-production period, there are two physical processes/stages controlling gas emission versus time; rapid gas decay - 'Stage 1' and slow gas decay - 'Stage 2' (Lunarzewski, 2003):

Stage 1 can be identified in the following three initial periods:

- One month - the most rapid decay - up to $50 \%$ of final gas emission;

- Two months - second rapid decay - up to $70 \%$ of final gas emission; and

- Six to fourteen months - stabilized period. 


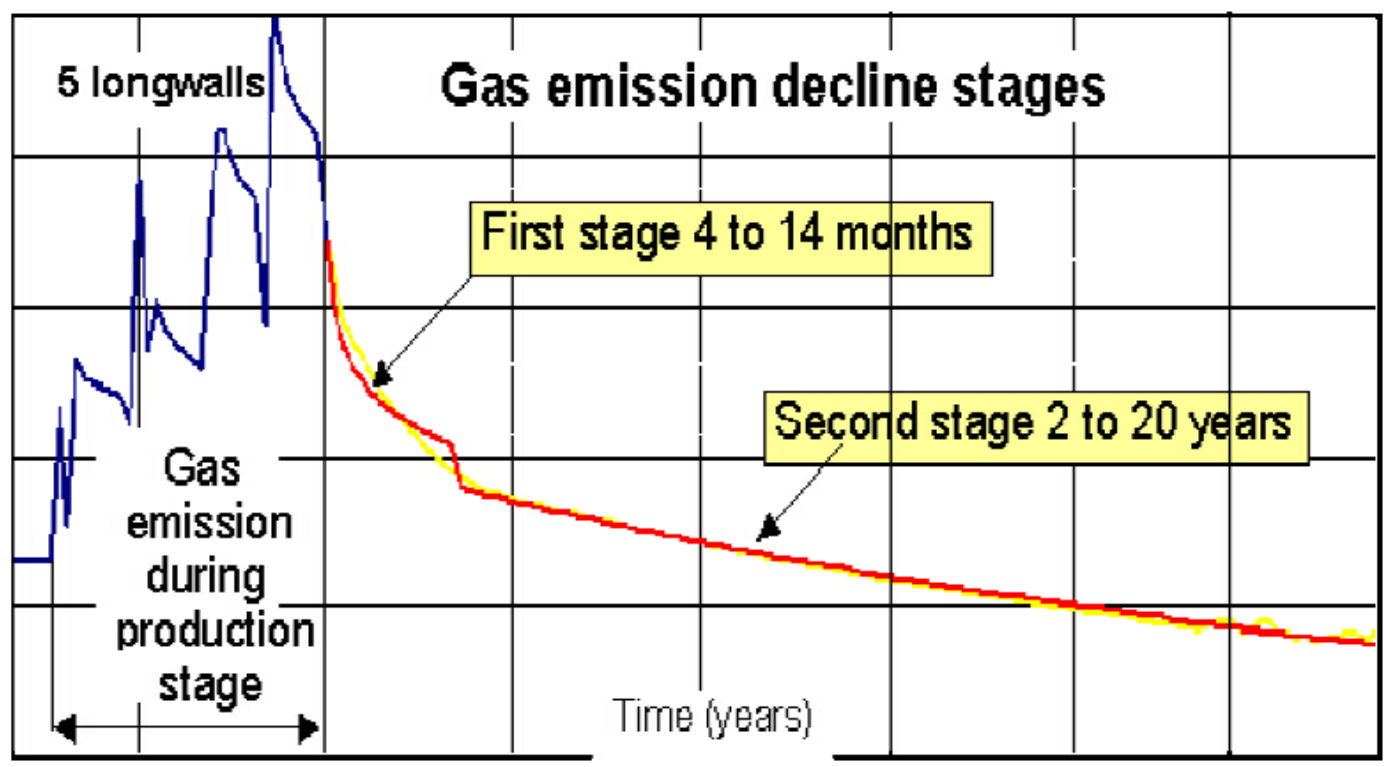

Figure 3.4 Longwall extraction and sealed gob gas emission trend changes (Lunarzewski, 2003)

Lunarzewski (1993) proposed the following logarithmic approximation function to fit the emission rate curve:

$$
\text { Gas Emission Rate }=-A \cdot \ln (\text { Time })+B
$$

Coefficient ' $A$ ' is dependent on: 1) roof and/or floor gas sources position; 2) gas emission rate (permeability); 3) mining depth; and 4) barometric pressure changes.

Coefficient 'B' defines gas emission initial range and strata permeability and is dependent on: 1) the final methane emission rate; 2) gob capacity; 3) specific gas emission (SGE); and 4) sealed gob area tightness.

Stage 2 can continues up to 20 years after the cessation of longwall production, and can use the exponential approximation function to obtain the best fitting: 


$$
\text { Gas Emission Rate }=C \cdot e^{-D \cdot(\text { Time })}
$$

Coefficients ' $C$ ' and ' $D$ ' define gas reservoir capacity and are dependent on: 1) final methane emission rate; 2) gobs capacity; 3) roof and/or floor gas sources position, and 4) virgin and remaining in-situ gas contents.

If the coal spontaneous combustion event or a large mine fire occurs in an underground mine, mine operators often decide to control and, if possible, extinguish it by sealing the affected mine area. A number of methods can be used for this purpose. Among these, the most practical and powerful method of dealing with mine fire is to inject inert gas into the sealed mine volume. This technique originally rose in the 1950's but was significantly developed through the 1980's. The purposes of using this technique can be listed as follows (McPherson, 1993):

- To accelerate the development of an inert atmosphere in a newly sealed zone and to prevent the creation of an explosive mixture when it is re-opened;

- To prevent concealed heating in zones that are highly susceptible to spontaneous combustion;

- To reduce the explosion risk during sealing or stopping-off procedures. Generally speaking, two gases which are carbon dioxide $\left(\mathrm{CO}_{2}\right)$ and nitrogen $\left(\mathrm{N}_{2}\right)$ are often used as inert gases.

Carbon dioxide has a density of 1.52 relative to air. This makes it particularly useful for the treatment of fires in low-lying areas such as dip workings or inclined drifts (Froger, 1985). Carbon dioxide has high efficiency to finish the development of an inert atmosphere. When it is injected, it can significantly change 
flammable limits of combustible gases, and minimize their explosive ranges to reduce the explosion risk. However, the use of carbon dioxide as an inert gas has several disadvantages. Because its molecular weight is heavier than air, it is hard to mix with combustible gases in the sealed volume and also easily forms " $\mathrm{CO}_{2}$ layer". Carbon dioxide is also adsorbed readily by coal surfaces, while drives the adsorbed methane from the coal, which means the concentration of carbon dioxide, may be reduced after injection. In addition, the most important disadvantage is the cost of producing carbon dioxide; it is considerably more expensive than nitrogen.

Compared with carbon dioxide, although the inertization efficiency of nitrogen is not as good as carbon dioxide, it still widely considered as an ideal inert gas. Nitrogen has almost the same density as the air. Therefore, it mixes readily without stratification. Nitrogen is a by-product of the commercial production of oxygen and is much less expensive than carbon dioxide. Also, high injection rate can be guaranteed. Experiences shows that the maximum gas feed rate into the mine typically is within the range 1 to $6 \mathrm{~m}^{3} / \mathrm{s}$ (McPherson, 1993).

\subsection{Mathematical Model}

\subsubsection{Control volume approach}

According to the law of mass conservation, the mass may be neither created nor destroyed. With respect to a constant sealed volume, the law of conservation of mass can be simply stated as: 


\begin{tabular}{|c|c|c|c|}
\hline $\begin{array}{l}\text { Rate of mass } \\
\text { efflux from } \\
\text { sealed volume }\end{array}$ & $\begin{array}{l}\text { Rate of mass } \\
\text { influx into } \\
\text { sealed volume }\end{array}$ & + & $\begin{array}{l}\text { Rate of accumula- } \\
\text { tion of mass within } \\
\text { sealed volume }\end{array}$ \\
\hline
\end{tabular}

Considering a general control volume ${ }^{2}$ located in a fluid flow field as shown in Figure 3.5, for the small element of area $d A$ on the control surface, assuming the velocity vector is $\boldsymbol{v}$ and $\theta$ is the angle between the velocity vector and the outward directed unit normal vector, $\boldsymbol{n}$ to $d A$. From vector algebra, the rate of mass efflux can be rewritten as (Welty, et al., 2001):

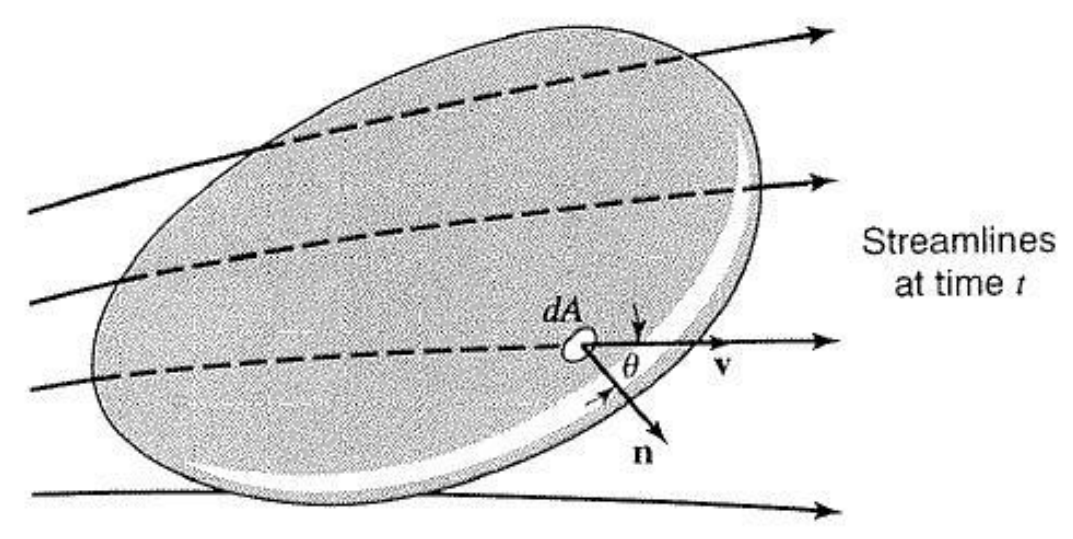

Figure 3.5 Fluid flow through a control volume

$$
\rho(\mathbf{v} \cdot \mathbf{n}) d A=\rho v d A|\mathbf{v}||\mathbf{n}| \cos \theta
$$

Physically, this dot product represents the amount of mass flowing through a unit cross-sectional area per unit time. If integrating this quantity over the entire control surface, the net outward flow of mass across the control surface, or the net mass efflux from the control volume can be expressed as:

\footnotetext{
${ }^{2}$ A control volume: A definite volume specified in space. Matter in a control volume can change with time as matter enters and leaves its control surface.
} 


$$
\iint_{C . S .} \rho(\mathbf{v} \cdot \mathbf{n}) d A
$$

On the other hand, the rate of accumulation of mass within the control volume may be expressed as:

$$
\frac{\partial}{\partial t} \iiint_{C . V} \rho d V
$$

The integral expression for the mass balance over a general control volume becomes:

$$
\iint_{C . S .} \rho(\mathbf{v} \cdot \mathbf{n}) d A+\frac{\partial}{\partial t} \iiint_{C . V} \rho d V=0
$$

\subsubsection{Ideal gas law}

An ideal gas is defined as one in which all collisions between atoms or molecules are perfectly elastic and in which there are no intermolecular attractive forces. One can visualize it as a collection of perfectly hard spheres which collide but otherwise do not interact with each other. In such case, all the internal energy is in the form of kinetic energy and any change in internal energy is accompanied by a change in temperature (Nave, 2011).

The ideal gas law is the equation of state of a hypothetical ideal gas. It is a good approximation to the behavior of many gases under many conditions, al-

though it has several limitations (Wikipedia, 2011). The state of an amount of a specified gas is determined by its pressure, volume, and temperature and is established as: 


$$
P V=n R T
$$

where: $P$ is the partial pressure of a given gas;

$V$ is the sealed volume;

$n$ is measured moles of the gas;

$R$ is the universal gas constant;

$T$ is the absolute temperature.

As the amount of substance could be given in mass instead of moles, sometimes an alternative form of the ideal gas law is useful. The number of moles $(n)$ is equal to the mass $(m)$ divided by the molar mass $(M)$ :

$$
n=\frac{m}{M}
$$

By replacing $n$ and defining $R_{\mathrm{g}}$ as the specific gas constant, Eq (3.19) can be rewritten as:

$$
P V=m R_{g} T
$$

The ideal gas law equation demonstrates that a connection between mass and pressure.

\subsubsection{Mathematical derivation}

A mathematical model is developed to simulate the gas species changes in a sealed mine area. Figure 3.6 shows the airflow exchanges between the sealed volume and its surroundings. In the sealed volume $(V)$, the atmosphere consists of the following nine common gases (reasons of selecting gas species 
will be discussed in Chapter 4): $\mathrm{CH}_{4}, \mathrm{CO}, \mathrm{N}_{2}, \mathrm{C}_{2} \mathrm{H}_{2}, \mathrm{C}_{2} \mathrm{H}_{4}, \mathrm{C}_{2} \mathrm{H}_{6}, \mathrm{CO}_{2}, \mathrm{H}_{2}$ and $\mathrm{O}_{2}$. The volume occupied by each gas is denoted by subscripts with corresponding chemical formula. The total pressure in the sealed volume $\left(P_{t}\right)$ is the sum of the partial pressures of the individual gases. The barometric pressure outside the sealed volume is shown as $P_{b}$. Apparently, if $P_{\mathrm{t}}<P_{b}$, the outside air flows through the mine seals into the sealed volume and this process is called airinflowing. Conversely, if $P_{\mathrm{t}}>P_{\mathrm{b}}$, air in the sealed volume flows out and it is called gas-outflowing. In addition, this model also considers the inflow of combustible gas, mainly $\mathrm{CH}_{4}$ from surrounding strata to the sealed volume, and the effects of injecting inert gas into the sealed volume to prevent potential gas explosion.

Therefore, the concentration and partial pressure of each gas in the sealed volume would change with time and the changes are controlled by the inflows and outflows as well as by the atmospheric pressure.

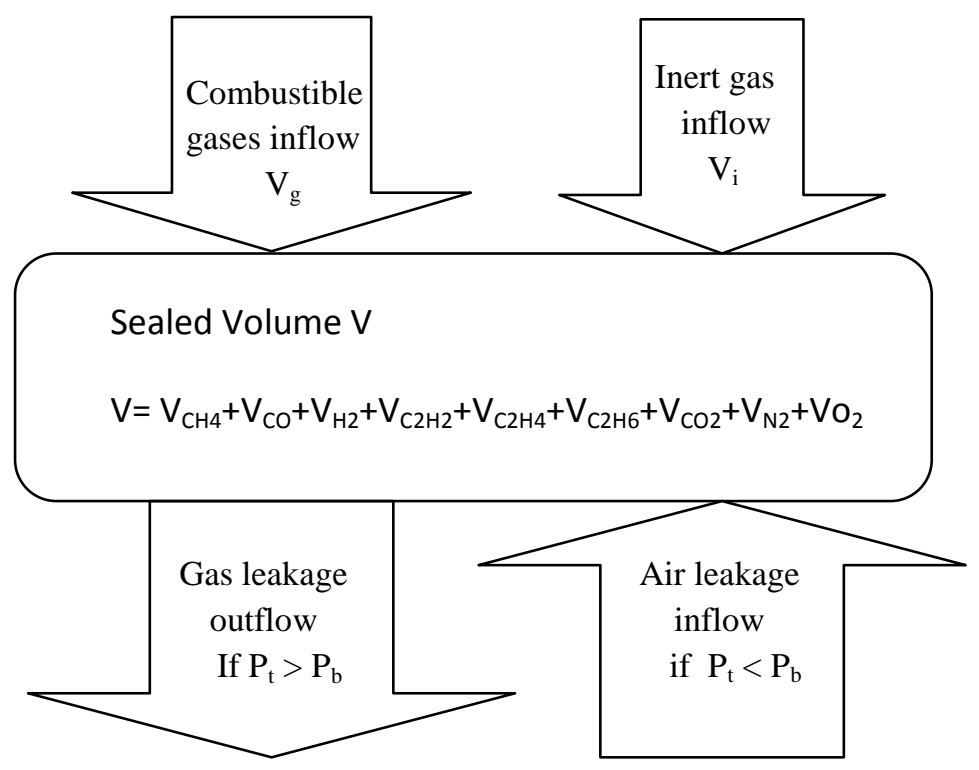

Figure 3.6 Volume of the sealed atmosphere and its leakage depending on the differential pressure (after Zipf \& Mohamed, 2010) 
The following assumptions are made in developing the dynamic gas species changes model:

1) The volume of the sealed mine area $(V)$ is constant.

2) Generally, two categories of added gases are expected in the sealed mine area. They are injected inert gas and mine gases (Mainly $\mathrm{CH}_{4}$ ). The injected inert gas usually enters the sealed area as a turbulent jet via the mine seals or surface gob wells. Due to such a turbulent jet, a turbulent flow often takes place in the sealed volume. The transversal mixing (Perpendicular to the flow direction) is accomplished within a very short distance while the longitudinal mixing (in flow direction) takes place also. For the coal mine gases (Mainly $\mathrm{CH}_{4}$ ), they are emitted from all the surrounding strata into the sealed mine volume and can be expected to mix with the original atmospheric compositions very soon. Therefore, any added gases can be considered as mixed instantaneously.

3) The mine sealed area often generally reflects the rectangle volume. The typical one is a mine entry or a gob area. Once it needs to be sealed, the inby and outby mine seals at the both sides of the area are going to be built. Considering the previous assumption, a turbulent flow induced by the inert gas injection work can exist in the seal area; therefore, a zone of homogeneous mixed composition can be formed within a short period. Hence, it assumes that the gas throughout the whole sealed volume is homogeneous.

4) The gas ingredient of the gas-outflowing flow is identical to that of the sealed atmosphere. 
5) The inert gas argon $\left(A_{r}\right)$ concentration in the sealed volume is negligible and assumed zero.

6) The temperature in the sealed area can be considered as constant. Since absolute temperature is used in the ideal gas law, the possible variation in temperature in a sealed mine volume (unless in fire situation) will be insignificant.

The model includes nine gas species and their mathematical change equations as a timely matter. Considering $\mathrm{N}_{2}$ as an example to demonstrate the mathematical derivation:

In the mathematical model, a negative value indicates an influx of mass to the sealed volume while a positive value for an efflux to leak out of the volume. For the air-inflowing condition, Eq. (3.18) is applied to express the total amount of mass in the sealed volume as a function of time, for the control volume (mine sealed volume) shown:

$$
\begin{gathered}
\iint_{C . S .} \rho(\mathbf{v} \cdot \mathbf{n}) d A=-\dot{m}_{a i r}-\dot{m}_{\mathrm{CH}_{4}}-\dot{m}_{\mathrm{N}_{2}}-\dot{m}_{\mathrm{CO}_{2}} \\
\frac{\partial}{\partial t} \iiint_{C . V} \rho d V=\frac{d}{d t} \int_{M_{0}}^{M} d M=\frac{d}{d t}\left(M-M_{0}\right)
\end{gathered}
$$

where: $\dot{m}_{\text {air }}$ is the inflow rate of air in the control volume;

$\dot{m}_{\mathrm{CH}_{4}}$ is the inflow rate of methane in the control volume;

$\dot{m}_{\mathrm{N}_{2}}$ is the inflow rate of nitrogen in the control volume;

$\dot{m}_{\mathrm{CO}_{2}}$ is the mass inflow rate of carbon dioxide in the control volume;

$M$ is the total mass in the control volume at any time; 
$M_{0}$ is the initial mass in the control volume.

Writing the complete expression yields:

$$
\iint_{C . S .} \rho(\mathbf{v} \cdot \mathbf{n}) d A+\frac{\partial}{\partial t} \iiint_{C . V} \rho d V=-\dot{m}_{\text {air }}-\dot{m}_{\mathrm{CH}_{4}}-\dot{m}_{\mathrm{N}_{2}}-\dot{m}_{\mathrm{CO}_{2}}+\frac{d}{d t}\left(M-M_{0}\right)=0
$$

Separating variables and solving for $M$ gives

$$
M=M_{0}+\left(\dot{m}_{\text {air }}+\dot{m}_{\mathrm{CH}_{4}}+\dot{m}_{\mathrm{N}_{2}}+\dot{m}_{\mathrm{CO}_{2}}\right) t
$$

Now, letting $m_{N_{2}}$ be the amount of $N_{2}$ in the control volume at any time. The concentration by weight of $\mathrm{N}_{2}$ may be expressed as:

$$
\frac{m_{N_{2}}}{M}=\frac{m_{N_{2}}}{M_{0}+\left(\dot{m}_{\text {air }}+\dot{m}_{\mathrm{CH}_{4}}+\dot{m}_{\mathrm{N}_{2}}+\dot{m}_{\mathrm{CO}_{2}}\right) t}
$$

On the other side, air consists of nitrogen and oxygen. Based on the mass percentage of gas in the air, the nitrogen in the air can be expressed as $0.75 \dot{m}_{\text {air }}$.

Using the definition, applying Eq. (3.18) to the $\mathrm{N}_{2}$ and obtaining:

$$
\iint_{C . S .} \rho(\mathbf{v} \cdot \mathbf{n}) d A=-\dot{m}_{N_{2}}-0.75 \dot{m}_{\text {air }}
$$

and

$$
\frac{\partial}{\partial t} \iiint_{C . V} \rho d V=\frac{d}{d t} \int_{m_{N_{2}(0)}}^{m_{N_{2}}} d m_{N_{2}}=\frac{d m_{N_{2}}}{d t}
$$

The complete expression is now:

$$
\iint_{C . S .} \rho(\mathbf{v} \cdot \mathbf{n}) d A+\frac{\partial}{\partial t} \iiint_{C . V} \rho d V=-\dot{m}_{N_{2}}-0.75 \dot{m}_{\text {air }}+\frac{d m_{N_{2}}}{d t}=0
$$

Applying the Ideal Gas Law, Eq. (3.21) yields:

$$
P_{N_{2}} V=m_{N_{2}} R_{N_{2}} T
$$


Considering the air-inflowing condition, only the normal air can leak through seals into the sealed volume. Therefore, $\dot{m}_{\text {air }}$ can be expressed as:

$$
\dot{m}_{\text {air }}=Q_{L} \rho_{\text {air }}
$$

where: $\rho_{\text {air }}$ is the air density;

$Q_{L}$ is the inflow rate of air leakage, and can be obtained from Eq. (3.12).

Combing Eq. (3.12), Eq. (3.29), Eq. (3.30) and Eq. (3.31) to give a system of equations:

$$
\left\{\begin{array}{l}
-\dot{m}_{N_{2}}-0.75 \dot{m}_{\text {air }}+\frac{d m_{N_{2}}}{d t}=0 \\
P_{N_{2}} V=m_{N_{2}} R_{N_{2}} T \\
\dot{m}_{\text {air }}=Q_{L} \rho_{\text {air }} \\
Q_{L}=n \sqrt{\frac{P_{b}(t)-P_{t}(t)}{R}}
\end{array}\right.
$$

The developed equation can be used to describe the timely-dependent change of nitrogen in the sealed volume under the condition of air-inflowing scenario.

For gas-outflowing condition, Eq. (3.18) is applied to express the total amount of mass in the sealed volume as a function of time:

$$
\begin{aligned}
& \iint_{C . S .} \rho(\mathbf{v} \cdot \mathbf{n}) d A=+\dot{m}_{m i x}-\dot{m}_{\mathrm{CH}_{4}}-\dot{m}_{\mathrm{N}_{2}}-\dot{m}_{\mathrm{CO}_{2}} \\
& \frac{\partial}{\partial t} \iiint_{C . V} \rho d V=\frac{d}{d t} \int_{M_{0}}^{M} d M=\frac{d}{d t}\left(M-M_{0}\right)
\end{aligned}
$$

where: $\dot{m}_{\text {mix }}$ mass leakage rate from the sealed volume at a given time; 
$\dot{m}_{\mathrm{CH}_{4}}$ is the inflow rate of air in the control volume;

$\dot{m}_{\mathrm{N}_{2}}$ is the inflow rate of air in the control volume;

$M$ is the total mass in the control volume at any time;

$M_{0}$ is the initial mass in the control volume.

Writing the complete expression yields:

$$
\iint_{C . S .} \rho(\mathbf{v} \cdot \mathbf{n}) d A+\frac{\partial}{\partial t} \iiint_{C . V} \rho d V=+\dot{m}_{m i x}-\dot{m}_{\mathrm{CH}_{4}}-\dot{m}_{\mathrm{N}_{2}}-\dot{m}_{\mathrm{CO}_{2}}+\frac{d}{d t}\left(M-M_{0}\right)=0
$$

Separating variables and solving for $M$ gives

$$
M=M_{0}+\left(\dot{m}_{\mathrm{CH}_{4}}+\dot{m}_{\mathrm{N}_{2}}+\dot{m}_{\mathrm{CO}_{2}}-\dot{m}_{m i x}\right) t
$$

Now, letting $m_{N_{2}}$ be the amount of $N_{2}$ in the control volume at any time. The concentration by weight of $\mathrm{N}_{2}$ may be expressed as:

$$
\frac{m_{N_{2}}}{M}=\frac{m_{N_{2}}}{M_{0}+\left(\dot{m}_{\mathrm{CH}_{4}}+\dot{m}_{\mathrm{N}_{2}}+\dot{m}_{\mathrm{CO}_{2}}-\dot{m}_{\text {mix }}\right) t}
$$

Using the definition, applying Eq. (3.18) to the $\mathrm{N}_{2}$ and obtaining:

$$
\iint_{C . S .} \rho(\mathbf{v} \cdot \mathbf{n}) d A=-\dot{m}_{N_{2}}+\frac{m_{N_{2}}}{M} \dot{m}_{\text {mix }}
$$

and

$$
\frac{\partial}{\partial t} \iiint_{C . V} \rho d V=\frac{d}{d t} \int_{m_{N_{2}(0)}}^{m_{N_{2}}} d m_{N_{2}}=\frac{d m_{N_{2}}}{d t}
$$

The complete expression is now:

$$
\iint_{C . S .} \rho(\mathbf{v} \cdot \mathbf{n}) d A+\frac{\partial}{\partial t} \iiint_{C . V} \rho d V=-\dot{m}_{N_{2}}+\frac{m_{N_{2}}}{M} \dot{m}_{\text {mix }}+\frac{d m_{N_{2}}}{d t}=0
$$

Applying the Ideal Gas Law, Eq. (3.21) yields: 


$$
P_{N_{2}} V=m_{N_{2}} R_{N_{2}} T
$$

Considering the gas-outflowing condition, the gas mixture would leak air through seals into the active mine. Therefore, $\dot{m}_{m i x}$ can be expressed as:

$$
\dot{m}_{\text {mix }}=\rho_{\text {mix }} Q_{L}
$$

where: $\rho_{\text {mix }}$ is the density of gas mixture leaking through the mine seals at standard pressure and temperature at a given time;

$Q_{L}$ is the inflow rate of air leakage, and can also be obtained from Eq. (3.12).

Combing Eq. (3.12), Eq. (3.40), Eq. (3.41) and Eq. (3.42) to give a system of equations:

$$
\left\{\begin{array}{l}
-\dot{m}_{N_{2}}+\frac{m_{N_{2}}}{M} \dot{m}_{\text {mix }}+\frac{d m_{N_{2}}}{d t}=0 \\
P_{N_{2}} V=m_{N_{2}} R_{N_{2}} T \\
\dot{m}_{\text {mix }}=\rho_{\text {mix }} Q_{L} \\
Q_{L}=n \sqrt{\frac{P_{b}(t)-P_{t}(t)}{R}}
\end{array}\right.
$$

The developed equation can be used to describe the time-dependent change of nitrogen in the sealed volume under the condition of gas-outflowing scenario.

In addition, the same mathematical derivation procedure can be applied for the other gas species in the sealed volume.

In summary, the mathematical model of simulating atmosphere gas species $s$ in a coal mine sealed volume can be described as follows: 
When the total gas pressure in the sealed area is lower than the atmospheric pressure outside, $P_{\mathrm{t}}(t)<P_{\mathrm{b}}(t)$, it is an air-inflowing condition. The normal mine air flows into the sealed volume.

$$
\left\{\begin{array}{l}
-\dot{m}_{i}+\frac{d m_{i}}{d t}=0 \\
P_{i}(t) V=m R_{i} T \\
P_{t}(t)=\sum_{i=1}^{9} P_{i}(t) \\
Q_{L}=n \sqrt{\frac{P_{b}(t)-P_{t}(t)}{R}}
\end{array}\right.
$$

When the total gas pressure in the sealed area is higher than the atmospheric pressure outside, $P_{\mathrm{t}}(t)>P_{b}(t)$, it is a gas-outflowing condition. The gases flow out of the sealed volume.

$$
\left\{\begin{array}{l}
\frac{m_{i}}{M(t)} \dot{m}_{\text {mix }}-\dot{m}_{i}+\frac{d m_{i}}{d t}=0 \\
P_{i}(t) V=m R_{i} T \\
P_{t}(t)=\sum_{i=1}^{9} P_{i}(t) \\
Q_{L}=n \sqrt{\frac{P_{b}(t)-P_{v}(t)}{R}} \\
M(t)=\sum_{i=1}^{9} m_{i} \\
\dot{m}_{\text {mix }}=\rho_{\text {mix }} Q_{L} \\
\rho_{\text {mix }}=\sum_{i=1}^{9} \frac{m_{i}}{M(t)} \rho_{i}
\end{array}\right.
$$

The variables and constants in equations are defined as follows: The subscript " $i$ " represents each of the nine gases in the sealed volume. They are listed as $i=1,2 \ldots, 9$ for $\mathrm{CH}_{4}, \mathrm{~N}_{2}, \mathrm{O}_{2}, \mathrm{CO}, \mathrm{CO}_{2}, \mathrm{H}_{2}, \mathrm{C}_{2} \mathrm{H}_{2}, \mathrm{C}_{2} \mathrm{H}_{4}$ and $\mathrm{C}_{2} \mathrm{H}_{6}$, respectively. Term $m_{\mathrm{i}}$ is the total mass of gas $i$ in the volume and is a function of time. Term 
$\dot{m}_{i}$ is the rate of change of gas $i$ in the volume. In an air-inflowing process, they are defined as:

$$
\begin{aligned}
& \dot{m}_{1}=\rho_{1} Q_{C_{4}} \\
& \dot{m}_{2}=0.75 \rho_{\text {air }} Q_{L}+\rho_{2} Q_{N_{2}} \\
& \dot{m}_{3}=0.25 \rho_{\text {air }} Q_{L} \\
& \dot{m}_{5}=\rho_{5} Q_{C O_{2}} \\
& \dot{m}_{4}=\dot{m}_{6}=\dot{m}_{7}=\dot{m}_{8}=\dot{m}_{9}=0
\end{aligned}
$$

In the gas-outflowing process, they are defined as:

$$
\begin{aligned}
& \dot{m}_{1}=\rho_{1} Q_{C_{4}} \\
& \dot{m}_{2}=\rho_{2} Q_{N_{2}} \\
& \dot{m}_{5}=\rho_{5} Q_{C_{2}} \\
& \dot{m}_{3}=\dot{m}_{4}=\dot{m}_{6}=\dot{m}_{7}=\dot{m}_{8}=\dot{m}_{9}=0
\end{aligned}
$$

In these equations, $Q_{C H 4}$ is the $\mathrm{CH}_{4}$ volumetric inflow rate, $Q_{N 2}$ and $Q_{C O 2}$ are the volumetric inflow rates of $\mathrm{N}_{2}$ and $\mathrm{CO}_{2}$ injected into the sealed volume. They are assumed to be $100 \%$ pure. $\rho_{\text {air }}$ is the air density.

$R_{\mathrm{i}}$ is the specific gas constant of gas $i$.

$\rho_{i}$ is the density of gas $i$ at standard pressure and temperature.

$P_{\mathrm{i}}$ is the partial pressure of gas $i$ at a given time.

$P_{\mathrm{t}}$ is the total pressure or the sum of the partial pressures of all individual gases at a given time. 
$P_{\mathrm{b}}$ is the barometric pressure outside of the sealed area. It could change significantly over time

$n$ is the number of the mine seals used.

\subsection{Verification Case Study}

\subsubsection{Background information}

The verification case study is conducted at a coal mine located in the southern West Virginia. Due to the elevated CO concentration event found in a number of crosscuts adjacent to the gob area on the tail-entry side of an active longwall panel, mine operators carried out some mitigation measures such as water pumping and $\mathrm{CO}_{2}-\mathrm{N}_{2}$ injection to control the a suspicious "oxidation" event in the longwall gob. Figure 3.7 shows the location of longwall panel in the mine.

The longwall panel with a plow operation is $1,000 \mathrm{ft}(304.8 \mathrm{~m})$ wide (center to center) and about $10,000 \mathrm{ft}(3048 \mathrm{~m})$ long. Figure 3.8 shows the portion of the longwall panel of interest and its ventilation airflow pattern. The mining direction is from top to the bottom in the figure. The tailentry of the panel is on the left

while the headentry on the right. At the time of the elevated CO event, a $1,500 \mathrm{ft}$ (457.2 m) long block of the longwall panel has been mined and the face is between breaks 55 and 56 as shown in Figure 3.8.

The company has tried two methods to control the suspicious "oxidation" event. The first effort was to pump water to cool down any potential "hot" spots in the gob, the pumping through the gob well $9 \mathrm{~F}-1$ within first five days. A total 
amount nearly 2 million gallons of water has been pumped into the mine. However, this effort was ineffective to significantly reduce the $\mathrm{CO}$ level. Then a total of 48 hours $50 \%-50 \% \mathrm{CO}_{2}-\mathrm{N}_{2}$ mixture was injected initially through the gob well then through bleeder fan shaft. The $\mathrm{CO}_{2}-\mathrm{N}_{2}$ injection indeed had strong impacts on the gas compositions in the panel. After the first injection stopped about 40 hours later, the second $\mathrm{CO}_{2}-\mathrm{N}_{2}$ mixture injection was re-commenced to inert the gob and that effort continued for 6 days. The Main Events during the CO mitigation are also listed in the Table 3.7.

Table 3.7 Chronicle of Main Events

\begin{tabular}{|c|c|c|}
\hline Date & Time & Main Events \\
\hline Day 1 & 6:00PM & Elevated $\mathrm{CO}$ found \\
\hline Day 12 & 8:00 PM & 1st Water Pump Started \\
\hline Day 14 & 2:35 PM & $1^{\text {st }}$ Water Pumping Stopped, 1,400,000 gallons pumped \\
\hline Day 15 & 3:35 PM & 2nd Water Pumping Started \\
\hline Day 16 & 4:00 AM & $2^{\text {nd }}$ Water Pumping completed, $1,890,000$ gallons pumped \\
\hline Day 20 & $5: 00 \mathrm{AM}$ & $1^{\text {st }} 50 \%-50 \% \mathrm{CO}_{2}-\mathrm{N}_{2}$ Injected into gob \\
\hline Day 20 & 5:00 AM & $\mathrm{CO}_{2}$ Injection via gob well at $600 \mathrm{scfm}\left(0.28 \mathrm{~m}^{3} / \mathrm{s}\right)$ \\
\hline Day 20 & 5:00 AM & $\mathrm{N}_{2}$ Injection via bleeder shaft, $1,200 \mathrm{scfm}\left(0.57 \mathrm{~m}^{3} / \mathrm{s}\right)$ \\
\hline Day 22 & $9: 30 \mathrm{AM}$ & $\begin{array}{l}\mathrm{CO}_{2}-\mathrm{N}_{2} \text { Injection stopped, } 4.8 \mathrm{M} \mathrm{ft}^{3}\left(0.136 \mathrm{M} \mathrm{m}^{3}\right) \mathrm{CO}_{2} \& 5.1 \mathrm{M} \mathrm{ft}^{3}(0.144 \\
\left.\mathrm{M} \mathrm{m}^{3}\right) \mathrm{N}_{2} \text { Injected }\end{array}$ \\
\hline Day 24 & 5:00 AM & Bleeder Fan turned off \\
\hline Day 24 & 5:00 AM & $2^{\text {nd }} 50 \%-50 \% \mathrm{CO}_{2}-\mathrm{N}_{2}$ Injected into gob \\
\hline Day 24 & $5: 30 \mathrm{AM}$ & $\mathrm{CO}_{2}$ Injection via gob well at $1,400 \mathrm{scfm}\left(0.67 \mathrm{~m}^{3} / \mathrm{s}\right)$ \\
\hline Day 24 & 5:30 PM & $\mathrm{N} 2$ Injection via bleeder shaft at $1,600 \mathrm{scfm}\left(0.75 \mathrm{~m}^{3} / \mathrm{s}\right)$ \\
\hline Day 24 & 7:30 AM & Additional $\mathrm{N}_{2}$ generator in service \\
\hline Day 30 & 8:00 PM & $2^{\text {nd }} \mathrm{CO}_{2}-\mathrm{N}_{2}$ injection reduced \\
\hline
\end{tabular}




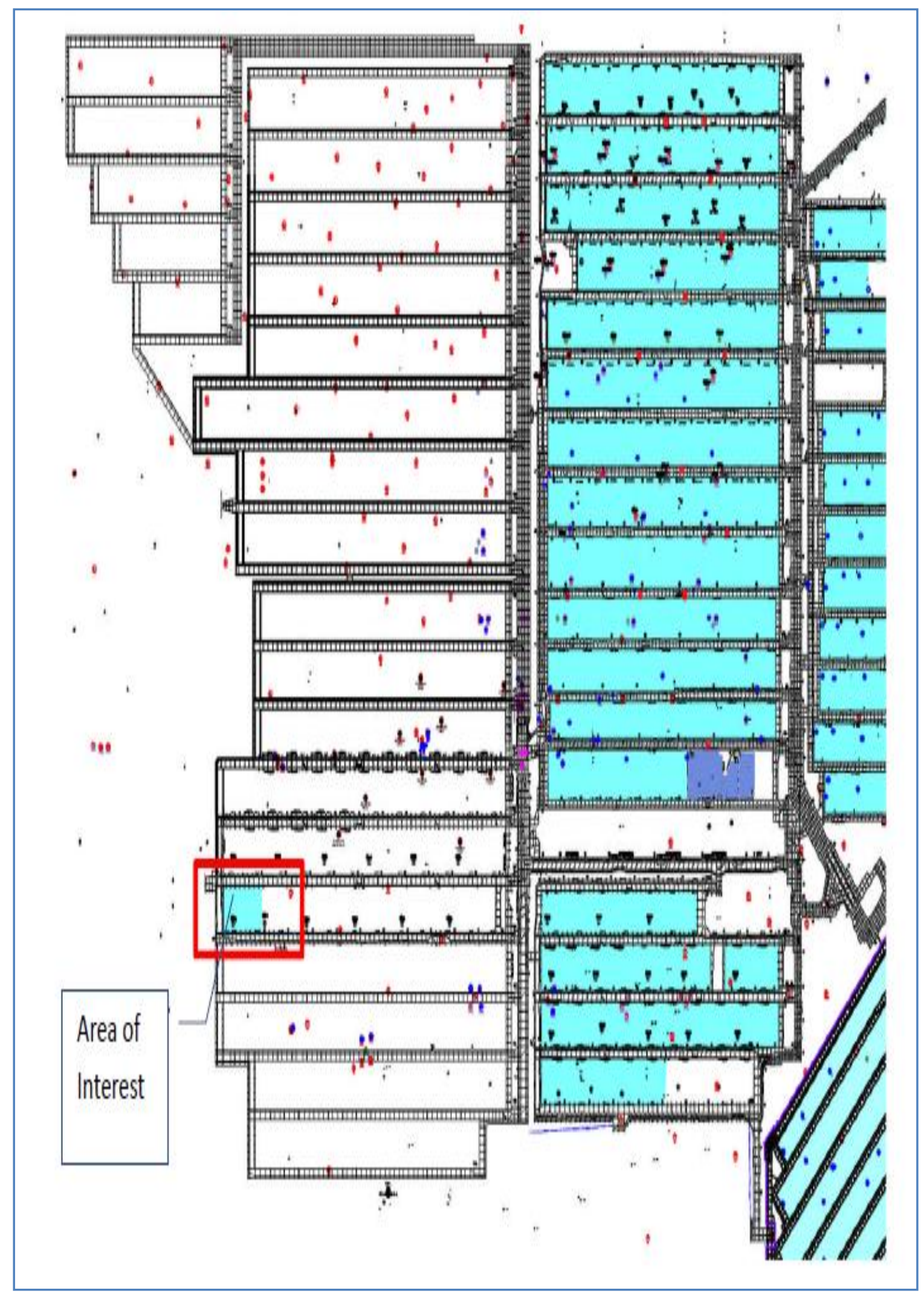

Figure 3.7 Area of interest in the coal mine 


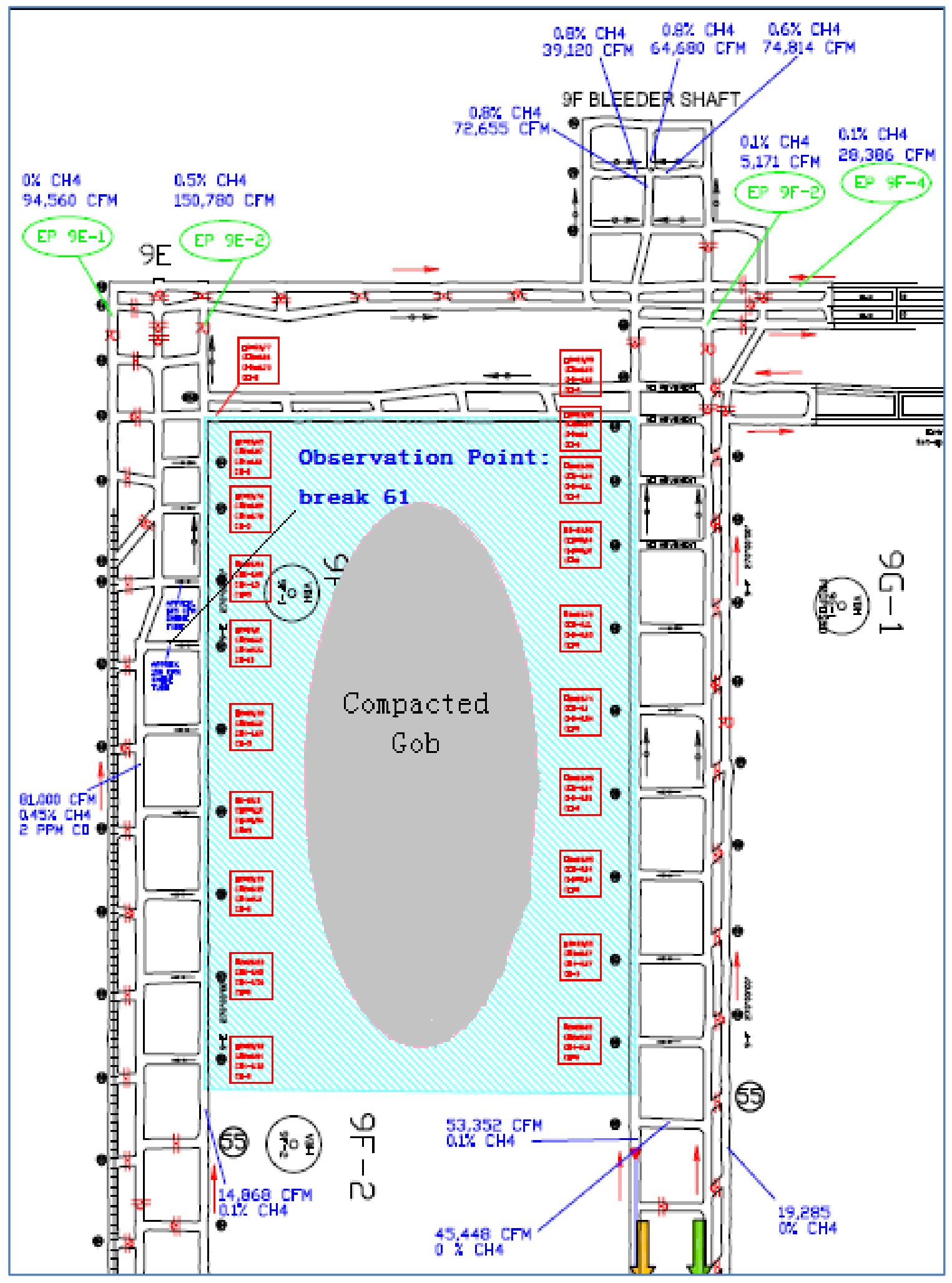

Figure 3.8 Interested sealed area in the longwall panel and its ventilation airflow pattern 


\subsubsection{Simulation strategy}

Validating the accuracy of the established mathematical simulation model has been done in the isolated gob area which found $\mathrm{CO}$ event as stated in the previous section. Based on the mitigation measures carried out by the mine company, three typical stages are divided. They are:

(1) Stage 1: The stage of water pumping period. The first effort performed by the mine company was to pump the water into the suspected "hot" spots in the gob area to flush the potential coal oxidation location. Water was pumped twice into the gob area. Nearly 3.3 million water gallons (12.5 M liters) was pumped into the underground and the whole water pumping stage is about 312 hours. Unfortunately, this effort was considered as ineffective.

(2) Stage 2: The first $\mathrm{CO}_{2}-\mathrm{N}_{2}$ mixtures injection. After the effort to control the $\mathrm{CO}$ event by pumping water, mine managers then began to perform a 48 hours $\mathrm{CO}_{2}-\mathrm{N}_{2}$ mixture injection into the gob area to reduce $\mathrm{CO}$ concentration. The gas ratio of $\mathrm{CO}_{2}-\mathrm{N}_{2}$ is about $50 \%-50 \% . \mathrm{CO}_{2}$ was injected via the gob well while $\mathrm{N}_{2}$ was injected via the exhaust shaft. A total of $4.8 \mathrm{M} \mathrm{ft}^{3}\left(0.136 \mathrm{M} \mathrm{m}^{3}\right) \mathrm{CO}_{2}$ and $5.1 \mathrm{M} \mathrm{ft}^{3}\left(0.144 \mathrm{M} \mathrm{m}^{3}\right) \mathrm{N}_{2}$ was injected after completing the first $\mathrm{CO}_{2}-\mathrm{N}_{2}$ Injection. However, the bleeder fan kept running through the whole stage.

(3) Stage 3: The second $\mathrm{CO}_{2}-\mathrm{N}_{2}$ mixture injection. After the first injection stopped about 43 hours later, the mine fan was turned off and managers started to do the second $\mathrm{CO}_{2}-\mathrm{N}_{2}$ mixtures injection. It continued for about 6 days until the injection rate was reduced again since an inert state in the monitored area within the panel was reached. During this period, $\mathrm{CO}_{2}$ injection rate is about $1,400 \mathrm{scfm}$ 
$\left(0.67 \mathrm{~m}^{3} / \mathrm{s}\right)$ and the initial injection rate of $\mathrm{N}_{2}$ injection initial rate is about 1,600 $\operatorname{scfm}\left(0.75 \mathrm{~m}^{3} / \mathrm{s}\right)$, then another nitrogen generator is in service to increase injection rate at $1,900 \mathrm{scfm}\left(0.87 \mathrm{~m}^{3} / \mathrm{s}\right)$.

Hence, comparing to the stages 1 and 2, stage 3 has good characteristics of a sealed area and also has the conditions closest to all assumptions made by the developed simulation model. Thus, the verification simulation is conducted in this stage. The calculation parameters used are listed as follows:

- Initial gas compositions are: $\mathrm{CH}_{4}: 1.05 \%$; CO: 10ppm; $\mathrm{N}_{2}: 77.21 \%$; $\mathrm{C}_{2} \mathrm{H}_{6}: 100 p p m ; \mathrm{CO}_{2}: 0.19 \% ; \mathrm{H}_{2}: 20 p p m$ and $\mathrm{O}_{2}: 20.61 \%$.

- The barometric pressure fluctuation curve used is the typical pressure wave for Central Appalachia coalfield basin as stated in the section 3.2.1.

- The temperature of the sealed area is set as $30^{\circ} \mathrm{C}(303 \mathrm{~K})$.

- The total sealed volume is $4,200,856 \mathrm{ft} 3\left(118,955 \mathrm{~m}^{3}\right)$ (Including all entry spaces but excluding compacted zone in the gob).

- The flowrate of $\mathrm{CH}_{4}$ can considered as the summation of two parts, which are the $\mathrm{CH}_{4}$ from the vertical gob well $9 \mathrm{~F}-1$ due to the gas drainage production $(360 \mathrm{cfm})$ and the $\mathrm{CH}_{4}$ in ventilated mine air from the gob area $(105,780 \mathrm{cfm}$ with a concentration of $0.5 \%$ but excluding the $\mathrm{CH}_{4}$ in incoming air (Equivalent 113,668 cfm with a concentration of $0.06 \%)$. Therefore, the $\mathrm{CH}_{4}$ volumetric inflow rate in the sealed area is $820 \mathrm{cfm}\left(0.38 \mathrm{~m}^{3} / \mathrm{s}\right) . \mathrm{CO}_{2}$ injection rate is $1,400 \mathrm{scfm}\left(0.67 \mathrm{~m}^{3} / \mathrm{s}\right), \mathrm{CO}$ generation rate is estimated at $0.126 \mathrm{cfm}\left(7.65 \mathrm{E}-05 \mathrm{~m}^{3} / \mathrm{s}\right)$ and $\mathrm{N}_{2}$ injec- 
tion average rate is $1,783 \mathrm{cfm}\left(0.84 \mathrm{~m}^{3} / \mathrm{s}\right)$. In this case, the equivalent mass inflow rates are $0.2581 \mathrm{Kg} / \mathrm{s}, 1.234 \mathrm{Kg} / \mathrm{s}, 8.27 \mathrm{E}-05 \mathrm{Kg} / \mathrm{s}$ and $0.9804 \mathrm{Kg} / \mathrm{s}$, respectively.

- A total of 20 mine seals is used to isolate the mine gob area, and the equivalent air resistance for each of seals is $3.5 \mathrm{E}-06 \mathrm{in} \cdot \mathrm{min}^{2} / \mathrm{ft}{ }^{6}(3913$ N. $\left.S^{2} / m^{8}\right)$.

\subsubsection{Results comparison}

Based on gas samples collected from the break 61 on the tail entry side, both the measured gas concentrations and the results by the simulation model (marked as solid lines) for all gases in the gob area are plotted and are compared with each other in the following figure.

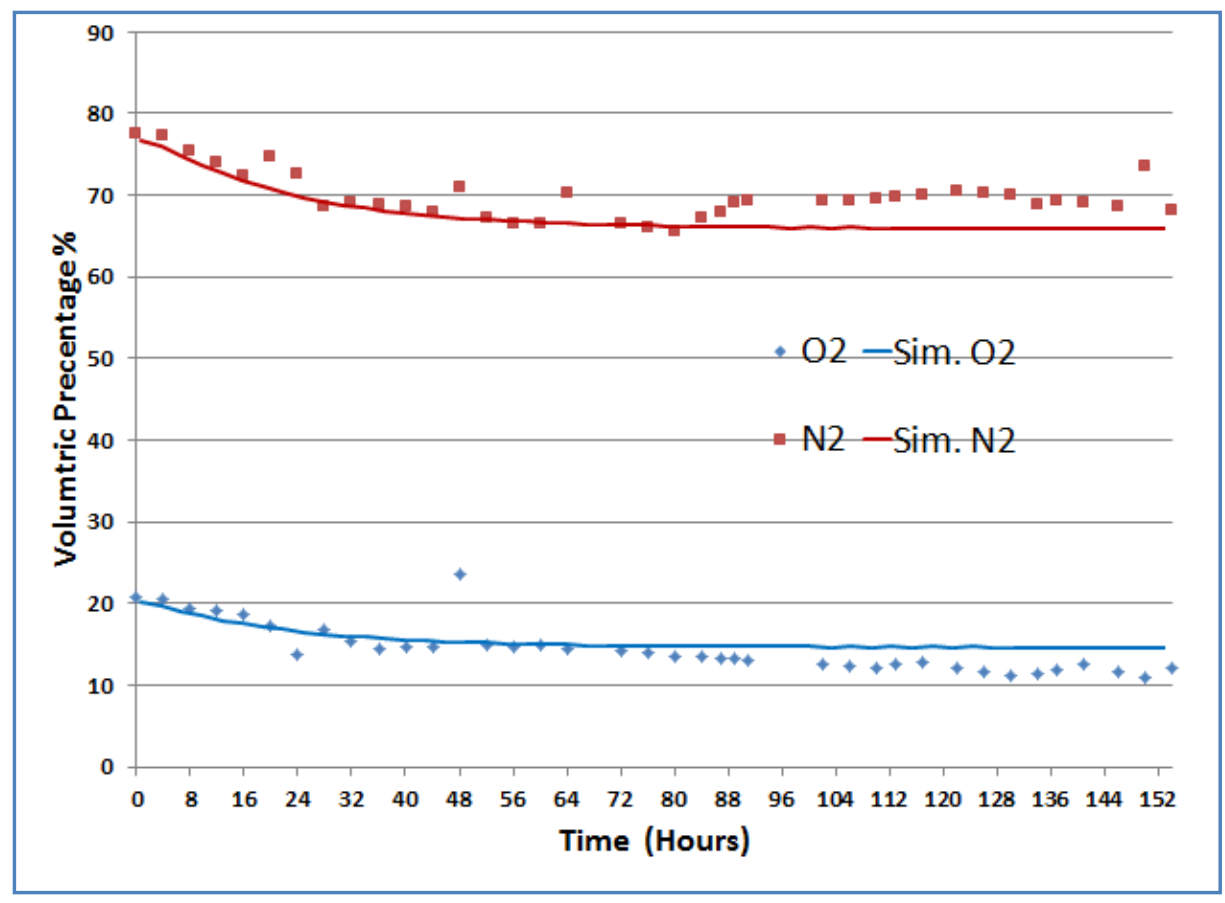

a) $\mathrm{O}_{2}$ and $\mathrm{N}_{2}$ 


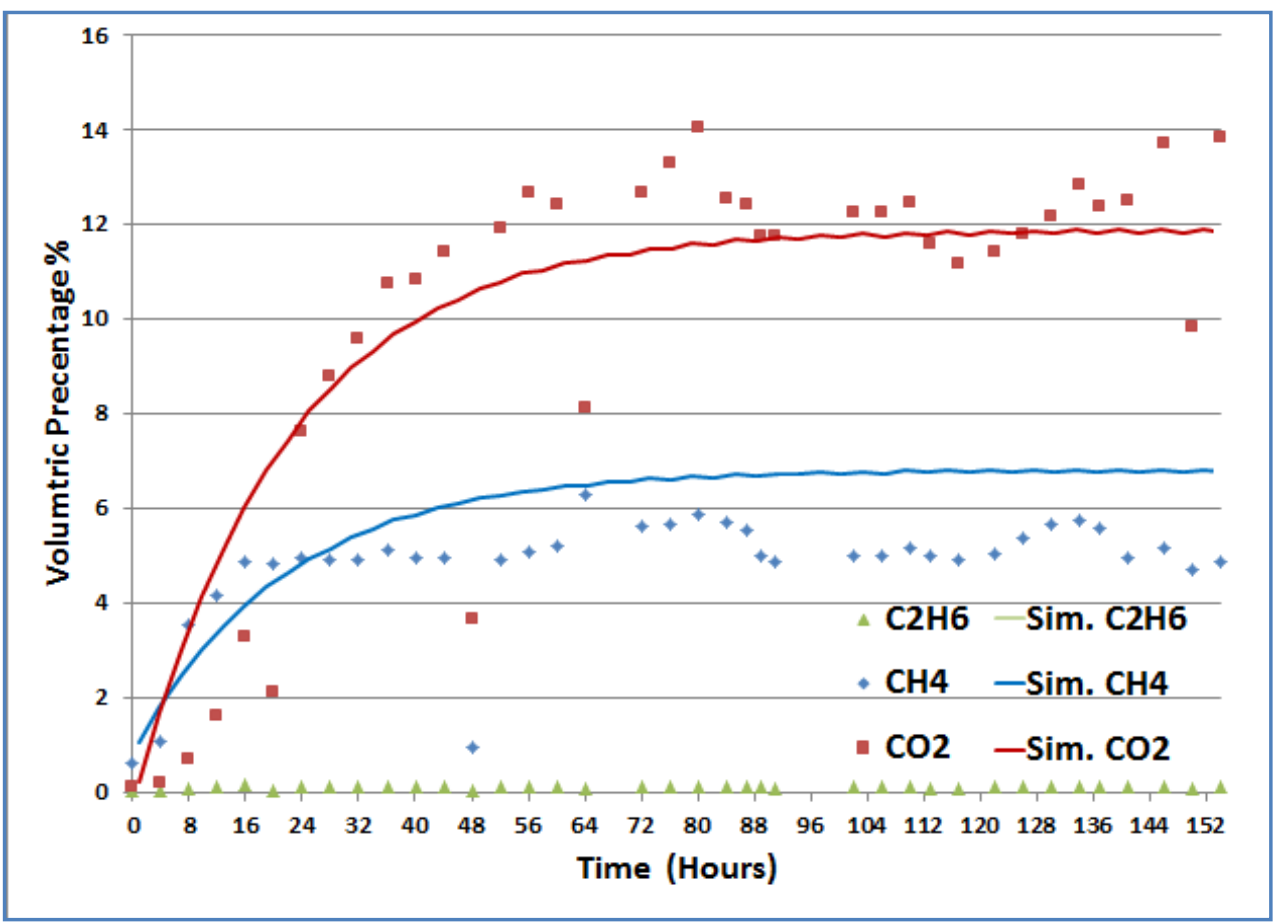

b) $\mathrm{CH}_{4}, \mathrm{CO}_{2}$ and $\mathrm{C}_{2} \mathrm{H}_{6}$

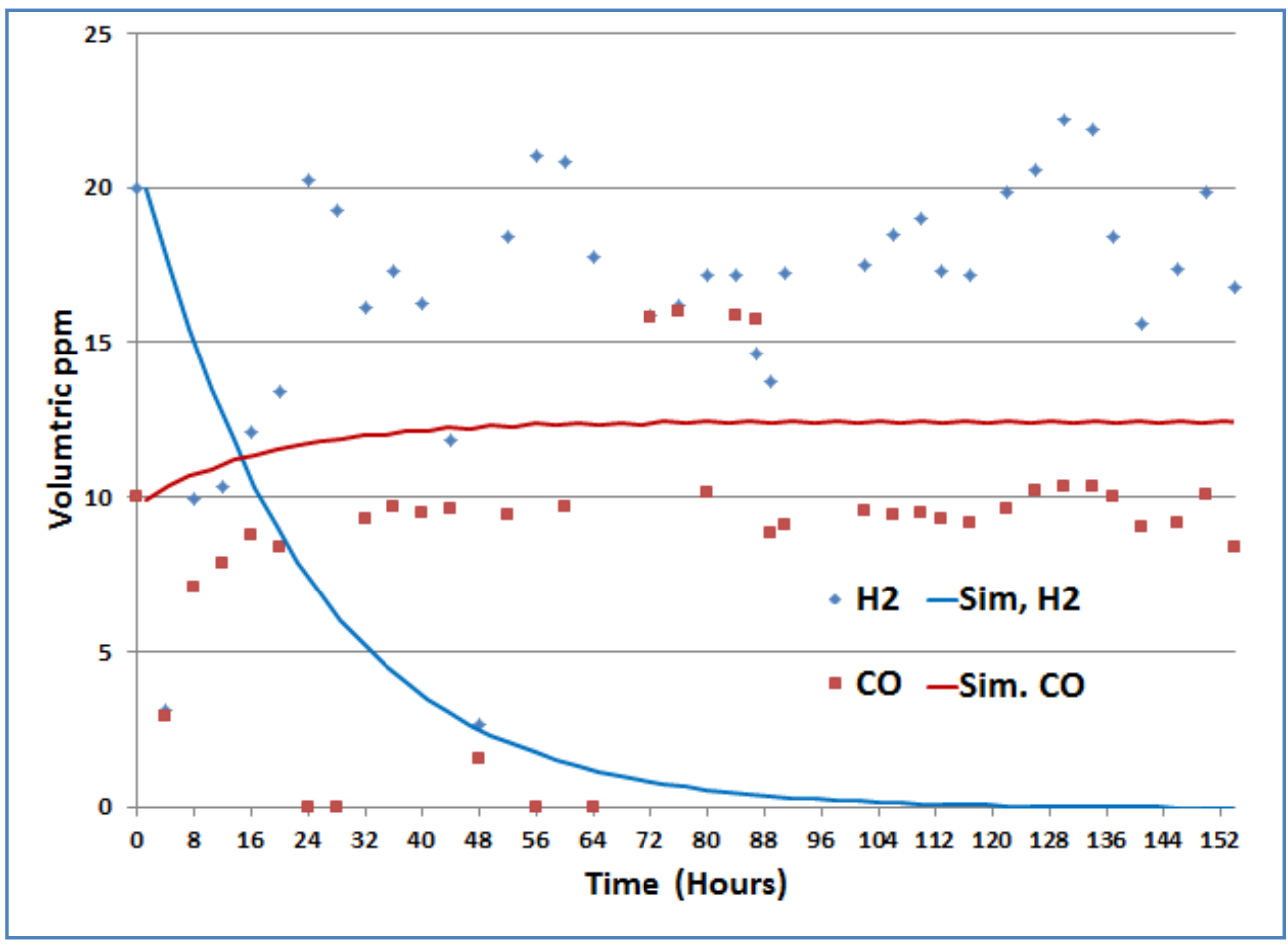

c) $\mathrm{H}_{2}$ and $\mathrm{CO}$

Figure 3.9 Simulation results vs. Field measurement data 
Figure 3.9 shows development trends of the gas species in the sealed volume. And it also can be seen that the injection of $\mathrm{CO}_{2}-\mathrm{N}_{2}$ has strong impacts on the gas gas species $\mathrm{s}$ in the sealed area. Due to continuous $\mathrm{CH}_{4}$ inflow from surrounding strata and $\mathrm{CO}_{2}$ injection from outside, the concentrations of $\mathrm{CH}_{4}$ and $\mathrm{CO}_{2}$ keep building up. But the simulation results also show that $\mathrm{N}_{2}$ maintains high percentage concentration with a small deceasing trend. For other gases, $\mathrm{C}_{2} \mathrm{H}_{6}$ and $\mathrm{O}_{2}$ have both decreasing trends. Over all, compared with field measurement data, the simulation results agree well with field measurement data for most gas species except $\mathrm{H}_{2}$ and $\mathrm{CO}$. It should be noted that the total amounts and the concentrations of these two gases are very small in comparison to the gases mentioned previously. The differences between the simulation results and the actual data are in the ppm level for these two gases. The reasons may be a small scale of coal oxidation at normal temperature could occurred in the longwall gob, and the "piston effect" caused by the injected inert gases may result in a heterogeneous mixing process. However, it should be noted that all the simulation results can well show the development trends of each of the gas species over a time period.

\subsection{Summary}

- Explosions originated from or around the sealed areas in underground coal mines present a serious safety threat for coal miners. Generally, the gas compositions in a sealed mine area change greatly, especially within the first few weeks or months after being sealed. Therefore, a mathemati- 
cal model to simulate such dynamic gas species changes is urgently desired.

- Barometric pressure, as one of the most important factors controlling the mine sealed atmospheric gas species changes, is detail analyzed. Proper mathematical functions to represent three typical barometric pressure fluctuation curves in U.S. main coal field locations, which are Northern Appalachian coalfield, Central Appalachian coalfield and Illinois Basin, are fitted by using mathematical curve fitting approach based on measurements of local barometric pressure data. In addition, these fitted curves are also classified for different time periods, which include the diurnal pressure fluctuation curve, the monthly pressure fluctuation curve and the annual barometric pressure fluctuation curve.

- Coal mine seal, as another important influential factor, is also discussed in this chapter. By using Kirchhoff's Voltage Law (KVL), its effects can be characterized. The proposed characteristic equation is easily integrated into the simulation model.

- The categories of gases making up the sealed atmosphere are listed and their changing characteristics are also stated. By in-depth analysis, it is found that they have great impacts on the mine sealed atmosphere. Therefore, they should be considered well when developing the simulation model.

- A step-wise dynamic mathematical simulation model is developed to simulate the gas species changes in a sealed mine area. This model is de- 
rived based on the control volume approach but follows the law of mass conservation and the ideal gas law. It can handle up to nine different gas species, and two processes which are air-inflowing and gas-outflowing conditions are used to characterize the mass exchange between a sealed area and active workings.

- A verification case study is conducted at the end of this chapter. Comparing results calculated from the time-dependent mathematical simulation model with the actual field measurement data, the simulation mode has good accuracy to predict the gas species changes over a time period. 


\section{CHAPTER 4 MODIFIED COWARD EXPLOSIBILITY DIAGRAM METHOD}

\subsection{Introduction}

Gas explosion is a violent combustion phenomenon. Generally, it is a complicated chemical reaction, consisting of many steps and may include a series of complicated chain reactions. Simply speaking, It is possible to analyze influence factors of the chemical by considering the combustion in a way as a bimolecular reaction, in which a combustible $A$ and an oxidizer $B$ react chemically with one combustion product $M$ under liberation of the heat $Q$ (Greuer, 1974) :

$$
A+B \rightarrow M+Q
$$

If $\bar{a}, \bar{b}$ and $\bar{m}$ are the molar concentrations of $A, B$ and $M$, the reaction rate can be defined as:

$$
\frac{d \bar{m}}{d t}=k \bar{a} \bar{b}
$$

Where $K$ is called the reaction rate constant; If using the volumetric concentrations $a, b$ and $m$ instead of the above molar concentrations, the ideal gas law could be used here to set up their relationships, yields:

$$
\begin{aligned}
& \bar{a}=\frac{P}{R T} a \\
& \bar{b}=\frac{P}{R T} b
\end{aligned}
$$

where $P$ is the total gas pressure, $T$ is the absolute temperature and $R$ is the universal gas constant. Thus: 


$$
\frac{d \bar{m}}{d t}=k\left(\frac{P}{R T}\right)^{2} a b
$$

The above equation shows that the reaction rate is proportional to the product $a^{*} b$ of the volume concentration and the square of the total pressure $P$, but inversely proportional to the square of the temperature $T$ (Greuer, 1974). Thus, it can be seen that various factors could greatly affect the gas explosibility.

In process industries, a gas explosion is defined as a process where combustion of a premixed gas cloud, i.e. fuel-air or fuel/oxidizer is causing rapid increase of pressure. Gas explosions can occur in process equipment or buildings or an open process area or a confined area. Figure 4.1 shows that common events included both before and after a gas explosion process.

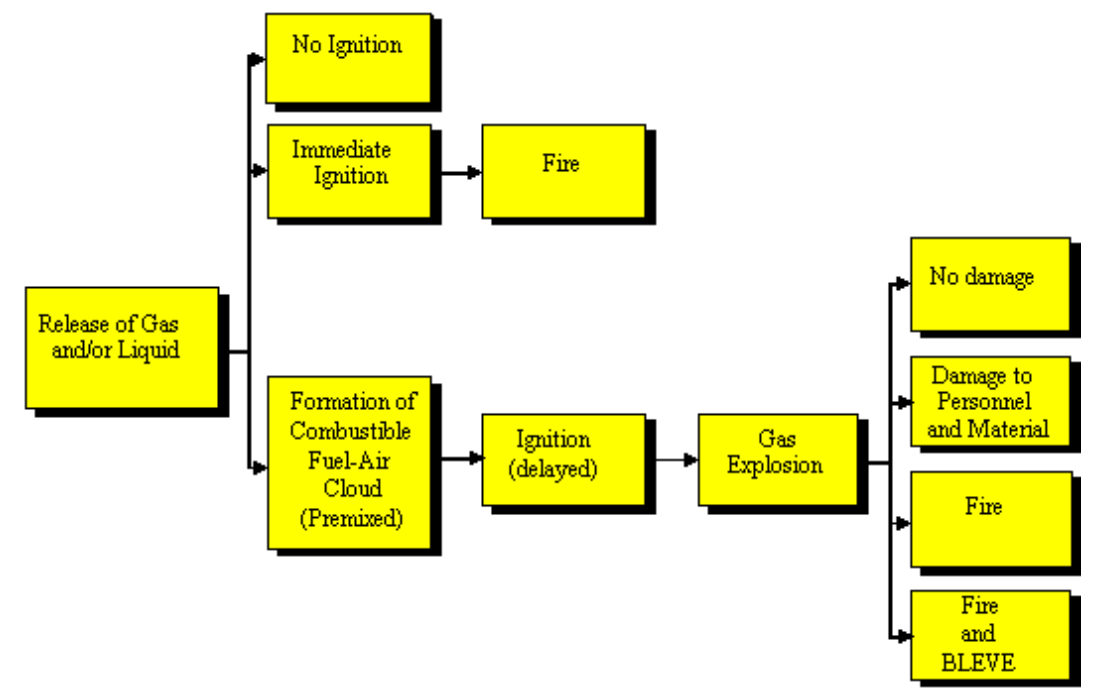

Figure 4.1 An event tree showing typical consequences of accidental releases of combustible gas or liquid into the atmosphere (Bjerketvedt, et al., 1997)

Loss experience shows that prevention of gas explosions by reducing the risk of accidental releases, formation of explosive clouds and ignition only, is not sufficient (Bjerketvedt, et al., 1997). In the mining industry, mine gas explosions still present a serious safety threat in the worldwide. As stated earlier, a total of 
157 gas explosions were responsible for 755 fatalities in Chinese coal mines in 2009. In the U.S., gas explosions are also the most dangerous hazard. "The worst mining disaster in American History", Monongah mine disaster, caused the lives of 362 workers including children to be lost. In recent years, coal mine gas explosions also continue to happen now and then. In 2006, Sago mine disaster killed 12 miners and Upper big branch (UBB) mine disaster, which occurred on April 5, 2010, resulted in 29 miners' death. UBB mine accident is also the worst mine disaster in the United States since 1970.

Normally, underground mine air consists of about $21 \%$ oxygen, $79 \%$ nitrogen and less than $1 \%$ methane. But depending on the geologic characteristics of the coal, composition of mine atmosphere always keeps changing due to continued liberating methane, hydrogen sulfide, or other gases into the mine, especially for the abandoned mine area. Another measure, such as nitrogen injection to mitigate the risk of mine gas explosion, also has strong impacts on the composition of a mine atmosphere. Therefore, determination of the mine gas explosibility is critical for mine rescues or controlling the severity of a mine accident, especially for the gas explosion event.

This chapter presents a modified Coward explosibility diagram method which has great and significant improvements for the original Coward explosibility diagram method. The proposed modified method actually considers more influence factors which can affect the explosibility of the gas-mixture, and therefore enhance the usefulness of the Coward method, and thus, it can effectively avoid the potential wrong judgments when determining the mine gas explosibility but 
give more accurate results. The modified Coward explosibility diagram method can also provide some baselines which can be used to assist any mine rescue strategy works.

\subsection{The Coward Explosibility Diagram}

The Coward explosive triangle (Coward \& Jones, 1952) is considered a fast and easy way to determine the explosibility of the mixture of air and combustible gases. In its original version, it considered only three combustible gases (i.e., $\mathrm{CH}_{4}, \mathrm{CO}$ and $\mathrm{H}_{2}$ ). When the three combustible gases mix with normal air, the explosibility of the mixture depends on the percentages of the combustible gases and the oxygen. Figure 4.2 shows the individual explosive triangles for the three combustible gases. Each of the explosibility triangles is defined by three characteristic points, the lower and upper flammable limits, and the nose flammable limit for the minimum oxygen concentration to support the explosion. The characteristic points for the three combustible gases are listed in Table 4.1. The explosibility triangle for a combustible gas divides the plot area into five distinctive zones. Taking the explosibility triangle of gas $\mathrm{CO}$ in Figure 4.2 as an example, point A represents the fresh air, point B represents 100\% combustible gas, and the origin of the graph represents $100 \%$ inert gas. Any mixture of air, combustible gas and inert gas can be represented by a point inside the diagram. The zone located above line $A B$ is a zone impossible to form an air-gas mixture. The area on the left of line $A E$ is the non-explosive zone, also known as the absolute safe zone. Triangle COD is the zone with potential for an explosion, which means 
once a sufficient ignition energy is provided, the explosion could happen. The airgas mixture in triangle $A O C$ is not-explosive. However, it could become explosive if a sufficient amount CO is infused. Zone ODBE is also a not-explosive one but could become so as more fresh air is introduced.

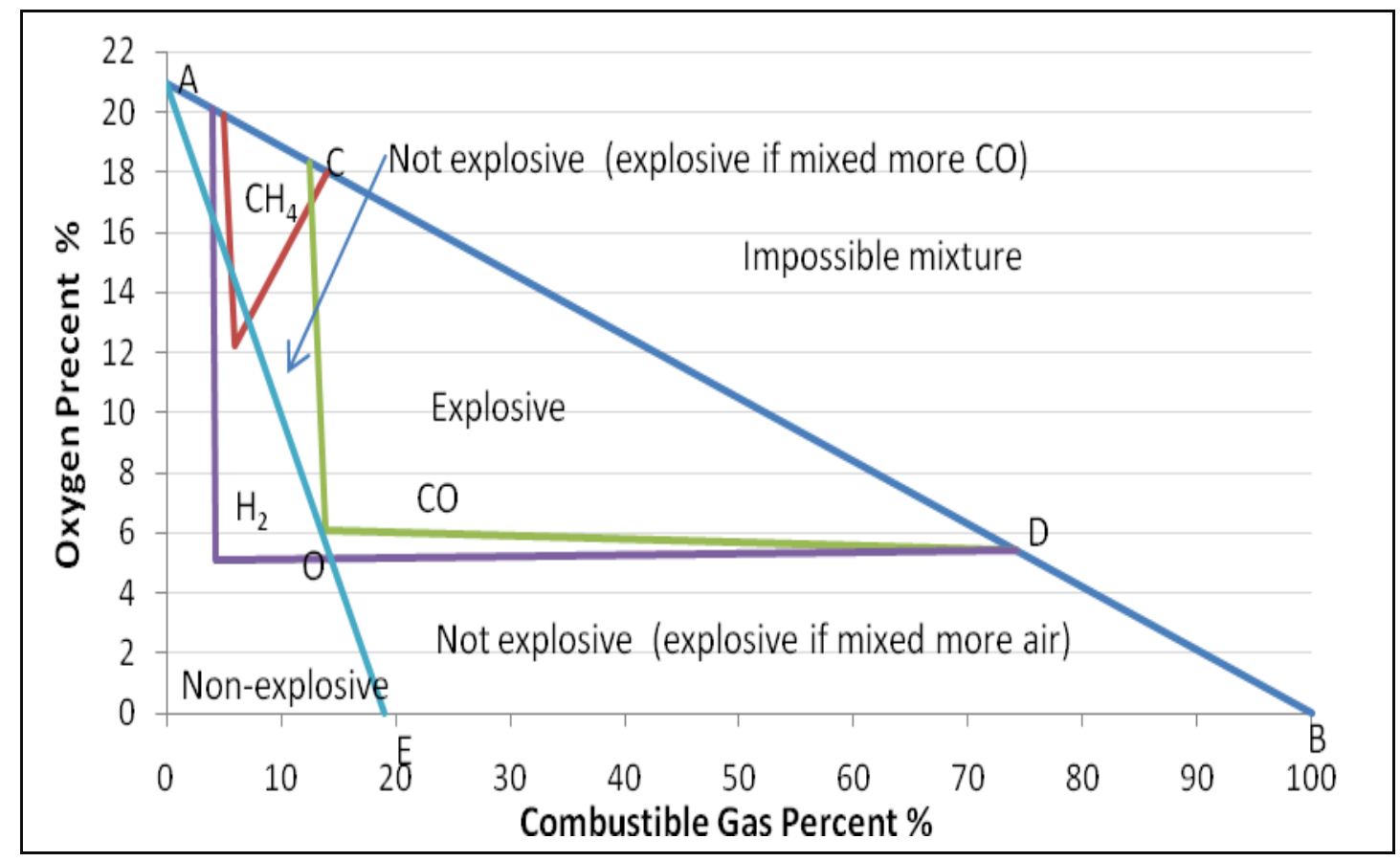

Figure 4.2 Coward explosive triangles for methane, carbon monoxide and hydrogen

Figure 4.2 just shows the explosive triangle with only one individual single combustible gas existing. If the gas-mixture consists of two or three combustible gases, the procedure of generating the resultant Coward triangle can be described as follows (McPherson, 1993):

- Determine the total combustibles percentage. If the volume percentages of the three combustible gases are $C_{1}, C_{2}$ and $C_{3}$, respectively. The total combustibles percentage is:

$$
C_{T}=C_{1}+C_{2}+C_{3}
$$


- Determine the gas flammability. The Le Chatelier's principle in the form of Eq. (4.7) is used to determine upper, lower and nose flammable limits of the mixed gases. To apply this equation for the lower flammable limit of the mixture $\left(L_{\mathrm{mix}}\right)$, the lower limits of the three gases are substituted in the places of $L_{1}, L_{2}$ and $L_{3}$. The upper and nose flammable limits can also be calculated with the same procedure.

$$
\frac{C_{T}}{L_{\text {mix }}}=\frac{C_{1}}{L_{1}}+\frac{C_{2}}{L_{2}}+\frac{C_{3}}{L_{3}}
$$

- Determine the required excess nitrogen. An effective way to render an air-gas mixture into a non-explosive one is to inject an excessive volume of nitrogen $\left(N_{\mathrm{ex}}\right)$ into the mixture as shown in Eq. (4.8). In this equation, $L_{n}$ is the nose flammability of the mixed gases; $N_{+}$is the volumes of excess nitrogen to be added in order to make flammable gases extinctive. Table 4.1 also presents the excess nitrogen if the combustible content consisted of one gas only.

$$
N_{e x}=\frac{L_{n}}{P_{T}}\left\{N_{1}^{+} C_{1}+N_{2}^{+} C_{2}+N_{3}^{+} C_{3}\right\}
$$

- Determine the oxygen percentage at the nose limit $\left(O_{n}\right)$.

$$
O_{n}=0.2093\left(100-N_{\mathrm{ex}}-L_{n}\right)
$$

\begin{tabular}{|c|c|c|c|c|c|}
\hline \multirow{2}{*}{ Gas } & \multicolumn{2}{|c|}{ Flammable Limits } & \multicolumn{2}{|c|}{ Nose Limits } & \multirow{3}{*}{$\begin{array}{c}\text { Nitrogen to be added to make } \\
\text { mixture extinctive: }\left(N+\mathrm{m}^{3} \text { of }\right. \\
\text { nitrogen per } \mathrm{m}^{3} \text { of combustible } \\
\text { rac) } \\
6.07\end{array}$} \\
\hline & Lower & Upper & Gas & Oxygen & \\
\hline Methane $\left(\mathrm{CH}_{4}\right)$ & 5.00 & 14.00 & 5.90 & 12.20 & \\
\hline Hydrogen $\left(\mathrm{H}_{2}\right)$ & 4.00 & 74.20 & 4.30 & 5.10 & 4.13 \\
\hline Carbon monoxide (CO) & 12.50 & 74.20 & 13.8 & 6.10 & 16.59 \\
\hline
\end{tabular}

Table 4.1 Vertices of the explosive triangles (percentages) 
Using the data obtained from these equations, the explosibility triangle for the air-gas mixture can be constructed, and the state point expressed by the concentrations of oxygen and total combustible gases can be plotted on the same diagram. The relative position between the explosibility triangle and the state point shows the explosibility status of the air-gas mixture at current state and the explosibility potential when condition changes.

\subsection{Common Combustible Gases in Sealed Mine Atmosphere}

In a sealed mine volume, the following categories of gases make up the sealed mine atmosphere. They are: (1) atmospheric gases; (2) products of chemical reactions in underground mines including low temperature coal oxidation, combustion or gas explosions; (3) gases emitted from the virgin coal seams, such as $\mathrm{CH}_{4}, \mathrm{CO}_{2}$ and $\mathrm{H}_{2}$; and (4) other inert gas, $\mathrm{N}_{2}$ or $\mathrm{CO}_{2}$ injected into the sealed volume in order to extinguish the mine fire events or minimize the risk of potential explosions.

Atmospheric gases refer to the gases can be found in an ambient gas sample. Almost $99 \%$ of it consists of nitrogen $\left(\mathrm{N}_{2}\right)$ and oxygen $\left(\mathrm{O}_{2}\right)$; and the remaining part is made up by very small quantities of argon (Ar) and carbon dioxide $\left(\mathrm{CO}_{2}\right)$.

The second category of gases is the products of chemical reactions occurring in underground mines. Typically, the chemical reactions include two different forms, one is the coal oxidation or mine fire, and the other is mine gas explosion. 
Coal oxidation is an irreversible exothermic reaction and its reaction rate increases with temperature. When the heat produced by the coal oxidation is not adequately dissipated by conduction or convection, the temperature in the coal mass increases. This increase in temperature leads to an increase in the coal oxidation rate. If not averted with appropriate action, this process results in thermal runaway and a fire ensues (Yuan \& Smith, 2011).

Spontaneous heating is a low temperature coal oxidation reaction which takes place when coal is exposed to air. Once it is intensified, coal mine fires will result. To quantify the products of a mine fire, it is important to understand the whole process of coal burning. Generally, the following processes are believed to occur in sequence (Wang, 2004):

- Distillation of gases from the coal;

In this stage, the gaseous products of low-temperature oxidation at the very early stages are carbon monoxide $(\mathrm{CO})$, carbon dioxide $\left(\mathrm{CO}_{2}\right)$, water vapor $\left(\mathrm{H}_{2} \mathrm{O}\right)$. Methane $\left(\mathrm{CH}_{4}\right)$ and hydrogen $\left(\mathrm{H}_{2}\right)$ are also produced.

- Oxidation of the coal on its surface with the emission of heat and light; Gaseous products during this stage include the alkane $\left(\mathrm{C}_{n} \mathrm{H}_{2 n+2}\right)$, alkene $\left(\mathrm{C}_{n} \mathrm{H}_{2 n}\right)$ and alkyne $\left(\mathrm{C}_{n} \mathrm{H}_{2 n-2}\right)$ series of hydrocarbon gases. The progression of evolving gases is dependent on the temperature of oxidation (Yuan \& Smith, 2011) .

- Flaming combustion.

When a flaming combustion occurs, the combustible gases can burn to a degree that is governed by the quantity of oxygen in the air. The final mixture 
leaving the fire zone is a result of the gases of distillation and the extent to which the fire has become fuel-rich. In general, the above processes can be summarized as the following chemical equation:

$$
a \mathrm{Coal}+b \mathrm{O}_{2}=c \mathrm{CO}+d \mathrm{CO}_{2}+e \mathrm{H}_{2} \mathrm{O}+f \mathrm{C}_{x} \mathrm{H}_{y}
$$

In the equation, $a, b, c, d, e$ and $f$ are stoichiometric coefficients. Field experiences show $\mathrm{C}_{x} \mathrm{H}_{y}$ is generally the alkane $\left(\mathrm{C}_{n} \mathrm{H}_{2 n+2}\right)$, alkene $\left(\mathrm{C}_{n} \mathrm{H}_{2 n}\right)$ or alkyne $\left(\mathrm{C}_{n} \mathrm{H}_{2 n-2}\right)$ series of hydrocarbon gases.

Chamberlain, et al. (1973) found that CO is the most sensitive indicator of the early stages of coal oxidation, and the continuous monitoring of this gas provides the earliest detection of self-heating. Other gases have also been observed, such as $\mathrm{CO}_{2}, \mathrm{CH}_{4}, \mathrm{H}_{2}$, and higher hydrocarbons (Xie, et al., 2011). $\mathrm{CO}_{2}$ production increases with increasing temperature and is also useful in determining the state of a fire. Zhou \& Wu (1996) conducted a series of experimental tests to determine the order of gaseous products when the coal samples are heated. They reported the order is: carbon monoxide $(\mathrm{CO}) \rightarrow$ hydrogen $\left(\mathrm{H}_{2}\right) \rightarrow$ ethylene $\left(\mathrm{C}_{2} \mathrm{H}_{4}\right) \rightarrow$ propylene $\left(\mathrm{C}_{3} \mathrm{H}_{6}\right) \rightarrow$ acetylene $\left(\mathrm{C}_{2} \mathrm{H}_{2}\right) \rightarrow$ other higher hydrocarbons.

In addition, mine gas explosions can also generate hydrocarbon gases. The chemical reaction equations of the methane explosion depending on the degree of sufficiency of oxygen in the mine space can be listed as:

$$
\begin{aligned}
& \mathrm{CH}_{4}+2 \mathrm{O}_{2}=\mathrm{CO}_{2}+2 \mathrm{H}_{2} \mathrm{O} \\
& 2 \mathrm{CH}_{4}+3 \mathrm{O}_{2}=2 \mathrm{CO}+4 \mathrm{H}_{2} \mathrm{O} \\
& 3 \mathrm{CH}_{4}+5 \mathrm{O}_{2}=2 \mathrm{CO}+\mathrm{CO}_{2}+6 \mathrm{H}_{2} \mathrm{O}
\end{aligned}
$$


In summary, in coal oxidation, mine fires or explosions, acetylene $\left(\mathrm{C}_{2} \mathrm{H}_{2}\right)$, ethylene $\left(\mathrm{C}_{2} \mathrm{H}_{4}\right)$ and ethane $\left(\mathrm{C}_{2} \mathrm{H}_{6}\right)$ are often found in the underground air. Although the total amount of these gases is not large, they are significant to affect the explosibility of the mine gas-mixture. The characteristic points for the added combustible gases are listed in Table 4.2.

Table 4.2 Vertices of explosive triangles (percentages)

\begin{tabular}{lccccc}
\hline \multirow{2}{*}{ Gas } & \multicolumn{2}{c}{ Flammable Limits } & \multicolumn{2}{c}{ Nose Limits } & \begin{tabular}{c} 
Nitrogen to be added to make \\
mixture extinctive: $\left(N+\mathrm{m}^{3}\right.$ of \\
\cline { 2 - 5 } nitrogen per m ${ }^{3}$ of combustible
\end{tabular} \\
\cline { 2 - 5 } Ethylene $\left(\mathrm{C}_{2} \mathrm{H}_{4}\right)$ & Lower & Upper & Gas & Oxygen & gas) \\
Ethane $\left(\mathrm{C}_{2} \mathrm{H}_{6}\right)$ & 2.75 & 28.60 & 2.89 & 6.06 & 15.60 \\
Acetylene $\left(\mathrm{C}_{2} \mathrm{H}_{2}\right)$ & 3.00 & 12.50 & 3.12 & 8.41 & 12.80 \\
\hline
\end{tabular}

\subsection{The Corrections of UFL and LFL}

The lower and upper flammable limits specify the range of the proportion of combustible gases in a mixture in between this mixture is flammable. Flammable limits consist of two individual limits; one is the lower flammable limit (LFL). Below this flammable limit, the mixture is too lean to burn; therefore, LFL describes the leanest mixture that still sustains a flame. The other is the upper flammable limit (UFL). Above the upper flammable limit, the mixture is too rich to burn. Thus, it gives the richest flammable mixture. On the other hand, the quantitative difference between the two flammability limits is called the explosive range. Once an ignition source is introduced, a flammable mixture will burn or explode if its concentration is within the explosive range.

Knowing the flammable limits is very important for designing any safety strategies (Britton, 2002). Generally, mine gas mixture consists of combustible, 
oxidizing, and inert gases. However, it is also known that the temperature, pressure, and the concentration of the inert gas can greatly influence flammability limits. The following sections in-depth discuss the influence effects by each environmental factor.

\subsubsection{Effects of nitrogen and carbon dioxide}

Due to the inert effects by the inert gas, once the inert gas is mixed into the gas-mixture, it can greatly change the flammable limits. In general, when an inert gas is added to a hydrocarbon gas/air mixture, the result is an increase in the lower flammable limit concentration and a decrease in the upper flammable limit concentration. Figure 4.3 shows the influence of nitrogen, water vapor, and carbon dioxide, etc. on the limits of flammability of methane in the air. The different effects of the three gases are ascribed to their different heat capacity; as carbon dioxide has the greatest heat capacity; it has the greatest extinctive effect on flame. The corresponding curve for argon in the same figure agrees with this supposition, as argon has a smaller heat capacity than nitrogen. The curve for helium, a gas of heat capacity equal to argon, shows that this is not the only factor determining extinctive effect of an inert gas; apparently the high thermal conductivity of helium makes it a more efficient flame extinguisher than argon. It seems, however, that the effect of different thermal conductivities is insignificant unless the difference is great. Therefore, the flammable limits must be corrected once the inert gas is mixed into the gas-mixture. 


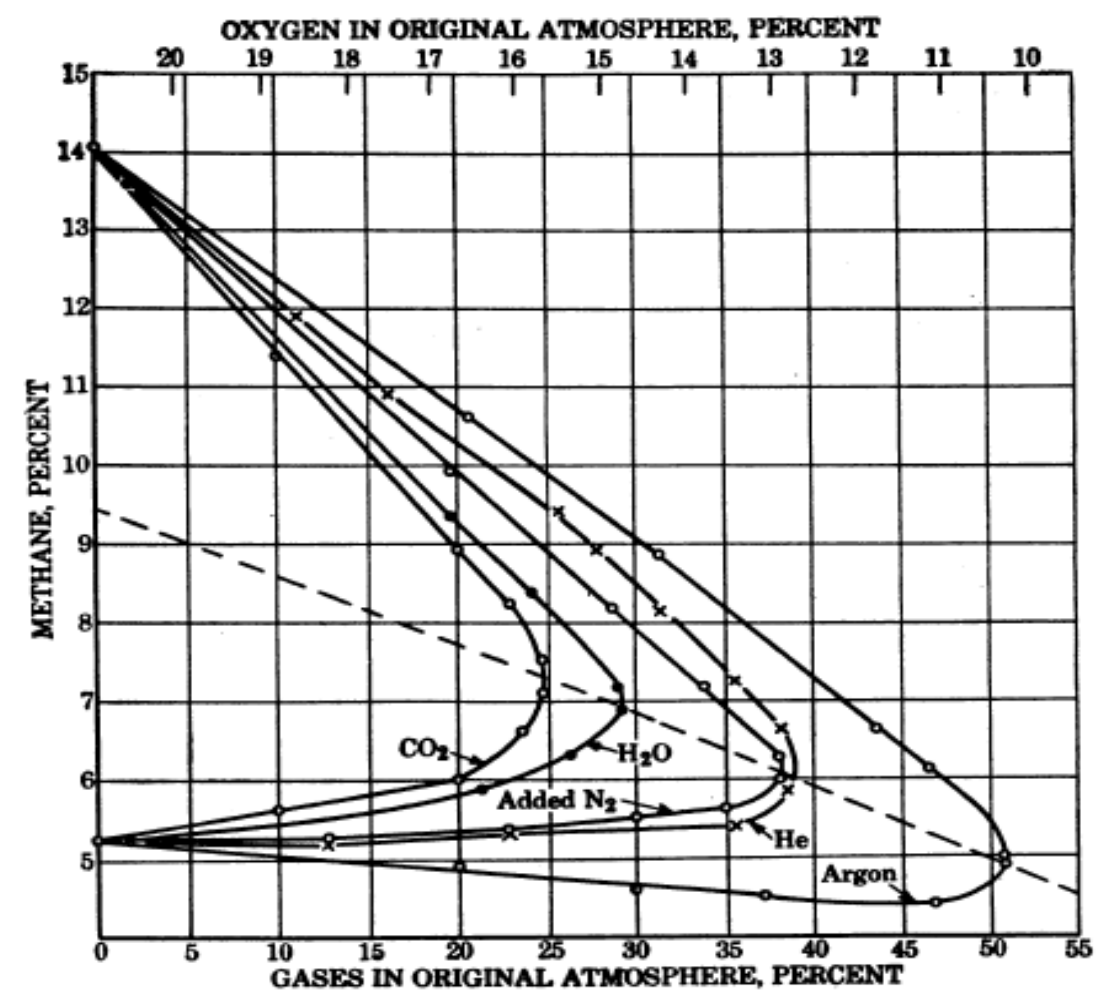

Figure 4.3 Limits of flammability of methane in separate mixtures of air with carbon dioxide, water vapor, nitrogen, helium and argon (Coward \& Jones, 1952; Zabetakis, 1965)

Generally, there are two important inert gases that can reduce the flammability of an underground mine atmosphere. They are nitrogen $\left(\mathrm{N}_{2}\right)$ and carbon dioxide $\left(\mathrm{CO}_{2}\right)$. Part of $\mathrm{N}_{2}$ originally comes from the normal air and the other is injected into the sealed volume in order to extinguish mine fires or minimize the risk of potential explosions, so as $\mathrm{CO}_{2}$.

Kondo, et al., (2006b) conducted a series of experimental studies, and the effect of inert gas dilution on the flammability limits was measured carefully for a number of fuel gases in order to make an accurate numerical analysis of the data (Kondo, et al., 2008). Then, he proposed an extension of Le Chatelier's formula to apply to mixtures containing inert gas. The equations can be used to fit the in- 
ert gas dilution effect on the flammable limits of fuel gases very well. Hence, his method is going to be used to correct the flammable limits of combustible gases. Figure 4.4 shows his research works.

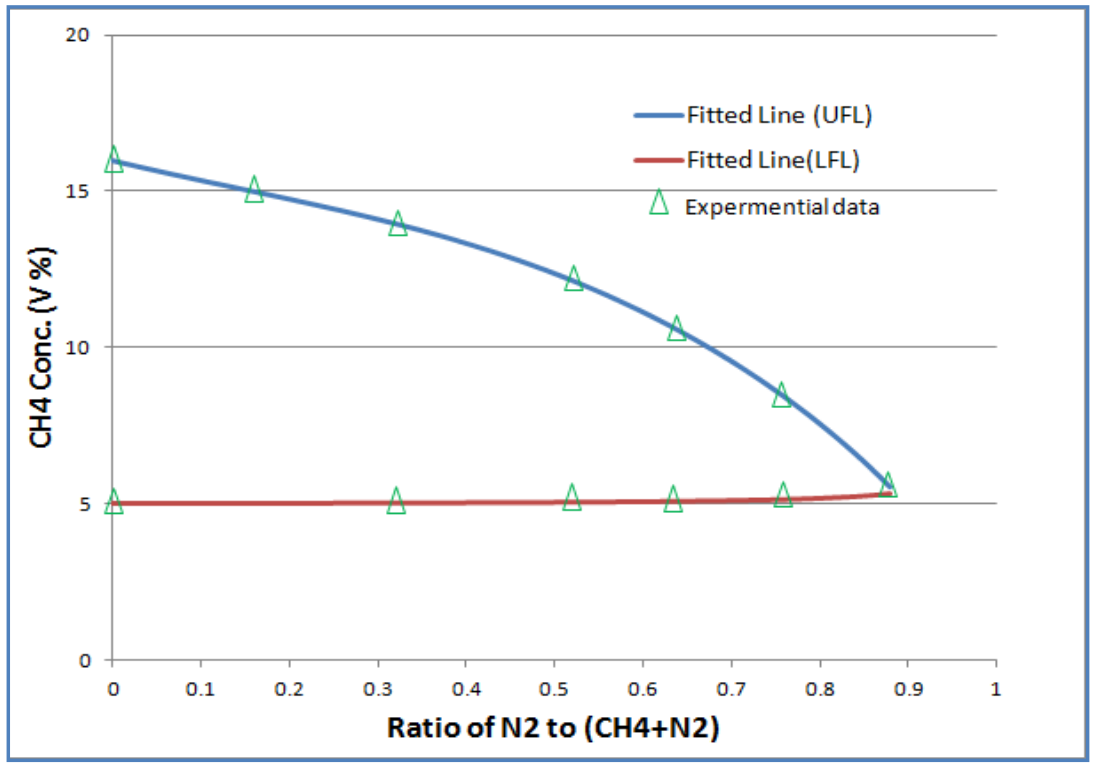

a) Flammable limits affected by N2

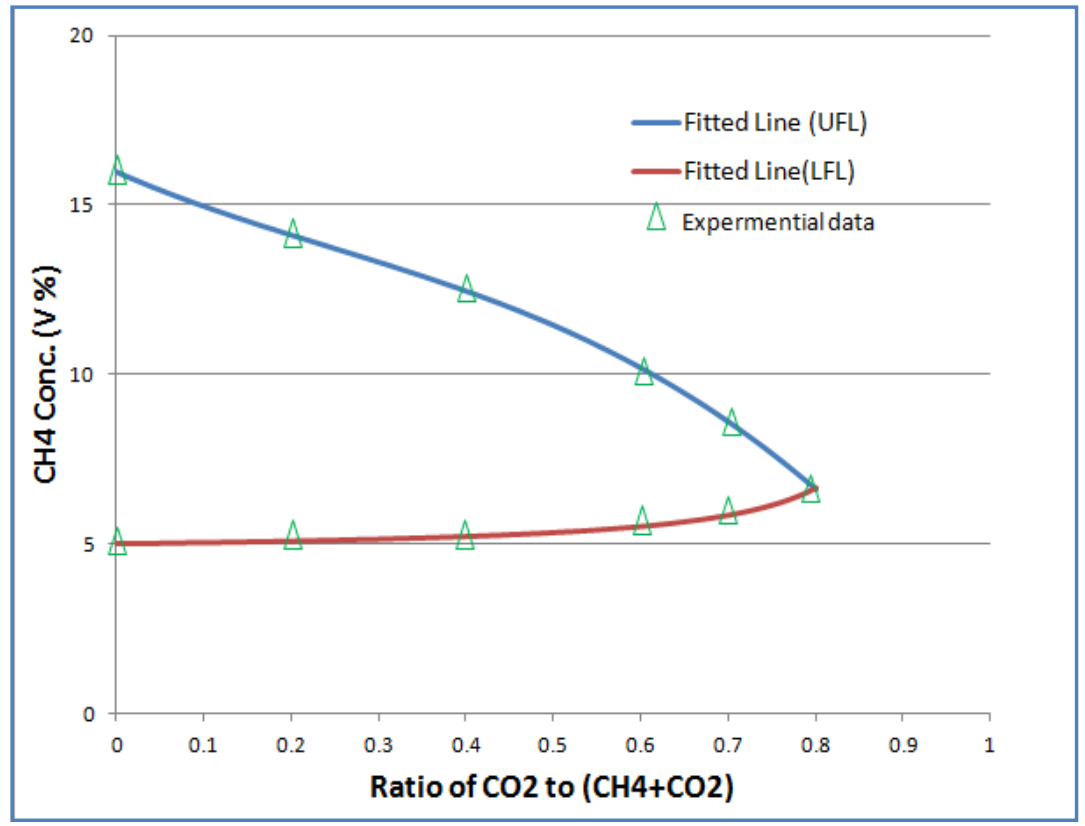

b) Flammable limits affected by $\mathrm{CO}_{2}$

Figure 4.4 Comparison between the observed and calculated values of flammability limits of methane-nitrogen blend of various compositions (Kondo, et al., 2006a) 
For the inert effects due to the added nitrogen, the following extension Le Chatelier's equations can be used to determine the new flammability limits (Kondo, et al., 2006a):

For the lower flammable limits (LFL):

$$
\frac{c_{1}}{L^{\prime}}=\frac{c_{1}}{L}+a c_{i n}
$$

For the upper flammable limits (UFL):

$$
\frac{c_{1} n_{1}}{100-\left(U^{\prime} / c_{1}\right)}=\frac{c_{1} n_{1}}{100-U}+b c_{i n}+c c_{i n}^{2}+d c_{i n}^{3}
$$

where: $L$ is the lower flammable limit of the combustible gas in air;

$U$ is the lower flammable limit of the combustible gas in air;

$L^{\prime}$ is the corrected lower flammable limit mixture of the blend and air;

$U^{\prime}$ is the corrected lower flammable limit mixture of the blend and air;

$c_{1}$ is the fraction of combustible gas in an assumed blend gas only consisted of this combustible gas and the nitrogen.

$c_{i n}$ is the fraction of inert gas in the above assumed blend gas. Hence, $C_{1}+C_{i n}=1$;

$n_{1}$ is the moles of oxygen when one mole of combustible gas is consumed at the upper flammable limit. It can be estimated as:

$$
n_{1}=\frac{0.21(100-U)}{U}
$$


$a, b, c$, and $d$ are parameters determined in the experiments, and their values can be referred in Table 4.3.

Table 4.3 Parameters values (Kondo, et al., 2006a)

\begin{tabular}{lcccc}
\hline Gas & $\mathrm{a}$ & $\mathrm{b}$ & $\mathrm{c}$ & $\mathrm{d}$ \\
\hline Methane $\left(\mathrm{CH}_{4}\right)$ & -0.00182 & 0.00144 & 0.00107 & -0.00178 \\
Ethylene $\left(\mathrm{C}_{2} \mathrm{H}_{4}\right)$ & -0.0266 & 0.00050 & 0.00046 & -0.00077 \\
General Hydrocarbon gases & -0.00817 & 0.00122 & 0.00187 & -0.00242 \\
\hline
\end{tabular}

For the inert effects due to the added carbon dioxide, the following revised Le Chatelier's equations can be used to determine the new flammability limits (Kondo, et al., 2006b):

For the lower flammable limits (LFL):

$$
\frac{c_{1}}{L^{\prime}}=\frac{c_{1}}{L}+p c_{i n}
$$

For the upper flammable limits (UFL):

$$
\frac{c_{1} n_{1}}{100-\left(U^{\prime} / c_{1}\right)}=\frac{c_{1} n_{1}}{100-U}+q c_{i n}+r c_{i n}^{2}+s c_{i n}^{3}
$$

where: $L$ is the lower flammable limit of the combustible gas in air;

$U$ is the lower flammable limit of the combustible gas in air;

$L^{\prime}$ is the corrected lower flammable limit mixture of the blend and air;

$U^{\prime}$ is the corrected lower flammable limit mixture of the blend and air; 
$c_{1}$ is the fraction of combustible gas in an assumed blend gas only consisted of this combustible gas and the nitrogen.

$c_{i n}$ is the fraction of inert gas in the above assumed blend gas. Hence, $C_{1}+C_{i n}=1$;

$n_{1}$ is the moles of oxygen when one mole of combustible gas is consumed at the upper flammable limit. It can be estimated as:

$$
n_{1}=\frac{0.21(100-U)}{U}
$$

$p, q, r$, and $s$ are parameters determined in the experiments, and their values can be referred in Table 4.4

Table 4.4 Parameters values (Kondo, et al., 2006b)

\begin{tabular}{lcccc}
\hline Gas & $\mathrm{p}$ & $\mathrm{q}$ & $\mathrm{r}$ & $\mathrm{s}$ \\
\hline Methane $\left(\mathrm{CH}_{4}\right)$ & -0.01259 & 0.00072 & 0.00220 & -0.00258 \\
Ethylene $\left(\mathrm{C}_{2} \mathrm{H}_{4}\right)$ & -0.001042 & -0.00083 & 0.00214 & -0.00115 \\
General Hydrocarbon gases & -0.01148 & -0.00111 & 0.00536 & -0.00401
\end{tabular}

\subsubsection{Effects of temperature}

To propagate a flame, the layer of unburned gas next to the burning layer must be brought to such a temperature that it will "burst into flame" rapidly. If the unburned gas is already at a temperature above that of the laboratory, less heat has to be supplied from the burning layer; therefore, the lower limit will decrease and the upper limit will increase at a higher initial temperature. Thus, a gas mix- 
ture, which is not flammable at one temperature, can become flammable if temperature increases (Arnaldos, et al., 2011). In other words, the range of flammability should be widened when the temperature is increased (Coward, et al., 1952). Figure 4.5 shows that the change patterns of the upper flammable limit (UFL) and the lower flammable limit (LFL) when temperature increases.

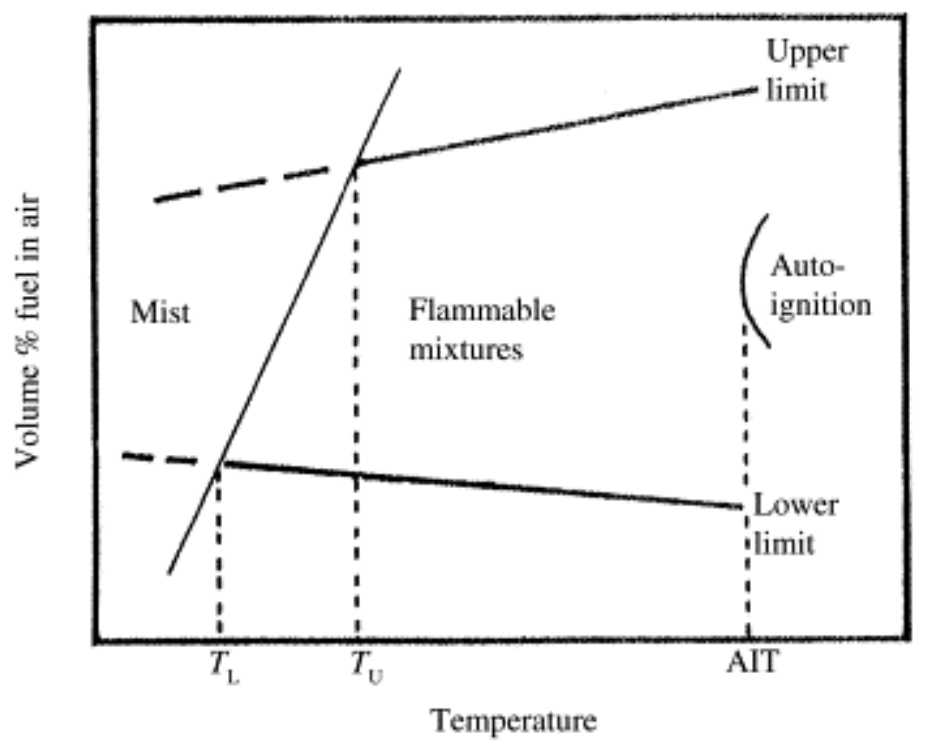

Figure 4.5 Variation of flammability limits as a function of temperature (Arnaldos, et al., 2011)

For the lower flammable limit, (Burgess \& Wheeler, 1911) showed that the heat liberated by a mole of a lower limit mixture at ambient temperature and pressure was approximately constant. This is called the Burgess-Wheeler law. Based on the Burgess-Wheeler law, a equation to predict the value of lower flammable limit (LFL) when the temperature changes is written as (Drysdale, 1985):

$$
\frac{L F L_{T}}{L F L_{298}}=1-\frac{T-298}{T_{\min }-298}
$$

where: $\mathbf{L F L _ { T }}$ is the lower flammable limit at the given temperature, $\mathrm{T}$; 
$L F L_{298}$ is the lower flammable limit at the temperature of 298 $\mathrm{K}$;

$T$ is the current absolute temperature, $\mathrm{K}$; $T_{\min }$ is the minimum temperature which must be reached to allow flame propagation.

Zabetakis, et al. (1959a) attempted to extend the law of Burgess-Wheeler by adding the enthalpy required to raise a limit mixture from ambient temperature to the initial test temperature on the basis of the findings of a constant adiabatic flame temperature:

$$
L F L \cdot\left(-\Delta H_{c}\right)+C_{p} \Delta T=k
$$

where: $C_{p}$ is the specific heat of fuel-air mixture;

$\Delta H_{c}$ is the heat of combustion of the fuel.

When the LFL is known at a given temperature, $T_{0}$, Eq (4.21) can be rewritten as:

$$
\frac{L F L(T)}{L F L\left(T_{0}\right)}=1-\frac{c_{p} \cdot 100}{L F L\left(T_{0}\right)\left(-\Delta H_{c}\right)}\left(T-T_{0}\right)
$$

Eq. (4.22) is called the modified Burgess-Wheeler law. It is validated by comparing the experimental data and calculation data (Rowley, et al., 2010), and is also considered to be a reasonable equation.

Increasing the temperature also increase the upper flammable limits for fuel gases. One correlation equation for the temperature dependence of the upper flammable limit can be written as (Vanderstraeten, et al., 1997): 


$$
U F L(T)=U F L\left(T_{0}\right)\left\lfloor 1+c\left(\frac{T-T_{0}}{100}\right)\right\rfloor
$$

where: $\operatorname{UFL}(T)$ is the upper flammable limit at the current temperature $\mathrm{T}$;

$\operatorname{UFL}\left(T_{0}\right)$ is the upper flammable limit at a given temperature,

$$
T_{0}=20^{\circ} \mathrm{C}
$$

$c$ is the coefficient obtained from the experimental measurements,

$$
\text { and } c=0.0854 \text {. }
$$

\subsubsection{Effects of pressure}

The normal variations of atmospheric pressure do not appreciably affect the limits of flammability (Carona, et al., 1999). However, once the mine area is sealed, due to the continuing gas emission, the inside pressure of the sealed area is going to build up; then the inside pressure becomes higher than the ambient atmospheric pressure. The direct observation has shown that the pressure variation has a considerable influence on the upper flammable limit but a small

effect on the lower flammable limit. Figure 4.6 shows the changes of flammable limits of two typical hydrocarbon gases (Propane and Methane) under different environmental pressures. 

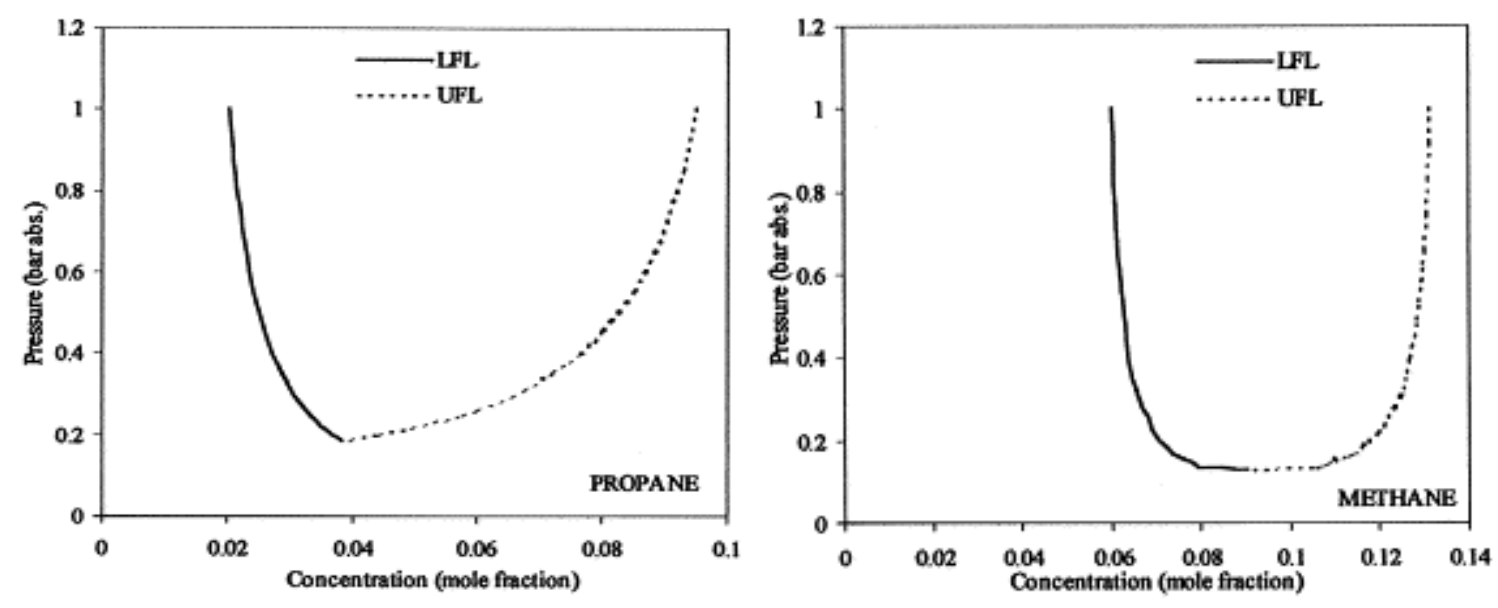

Figure 4.6 Variation of flammable limits for different gas-mixture, as a function of pressure (Arnaldos, et al., 2001)

Researchers have done a lot of work to identify the relationship between the ambient pressure and the flammable limits. Vanderstraeten, et al. (1997) summarized their experiment results and proposed a second order equation to describe the upper flammable limit as a function of pressure:

$$
U F L(P)=U F L\left(P_{0}\right)\left\lfloor 1+a\left(\frac{P}{P_{0}}-1\right)+b\left(\frac{P}{P_{0}}-1\right)^{2}\right\rfloor
$$

where: $U F L(P)$ is the upper flammable limit at the current pressure $P$;

$\operatorname{UFL}\left(P_{0}\right)$ is the upper flammable limit when ambient pressure is the normal pressure $P_{0}$;

$a$ and $b$ are the coefficients and listed in Table 4.5. 
Table 4.5 Coefficients in Eq. (4.24)

\begin{tabular}{cccc}
\hline Temperature $\left({ }^{\circ} \mathrm{C}\right)$ & Upper flammable limit (UFL) (\%) & $\mathrm{a}$ & $\mathrm{b}$ \\
\hline 20 & & 0.0466 & -0.000269 \\
100 & & 0.0552 & -00000357 \\
200 & Obtained from Eq.(4.23) & 0.0683 & -0.000541 \\
410 & & 0.0782 & -0.000691 \\
\hline
\end{tabular}

It should be note that the upper flammable limit should first be calibrated by the temperature to obtain the temperature-based upper flammable limit ( $\left.U F L\left(P_{0}\right)\right)$ when the pressure remains at the condition of the normal pressure. Then, the Eq. (4.24) is used to convert $U F L\left(P_{0}\right)$ to $U F L(P)$ at an elevated pressure.

\subsection{Redefining the Nose Limit}

Generally, nose limits are obtained in the experiments. Without such fundamental data, it is not possible to construct the Coward explosive triangle. However, the original Coward method only provides the nose limits for three combustible gases which are $\mathrm{CH}_{4}, \mathrm{CO}$ and $\mathrm{H}_{2}$. In order to expand the Coward diagram, the nose limits for more combustible gases must be known. On the other hand, due to different experimental equipment or conditions in the laboratory, various experimental results may be obtained. These may induce the problems when applying the Coward method. Hence, a mathematical model to derivate the noses limit based on other chemical parameters is needed. Noting that the acetylene 
has widest explosive range among all common combustible gases, (Muzyczuk, 1974) developed a series of equations to calculate the noses limit as follows:

$$
\begin{aligned}
& \left\{\begin{array}{l}
C_{i, j}=\frac{\left(1+g_{j}\right) L_{i}}{1+\frac{g_{j} L_{i}}{U_{i}}} \\
K_{i, j}=h_{j}\left(\frac{1}{L_{i}}-\frac{1}{U_{i}}\right)
\end{array}\right. \\
& \mathrm{O}_{i, j}=0.2093\left[100-C_{i, j}\left(1+K_{i, j}\right)\right]
\end{aligned}
$$

Where $K_{i, j}$ is the inert ratio of inert gas " $j$ " to combustible gas " $i$ ". $L_{i}$ and $U_{i}$ are the upper and lower flammability of combustible gas " $i$ ", respectively. $C_{i, j}$ and $O_{i, j}$ are the gas percentages of the combustible and oxygen which are also known as the vertex of the nose limit. $g$ and $h$ are coefficients with respect to the specific inert gas, their values are shown in Table 4.6.

Table 4.6 Inert gas coefficients

\begin{tabular}{ccc}
\hline Coefficient & Inert gas is Nitrogen $\left(\mathrm{N}_{2}\right)$ & Inert gas is Carbon dioxide $\left(\mathrm{CO}_{2}\right)$ \\
\hline $\mathrm{g}$ & 0.054 & 0.321 \\
$\mathrm{~h}$ & 71.77 & 44.23 \\
\hline
\end{tabular}

\subsection{Determination of Quantity of Excess Inert Gas}

The upper and lower limits are defined completely in the previous sections. However, for a resultant explosive triangle, the oxygen content at the nose limit remains to be found before the explosibility triangle for the mixture can be constructed. To find the oxygen content at the nose limit, the determination of the excess inert gas that has to be added in order to make flammable gases extinctive must be done first. These values are provided in Table 4.1 and Table 4.2 
based on the experimental results. However, as discussed in the previous section, different values of the excess inert gases with respect to various combustible gases should be known before effectively expanding the Coward method. Fortunately, once the nose limit for each individual combustible gas is known, the explosibility triangle for multiple combustible and inert gases can be deviated based on some characteristics in the Coward triangle.

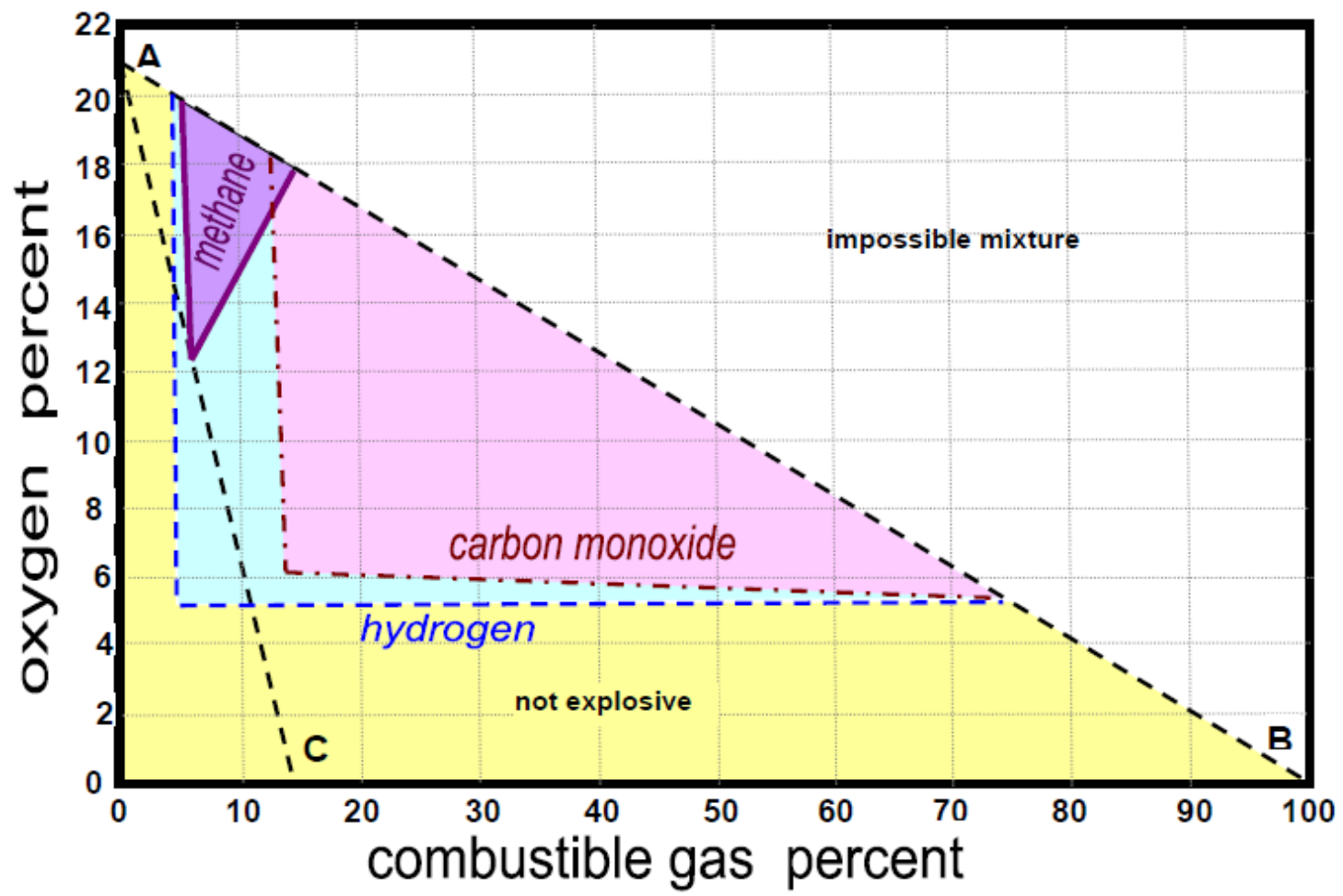

Figure 4.7 Coward explosive triangle for methane, carbon monoxide and hydrogen (McPherson, 1993)

To show the procedure, the methane is considered as an example first in Fig. 4.7. If starting from any point on the line $A B$ and adding more nitrogen, the gas point shall move in a straight line towards the origin, $\mathrm{O}$. The mixture will become extinctive when crossing the line AC. At that moment, an amount of inert gas added which is expressed by per unit volume of methane, is a constant. 
(This follows from the fact that both $A B$ and $A C$ are straight lines.) As it can commence at any position on $A B$, let us choose point $B$. As nitrogen is added, this point will move towards $\mathrm{O}$. At time it crosses the extinction line at point $\mathrm{C}$, the methane concentration is $N_{c}$. The remaining $\left(100-N_{c}\right)$ percent is nitrogen. Therefore, adding at a volume of at least $\left(100-N_{c}\right) / N_{c}$ of nitrogen for each $\mathrm{m}^{3}$ of methane is necessary to make the gas mixture totally non-explosive. A similar exercise can be carried out for each combustible gas. By mathematical transformation, the expression equation of the excess amount of inert gas can be written as:

$$
N_{e x}=\frac{100}{\frac{21 N_{c}}{21-N_{o}}}-1
$$

where: $N_{e x}$ is the excess amount of inert gas;

$N_{c}$ is the oxygen percentage at the nose limit;

$N_{o}$ is the combustible gas percentage at the nose limit

\subsection{Development of Safety Factor to Assist Using the Coward Me- thod}

The determination of the explosibility is critical for mine rescues or controlling the severity of a mine accident, especially for the gas explosion event. After a server coal mine fire or an explosion event, a common practice is to seal the related area, and then inject the inert gas $\left(\mathrm{N}_{2}\right.$ and/or $\left.\mathrm{CO}_{2}\right)$ into the sealed area to extinguish the fire and prevent potential explosions. At the same time, rescue 
works will be immediately planned. In order to prevent the risk associated with a potential secondary explosion, the rescue workers are not allowed to go underground until the atmosphere of the sealed area no longer has the explosibility potential. Therefore, mining engineers must precisely know how dangerous the situation is or what is the risk degree.

The Coward explosibility method can clearly identify the explosive status of mine atmosphere and track its explosibility trend as the compositions of the mine atmosphere change. However, the Coward diagram can only point out the explosibility of the mine gas, but it lacks the ability to show the safety margin. For instance, considering there are two gas-mixture samples which are point P1 and point P2 shown in Figure 4.8. By comparing the positions of these two state points with the explosive triangle, it clearly shows that the status at P2 is much safer than that at P1. Thus, their safety margins are significantly different from each other and the status $\mathrm{P} 2$ is better for performing the rescue works. On the other hand, since the composition changes with the time, both the location and shape of the explosibility triangle as well as the state point will change with time. Since point $\mathrm{P} 1$ is located very near the explosibility triangle, it may easily move from the not-explosive zone to explosive zone in case air is added to the sealed atmosphere. Therefore, a sound measure to measure the safety margin is needed in dealing with the explosibility of a sealed mine atmosphere. 


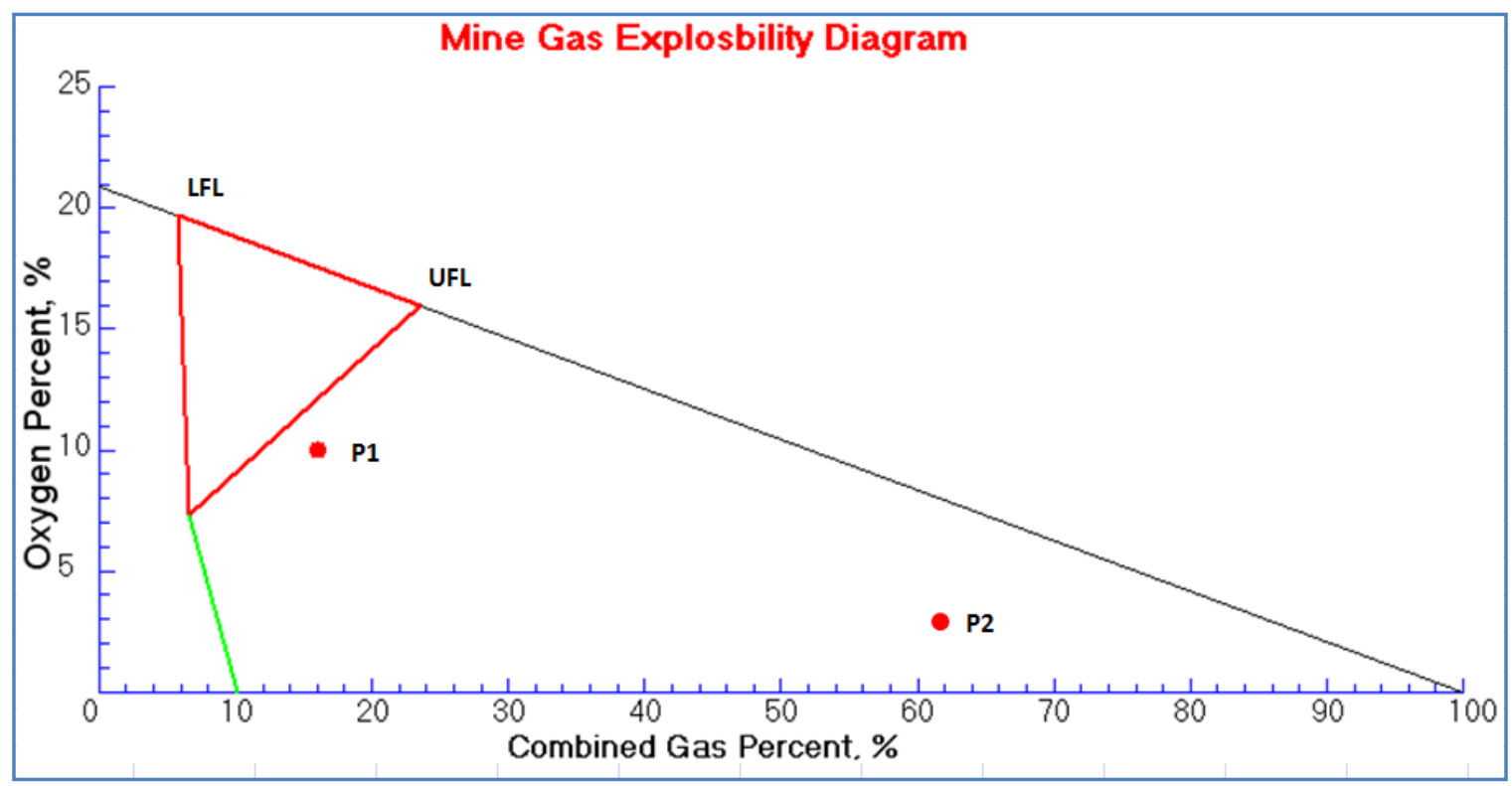

Figure 4.8 Comparing scenarios with different risks

A new concept, explosibility safety factor (SF), is introduced and defined to improve the safety for the rescue works when using the Coward method. It can clearly show how dangerous the current atmospheric status is if the state point locates in any not-explosive zones.

Recalling the contents in Chapter 3, three following categories of gases make up the gas-exchanges in a sealed volume of coal mines. They are the combustible gas flow, the inert gas flow and the fresh air flow. Precisely, they all can be well expressed in the Coward explosibility diagram. Figure 4.9 shows that directions of a state point can be shifted by the addition of more combustible gas, more air or more inert gas (Holding, 1992). When the combustible gas is added to or subtracted from a sealed volume while a constant ration between air and inert gas is maintained, the point representing the sealed atmosphere will move along a line joining the current state point to the $100 \%$ combustible point. If, instead of adding or subtracting combustible gas, air is added to the sealed atmos- 
phere while a constant ratio between combustible gas and inert gas is maintained, the point will move from the current state point to the normal fresh air point. Similarly, if more inert gas is added, the point will move toward to the origin of the diagram.

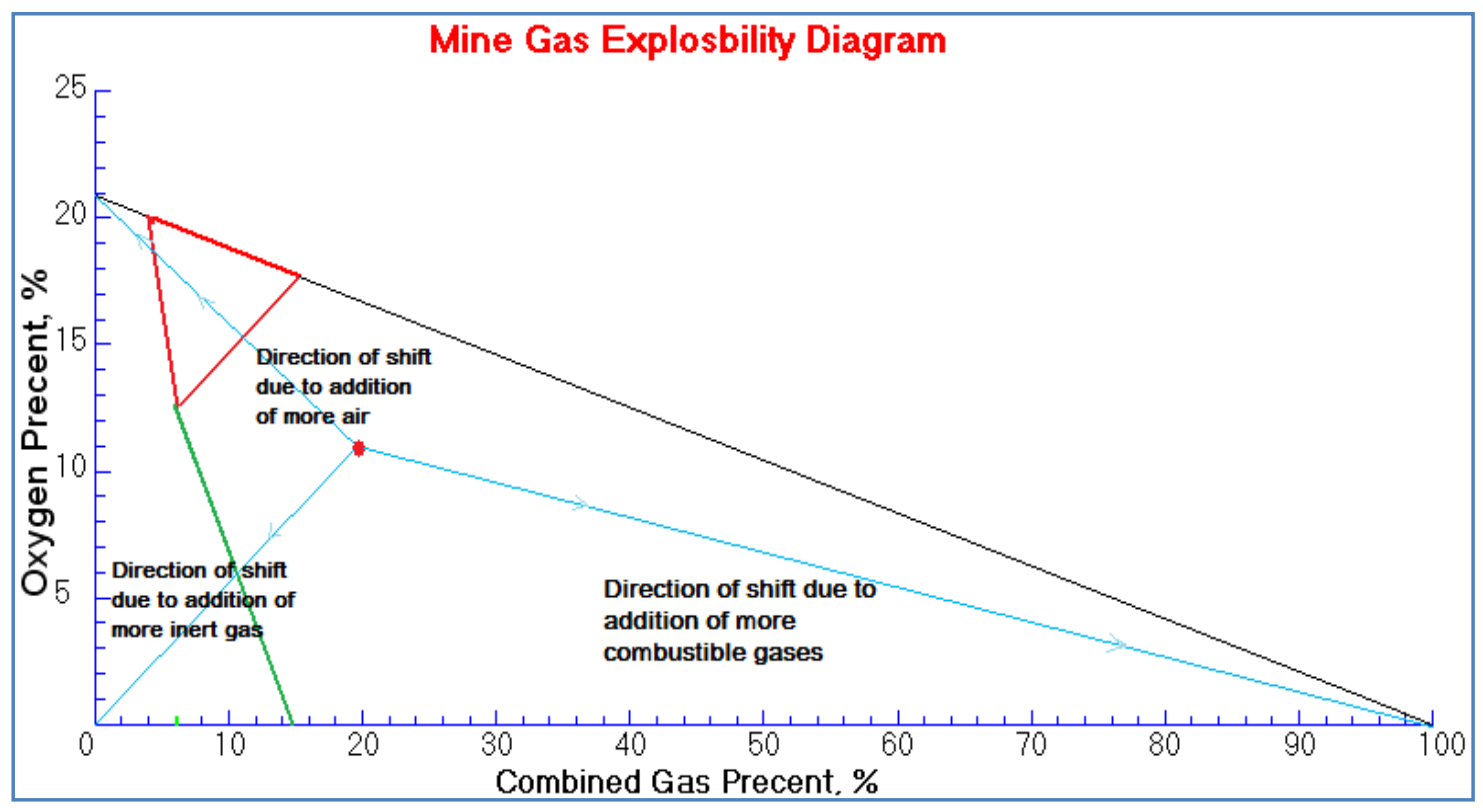

Figure 4.9 Illustration of Coward diagram characterizes

Based on the characteristics of the Coward explosibility diagram stated in the section 4.2, considering the point moving direction laws, the zones in the diagram can be redefined as follows (Referring Figure 4.10 to Figure 4.14):

- Zone BNC. It is the zone with potential of explosion, also called the explosibility triangle.

- Zone $A B N$. It is a not-explosive zone, but the status point in this zone has a special feature. By analyzing its potential moving direction, it can be found that there may appear two sets of the upper and lower flammable limits. One is induced by adding more combustible gas and the other is created by reducing the air quantity. Let's define the corres- 
ponding upper and lower flammable limits as $U_{c}, U_{a}, L_{c}$, and $L_{a}$, respectively. Hence, the explosibility safety factor (SF) is going to be defined as the following equation.

$$
S F=0.6 \times \frac{L_{U_{c} P}}{E L_{c}}+0.2 \times \frac{L_{U_{a} P}}{E L_{a}}+0.2 \times \frac{A_{P B C N}}{A_{B C N}}
$$

where: $L$ is the length between the two subscripts;

$A$ is the area represented by subscripts;

$E L_{c}$ is the explosive range induced by adding or subtracting more combustible gas;

$E L_{a}$ is the explosive range induced by adding or subtracting the air quantity.

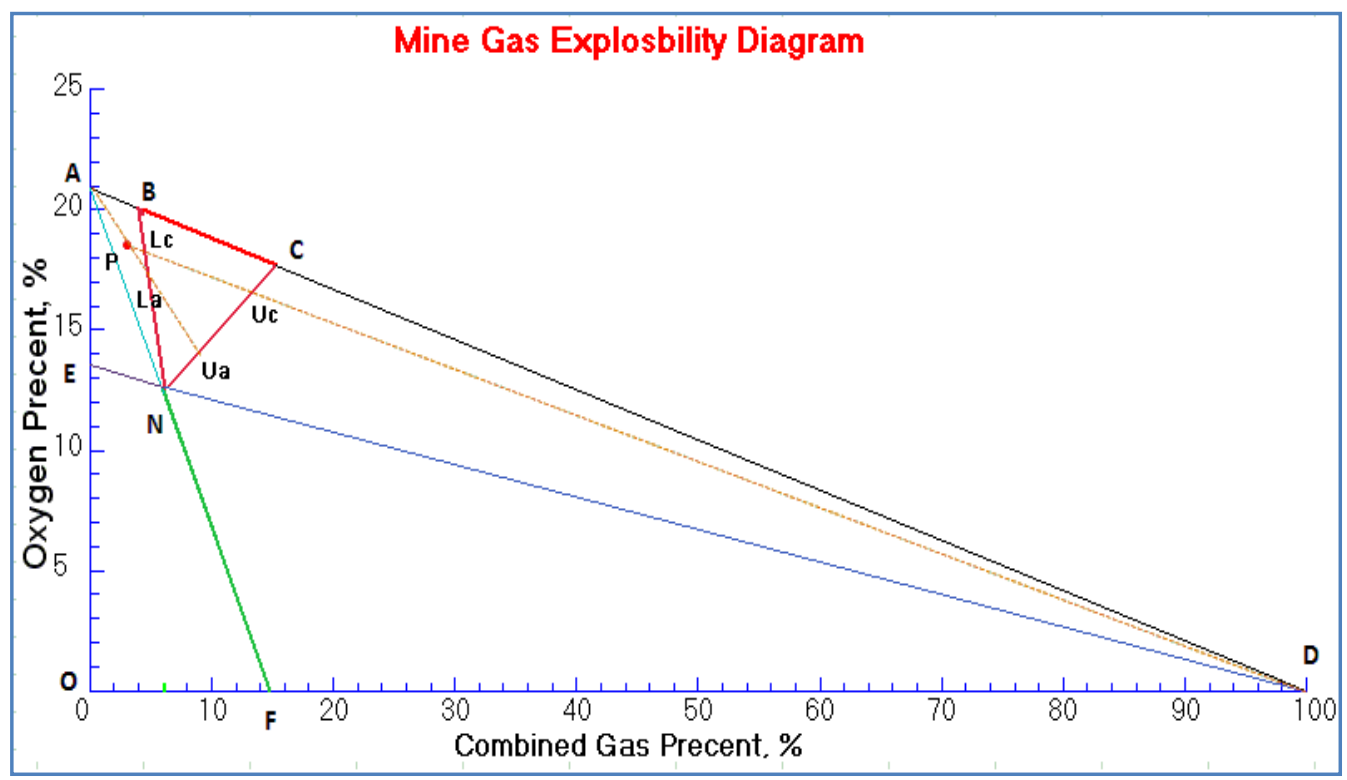

Figure 4.10 Defining SF for Zone ABN

Under this scenario, the possibility that the status point moves into the explosibility triangle with following the line PD is greater than that with following the line AP. In other words, the gas-mixture is easier 
to mix with more combustible gases going into the explosibility triangle than to reduce the contained air quantity to enter the triangle. Therefore, a lager weighting factor (0.6) is assigned in the first term in Eq. (4.28) and a small weighting factor $(0.2)$ is assigned for other two terms. This idea is also carried on to determine the weighting factors for the following zones.

- Zone CDN. It is also a not-explosive zone, and it could become explosive if more fresh air is infused or combustible gas is reduced. It is also like the zone ABN mentioned above. Two sets of the upper and lower flammable limits can also be generated. They are shown in the Figure 4.11 and are also noted as $U_{c}, U_{a}, L_{c}$, and $L_{a}$. Therefore, the explosibility safety factor (SF) is defined as:

$$
S F=0.2 \times \frac{L_{L_{c} P}}{E L_{c}}+0.6 \times \frac{L_{L_{a} P}}{E L_{a}}+0.2 \times \frac{A_{P B C N}}{A_{B C N}}
$$

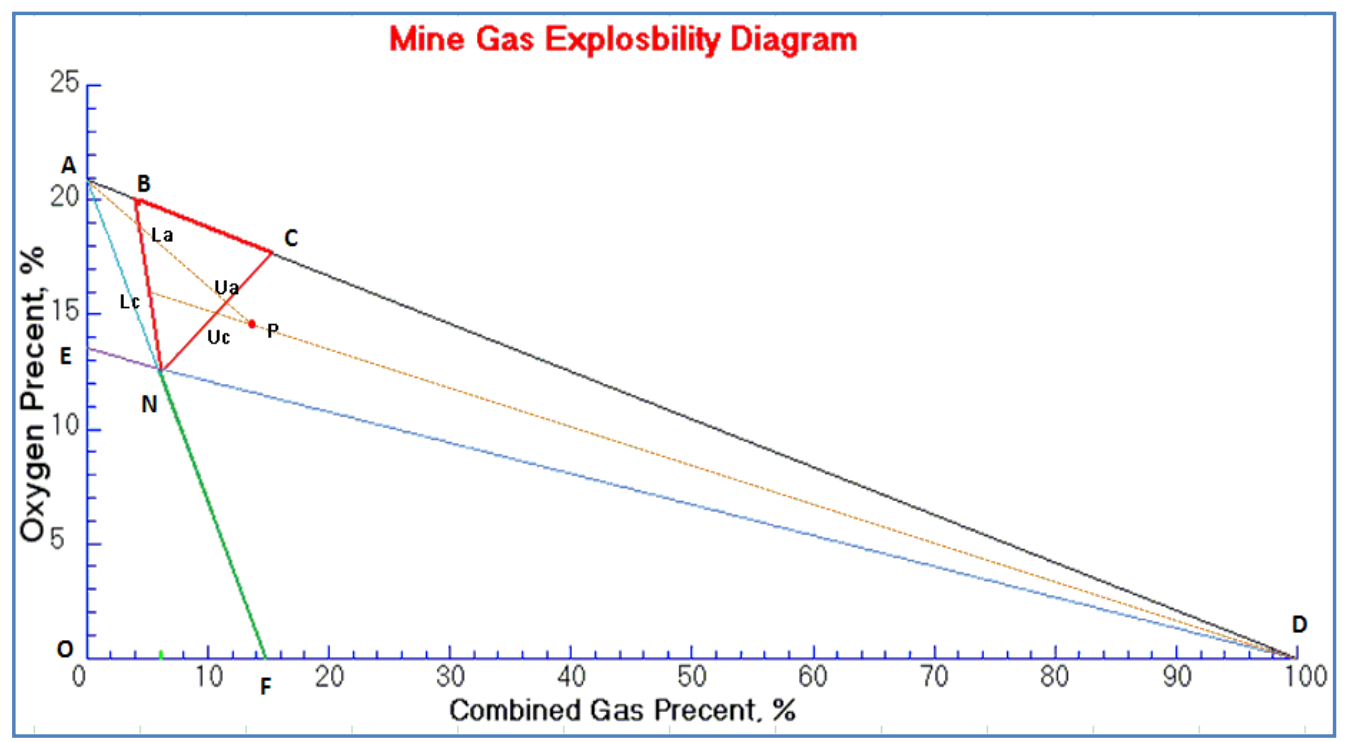

Figure 4.11 Defining SF for Zone CDN 
- Zone DFN. It is still a not-explosive zone. Different from the previous two, there is only a set of upper and lower flammable limits that can be touched in this zone, which means only one of three potential moving lines can intersect the explosive triangle. Under this scenario, the explosibility safety factor (SF) is defined as:

$$
S F=0.7 \times \frac{L_{L_{a} P}}{E L_{a}}+0.3 \times \frac{A_{P B C N}}{A_{B C N}}
$$

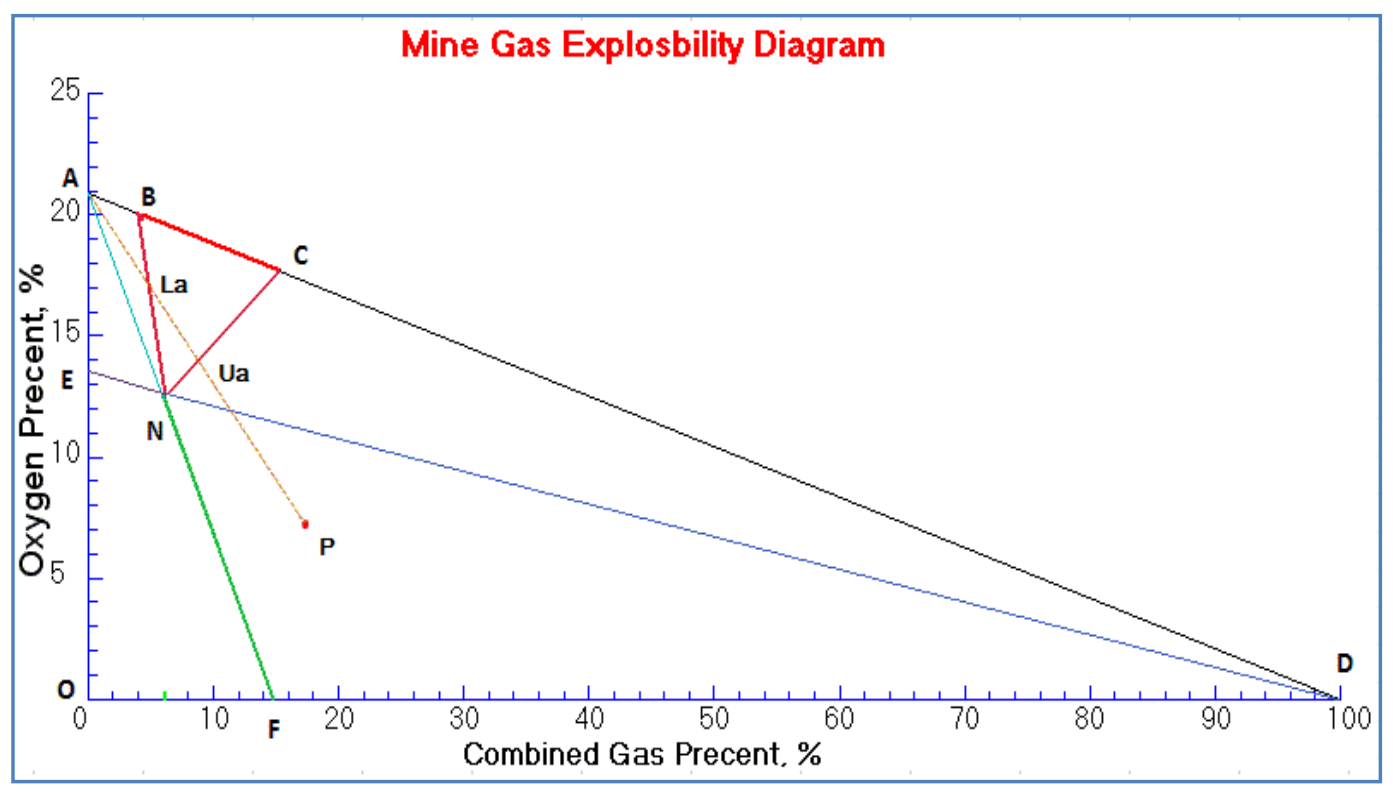

Figure 4.12 Defining SF for Zone DFN

- Zone AEN. It is a non-explosive zone. Different from the previous two, there is only a set of the upper and lower flammable limits can be touched in this zone, which means only one of three potential moving lines can intersect the explosive triangle. Under this scenario, the explosibility safety factor (SF) is defined as:

$$
S F=3 \times\left(0.7 \times \frac{L_{U_{c} P}}{E L_{c}}+0.3 \times \frac{A_{P B C N}}{A_{B C N}}\right)
$$


However, it should be noted that the point in this zone has a high safety degree since it already locates in the non-explosive zone. But the SF calculated here is only for theoretical analysis. The point will move to the zone $A B N$ when more combustible gas is added. Therefore, once this happens, another SF calculation equation may apply.

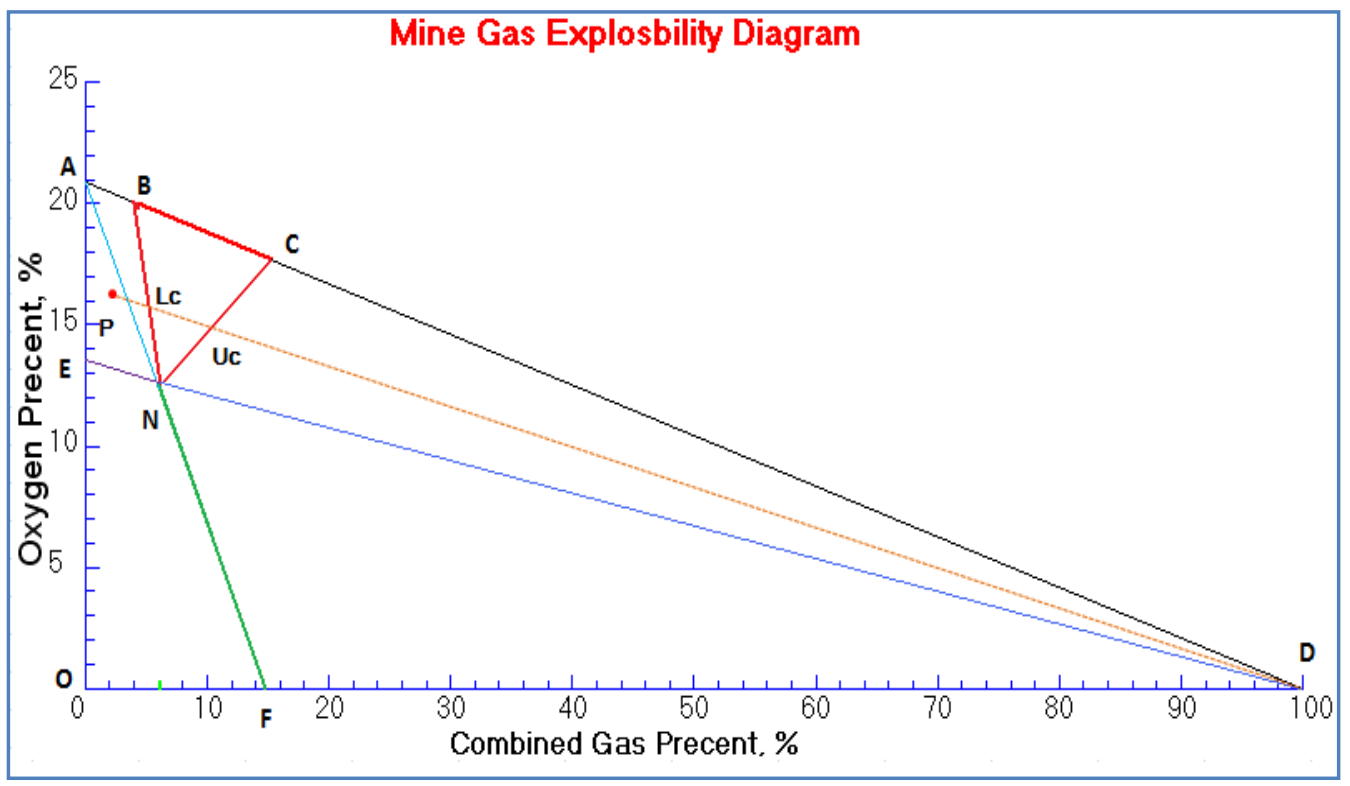

Figure 4.13 Defining SF for Zone AEN

- Zone ENFO. It is the non-explosive zone, and can be considered as the "true" absolute safety zone. Whatever any gases (Combustible gas, inert gas or fresh air) is added, its moving direction will not intersect the explosive triangle. Under this scenario, the explosibility safety factor (SF) is defined as:

$$
S F=5 \times \frac{A_{P B C N}}{A_{B C N}}
$$




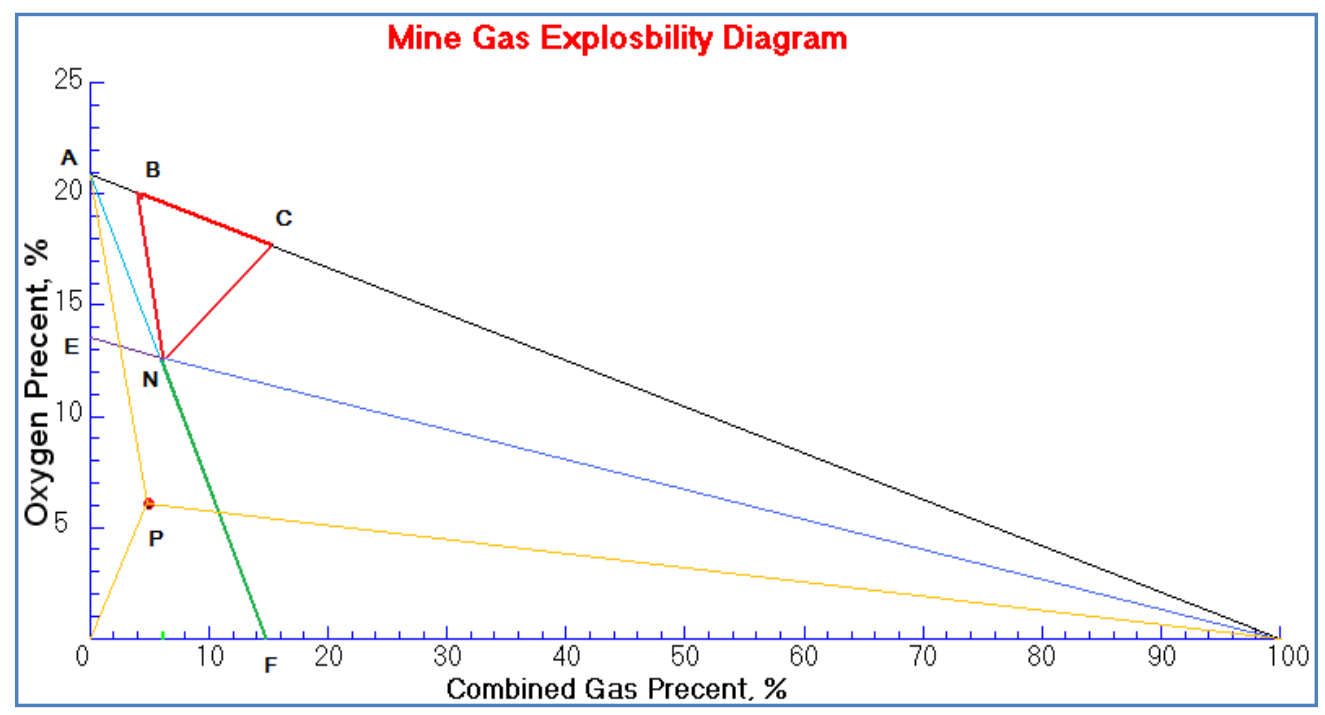

Figure 4.14 Defining SF for Zone ENFO

To demonstrate the proposal safety factor determination method, a total of 1345 mine gas samples are selected from three different mine fire events. Based on the Eq. (4.27) (4.31), the distribution of safety factors is plotted as shown in Figure 4.15. Then, a simple statistics study has been done to investigate the partition of range for the Safety Factor. The percentage numbers in this figure mean how many gas samples are located in the corresponding range. According to these results, a proper index system is proposed and is also listed in Table 4.7.

Table 4.7 Recommended SF Values for different risk levels

$\begin{array}{lll}\text { Risk levels } \quad \text { Ranges } & \text { Interpretations }\end{array}$

Very High $\quad>1$ and $\leq 2.9$

High $\quad>2.9$ and $\leq 4.5$

Medium $\quad>4.5$ and $\leq 6$

Low
High risk danger. Mine atmosphere should be phlegmatized. Not recommend to do any reuse works

Still high. Mine atmosphere should be watched very carefully. Not recommend to do any reuse works Reuse works can be done unless the current mine atmosphere is maintained very well. No risk exists, and reuse works can proceed 


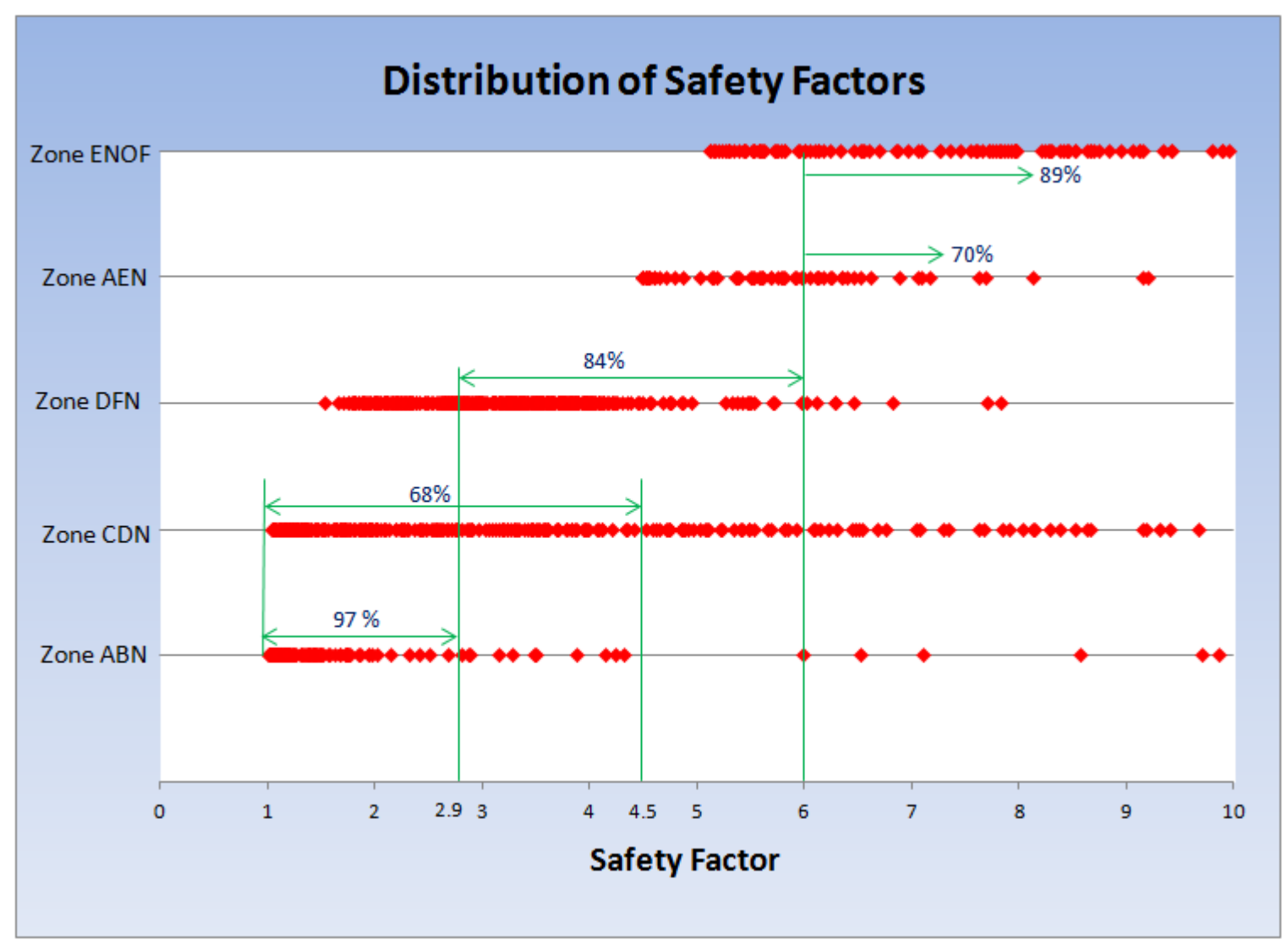

Figure 4.15 SF distributions based on mine gas samples

\subsection{Modified Coward Explosibility Diagram Method}

The Coward explosive triangle is a fast and easy way to determine the mine gas explosibility. However, the fundamental parameters wrong using or potential negative influential factors may result in certain errors when it is applied. Compared with the original method, the modified Coward explosibility diagram conquers these problems and enhances the accuracy of the method. The major works made for such improvements are: (1) Expand the combustible gas species in the original version. It becomes better for dealing with the explosibility of mine gas, especially when facing a mine fire event or other mine accidents. (2) Devel- 
op a procedure to correct the Lower Flammable Limit (LFL) and the Upper Flammable Limit (UFL) in accordance with effects by the environmental temperature, the pressure or the contained inert gas. (3) Redefine the nose limit for each combustible gas. The traditional method to obtain these values only relies on the experimental approach. However, the new calculation method can derive them based on the UFL and LFL by a series of regression equations. Thus, it can enhance to popularize the Coward method. (4) Develop an equation to calculate the excess amount of inert gas for each combustible gas. (5) Introduce and define the concept of the explosibility Safety Factor (SF) when using the Coward method. Such factors can clearly notify mining engineers about the potential explosive risk in a sealed mine gas atmosphere.

The process of the modified Coward explosibility triangle diagram method can be described briefly as shown in Figure 4.16.

\subsection{Cross-verification Study}

In order to ensure the reliability of the judgments made using the modified Coward explosibility diagram method, the USBM explosibility diagram is used as a supplemental method to double check the results. The monitored atmospheric composition data both from normal underground coal mine atmosphere and various spontaneous combustion/fire/explosion events after the mine was sealed were investigated by these two methods. In additional, the original Coward diagram is also used to drive the gas-mixture explosibility. 


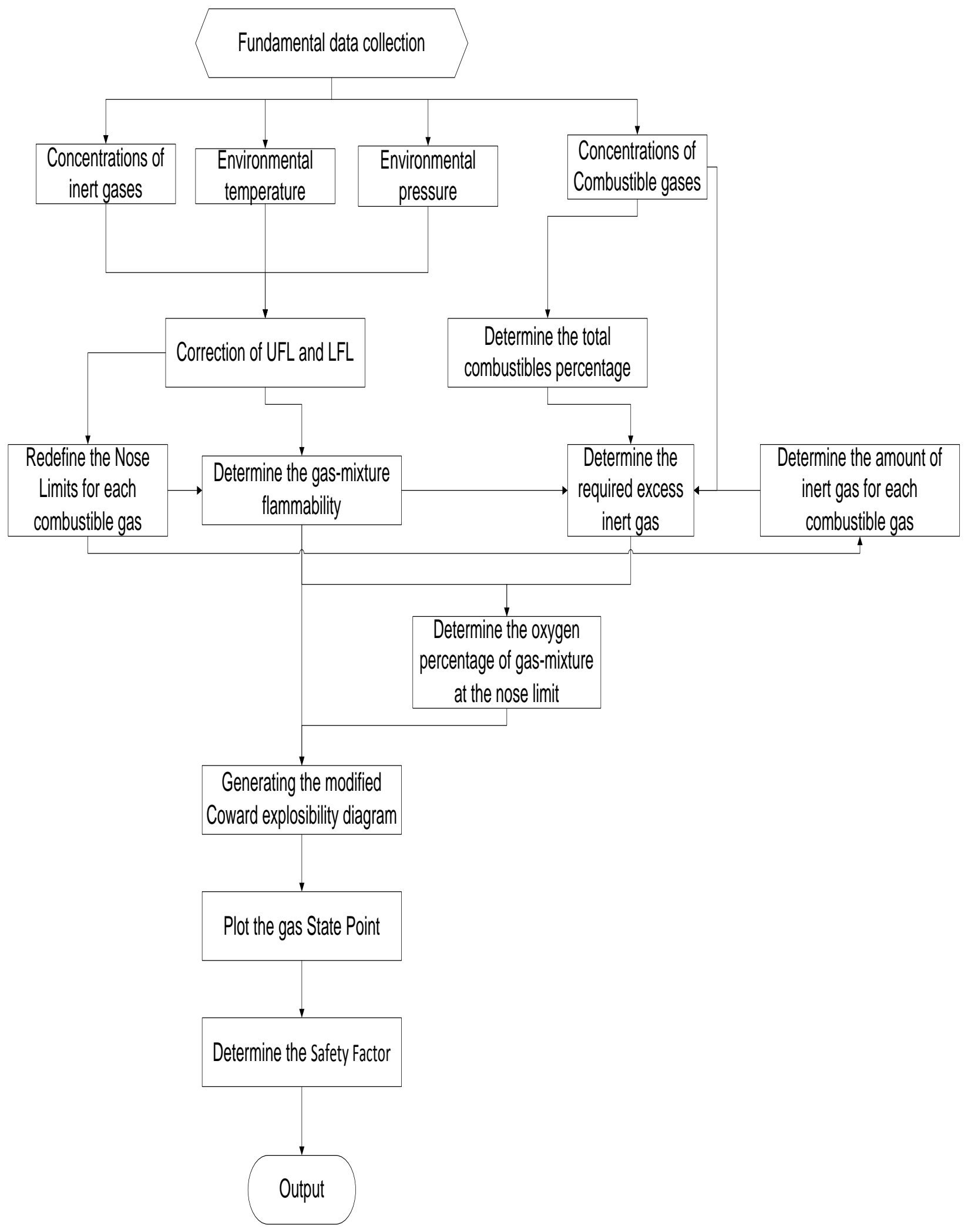

Figure 4.16 Flowchart of modified Coward explosibility method 
Table 4.8 shows the raw data for a total of 27 gas samples recorded from the mine atmosphere monitoring system. Figure 4.17 shows the state points of the mine atmosphere and the explosibility triangles using the modified Coward method, USBM explosibility diagram method and original Coward method following the order of gas samples which are listed in Table 4.8.

Table 4.8 Composition data recorded during a real mine fire

\begin{tabular}{|c|c|c|c|c|c|c|c|c|c|c|c|c|}
\hline \multirow[b]{2}{*}{$\begin{array}{l}\text { Sam- } \\
\text { ple } \\
\text { Num } \\
\text { ber }\end{array}$} & \multirow[b]{2}{*}{$\mathrm{O}_{2} \%$} & \multirow[b]{2}{*}{$\mathrm{N}_{2} \%$} & \multirow[b]{2}{*}{$\begin{array}{c}\mathrm{CO}_{2} \\
\%\end{array}$} & \multirow[b]{2}{*}{$\begin{array}{c}\mathrm{CH}_{4} \\
\%\end{array}$} & \multirow[b]{2}{*}{$\begin{array}{l}\mathrm{CO} \\
\mathrm{ppm}\end{array}$} & \multirow[b]{2}{*}{$\begin{array}{c}\mathrm{H}_{2} \\
\mathrm{ppm}\end{array}$} & \multirow[b]{2}{*}{$\begin{array}{l}\mathrm{C}_{2} \mathrm{H}_{2} \\
\text { ppm }\end{array}$} & \multirow[b]{2}{*}{$\begin{array}{l}\mathrm{C}_{2} \mathrm{H}_{4} \\
\mathrm{ppm}\end{array}$} & \multirow[b]{2}{*}{$\begin{array}{l}\mathrm{C}_{2} \mathrm{H}_{6} \\
\text { ppm }\end{array}$} & \multicolumn{3}{|c|}{ Explosibility } \\
\hline & & & & & & & & & & $\begin{array}{c}\text { By } \\
\text { Modified } \\
\text { Coward }\end{array}$ & $\begin{array}{c}\text { By USBM } \\
\text { Method }\end{array}$ & $\begin{array}{c}\text { By original } \\
\text { Coward }\end{array}$ \\
\hline 1 & 20.24 & 78.59 & 0.11 & 1.06 & 53 & 0 & 0 & 0 & 0 & No & No & No \\
\hline 3 & 18.75 & 77.47 & 0.10 & 3.67 & 41 & 0 & 0 & 0 & 8 & No & No & No \\
\hline 4 & 18.61 & 77.19 & 0.11 & 4.09 & 48 & 0 & 0 & 0 & 9 & No & No & No \\
\hline 5 & 18.96 & 76.26 & 0.11 & 4.66 & 40 & 0 & 0 & 0 & 10 & No & No & No \\
\hline 6 & 17.19 & 77.03 & 0.19 & 5.59 & 55 & 0 & 0 & 0 & 17 & YES & YES & YES \\
\hline 9 & 12.65 & 80.45 & 0.13 & 6.76 & 49 & 0 & 0 & 0 & 15 & YES & No & No \\
\hline 10 & 11.30 & 81.89 & 0.17 & 6.63 & 54 & 0 & 0 & 0 & 16 & YES & No & No \\
\hline 11 & 10.40 & 85.49 & 0.10 & 4.00 & 56 & 0 & 0 & 0 & 14 & No & No & No \\
\hline 12 & 6.48 & 83.06 & 0.06 & 1.93 & 18 & 0 & 0 & 0 & 6 & No & No & No \\
\hline 13 & 7.90 & 81.09 & 0.12 & 10.88 & 48 & 0 & 0 & 0 & 17 & No & No & No \\
\hline 14 & 6.36 & 85.22 & 0.12 & 8.29 & 48 & 0 & 0 & 0 & 18 & No & No & No \\
\hline 20 & 4.57 & 84.24 & 0.15 & 11.03 & 41 & 0 & 0 & 0 & 26 & No & No & No \\
\hline 21 & 4.55 & 87.82 & 0.17 & 7.45 & 33 & 0 & 0 & 0 & 32 & No & No & No \\
\hline 22 & 3.61 & 88.44 & 0.16 & 7.78 & 24 & 0 & 0 & 0 & 33 & No & No & No \\
\hline 23 & 4.11 & 85.76 & 0.14 & 9.99 & 23 & 0 & 0 & 0 & 27 & No & No & No \\
\hline 24 & 2.99 & 85.34 & 0.19 & 11.47 & 23 & 0 & 0 & 0 & 31 & No & No & No \\
\hline 25 & 3.95 & 85.80 & 0.14 & 10.11 & 18 & 0 & 0 & 0 & 17 & No & No & No \\
\hline 26 & 2.76 & 85.50 & 0.21 & 11.52 & 17 & 0 & 0 & 0 & 29 & No & No & No \\
\hline 27 & 2.71 & 83.30 & 0.29 & 13.70 & 15 & 0 & 0 & 0 & 34 & No & No & No \\
\hline
\end{tabular}


It can be seen that all three methods get the same determinations of the mine gas explosibility for the gas samples 6 and 7. All are considered as explosive gas-mixtures. However, it also should be noted that conflicting scenarios happened when determining the explosibility for the gas samples 8, 9 and 10 . Samples 8,9 and 10 are considered as non-explosive by USBM method, and samples 9 and 10 are also as by the original Coward method, but they are all considered as explosive by the modified Coward method. One of the reasons is that more combustible gases are included in the modified triangle, thus, the explosive zone becomes larger. It is also should be noted that, all the state points in these cases are very close to the boundary line of the explosibility triangle. They are easily to be determined as non-explosive by USBM method or original Coward method but explosive by the modified Coward method. Hence, the modified method has better accuracy and safety than other two methods when being applied in practices.

In addition, it also can be seen that all three explosibility diagrams can well demonstrate the histories of the gas state points of the mine atmosphere during the whole sampling process. Due to $\mathrm{N}_{2}$ injection to control the mine fire event, the gas-mixture is non-explosive at beginning but explosive later and the final state point (red point) was out of the explosibility triangle and could be considered as non-explosive at that time. In this case, the oxygen concentration and the nitrogen concentration play important roles for the determination of explosibility. In a time period, the nitrogen concentration is comparatively low while the 
oxygen concentration is comparatively high and the gas-mixture in the sealed mine is judged to be explosive.

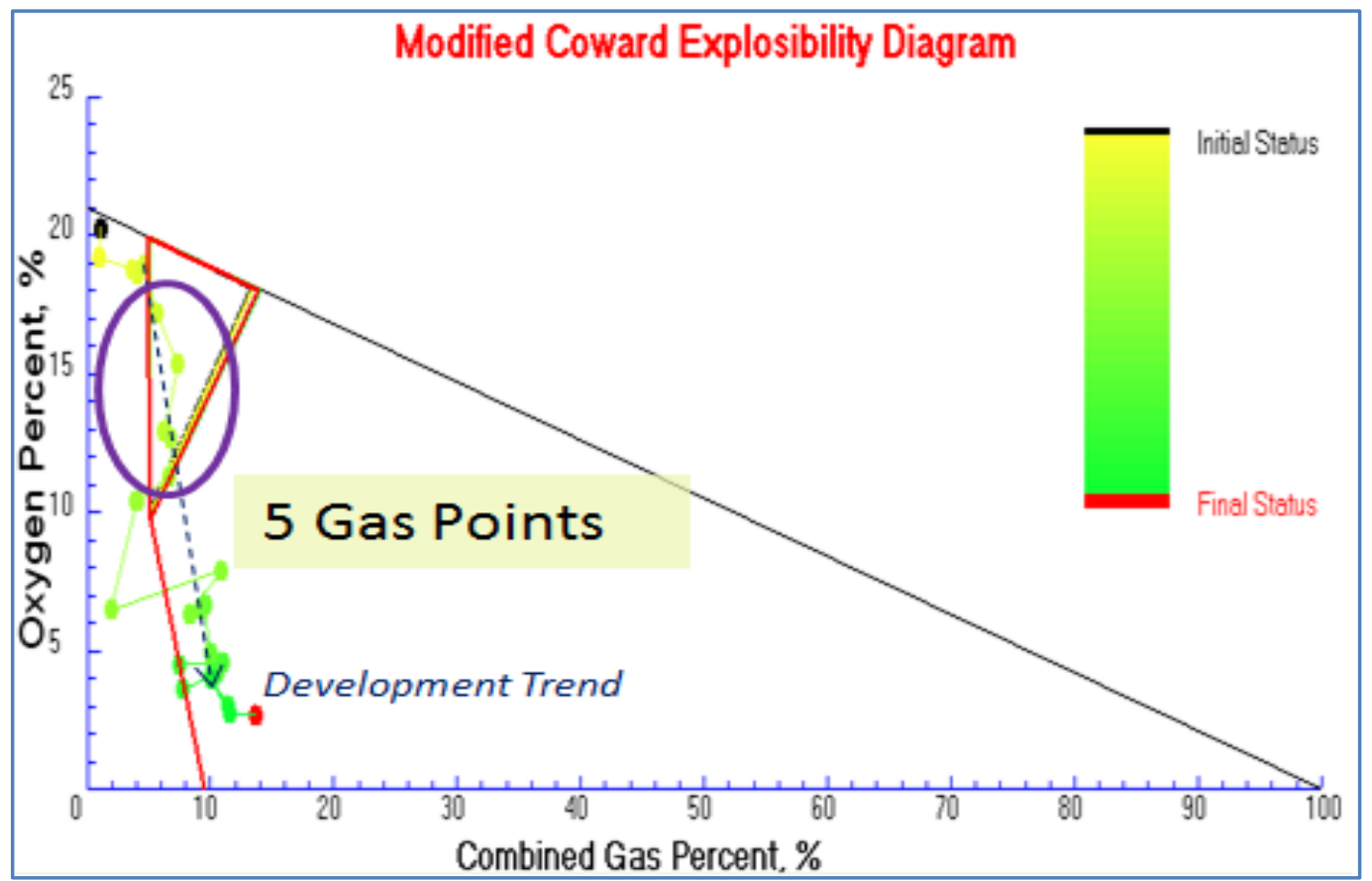

a) Results from modified Coward explosibility diagram

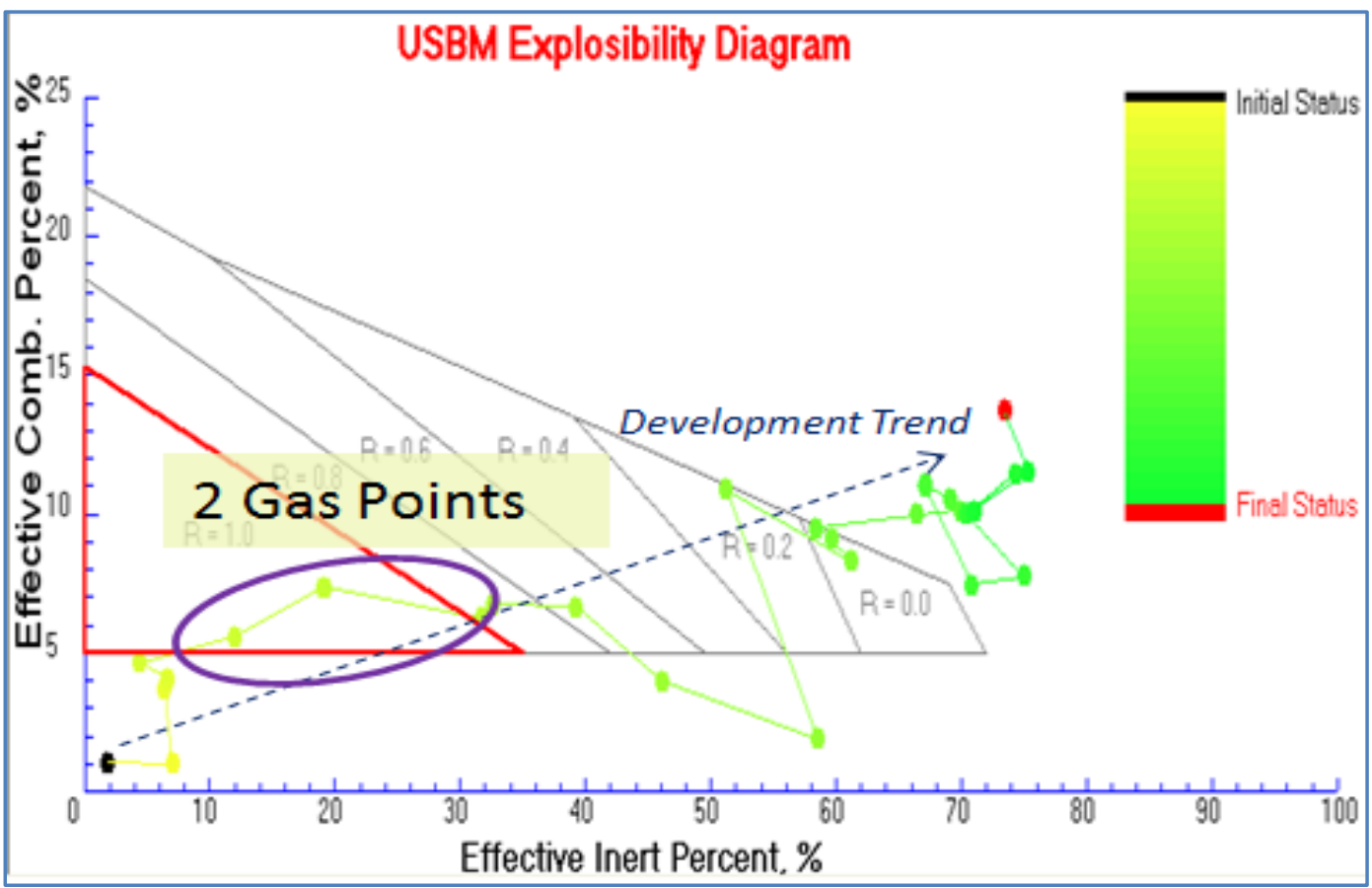

b) Results from USBM explosibility diagram 


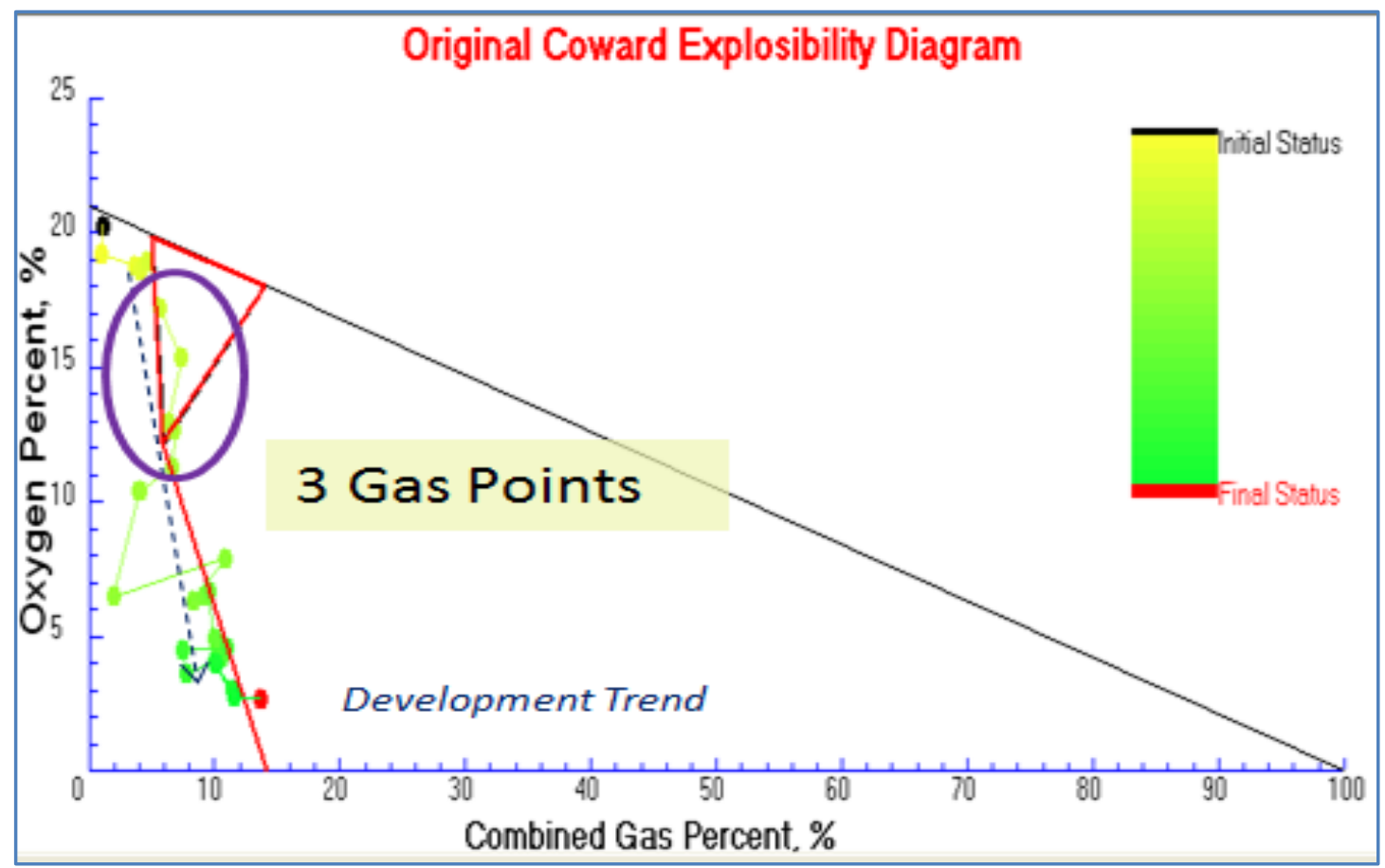

c) Results from original Coward explosibility diagram

Figure 4.17 Determining mine atmospheric explosibility using three methods for

\section{testing cases}

Due to the importance of the safety issue, determination of the mine gas explosibility must be very carefully calculated. Only based on the calculation results and other considerations, any other management can be performed. Therefore, it is highly recommended that two or more methods be used when analyzing the mine gas explosibility in order to avoid any potential problems from relying only one method. A comprehensive study should be done prior to any operations, particularly for planning and implementing a mine rescue strategy when facing any chemical reactions related to mine accident events (mine fire, gas explosion, dust explosion, etc.). 


\subsection{Summary}

- Determination of the explosibility is critical for mine rescues or controlling the severity of a mine accident, especially for a gas explosion event. In this chapter, a modified Coward explosibility diagram is proposed.

- The Coward explosibility diagram is expanded. Beside carbon monoxide (CO), methane $\left(\mathrm{CH}_{4}\right)$ and hydrogen $\left(\mathrm{H}_{2}\right)$ in the original version, acetylene $\left(\mathrm{C}_{2} \mathrm{H}_{2}\right)$, ethylene $\left(\mathrm{C}_{2} \mathrm{H}_{4}\right)$ and ethane $\left(\mathrm{C}_{2} \mathrm{H}_{6}\right)$ are now included into the new Coward explosibility diagram. Although the total amount of these gases is not large, they are significant to affect the explosibility of the gas mixture.

- Considering the effects of inert gas, temperature and environmental pressure on the flammable limits (general LFL and UFL), a method to correct the flammable limits is developed. Such correction can accurately obtain the "ture" flammable limits for each combustible gas and is also a very important fundamental work to determine the mine gas explosibility.

- A series of equation are used to redefine the nose limit for each combustible gas. It can provide precise parameter values with avoiding the experimental approach. Therefore, that is also good for popularizing the Coward method.

- Based on characteristics of the Coward triangle, an equation to calculate the excess amount of inert gas for each combustible gas is developed.

- Explosibility Safety Factor (SF) is introduced. Such factor can provide a better understanding of sealed mine atmosphere for mining engineers and 
also supportive guidelines when planning or implementing a mine rescue strategy for mine gas accident.

- Though the cross-verification study, the testing results from the modified Coward method agree with that from USBM explosibility method, and it should be noted that the modified one can provide more careful judgments for critical scenarios. 


\section{CHAPTER 5 CIMMAS PROGRAM DEVELOPMENT WITH VISUAL BASIC}

\subsection{Introduction}

As an integrated solution for analysis of the atmospheric status in sealed underground mine areas, a feasible and user friendly computer program which can cover all the previous research efforts should be developed. It is required that such computer program be capable of both predicting the gas species change trends and tracking of the explosibility of a mine atmosphere at any time points. Users can easily input data while the computer can automatically perform data preparations, information processing and transformation to final outputs with schematic and tabular views which are very helpful and useful for users to conduct the secondary analysis or prepare proper management strategies.

In this chapter, a detailed design and structure of a computer program named "CIMMAS" (Comprehensive and Integrated Model for Mine Atmospheric Status) is discussed. The software techniques or methods for developing CIMMAS are also examined. Finally, the component modules of the CIMMAS are explored and classified.

\subsection{Object-Oriented Programming (OOP) and Microsoft Visual}

\section{Basic Language}




\subsubsection{Object-Oriented Programming (OOP)}

Historically, a program has been viewed as a logical procedure that takes input data, processes it, and produces output data. Therefore, the programming challenge was seen as how to write the logic, not how to define the data (SearchSOA, 2011).

However, Object-Oriented Programming (OOP) is a programming paradigm using "objects" - data structures consisting of data fields and methods together with their interactions - to design applications and computer programs (Wikipedia, 2011). It was not commonly used in mainstream software application development until the early 1990s. Now, many modern programming languages

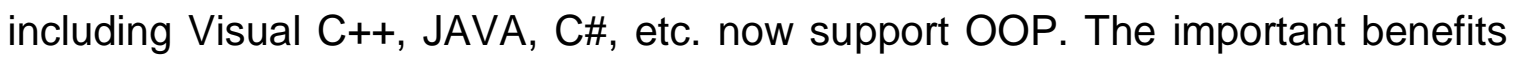
of applying OOP into software languages are listed as follows (SearchSOA, 2011):

- The concept of a data class makes it possible to define subclasses of data objects that share some or all of the main class characteristics. Called inheritance, this property of OOP forces a more thorough data analysis, reduces development time, and ensures more accurate coding.

- Since a class defines only the data it needs to be concerned with, when an instance of that class (an object) is run, the code will not be able to accidentally access other program data. This characteristic of data hiding provides greater system security and avoids unintended data corruption. 
- The definition of a class is reusable not only by the program for which it is initially created but also by other object-oriented programs.

- The concept of data classes allows a programmer to create any new data types which are not already defined in the language itself.

\subsubsection{Microsoft Visual Basic language}

Visual Basic (VB) language was derived from BASIC and enables the rapid application development (RAD) of graphical user interface (GUI) applications, access to databases using Data Access Objects, Remote Data Objects, or ActiveX Data Objects, and creation of ActiveX controls and objects. Moreover, Visual Basic is the third-generation event-driven programming language and integrated development environment (IDE) from Microsoft for its Component Object Model (COM) (Wikipedia, 2011).

Like the BASIC programming language, Visual Basic was designed to be easily learned and used by beginner programmers. The language not only allows programmers to create simple GUI applications, but can also develop complex applications. Programming in VB is a combination of visually arranging components or controls on a form, specifying attributes and actions of those components, and writing additional lines of code for more functionality. A programmer can put together an application using the components provided with Visual Basic 
itself. Programs written in Visual Basic can also use the Windows API, but doing so requires external function declarations.

\subsection{Design of CIMMAS}

\subsubsection{Graphical User Interface (GUI)}

Graphical user interface (GUI) is a type of user interface that allows users to interact with electronic devices with images rather than text commands. GUIs can be used in computers, hand-held devices such as MP3 players, portable media players or gaming devices, household appliances and office equipment. A GUI represents the information and actions available to a user through graphical icons and visual indicators such as secondary notation, as opposed to text-based interfaces, typed command labels or text navigation. The actions are usually performed through direct manipulation of the graphical elements (Wikipedia, 2011). The main view of "CIMMAS" program is shown in Figure 5.1.

\subsubsection{Structure of CIMMAS}

Based on the requirements for analyzing atmospheric status in a sealed mine area and characteristics of the models, an integrated software program is constructed in this dissertation using the structures as illustrated in Figure 5.2. 


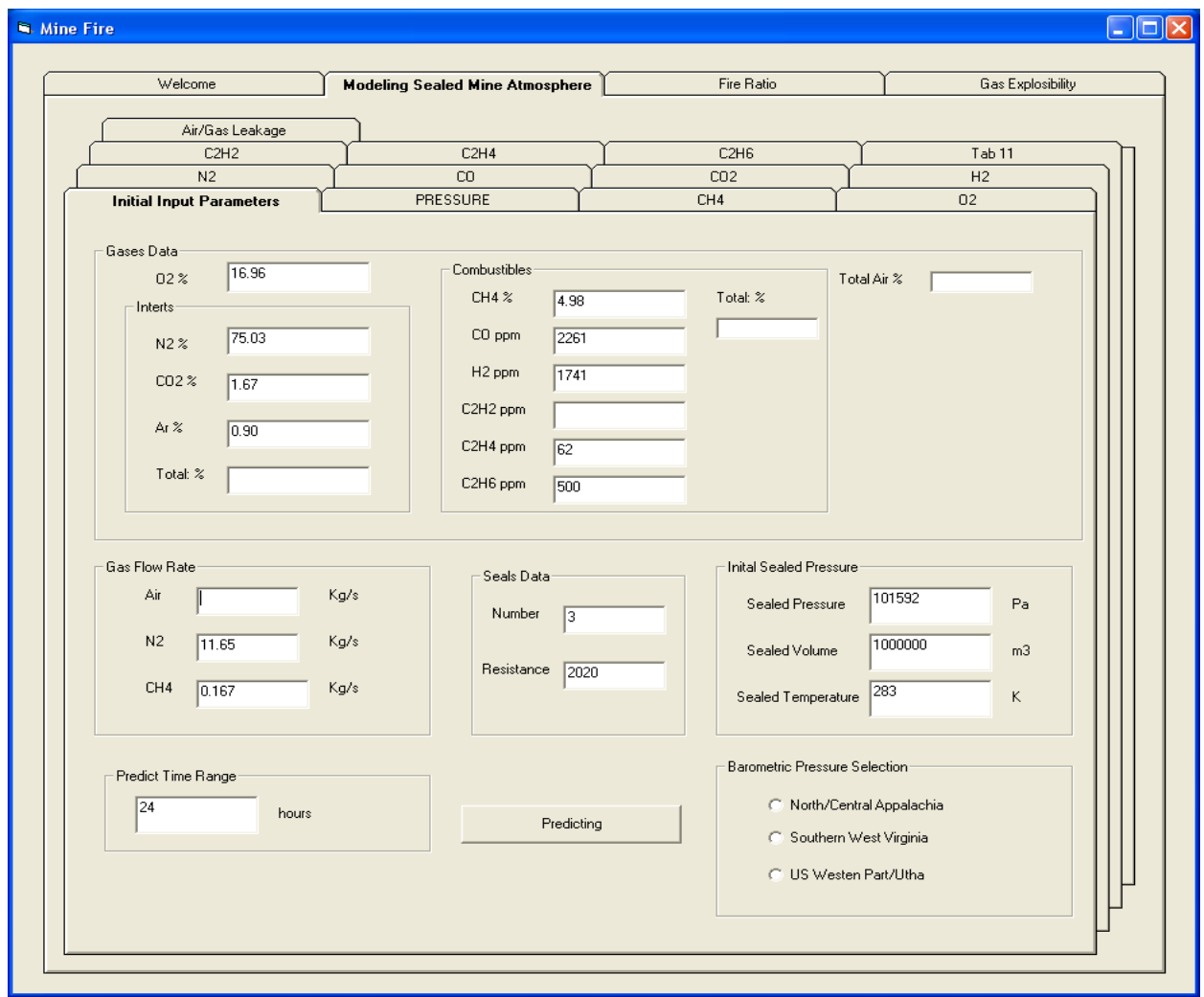

Figure 5.1 Main view of CIMMAS

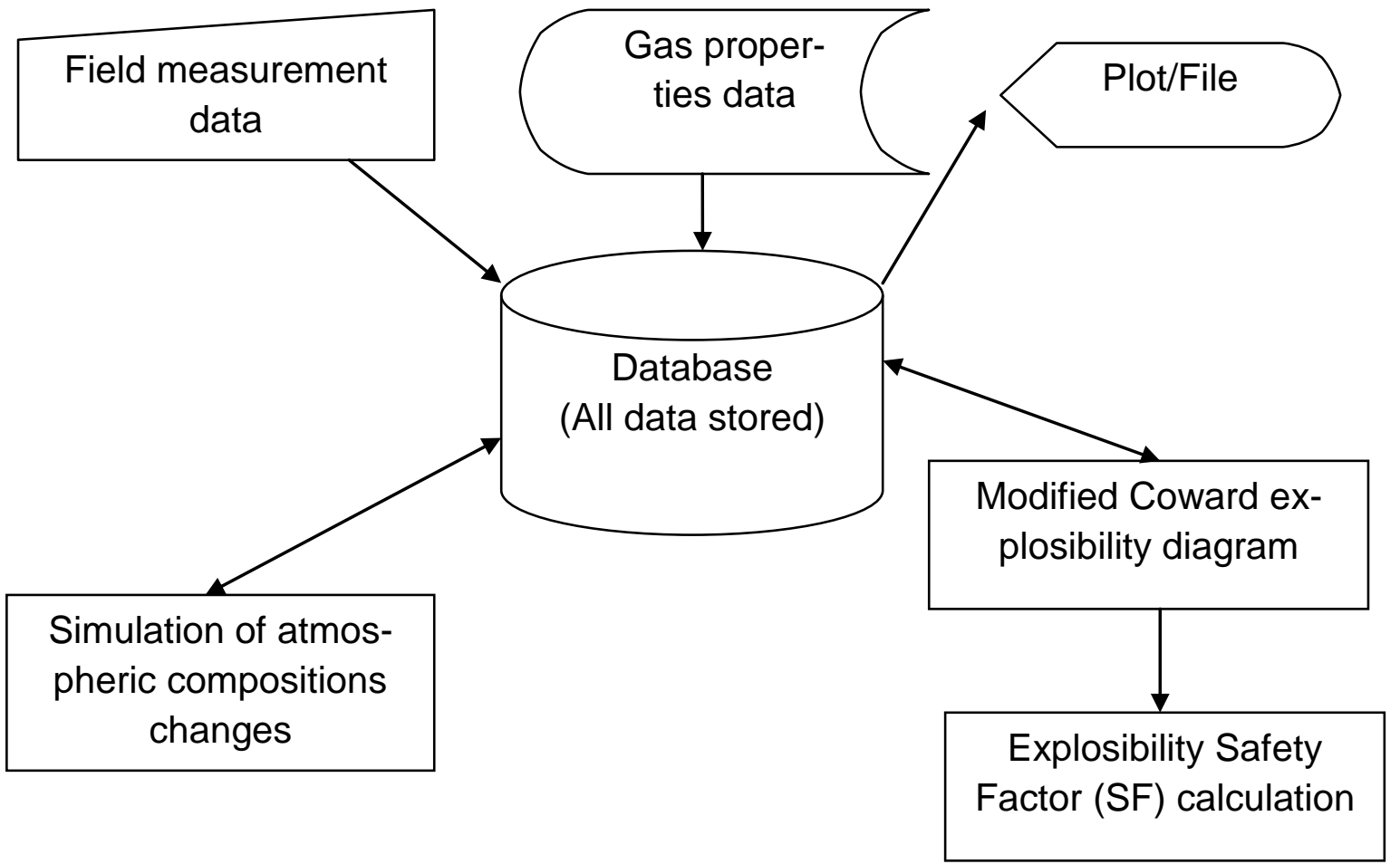

Figure 5.2 Schematic structure of the CIMMAS program system 
Basically, the software program has two modules, the first one is the module of simulating atmospheric gas species changes in a sealed mine area; the second one is the module of modified Coward explosibility diagram. Although the functional modules are independent with each other, they share the same data source. The results calculated from the module of simulating atmospheric gas species changes are stored in a database, and also can be used as the input data for the module of modified Coward explosibility diagram to determine the explosibility of a gas-mixture sample. Meanwhile, the database also handles with the results from the module of modified Coward explosibility diagram independently. All the data can be outputted by forms of tabular and graph. Such expressions can give users an intuitive impression.

In summary, the procedure of this computer program can be performed in various sequences as long as the required input data are available. A typical process of mine atmospheric status analysis would generally go through the following procedures (Figure 5.3).

\subsubsection{Required input data}

Generally, three categories of input data are required by CIMMAS. They are:

(1) Field measurement data: consist of data representing basic characteristics of the research object, including initial volumetric percentage for each gas species in mine sealed area (Mainly: $\mathrm{CH}_{4}, \mathrm{CO}, \mathrm{N}_{2}, \mathrm{C}_{2} \mathrm{H}_{2}, \mathrm{C}_{2} \mathrm{H}_{4}, \mathrm{C}_{2} \mathrm{H}_{6}$, $\mathrm{CO}_{2}, \mathrm{H}_{2}$ and $\left.\mathrm{O}_{2}\right)$, injection mass flowrate of inert gases $\left(\mathrm{CO}_{2}\right.$ and $\left.\mathrm{N}_{2}\right)$, ini- 
tial pressure of the sealed area, average environmental temperature behind the mine seals, total volume of the sealed area, air resistance of the mine seal, the number of seals used to isolate the mined-out area and coal mine gas (mainly $\mathrm{CH}_{4}$ ) emission rate from the surrounding rock strata in an underground mine.

(2) Barometric pressure data: the recommended typical barometric pressure curves, which are diurnal, monthly and annual barometric pressure fluctuation curves for three different locations (Northern Appalachian, Central Appalachian and Illinois coalfields) are already integrated into the software program based on measurements of local barometric pressures. However, if user has actual or more detailed barometric pressure data, the program can also allow them to input them during calculations. Hence, more accurate and reasonable results can be expected.

(3) Fundamental gas data: generally, the following two categories of gas data need to be inputted. They are: flammable limits and properties for each gas species. The gas flammable limits consist of two individual limits; one is the lower flammable limit (LFL) and the other is the upper flammable limit (UFL). The gas properties refer to the gas density and the gas constant. 


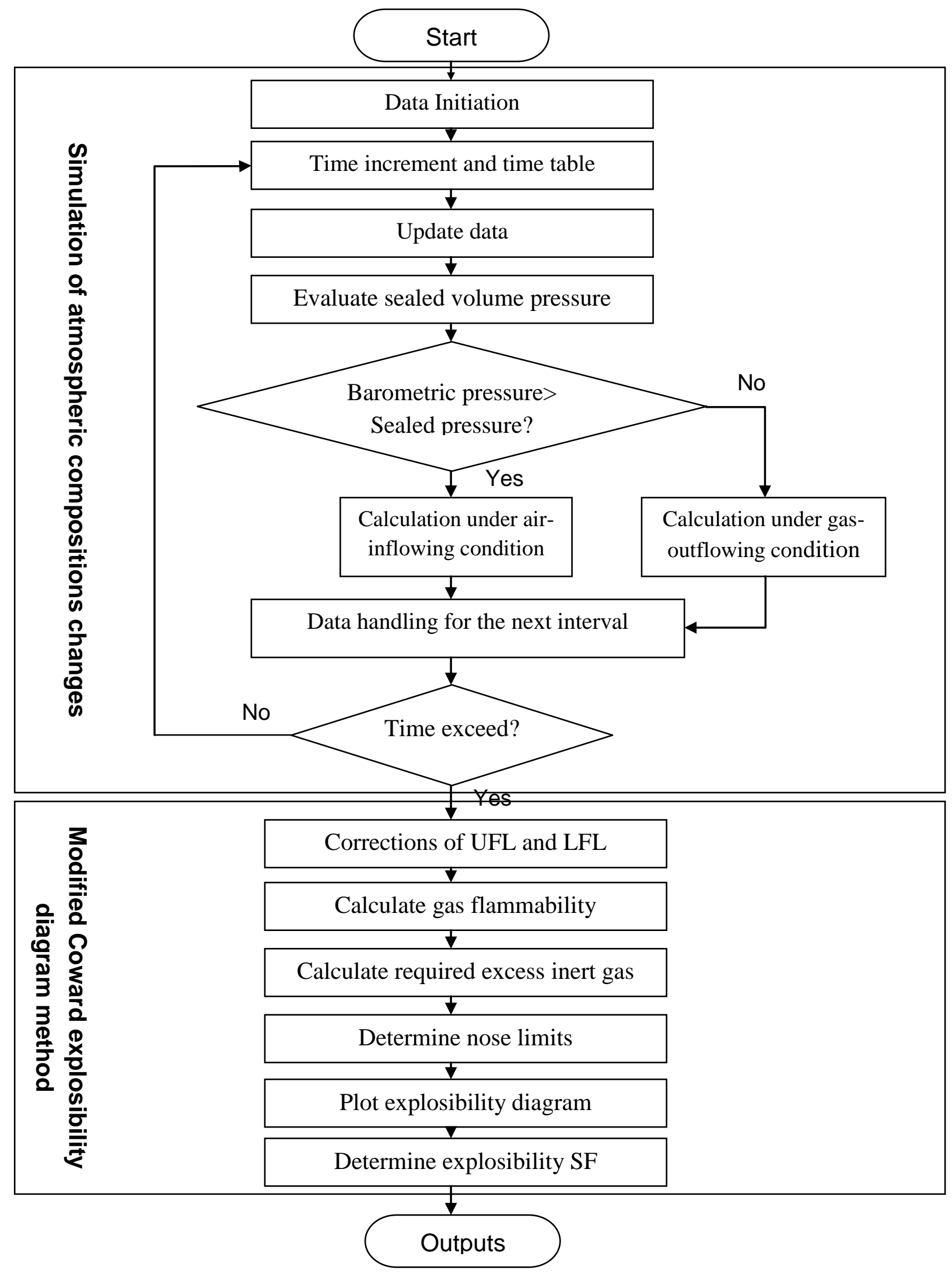

Figure 5.3 Typical data flow chart of sealed mine atmospheric status analysis 


\subsubsection{CIMMAS Modules}

As stated earlier, a number of functional modules are assigned to accomplish different drawing tasks in the developed system. These modules can be classified into the following major groups by their designated goals:

\subsubsection{Atmospheric gas species changes predication module}

Understanding the gas species changes over time in a sealed volume is very significant for effectively managing the sealed mine atmosphere. The most important factors for controlling the atmospheric compositions include: barometric pressure changes, mine seals, gas categories and their changes which has been detail analyzed in Chapter 3. These are incorporated into the developed mathematical model. Based on the control volume approach by following the law of mass conservation and the ideal gas law, the developed new mathematical model is programmed in this module. The program can handle up to nine different gas species, which are $\mathrm{CH}_{4}, \mathrm{CO}, \mathrm{N}_{2}, \mathrm{C}_{2} \mathrm{H}_{2}, \mathrm{C}_{2} \mathrm{H}_{4}, \mathrm{C}_{2} \mathrm{H}_{6}, \mathrm{CO}_{2}, \mathrm{H}_{2}$ and $\mathrm{O}_{2}$, and simulate their time-dependent changes in a sealed volume. Graphs or tablet files can be outputted by the software package for users to conduct secondary analysis in the future. 


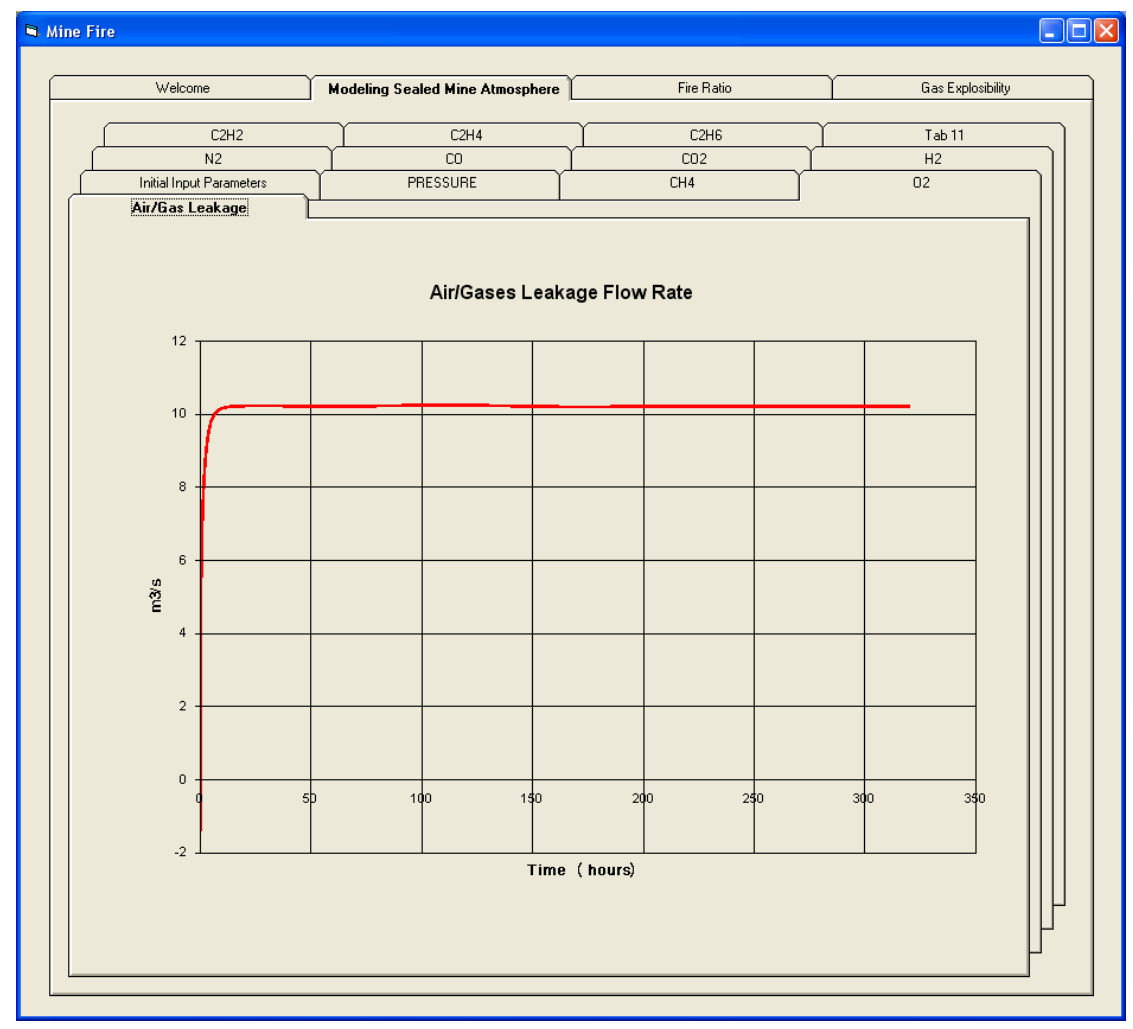

Figure 5.4 Screenshot of atmospheric gas species change predication module

\subsubsection{Explosibility analysis module}

The explosibility of the air-gas mixture depends on the composition of combustible gases, oxygen and inert gases. The modified Coward's method with considering more combustible gases found in coal mines to generate the explosibility triangle is incorporated into the program. All calculation procedures, including correcting the LFL and the UFL, redefining nose limits, determining the excess inert gas amount, etc. are computerized in the program module and the explosibility Safety Factors (SF) when using the Coward method are also outputted by the program. In addition, the software can also be able to track the explosibility change trend of a sealed mine atmosphere. All these are good for mining 
engineers to know the potential explosion risk of a mine sealed atmosphere and such applications of this module can contribute in effectively managing the sealed mine atmosphere.

Due to the importance of the safety issue, determination of the mine gas explosibility must be very carefully calculated. All mitigation measures or other managements can be established or performed only based on fully considering these calculation results. Therefore, it is highly recommended that two or more methods be used when analyzing the mine gas explosibility in order to avoid any potential error deviations (not sufficient accuracy, etc.) if only one single method is relied on. Due to this reason, the USBM explosibility diagram is also included in this program package for user to conduct a double check.

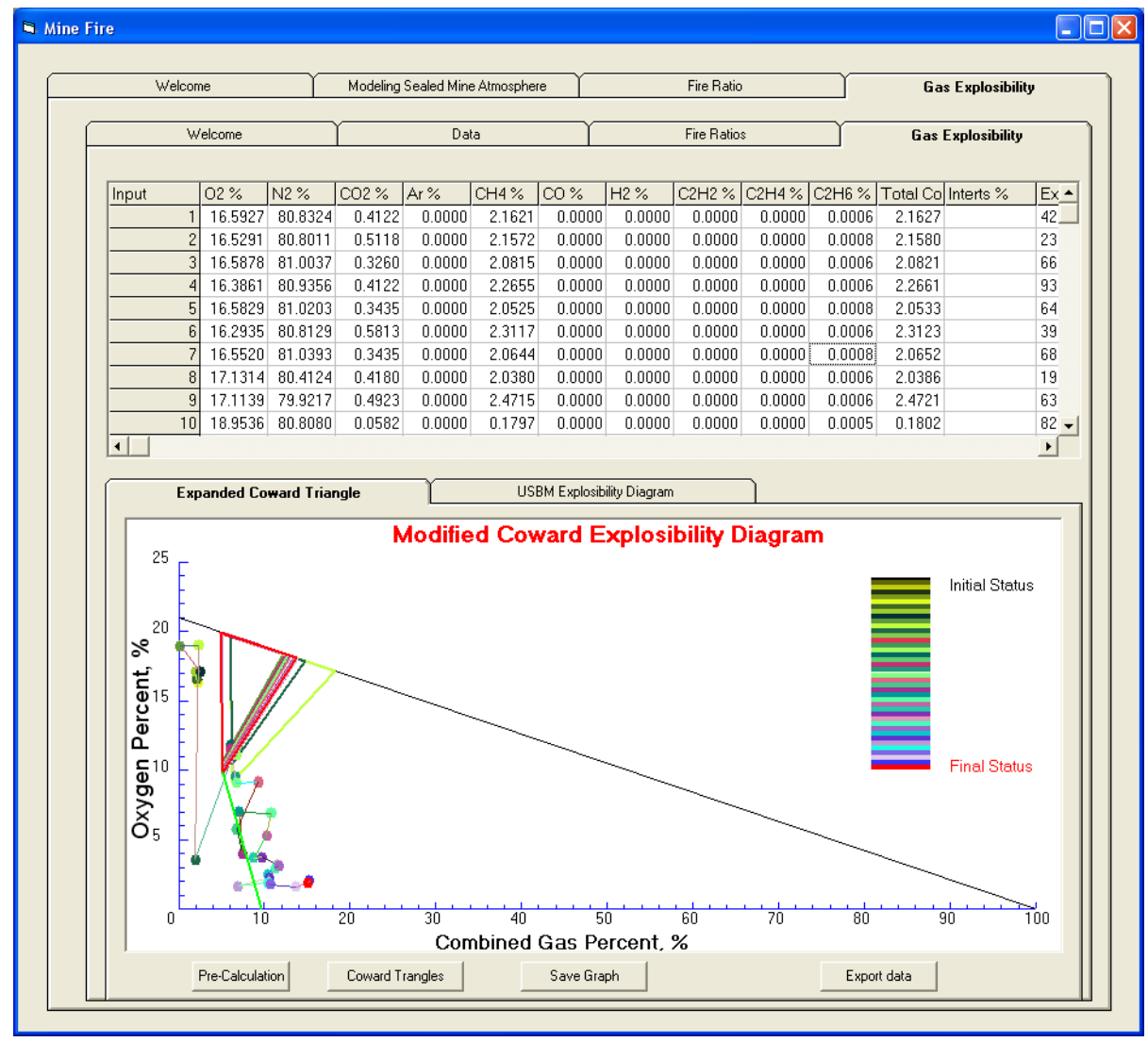

Figure 5.5 Screenshot of explosibility analysis module 


\subsection{Summary}

- Visual Basic 6.0, an Object Orientation Programming Language, is used to code the program of CIMMAS.

- A brief Graphical Users Interface (GUI) is also created in the computer software and it is helpful and useful for user to perform any calculations or analysis.

- The structure and the standard calculation procedure of the computer program "CIMMAS" are both stated. Two functional modules, which are the atmospheric gas species change predication module and the explosibility analysis module, are included in this computer program for analyzing the atmospheric status in sealed underground mine areas. 


\section{CHAPTER 6 ILLUSTRATIVE EXAMPLES OF CIMMAS}

\subsection{Introduction}

In order to implement various mathematical models developed in this research, a new software program, CIMMAS, has been developed for systematical analyses of the sealed mine atmospheric status. As previously stated, the software program is coded by Visual Basic Language, and can be run under the Windows Operating System. It is a useful tool to improve the mine safety management and also helps mining engineers better understand the behavior of the mine sealed volume. In this chapter, the following examples serve as an introduction of these new features of CIMMAS.

\subsection{Case Study 1}

\subsubsection{Description of case}

A mine's ventilation system is an important component of an underground mining system. It provides a sufficient quantity of air to the underground mine workings, to dilute methane and other contaminants, to maintain a suitable working environment and prevent accidents from happening. For the mined-out areas, in order to improve ventilation efficiency, underground coal mines normally choose to seal old mined areas so that ventilation to these areas is no longer needed. 
Typically, normal mine atmosphere contains about $21 \%$ oxygen and $79 \%$ nitrogen and less than $1 \%$ methane. But once a mined area is sealed, composition of the mine sealed atmosphere will begin to change, some coals will slowly oxidize and therefore remove oxygen and release carbon dioxide into the atmosphere of the abandoned area. However, with few exceptions, all underground coalbeds liberate methane, and thus the methane concentration within the sealed areas will increase (Zipf, et al., 2007). Generally speaking, methane is explosive in air when the concentration ranges from $5 \%$ to $16 \%$ by volume (Cashdollar, et al., 2000). Therefore, the sealed atmosphere finally will go through a critical period in which methane concentration is in the explosive range. It is reported that the time required for the atmosphere in the sealed area to pass beyond the upper explosive limit and become inert ranges from about 1 day to several weeks (Zipf, et al., 2007). In most cases, the mine's methane emission rate plays an important role in controlling the time range of so-called critical period.

In this case, an old coal mine area is simply sealed without any inertization. The simulation is performed to find how long the critical period would be.

\subsubsection{Data completion}

In order to cross-validate the developed mathematical model, the parameters used in this case are chosen from one of the previous research works (Zipf \& Mohamed, 2010), as following statements:

- Initial gas compositions are: $\mathrm{CH}_{4}: 0 \% ; \mathrm{N}_{2}: 79 \%$ and $\mathrm{O}_{2}: 21 \%$. 
- The barometric pressure fluctuation curve is change with 6,000 pa decreasing over 5 days.

- The temperature sealed is set as $10{ }^{\circ} \mathrm{C}(283 \mathrm{~K})$.

- The total sealed volume is $1,000,000 \mathrm{~m}^{3}$.

- The $\mathrm{CH}_{4}$ volumetric inflow rate in the sealed area is $0.25 \mathrm{~m}^{3} / \mathrm{s}$ and the equivalent mass inflow rate is $0.167 \mathrm{Kg} / \mathrm{s}$.

- In order to fit the leakage coefficient which is $0.00625 \mathrm{~m}^{3} / \mathrm{s} / \mathrm{Pa}^{1 / 2}$ presented in their model, the total of mine seals used to isolate the mined-out area is assumed as 1 , and the equivalent air resistance is $25,600 \mathrm{~N} \cdot \mathrm{S}^{2} / \mathrm{m}^{8}$.

\subsubsection{Simulation results}

Figure 6.1 shows the development trends of the gases in the sealed area. Due to continuous $\mathrm{CH}_{4}$ inflow from surrounding strata, all gas concentrations decrease except $\mathrm{CH}_{4}$. The increasing and high $\mathrm{CH}_{4}$ concentration would cause the sealed area to become inert itself. In addition, both the results calculated by the old model (Zipf \& Mohamed, 2010) and the new mathematical model presented in this paper are shown in this figure. The curved lines without markers are the calculation results calculated by Zipf's model, while the ones with markers indicate that they are calculated by the new mathematical model. It can be seen that the change rate of Zipf's model for each gas species is a little bit faster than that of the new model, which means the sealed mine area becomes self-inertized sooner based on their results. For an instance, the old model presents a $\mathrm{CH}_{4}$ 
concentration of $20 \%$ can be reached in about 9.3 days, but 11.2 days are needed for the new one.

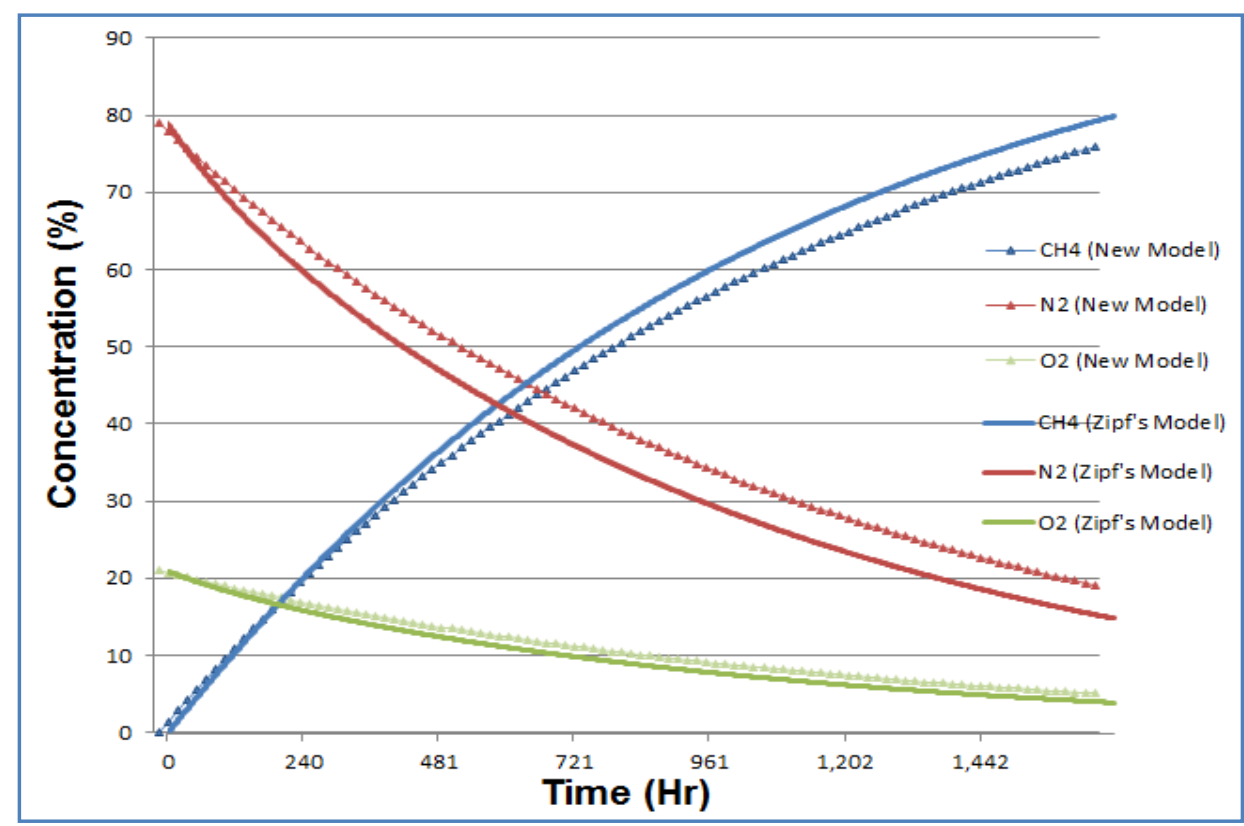

Figure 6.1 $\mathrm{CH}_{4}, \mathrm{~N}_{2}$, and $\mathrm{O}_{2}$ change over time in the sealed volume

A slight difference between the results from these two models can be explained as follows: a) Zipf's model was derived based on the time rate of change for each gas species, but the new model is developed by the control volume approach. The thermodynamic laws are for a system, a specific quantity of matter. More often, we are interested in what happens in a fixed volume. For example, the rates of heat or mass into and out of a system may be interested. For this reason, the control volume form of the system laws is of great importance. It assumes only the incompressibility of the fluid and therefore is a potentially more accurate approach. Hence, because a mine sealed volume is a typical control volume, this approach may provide a better way to characterize the evolution of the sealed mine atmosphere; b) The difference in the determination of the air/gas 
leakage rate also can contribute to the slight difference. In Zipf's model, the air leakage rate is only considered as the function of the differential pressure. However, it is defined as $Q_{L}=n \sqrt{\frac{P_{b}(t)-P_{t}(t)}{R}}$ in the new model, which is not only as a function of the differential pressure, but also has an important relationship with the number of mine seal used when performing sealing practices and the air resistance for a single mine seal. In other words, the number of seals and the quality can induce the air/gas leakage rate changes, and then make a great impact on the sealed mine atmosphere. Different combinations of these two parameters can results in different prediction results. Figure 6.4 shows that when different the number of mine seals is used to isolate the same volume in this case ( " $\mathbf{~ " ~}$ stands of 3 seals used; " $\checkmark$ " represents 5 seals used and " $X$ " for 7 seals). It can clearly see that developing trends of concentrations of each gas species in the volume are changed a lot by the effects of mine seal. It also shows that the number of mine seal is a very important parameter. In this case, more seals used may create more leakage and finally change the gas species' development trends. Therefore, in a practice application, it must be precisely estimated. 


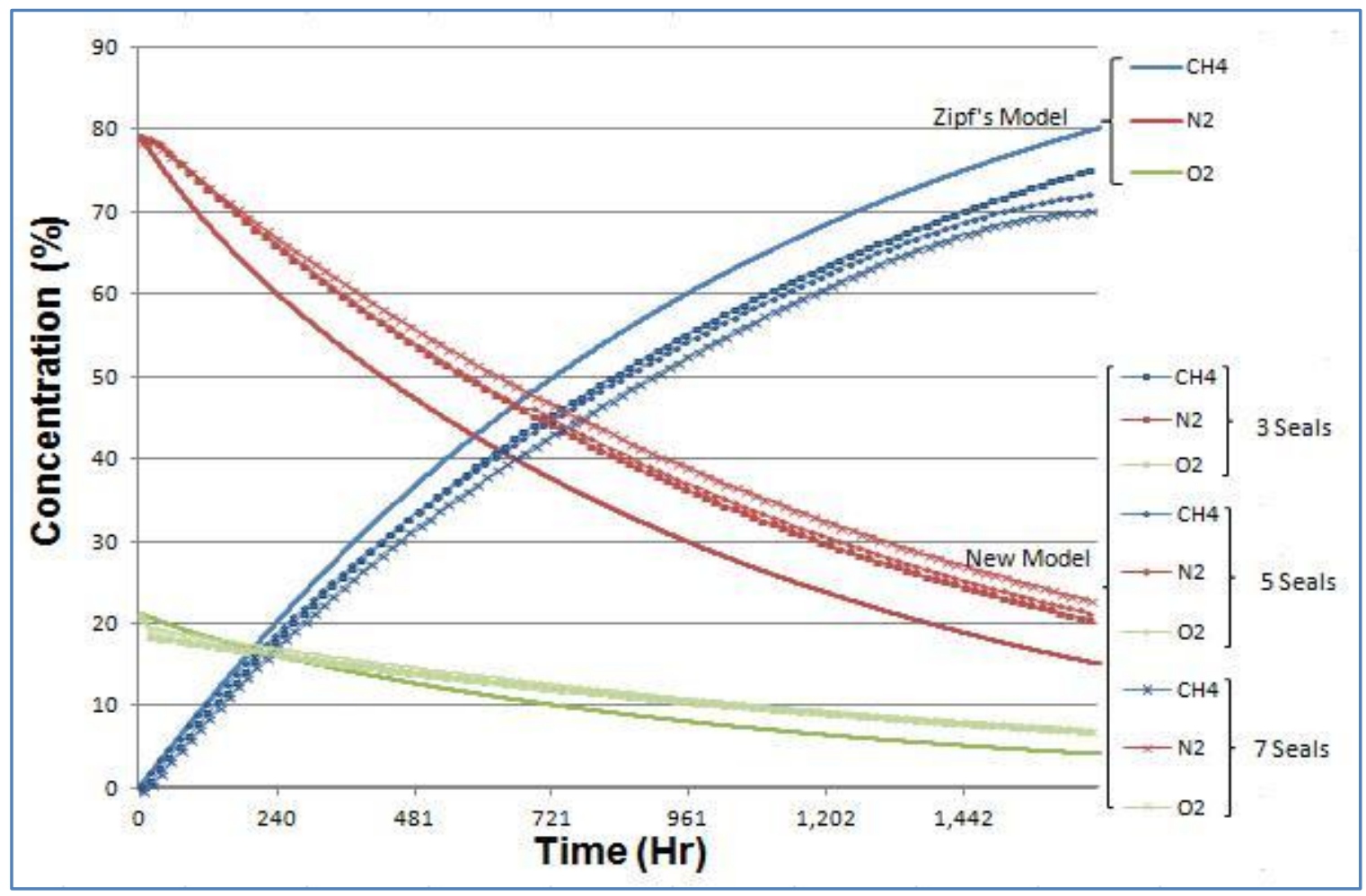

Figure 6.2 Effects of different number of mine seals used

In order to check its explosibility, the modified Coward diagram and the status points with a time step of 15 hours are determined and plotted in Figure 6.3 for the first fifteen days based on the mew model's calculation results shown in Figure 6.1. The area of explosibility triangle remains constant since only one combustible gas $\left(\mathrm{CH}_{4}\right)$ exists in this case. As methane is continuously emitted into the sealed volume, the gas status point always moves. The red triangle is that at the end of simulation duration. Figure 6.3 also shows that the status point moves from left into the explosive zone on the third day after the area is sealed and moves out of it on the right on the eighth day. In other words, the critical time to manage the atmosphere in the sealed area lasted 5 days. The red dot is the final state point of the simulation duration. 


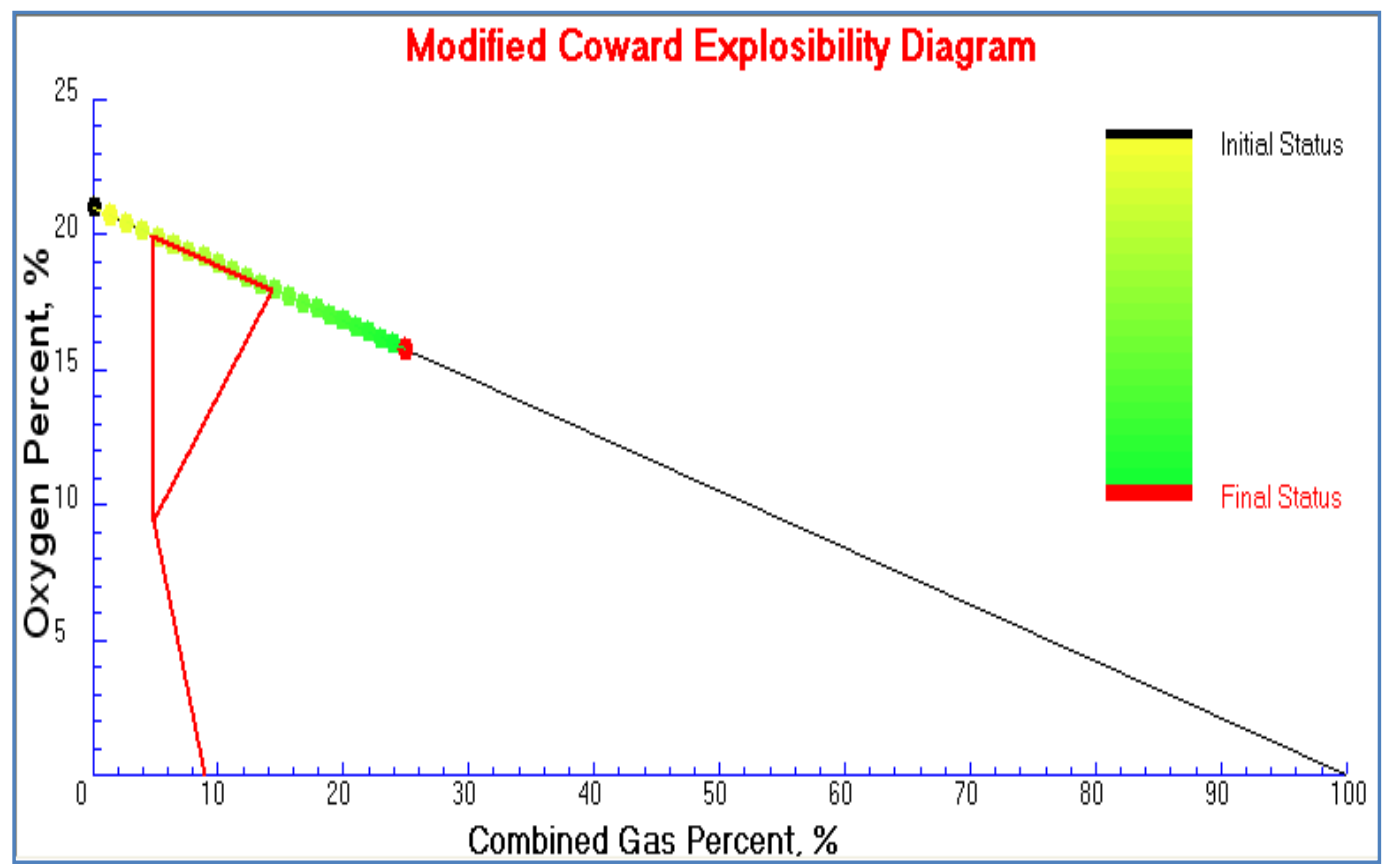

Figure 6.3 Explosibility analysis

\subsection{Case Study 2}

\subsubsection{Description of case}

In this case, inertization effort has been made to shorten the critical time period for managing the atmosphere in a sealed coal mine area.

Due to a mine fire event that happened in a mine gob in a Chinese coal mine, the longwall panel was sealed immediately, and mine operators carried out a mitigation measure which is $N_{2}$ injection to control the mine fire. The longwall panel uses the comprehensive mechanized coal mining method. Figure 6.4 shows the portion of the longwall panel of interest and its original ventilation airflow pattern. The mining direction is from left to the right in the figure. 


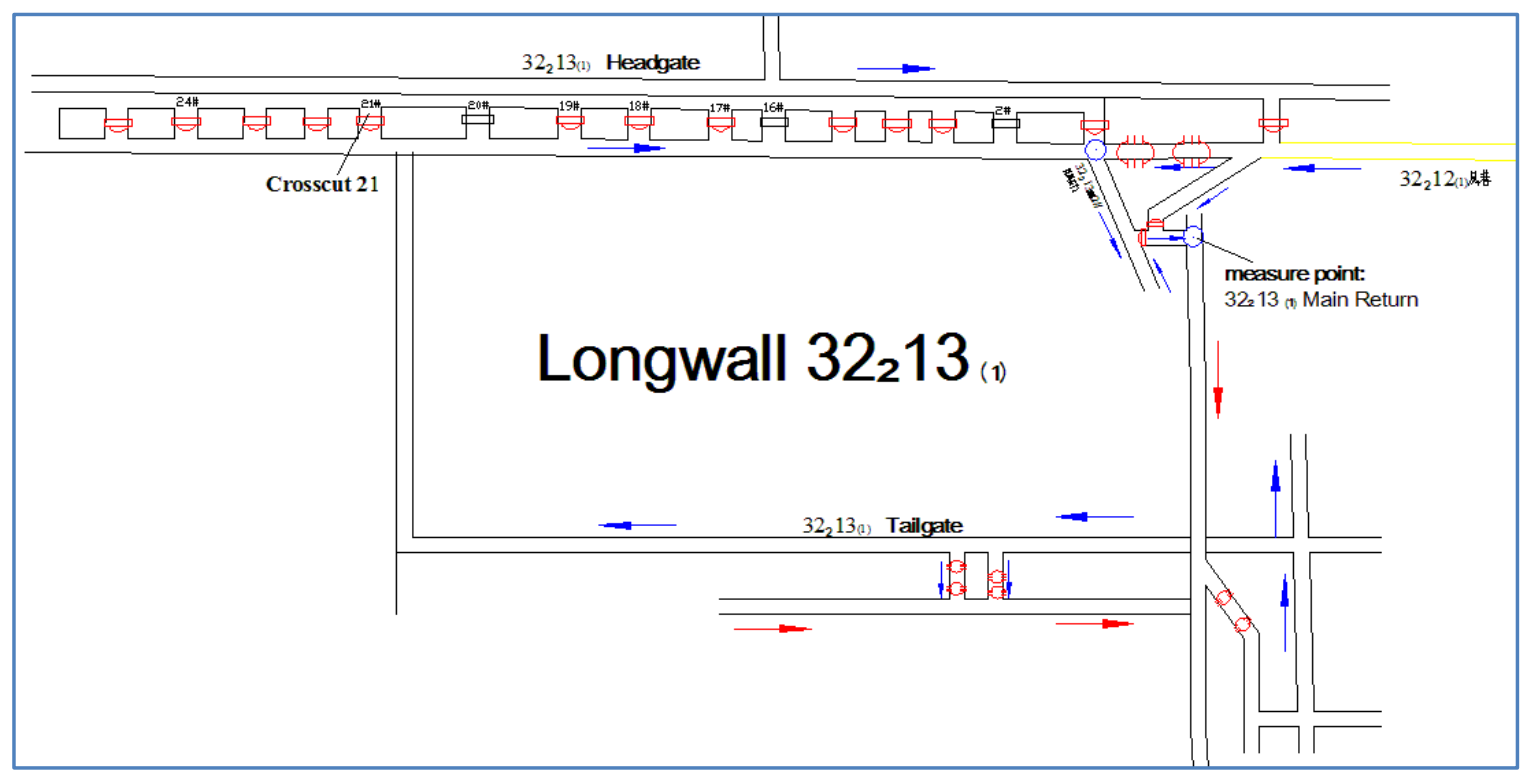

Figure 6.4 longwall panel layout

Table 6.1 Chronicle of Main Events

\begin{tabular}{ccc}
\hline Date & Time & Main Events \\
\hline Day 1 & $6: 20 \mathrm{AM}$ & Mine Fire found \\
Day 1 & $8: 40 \mathrm{PM}$ & Longall panel sealed \\
Day 1 & $23: 00 \mathrm{M}$ & $\mathrm{N}_{2}$ Injected into gob from surface with $8000 \mathrm{~m}^{3} / \mathrm{h}$ \\
Day 11 & $12: 00 \mathrm{AM}$ & Mine ventilation recover \\
\hline
\end{tabular}

\subsubsection{Data completion}

Two observation points are chosen to conduct the simulations in this case. One is the observation point at crosscut 21 and the other is the observation point at $32_{2} 13_{(1)}$ main return. Both the simulation results and the actual field measurements are going to be plotted and be compared later. The parameters used in this case are as following statements:

For the observation point at crosscut 21 : 
- Initial gas compositions are: $\mathrm{CH}_{4}: 0.55 \%$; $\mathrm{CO}: 125 p p m ; \mathrm{N}_{2}: 79.97 \% ; \mathrm{O}_{2}$ : $19.35 \% ; \mathrm{CO}_{2}: 0.9267 \%$ and $\mathrm{C}_{2} \mathrm{H}_{6}: 32 \mathrm{ppm}$.

- The barometric pressure fluctuation curve is fitted by using local data.

- The temperature sealed is set as $50{ }^{\circ} \mathrm{C}(323 \mathrm{~K})$.

- The total sealed volume is $178,500 \mathrm{~m}^{3}$.

- The $\mathrm{CH}_{4}$ volumetric inflow rate in the sealed area is $0.4 \mathrm{~m}^{3} / \mathrm{s}$ and the equivalent mass inflow rate is $0.2672 \mathrm{Kg} / \mathrm{s}$.

- The $\mathrm{N}_{2}$ volumetric inflow rate in the sealed area is $2.22 \mathrm{~m}^{3} / \mathrm{s}$ and the equivalent mass inflow rate is $2.588 \mathrm{Kg} / \mathrm{s}$.

- The total of mine seals used to isolate the mined-out area is 17 , and the equivalent air resistance is $2795 \mathrm{~N} . \mathrm{S}^{2} / \mathrm{m}^{8}$

For the observation point at $32_{2} 13_{(1)}$ main return, only initial gas percentages are changed. Others are the same as before.

- Initial gas compositions are: $\mathrm{CH}_{4}:$ 0.6981\%; CO: 1949 ppm; $\mathrm{N}_{2}$ : $79.4075 \% ; \mathrm{O}_{2}: 19.3615 \% ; \mathrm{CO}_{2}: 1.2041 \%$ and $\mathrm{C}_{2} \mathrm{H}_{6}: 39 p p m$.

\subsubsection{Simulation results}

The simulation results (marked as Sim.) and measured data for the observation points at crosscut 21 and $32_{2} 13_{(1)}$ main return are shown in Figure 6.5 and Figure 6.6, respectively. 


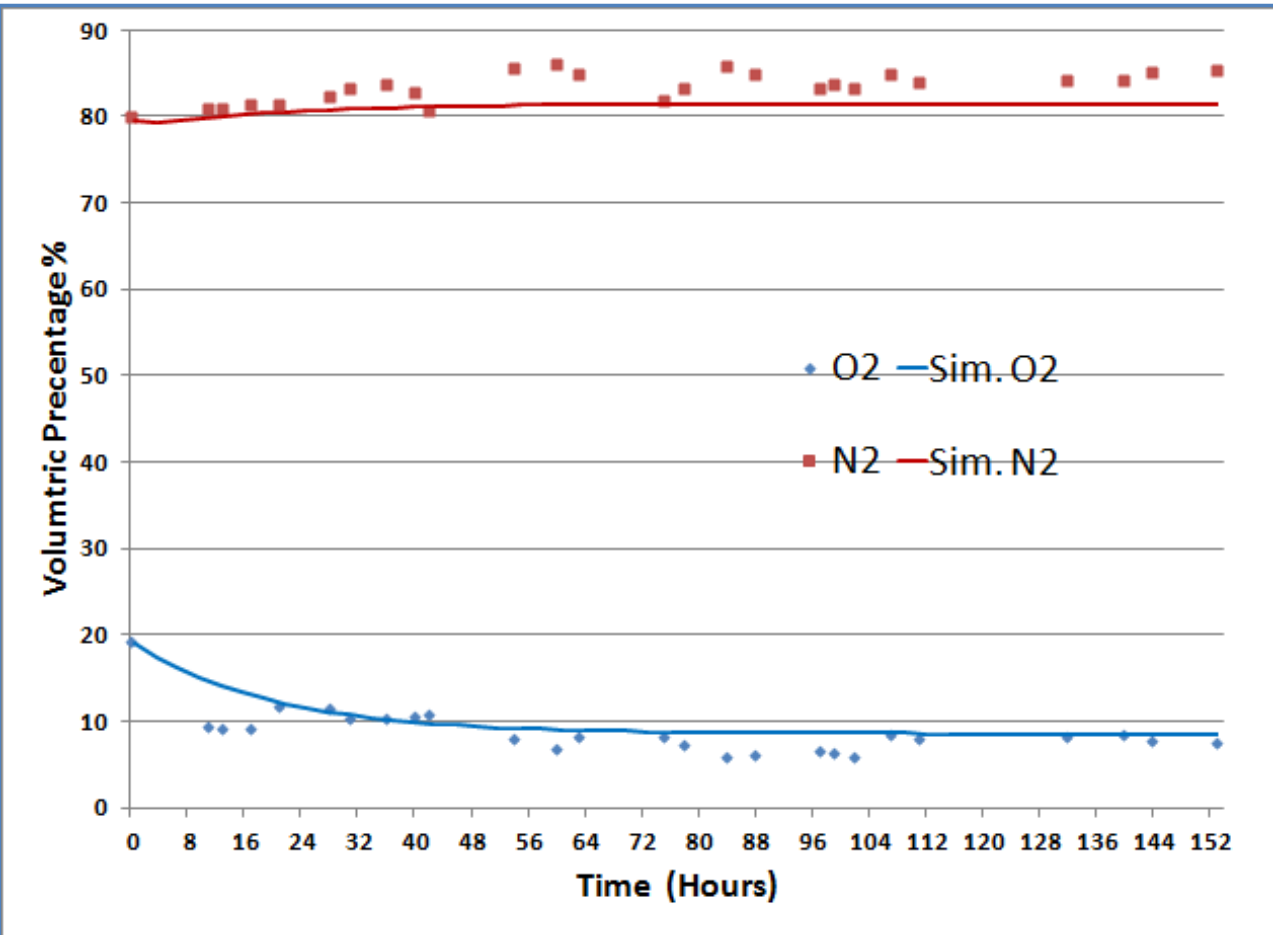

(a) $\mathrm{N}_{2}$ and $\mathrm{O}_{2}$

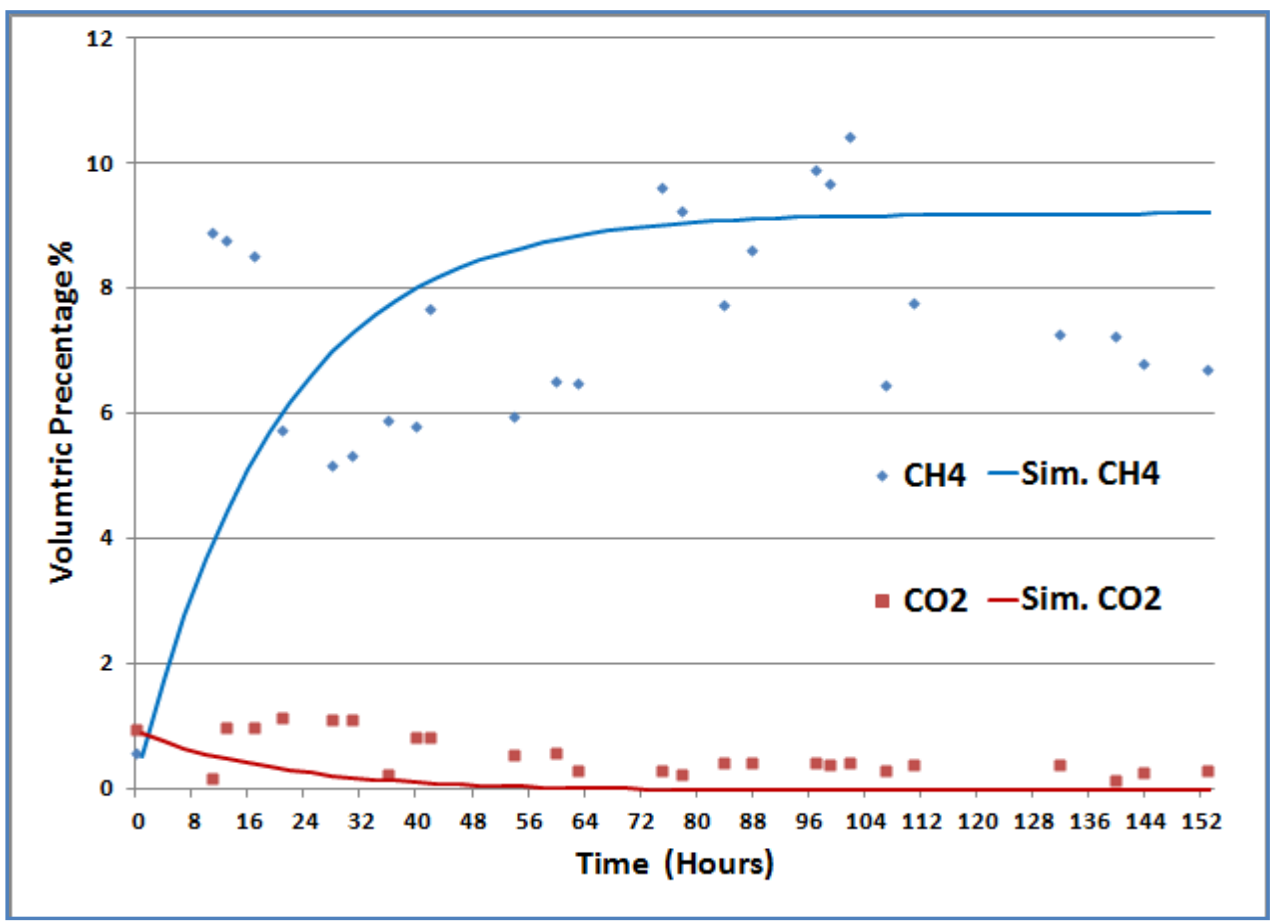

(b) $\mathrm{CH}_{4}$ and $\mathrm{CO}_{2}$ 


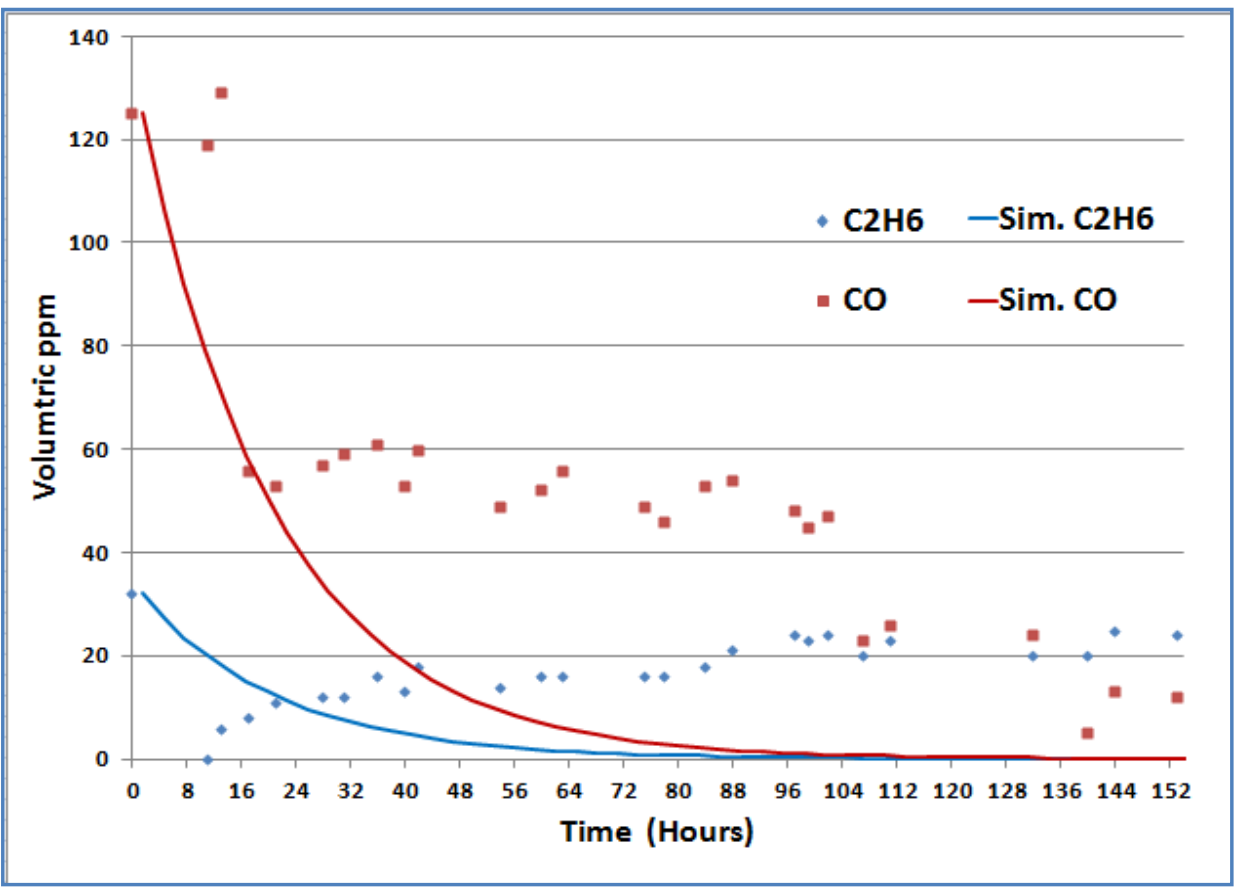

(c) $\mathrm{C}_{2} \mathrm{H}_{6}$ and $\mathrm{CO}$

Figure 6.5 Different gas species changes over time in the sealed volume at point crosscut 21

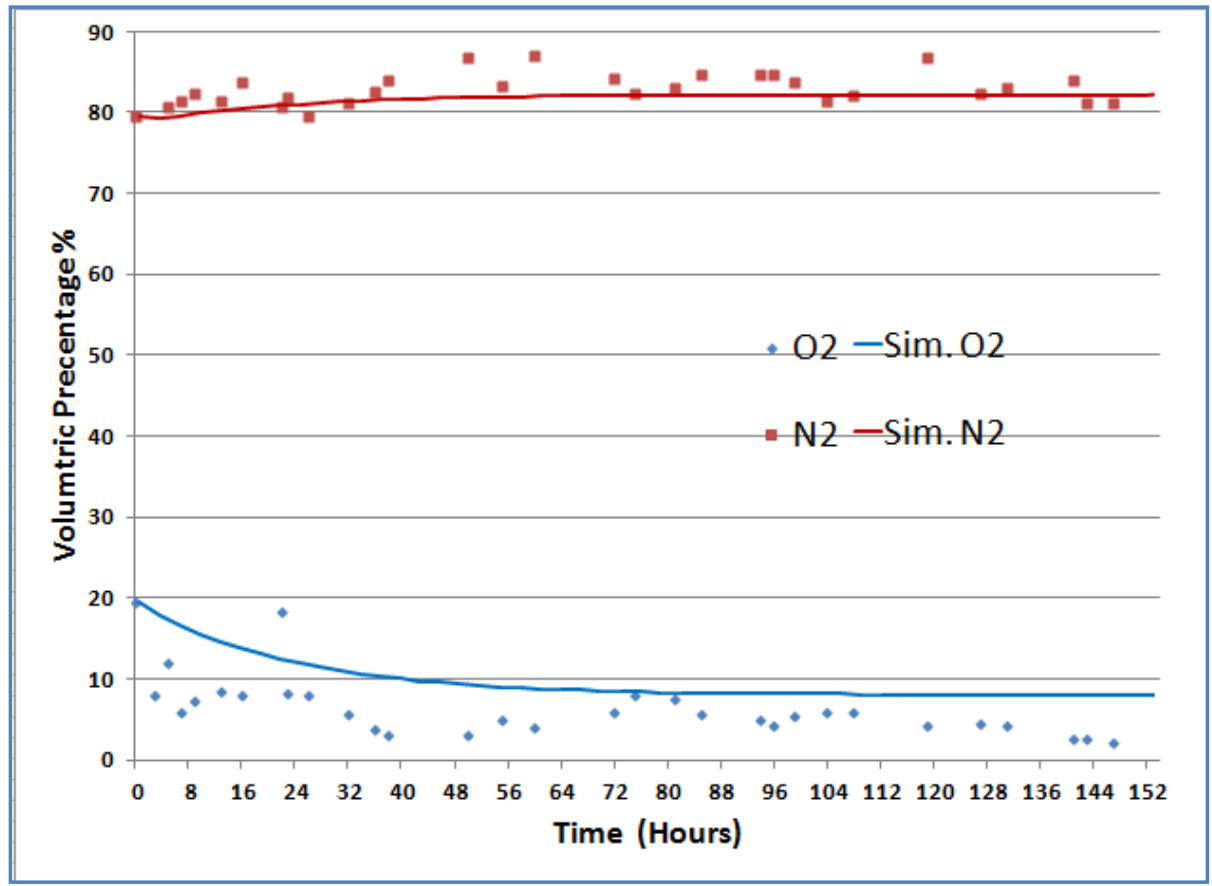

(a) $\mathrm{N}_{2}$ and $\mathrm{O}_{2}$ 


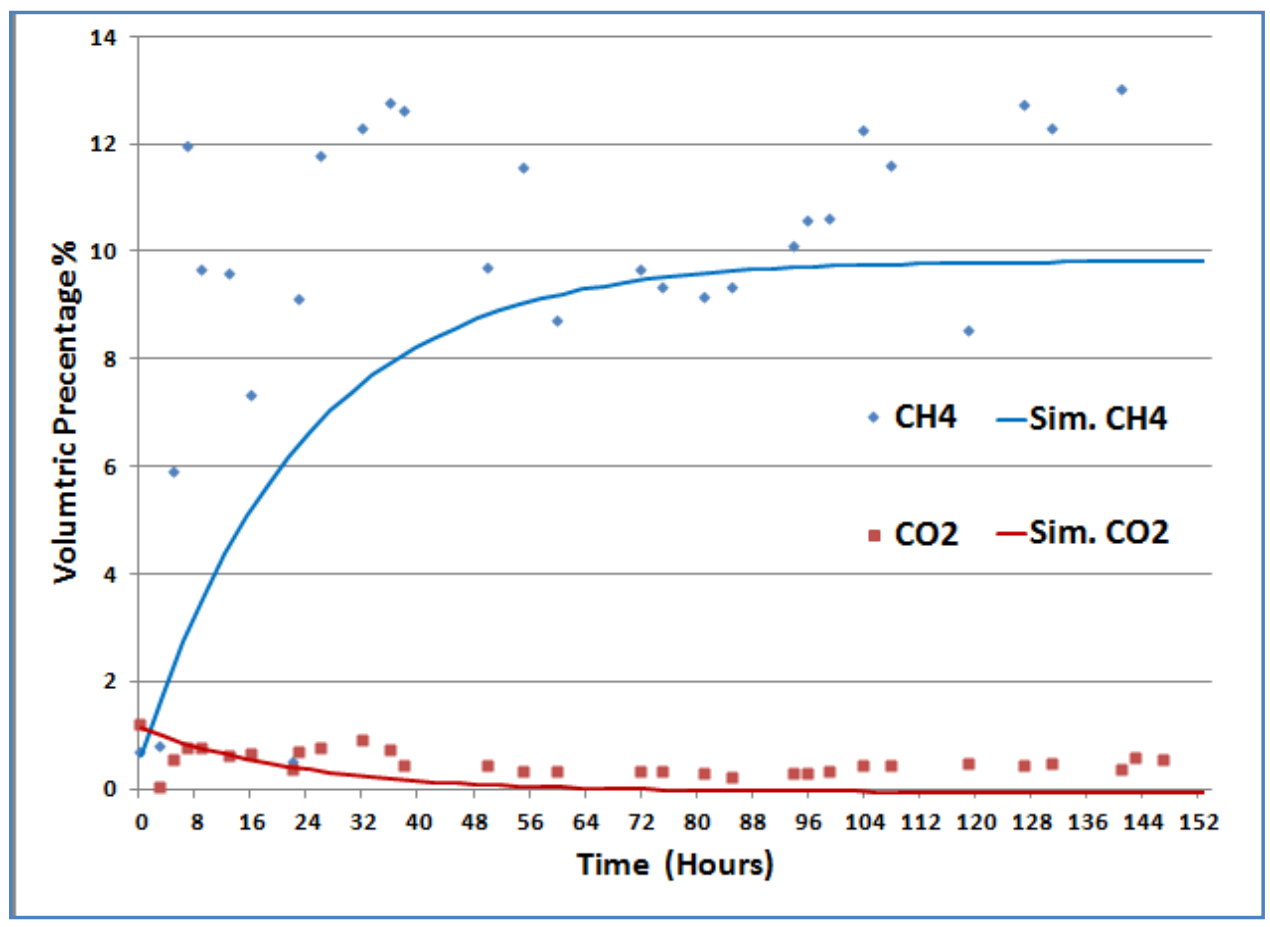

(b) $\mathrm{CH}_{4}$ and $\mathrm{CO}_{2}$

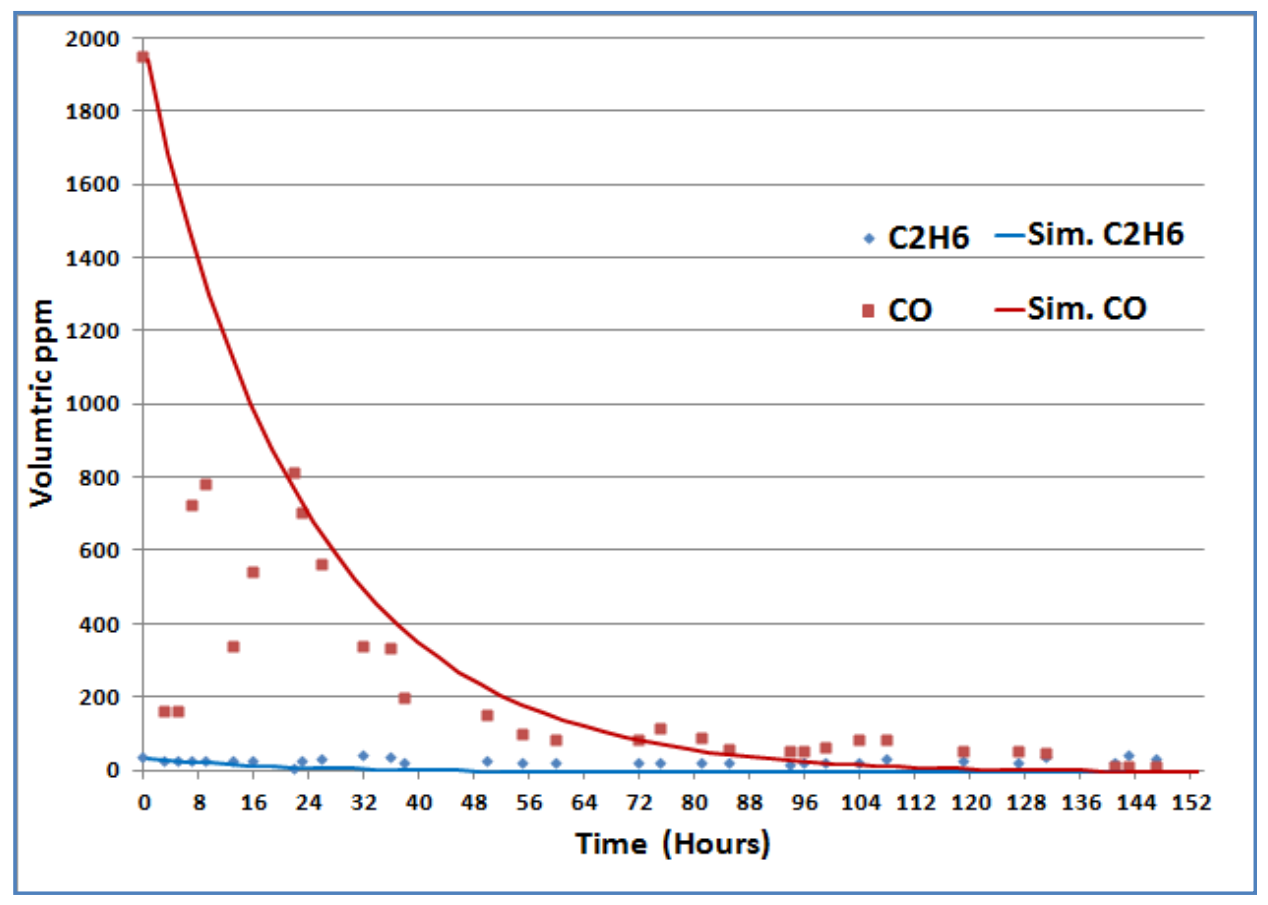

(c) $\mathrm{C}_{2} \mathrm{H}_{6}$ and $\mathrm{CO}$

Figure 6.6 Different gas species changes over time in the sealed volume at point $32_{2} 13_{(1)}$ main return 
Overall, a good agreement between the calculation result from the mathematical model and the actual measurement has been obtained for most gas species at these two observation points. It can be seen that all concentration changes of the gases in the sealed volume is changing over time. Because of the $\mathrm{N}_{2}$ injection, the concentration of $\mathrm{N}_{2}$ in the sealed volume increases (As shown in Figure $6.5 \mathrm{a}$ and $6.6 \mathrm{a})$. The concentration of $\mathrm{CH}_{4}$ also increases with time because of the high methane emission rate in this gassy mine. But the concentrations of the other gases, such as, $\mathrm{CO}, \mathrm{CO}_{2}$, etc. decrease due to the diluting effects of $\mathrm{N}_{2}$ injection.

It also can be seen that a poor matching of $\mathrm{CO}$ and $\mathrm{C}_{2} \mathrm{H}_{6}$ for the crosscut 21. The predicted $\mathrm{CO}$ and $\mathrm{C}_{2} \mathrm{H}_{6}$ concentrations drop more largely than the measured $\mathrm{CO}$ and $\mathrm{C}_{2} \mathrm{H}_{6}$ concentrations. But it has to be noted that a small scale of thermal event (coal oxidation or spontaneous combustion) is still going on in gob area when the monitoring $\mathrm{CO}$ and $\mathrm{C}_{2} \mathrm{H}_{6}$ concentration data were collected. However, the prediction model doesn't take into account any chemical reactions. The $\mathrm{CO}$ and $\mathrm{C}_{2} \mathrm{H}_{6}$ released from the spontaneous combustion can be employed to explain why the monitored concentrations are higher than the predicted.

In order to check the effectiveness of $\mathrm{N}_{2}$ inertization, for the first thirty hours after $\mathrm{N}_{2}$ injection, the explosibility of the mine atmosphere in the sealed area is determined using the modified Coward diagram method in a proper time step for sample collect points at the crosscut 21 and the main return as Figure 6.7. The resultant explosibility triangle and the actual atmosphere status point at each step are determined and plotted in same as Figure 6.7. It shows that the 
air-gas mixture is not explosive at the beginning. But as the nitrogen is injected and the methane keeps influx into the sealed area, the size of the explosibility triangle enlarges and the lower right side of the triangle moves toward the right. The point also moves toward the lower edge of the triangle. Initially, the air-gas mixture is out of the explosive triangle and can be considered as not-explosive but comes into it later, and, eventually, exits the explosive triangle. In summary, the totals of critical time for these two scenarios are about 8 and 7 hours, respectively. Therefore, it can be seen that the $\mathrm{N}_{2}$ injection has great impacts on inerting a mine sealed volume, and can shorten the critical time period to minimize the explosibility risk. 


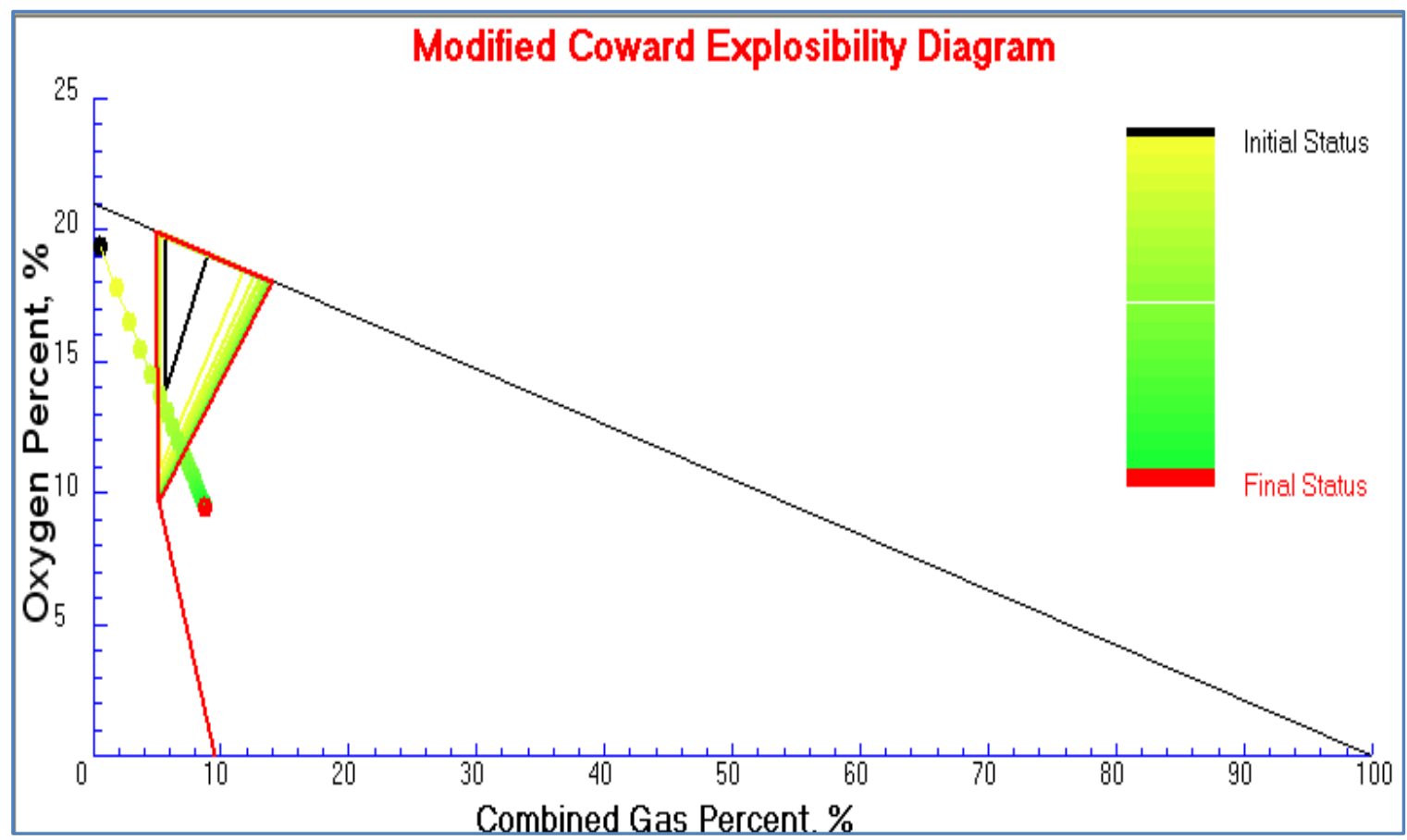

a) Crosscut 21

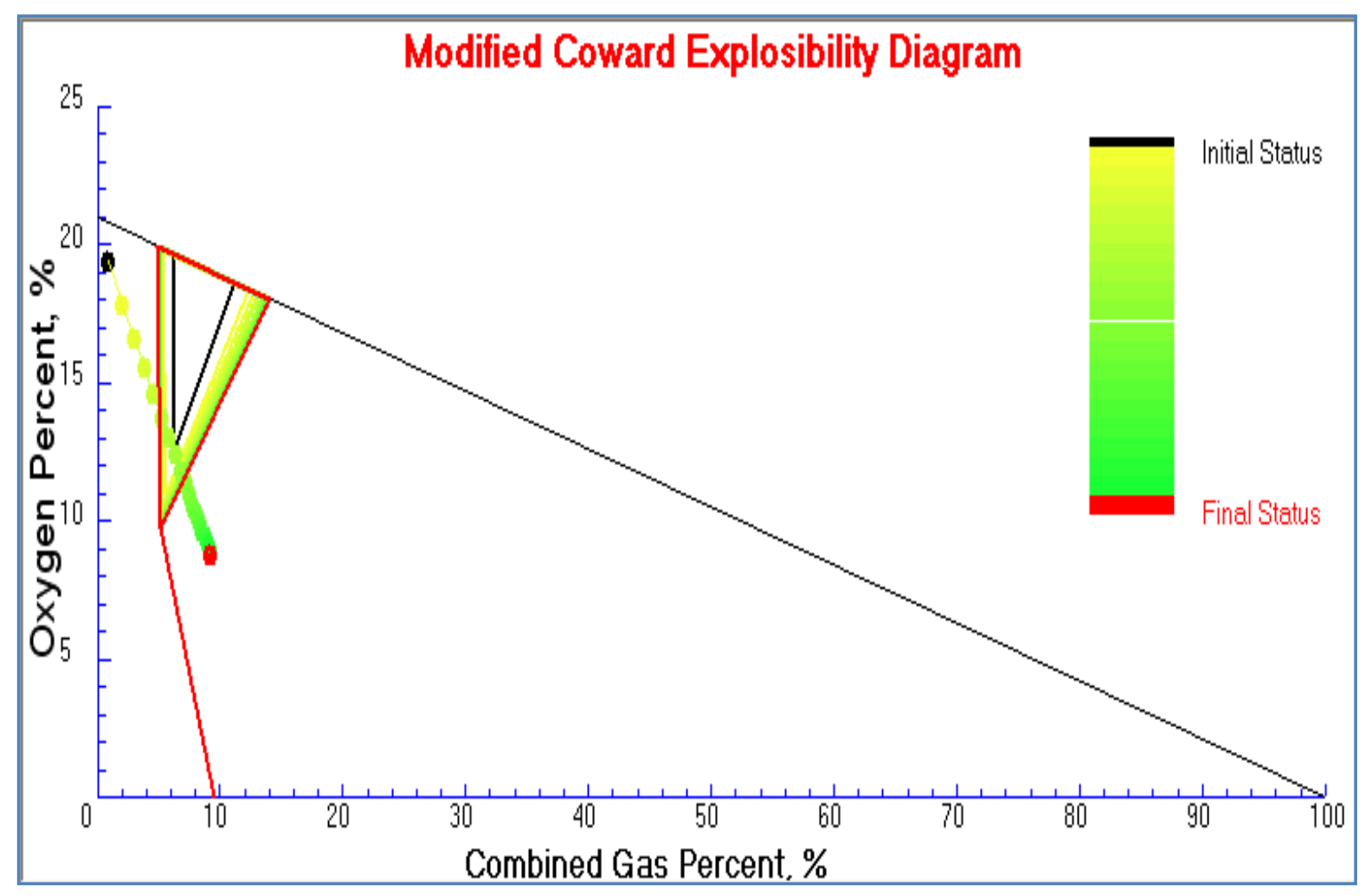

b) $32_{2} 13_{(1)}$ main return

Figure 6.7 Time-series plots of the explosibility triangles and the mixture points 


\section{CHAPTER 7 CONCLUSIONS}

\subsection{Summary and Conclusions}

Gas explosions originated from sealed mine areas in underground present a serious safety threat for coal miners and also have long been a concern and threat to mining engineers. A good understanding and reliable prediction of the status of the sealed coal mine atmosphere would contribute to the safe operation of coal mines. The dissertation research dedicates to improve the understanding the status of the sealed coal mine atmosphere and also to help mining engineers easily analyze the behavior of a coal sealed mine volume. This research work leads to the following conclusions:

- Based on the law of mass conservation and the ideal gas law, a step-wise dynamic mathematical model using the control volume approach to simulate the sealed mine atmospheric gas species changes over time has been developed.

- The atmospheric air prediction model proposed in the research is capable of predicting nine gas species including $\mathrm{CH}_{4}, \mathrm{CO}, \mathrm{N}_{2}, \mathrm{C}_{2} \mathrm{H}_{2}, \mathrm{C}_{2} \mathrm{H}_{4}, \mathrm{C}_{2} \mathrm{H}_{6}$, $\mathrm{CO}_{2}, \mathrm{H}_{2}$ and $\mathrm{O}_{2}$. An approach is based on identified the air-inflowing and the gas-outflowing process.

- Various influential factors affecting the atmospheric gas species changes in the sealed area have been extensively investigated and analyzed. The investigated influential factors include: (1) Barometric pressure: A set of mathematical functions are created to represent three typical barometric 
pressure fluctuation curves for three typical U.S. coal field locations using mathematical curve fitting approach based on the measured local barometric pressure data; (2) Coal mine seal: The impact of mine seals on the atmospheric air status is carefully investigated in this dissertation, and an equation is proposed to characterize the effects of mine seals on the atmosphere in the sealed mine area considering different types of the mine seal and the number used; (3) Gas species: the categories of gases which make up the sealed atmosphere are listed and their changing characteristics are also stated. All these influential factors have been incorporated into the mathematical model.

- Validation study of the atmosphere prediction model in the sealed mine area has been conducted in a real coal mine. A good agreement between the calculation result from the mathematical model and the actual measurement has been obtained.

- An improved and modified Coward explosibility diagram is proposed in this dissertation. Five improvements have been made to the original Coward explosibility diagram: (1) The original Coward diagram has been expanded to take into account more combustible gases, which are commonly found during a mine fire or a coal spontaneous combustion event; (2) Flammable limits (general LFL and UFL) as the fundamental parameters to determine the mine gas explosibility has been calibrated with the effects of environmental factors, such as temperature, pressure or contained inert gases, based on a proposed procedure; (3) A series of equations are used to re- 
define the nose limit for each combustible gas that is good for popularizing the Coward method; (4) An equation to calculate the excess amount of inert gas for each combustible gas is developed; (5) The concept of explosibility safety factor (SF) is introduced and defined to provide supportive guidelines when planning and implementing a mine rescue strategy.

- A cross-verification study has been conducted with both the original Coward method and the USBM explosibility diagram method. The results from the verification study shows that the modified Coward method has better accurate judgments on mine gas explosibility than the original Coward method.

- A new software program, CIMMAS (Comprehensive and Integrated Model for Mine Atmospheric Status), has been developed and also has included all the previous research findings. CIMMAS is coded with Visual Basic language, which is an Object Orientation Programming (OOP) Language. A very user-friendly Graphical Users Interface (GUI) is created to help users to operate the software easily. .

- Two functional modules of CIMMAS including the atmospheric gas species changes predication module and the explosibility analysis module is introduced and illustrated thoroughly and the structure of CIMMAS and its standard procedure are also stated. 


\subsection{Recommendations for the Future Research}

Based on the conclusions carried out in this research, the following work is recommended for any future studies:

(1) Chemical reaction, such as coal oxidation, may take place in the seal areas. In that case, it would result in the $\mathrm{CO}$ or $\mathrm{CO}_{2}$ production or $\mathrm{O}_{2}$ depletion. In order to represent them very well, to generate depletion rates should be considered. It is recommended to do experimental analysis or field measurements to determine their proper values and integrate them into the mathematical model.

(2) It can be seen that a lot of input parameters are needed when using the computer program to conduct the consulting works. Therefore, a summary of recommended values for different parameters with respect to different scenarios should be finished in the future. It can also be collected as a reference guide for the software program users.

(3) Generally, a coal mine have an atmosphere monitoring system, some atmospheric data can be collected from such system. Therefore, a new research direction is going to combine the computer software with the monitoring system. All the data can automatically be provided by the monitor detectors and the program outputs can also be calibrated timely. It is good for offering more accuracy results. 
(4) The concept of explosibility Safety Factor (SF) is the first time to propose. Although the developed equations to calculate the SF have already considered various explosibility scenarios and also combined their effects into the equations, the coefficients used may not be very perfect to identify risk levels for all possible circumstances in mine reality. Therefore, it suggests that they should be improved in the future research once more real mine gas sample data are available. In addition, the experimental study is also another approach which is highly recommended to investigate a set of precise coefficients.

(5) Coal mine seals play an important role to control the sealed mine atmosphere. Current mining regulations require mining companies to either ventilate or seal abandoned mining areas. Due to the mechanization production of the underground coal mining, a large abandon volume becomes more and more common and that puts a management challenge for mine operators. On the other hand, the high building cost of mine seals is also another economic judgment for mining engineers. Therefore, ventilating or sealing an underground area is a wisely selection. Mining engineers must balance the relationship between the ventilation capacity and the capital costs to effectively manage the mine abandon areas. 


\section{REFERENCES}

Arnaldos, J., Casal, J. \& Planas-Cuchi, E., 2011. "Prediction of flammability limits at reduced pressures." Chemical Engineering Science, 56(12), pp. 38293843.

Bjerketvedt, D., Bakke, J. R. \& Wingerden, K. V., 1997. "Gas explosion handbook. " Journal of Hazardous Materials, 52(1), pp. 1-150.

Brady, J., Burra, S. \& Calderwood, B. R., 2008. "The positive pressure chamber.

" Proc. 12th United States/North American Mine Ventilation Symposium, K. Wallace (ed.), University of Nevada, Reno, NV, pp. 171-177.

Breslin, J. A., 2010. One Hundred Years of Federal Mining Safety and Health Research, National Institute for Occupational Safety and Health, IC9520, 88pp.

Britton, L., 2002. "Using heats of oxidation to evaluate flammability hazards. " Process Safety Progress, 21(1), pp. 31-54.

Bruce, W. E. \& Koenning, T. H., 1987. "Computer modeling of underground coal mine ventilation circuits: selection and application of airway resistance values." Proceedings of the 3rd U.S. Mine Ventilation Symposium, J. Mutmansky (ed.), Penn State University, University Park, PA, pp. 519-525.

Burgess, M. J. \& Wheeler, R. V., 1911. "The lower limit of inflammation of mixtures of the paraffin hydrocarbons with air. " Trans. Chem. Soc., Volume 99, pp. 2013-2030. 
Calizaya, F. \& Stephens, M., 2006. "Studies of leakage flow in the U.S. underground coal mines. " Proc. 12th United States/North American Mine Ventilation Symposium, J. Mutmansky and R. Ramani (ed.), Penn State University, University Park, PA, pp. 599-606.

Carona, M., Goethalsa, M., De Smedta, G., Berghmansa, J., Vliegenb, S., Van't Oostb, E. and Van den Aarssenb, A., 1999. "Pressure dependence of the auto-ignition temperature of methane/air mixtures. " Journal of Hazardous Materials, 65(3), pp. 233-244.

Cashdollar, K. L., Zlochower, I. A., Green, G. M., Thomas, R. A. and Hertzberg, M., 2000. "Flammability of methane, propane, and hydrogen gases. " Journal of Loss Prevention in the Process Industries, Volume 13, pp. 327340.

CDC, 2009. Morbidity \& Mortality Weekly Report, 57(51): pp.1379-1383.

Chalmers, D. R., 2008. "Sealing design." Proc. 12th United States/North American Mine Ventilation Symposium, K. Wallace (ed.), University of Nevada, Reno, NV, pp. 219-223.

Chamberlain, E. A. \& Hall, D. A., 1973. "Practical early detection of spontaneous combustion. " Colliery Guardian, Volume 221, pp. 190-194.

CNN, 2011. Cable news network. [Online] http://articles.cnn.com/2011-0322/world/pakistan.mine.blast 1 methane-gas-explosion-minerescuers? s $^{1 / 4 P M}$ :WORLD.

Coward, H. F. \& Jones, G. W., 1952. Limits of Flammability of Gases and Vapors, U.S. Bureau of Mines, Bulletin 503, 121pp. 
Drysdale, D. D., 1985. An introducation to fire dynamics. Chichester: Wiley. 256pp.

Dwyer, J., Hansel, J. G. \& Pilips, T., 2003. "Temperature Influence on the Flammability Limits of Heat Treating Atmospheres. " Proceedings of the 22nd Heat Treating Scoiety Conference and the 2nd International Surface Engineering Congress, N. Dahotre, R. Gaste, R. Hill and O. Popoola (ed.), Indianapolis, IN, pp. 24-28.

Eddy, G. E. \& Rightmire, C. T., 1982. "Relationship of Methane Content of Coal Rank and Depth: Theoretical vs. Observed. " SPE/DOE Unconventional Gas Recovery Symposium, Pittsburgh, PA, pp. 117-122.

English, L. M., 1997. Gob Gas: A Synthesis of the Literature and an Empirical Model, Ph.D. Dissertation, West Virginia University, 165pp.

Enotes, 2012. Syncline and Anticline. [Online] http://www.enotes.com/syncline$\underline{\text { anticline-reference/syncline-anticline }}$

EPA, 2002. Greenhouse Gas Emissions and Sinks: 1990-2001, U.S.

Environmental Protection Agency, Contract Report No. 236R00001, 56pp.

EPA, 2004. Methane Emissions from Abandoned Coal Mines in the United

States: Emission Inventory Methodology and 1990-2002 Emissions

Estimates., U.S. Environmental Protection Agency, Contract Report No. 68W00092, 125pp.

EPA, 2008. U.S. Abandoned Coal Mine Methane Recovery Project

Opportunities, U.S. Environmental Protection Agency, Contract Report No. 430R08002, 77pp. 
Fauconnier, C. J., 1992. "Fluctuations in barometric pressure as a contributory factor to gas explosions in South African Mines. " Journal of the South African Institute of Mining and Metallurgy, 92(5), pp. 131-147.

Fauconnier, C. J. \& Beukes, J. D. R., 1978. "Some interesting observations about colliery fires and the weather. " International Journal of Mine Ventilation Socitey of South African, 31(4), pp. 57-84.

Foster-Miller, I., 1988. Improved ventilation of sealed mine gob, U.S. Bureau of Mines, Contract Report No. J0308029, 21pp.

Francart, W. \& Beiter, D., 1997. "Barometric Pressure Influence in Mine Fire Sealing. " Proc. 6th International Mine Ventilation Congress, R. Ramani (ed.), New York, NY, pp. 341-342.

Froger, C. E., 1985. "Firefighting expertise in French underground mines. " Proc. 2nd United States Mine Ventilation Symposium, Reno, NV, pp. 3-10. Greuer, R., 1974. Study of mine fire fighting using inert gases, U.S. Bureau of Mines Contract Report No. S0231075, 135pp.

GRI, 1996. A Guide to coalbed methane reservoir engineering, Chicago: Gas Research Institute.

Hemp, R., 1994. "The effect of changes in barometric pressure on mines in the Highveld of South Africa. " Journal of the South African Institute of Mining and Metallurgy, 100(6), pp. 133-146.

Holding, W., 1992. "A Re-look at explosibility diagrams. " Proceedings of the 5th International Mine Ventilation Congress, Johannesburg, Republic of South Africa, R. Hemp (ed.), pp. 171-181. 
Huang, S., 2010. China Coal Outlook 2010. Berijing, China: China Coal Industry Publishing House.

Jacobs, M. \& Porter, I., 1998. "Rapid generation of control charts for analysis of complex gas mixes in crisis situations. " Proceedings of coal 1998: Coal operators' conference, E. Baafi (ed.), University of Wollongong \& the Australian Institute of Mining and Metallurgy, Wollongong, Australia, pp. 641-648.

Kallu, R. R., 2009. Design of Reinforced Concrete Seals for Underground Coal Mines, Ph.D. Dissertation, West Virginia University, 216pp.

Kirchgessner, D. A., Piccot, S. D. \& Masemore, S., 2001. "An Improved Inventory of Methane Emissions from Coal Mining in the U.S.. " Journal of Air and Waste Management Association, 3, Volume 50, pp. 1904-1919.

Kissell, F. N., 2006. Handbook for methane control in mining, National Institute for Occupational Safety and Health, IC9468, 180pp.

Kondo, S., Takizawa, K., Takahashi, A. \& Tokuhashi, K., 2006a. "Extended Le Chatelier's formula for nitrogen dilution effect on flammability limits. " Fire Safety Journal, 41(3), pp. 406-417.

Kondo, S., Takizawa, K., Takahashi, A. \& Tokuhashi, K., 2006b. "Extended Le Chatelier's formula for carbon dioxide dilution effect on flammability limits. " Journal of Hazardous Materials, 138(1), pp. 1-8.

Kondo, S., Takizawa, K., Takahashi, A., Tokuhashi, K. and Sekiya, A., 2008. "A study on flammability limits of fuel mixtures. " Journal of Hazardous Materials, 155(3), pp. 440-448. 
Kukuczka, M., 1982. "A new method for determining explosibility of complex gas mixtures. " Mechanizacja I Automatuzacja Gornictwa, 164(11), pp. 36-39.

Lolon, S. \& Calizaya, F., 2009. "Computational fluid dynamics study on hot spot location in longwall gob. " Mining Engineering, 61(8), pp. 36-41.

Lunarzewski, L., 1998. "Gas emission prediction and recovery in underground coal mines. " International Journal of Coal Geology, 35(1-4), pp. 117-145.

Lunarzewski, L., 2003. Coal Mine Gas Emission Assessment for Sealed Goaf Area or Abandoned Mine. [Online] http://www.coalinfo.net.cn/coalbed/meeting/2203/papers/coal-mining/ Lunarzewski, L., 2010. "Coal mine goaf gas predictor (CMGGP). " Proc. Underground Coal Operators' Conference 2010, A. Nazj (ed.), University of Wollgang, Wollongong, Australia,

Luo, Y., 2009. Class Notes for MINE 632 - Advanced Mine Ventilation Engineering. Department of Mining Engineering,West Virginia University, Morgantown, WV, U.S.A..

McGrattan, K., Hostikka, S., Floyd, J., Baum, H. and Rehm, R., 2007. Fire Dynamics Simulator (Version 5) Technical Reference Guide, Gaithersburg, MD: NIST, 76pp.

McPherson, M. J., 1993. Subsurface Ventilation and Environmental Engineering. London, United Kingdom: Chapman \& Hall.

Mitchell, D. W., 1996. Mine Fires Prevention, Detection, Fighting. Chicago, IL: Inter-tec. Publishing Inc. 
MSHA, 2008. Final Rule on Sealing of Abandoned Areas. [Online] http://www.msha.gov/seals/sealssinglesource2007.asp

Muzyczuk, J., 1974. Determination of the coward explosibility triangle for complex gas mixtures. Katowice: Glownego Instytuty Gornictwa.

Nave, R., 2011. Ideal Gas Law. [Online] http://hyperphysics.phyastr.gsu.edu/hbase/kinetic/idegas.html

Oswald, N., Prosser, B. \& Ruckman, R., 2008. "Measured values of coal mine stopping resistance. " Proc. 12th United States/North American Mine Ventilation Symposium, K. Wallace (ed.), University of Nevada,Reno, NV, pp.103-106.

Peng, S. S., 2008. Coal Mine Ground Control. Hoboken, NJ: Wiley. 764pp.

Platzman, G. W., 1996. "The S-1 chronicle; a tribute to Bernhard Haurwitz Bull. " Amer. Meteor. Soc., Volume 77, pp. 1569-1577.

Ray, S. K., Singh, R. P., Sahay, N. \& Varma, N. K., 2004. "Assessing the status of sealed fire in underground coal mines. " Journal of Scientific and Industrial Research, 63(7), pp. 579-591.

Rocca, R. L., Riggi, D. \& Riggi, F., 2010. "Time series analysis of barometric pressure data. " European Journal of Physics, Volume 31, pp. 645-655.

Rowley, J. R., Rowley, R. L. \& Wilding, W. V., 2010. "Experimental determination and re-examination of the effect of initial temperature on the lower flammability of pure liquids. " Journal of Chemical Engineering Data, 55(3), pp. 3063-3067. 
Schophaus, N., Bluhm, S. \& Funnall, R., 2005. "Effects of ventilation leakage in deep, hot room and pillar operations. " Proceedings of the 8th International Mine Ventilation Congress, Brisbane, Austrailia, pp. 431-437.

SearchSOA, 2011. OOP. [Online]

http://searchsoa.techtarget.com/definition/object-oriented-programming

Smith, A. C., Diamond, W. P., Mucho, T. P. \& Organiscak, J. A., 1994.

Bleederless ventilation systems as a spontaneous combustion control measure in U.S. coal mines, U.S. Bureau of Mines, IC9377, 45pp.

Stephens, M., 2011. Laboratory and Numerical Modeling Used to Characterize Leakage in Underground Coal Mines, M.S. Thesis, University of Utah. 136pp.

Stevenson, J. W., 1968. "Effects of bleeder entries during atmospheric pressure changes. " Mining Engineering, Volume 6, pp. 61-64.

Timko, R. J. \& Derick, R. L., 2006. Methods to determine the status of mine atmospheres - an overview, National Institute for Occupational Safety and Health Document.

Timko, R. J., Kissell, F. N. \& Thimons, E. D., 1987. "Evaluating ventilation parameters of three coal mine gobs." Proceedings of the 3rd U.S. Mine Ventilation Symposium, J. Mutmansky (ed.), Penn State University, University Park, PA, pp. 533-543.

Vanderstraeten, B., Tuerlinckx, D., Berghmans, J., Vliegen, S., Vant Oost, E. and Smit, B., 1997. "Flammability limits of methanerair mixtures at elevated 
pressure and temperature. " Journal of Hazardous Materials, Volume 56, pp. 237-246.

Wang, D., 2004. Mine Ventilation and Safety. Xuzhou, China: China University of Mining and Technology Press, 265pp.

Weiss, E. S., Greninger, N. B., Stephan, C. R. \& Lipscomb, J. R., 1993. Strength characteristics and air-leakage determinations for alternative mine seal designs, U.S. Bureau of Mines RI 9477, 16pp.

Weiss, E. S., Slivensky, W. A., Schultz, M. J., Stephan, C. R. and Jackson, K. W., 1996. Evaluation of polymer construction material and water trap designs for underground coal mine seals, U.S. Bureau of Mines RI 9634, $56 \mathrm{pp}$.

Welty, J. R., Wicks, C. E., Wilson, R. E. \& Rorrer, G., 2001. Fundamentals of Momentum, Heat, and Mass Transfer. New York, NY: John Wiley \& Sons, Inc. 780pp.

Wikipedia, 2010. Pike River Mine disaster. [Online] http://en.wikipedia.org/wiki/Pike River Mine disaster

Wikipedia, 2011. GUI. [Online] http://en.wikipedia.org/wiki/Graphical user interface

Wikipedia, 2011. Ideal gas law. [Online] http://en.wikipedia.org/wiki/ldeal gas law

Wikipedia, 2011. Object Oriented Programming. [Online] http://en.wikipedia.org/wiki/Object-oriented programming 
Wikipedia, 2011. Visual Basic. [Online]

http://en.wikipedia.org/wiki/Visual Basic

Xie, J., Xue, S., Cheng, W. \& Wang, G., 2011. "Early detection of spontaneous combustion of coal in underground coal mines with development of an ethylene enriching system. " International Journal of Coal Geology, Volume 85, p. 123-127.

Yuan, L. \& Smith, A., 2007. Modeling the effect of barometric pressure changes on spontaneous heating in bleederless longwall panels, National Institute for Occupational Safety and Health Document.

Yuan, L. \& Smith, A. C., 2011. "CO and $\mathrm{CO}_{2}$ emissions from spontaneous heating of coal under different ventilation rates. " International Journal of Coal Geology, 88(1), pp. 24-30.

Yu, Q., 1992. Prevention of Coal Mine Methane. Xuzhou, China: China University of Mining \& Technology Press, 162pp. (in Chinese)

Zabetakis, M. G., Lambiris, S. \& Scott, G. S., 1959a. "The combustion of coal. " The 7th International Symposiumon Combustion, The Combustion Institute, Pittsburgh, PA, pp. 484.

Zabetakis, M. G., 1965. Flammability Characteristics of Combustible Gases and Vapors, U.S. Bureau of Mines, Bulletin 627, 69pp.

Zabetakis, M. G., Stahl, R. W. \& Watson, H. A., 1959b. Determining the explosibilty of mine atmospheres, U.S. Bureau of Mines, IC7901, 83pp.

Zhou, L., 2009. Improvement of the Mine Fire Simulation Program MFIRE, Ph.D. Dissertation, West Virginia University, 138pp. 
Zhou, X. \& Wu, B., 1996. Theory of Mine Fire Rescues and Applications. Beijing, China: Coal Mining Industry Press, 267pp. (in Chinese)

Zigmund, J. \& Janovsky, B., 2007. " 'Vybuchovy trojuhelnik': a software tool for evaluation of explosibility of coal mine atmosphere. " Journal of Loss Prevention in the Process Industries, 20(5), pp. 517-522.

Zipf, R. K. \& Mohamed, K. M., 2010. "Composition change model for sealed atmosphere in coal mines. " Proc. 13th United States/North American Mine Ventilation Symposium, S. Hardcastle and D.McKinnon (ed.), Laurentian University, Sudbury, ON, Canada, pp. 493-500.

Zipf, R. K., Sapko, M. J. \& Brune, J. F., 2007. Explosion Pressure design criteria for new seals in U.S. coal mines, National Institute for Occupational Safety and Health, IC9500, 76pp. 